\title{
Annexin A1 and annexin A5 in cardiovascular disease
}

Citation for published version (APA):

Kusters, D. H. M. (2015). Annexin A1 and annexin A5 in cardiovascular disease. [Doctoral Thesis, Maastricht University]. Maastricht University. https://doi.org/10.26481/dis.20150206dk

Document status and date:

Published: 01/01/2015

DOI:

$10.26481 /$ dis.20150206dk

Document Version:

Publisher's PDF, also known as Version of record

\section{Please check the document version of this publication:}

- A submitted manuscript is the version of the article upon submission and before peer-review. There can be important differences between the submitted version and the official published version of record.

People interested in the research are advised to contact the author for the final version of the publication, or visit the DOI to the publisher's website.

- The final author version and the galley proof are versions of the publication after peer review.

- The final published version features the final layout of the paper including the volume, issue and page numbers.

Link to publication

\footnotetext{
General rights rights.

- You may freely distribute the URL identifying the publication in the public portal. please follow below link for the End User Agreement:

www.umlib.nl/taverne-license

Take down policy

If you believe that this document breaches copyright please contact us at:

repository@maastrichtuniversity.nl

providing details and we will investigate your claim.
}

Copyright and moral rights for the publications made accessible in the public portal are retained by the authors and/or other copyright owners and it is a condition of accessing publications that users recognise and abide by the legal requirements associated with these

- Users may download and print one copy of any publication from the public portal for the purpose of private study or research.

- You may not further distribute the material or use it for any profit-making activity or commercial gain

If the publication is distributed under the terms of Article $25 \mathrm{fa}$ of the Dutch Copyright Act, indicated by the "Taverne" license above, 


\section{Annexin A1 and annexin A5 in cardiovascular disease}




\section{Colofon}

\section{(C) Dennis Kusters, Maastricht 2015}

Thesis Maastricht University

\section{ISBN: 978-94-6295-080-1}

Cover Design by Els Hulshof-Fober

Cover Photography by Guillaume van Eys

Printed by proefschriftmaken.nl || Uitgeverij BOXPress

Published by Uitgeverij BOXPress, 's-Hertogenbosch

All rights reserved. No part of this thesis may be reproduced, stored in a retrieval system or transmitted in any form or by any means, without the permission in writing from the author, or, when appropriate, of the publisher of the publication. 


\section{Annexin A1 and annexin A5 in cardiovascular disease}

\section{PROEFSCHRIFT}

Ter verkrijging van de graad doctor aan de Universiteit Maastricht, op gezag van de Rector Magnificus, Prof. Dr. L.L.G. Soete, volgens het besluit van het College van Decanen in het openbaar te verdedigen op vrijdag 6 Februari 2014 om 16.00 uur

door

Dennis Hubertus Martinus Kusters

Geboren op 10 november 1984 te Brunssum 


\section{Promotor}

Prof. Dr. C.P.M. Reutelingsperger

\section{Copromotor}

Dr. L.J. Schurgers

\section{Beoordelingscommissie:}

Prof. Dr. E.A.L. Biessen (Voorzitter)

Prof. Dr. B. Brachvogel (University of Cologne, Köln, Germany)

Prof. Dr. J. Frostegård (Karolinska Institute, Stockholm, Sweden)

Prof. Dr. F.M. Mottaghy

Prof. Dr. L.J. de Windt

Financial support by the Dutch Heart Foundation for the publication of this thesis is gratefully acknowledged.

Additional financial support for the publication of this thesis by Fonds voor het Hart and Stichting Hartsvrienden RESCAR is gratefully acknowledged.

Additional financial support for the publication of this thesis by MosaMedix and PharmaTarget is gratefully acknowledged. 
Docendo discimus.

Voor mijn ouders 



\section{CONTENTS}

Chapter 1 General introduction and outline of the dissertation.

Chapter 2 Molecular imaging to identify the vulnerable plaque - from basic research to clinical practice.

Chapter 3 Annexin A5-deficiency in ApoE--- mice promotes efferocytosis and inhibits atherosclerosis.

Chapter 4 Exogenous annexin A1 attenuates atherogenesis in $\mathrm{LDLR}^{-1-}$ mice on Western Type Diet.

Chapter 5 Annexin A1 ameliorates infarct size and LV systolic function following myocardial ischemia/reperfusion injury.

Chapter 6 Synthesis and NMR spectroscopic characterization of recombinant human annexin A1.

Chapter 7 General discussion and clinical implications.

Addendum Summary

Samenvatting

Valorization

Curriculum Vitae

Publications

Dankwoord 

Chapter 1

General introduction 


\section{Cardiovascular disease}

Cardiovascular disease (CVD) is a class of diseases that involve the heart, blood vessels or both. Despite great advances in diagnosis and therapy over the past decades, CVD remains the leading cause of death in the developed countries ${ }^{1,2}$. Globalization of Western life-style is associated with a sharp increase of cardiovascular related deaths in various emerging economies. Coronary and congenital heart disease, deep venous thrombosis, aortic aneurism, stroke and atherosclerosis are the most common types of CVD. Classical risk factors like high blood pressure, unhealthy diet, physical inactivity, tobacco use and harmful use of alcohol contribute to the development of CVD ${ }^{3}$.

Atherosclerosis is a progressive chronic inflammatory disease in which atherosclerotic lesions cause obstructions of large or medium sized arteries and is considered to be major cause of CVD (Figure 1B) ${ }^{4}$. Atherogenesis in humans commences around 20 years of age. Endothelial cell dysfunction causes leakage of cholesterol and low density lipoproteins (LDL) into the subendothelial layer (tunica intima) of the blood vessel ${ }^{5}$. This leakage occurs predominantly at sites with disrupted blood flow as a result of bifurcations or curvatures in the arteries ${ }^{6}$. Inflammation, cell death, vascular remodeling, thrombus formation and calcification contribute to progression of atherogenesis ${ }^{2,7}$. Over time, advanced atherosclerotic lesions develop which most often remain asymptomatic ${ }^{8}$. However, progression over many years may develop vulnerable lesions prone to rupture, that consist of a large necrotic core and a thin fibrous cap ${ }^{9}$. Depending on the location of the lesion, rupture and subsequent coagulation may lead to complete or partial vascular occlusion, causing an ischemic event.

Ischemia is basically a shortage of oxygen and glucose needed for cellular metabolism most often caused by (partial) occlusion of an artery. On the contrary, reperfusion is the restoration of blood flow to ischemic tissue ${ }^{10}$. Depending on the location of the occlusion, an ischemic event may lead to ischemic heart disease (Figure 1A), ischemic colitis (colon) or ischemic stroke (brain) ${ }^{11}$. Restoring blood flow after ischemia is essential for tissue functionality, but initiates a second phase of injury called reperfusion injury. Reperfusion injury shares many characteristics with normal inflammation, in which neutrophils are the most prevalent leukocyte within the first 24 hours ${ }^{12,13}$. Activated neutrophils release reactive oxygen species (ROS), proinflammatory cytokines and chemokines, activate the endothelium and results in the recruitment and activation of additional neutrophils. 
Moreover, activation of neutrophils can lead to NETosis, in which neutrophils excrete neutrophil extracullar traps (NETs) consisting of DNA and histones ${ }^{14}$.

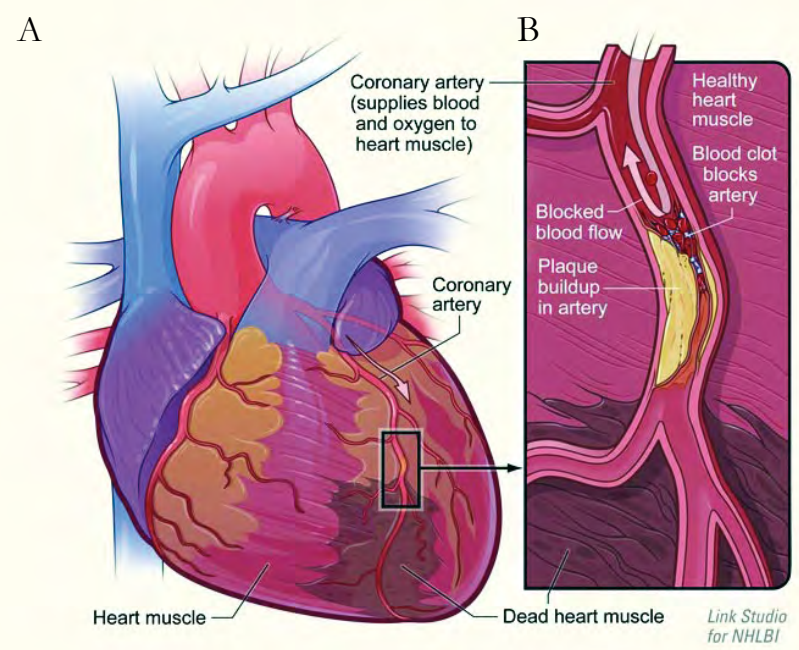

Figure 1 - Human heart with obstructed left anterior descending coronary artery (LAD) (A). LAD obstruction by blood cloth originating from remote artery (B). Image obtained from the National Institute of Health (NIH, Public Domain).

\section{Annexins}

Annexins are calcium dependent phospholipid binding proteins that belong to an evolutionary well conserved multigene family, with members of the family expressed throughout animal and plant kingdoms ${ }^{15}$. Vertebrates express 13 different annexins termed annexin A1 to A13. Roughly 30 years ago proteins like synexin ${ }^{16}$, lipocortin ${ }^{17}$ and calpectin ${ }^{18}$ were discovered. After intensive protein analysis, cDNA sequencing and gene cloning they turned out to share similar gene structure, sequence features and biochemical properties. In order to solve any confusion in terminology, the common name annexin was introduced ${ }^{15}$. This name is derived from the Greek annex meaning "bring/hold together" and was first used by Geisow in 1987, the term describes the principal property of most annexins ${ }^{19}$. Structurally, annexins are characterized by a C-terminal convex "tail" and an $\mathrm{N}$-terminal concave "head" (Figure 2) ${ }^{20}$. The C-terminus is tightly conserved throughout evolution and comprises four annexin repeats (eight in case of annexin A6) of 70 amino acids. These repeats contain a highly conserved $\alpha$-helical protein core domain and harbors the calcium-regulated membrane binding pockets ${ }^{21}$. The $\mathrm{N}$-terminal domain consists of 40 or fewer residues and is responsible for its specific function ${ }^{15}$. 

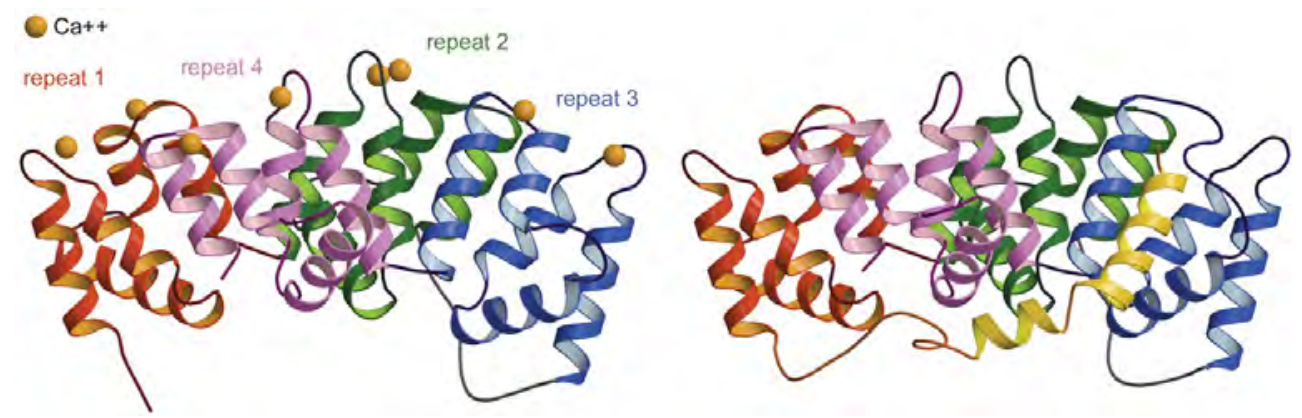

Figure 2 - Representation of ribbon structure of annexin $A 1$ in the presence and absence of $C a^{2+}$. The $\mathrm{N}$-terminus (yellow) integrates into repeat 3 in the absence of $\mathrm{Ca}^{2+}$ and is exposed on the surface in the presence of $\mathrm{Ca}^{2+}$.

Annexin A1 (anxA1) was discovered and characterized by its ability to suppress phospolipase A2 induced eicosanoid generation and was initially termed lipocortin ${ }^{22}$. Since its discovery, anxA1 has shown to be capable of modulating a number of biological processes. However, anxA1 is most well-known for its anti-inflammatory property ${ }^{23}$. It took some time before the cellular modus operandi of anxA1 was elucidated. The discovery that derivatives of buthyloxycarbonyl (Boc) blocked the anti-migratory effects of anxA1 on human neutrophils and in addition affected the calcium flux and L-selectin shedding was a major breakthrough. It demonstrated that the receptor for formylated peptides (FPR) was the target of anxA1 ${ }^{24}$. Both full-length anxA1 and the $\mathrm{N}$-terminal derived peptide (Ac2-26) are able to interact with FPR-2, which is present on all leukocytes ${ }^{21,25-28}$. This interaction inhibits neutrophil recruitment and increases phagocytosis by bridging apoptotic cells and phagocytes ${ }^{23,29,30}$. Generation of the anxA1 knock-out mouse has led to a greater understanding of the roles played by endogenous anxA1 ${ }^{31}$. In general, inflammation is exacerbated and prolonged if anxA1 is absent ${ }^{32}$. In humans, dysregulation of anxA1 is associated with progressive Crohns disease ${ }^{33}$, asthma ${ }^{34}$ and invasiveness of tumors ${ }^{35}$. Pharmacological treatment of inflammation using anxA1 and its $\mathrm{N}$-terminal peptide has been studied in animal models of neutrophil-dependent edema ${ }^{36}$, ischemia-reperfusion injury ${ }^{37,38}$ and acute peritonitis ${ }^{39}$, however, until now not in atherosclerosis. Treatment of ischemia-reperfusion injury with anxA1 showed a reduction of damage and neutrophil influx ${ }^{37}$, however did not show whether this reduction enhanced cardiac function.

Annexin A5 (anxA5) was initially discovered as a vascular anticoagulant and termed accordingly ${ }^{40}$. The anticoagulant property of anxA5 originates from its ability to inhibit prothrombinase activity ${ }^{41}$. After discovering similarity in structure and the presence 
of four annexin repeats it was termed annexin $\mathrm{A} 5{ }^{42}$. Since attaching a fluorescent- or radiolabel does not influence its ability to bind phosphatidylserine (PS), anxA5 is widely employed as molecular imaging agent to visualize apoptotic cells ${ }^{43}, 44$. This PS-binding enables treatment with anxA5 and results in suppression of inflammation ${ }^{45}$ and inhibition of atherosclerotic plaque development in mice ${ }^{46}$. Exogenous anxA5 reduced inflammation by acting on activated endothelium ${ }^{45}$ and target pro-inflammatory mediators ${ }^{47,48}$. Recent associations of anxA5 in processes like autophagy ${ }^{49}$, microcalcification ${ }^{50}$ and phagocytosis ${ }^{51}$ suggests a role for endogenous anxA5 in atherosclerosis and ischemia-reperfusion injury. In order to gain more insight into this role, the anxA5 knock-out mouse was generated. Deficiency of anxA5 is related to increased placental coagulation and subsequent fetus loss ${ }^{52}$, however, the anxA5 deficient mice do not appear to have a clear aberrant phenotype. Even though these deficient mice show altered bone development ${ }^{53}$, anxA5 appears not to be essential ${ }^{54,55}$. The only known human disease associated with anxA5 is in the antiphospholipid syndrome (APS), in which antibodies directed against anxA5 are thought to cause hypercoagulability ${ }^{56}$.

\section{Future perspectives}

Cardiovascular disease will remain amongst the primary causes of death in the developed countries for years to come. There is an increasing need for new imaging and treatment modalities. Atherosclerosis and ischemia-reperfusion injury have certain similarities that bare novel targets for diagnosis and treatment. Both ROS formation and release of NETs are detrimental to disease outcome but open novel treatment oppertunities. Cells that experience stress lose their phospholipid asymmetry and expose PS on the exoplasmic leaflet of their plasma membrane ${ }^{57}$. Targeting PS with annexin A5 has proven to be a strategy for non-invasive detection of plaque instability ${ }^{43,58}$. Annexins may serve as novel theranostic, where the ability to target apoptotic or inflammatory cells with a labeled protein should be the strategy. This approach is not restricted to cardiovascular disease alone, but has the potential to be expanded to other diseases that involve inflammation or stressed cells inter alia cancer, rheumatoid arthritis (RA) or inflammatory bowel disease (IBD). 


\section{Outline of the thesis}

This thesis aims to investigate roles of annexin A1 and annexin A5 in cardiovascular disease, more specifically in atherosclerosis and after ischemia-reperfusion injury. The general introductory chapter $\mathbf{1}$ gives a brief synopsis of cardiovascular diseases and elaborates on atherosclerosis and ischemia-reperfusion injury. Furthermore, this chapter introduces annexins in general and focuses on annexin A1 and annexin A5 in some more detail. Chapter 2 reviews the molecular imaging possibilities of vulnerable atherosclerotic lesions. Clinical and preclinical strategies are discussed separately. Targets aimed at inflammation, cell death, vascular remodeling, thrombus formation and calcification are considered. In addition, there is a short editorial about the socio-economic impact of molecular imaging. Chapter 3 confers about the role of endogenous annexin A5 in atherosclerosis. Therefore a new knock-out mouse was generated, the annexin A5 knock-out mouse was back-crossed with the apoE knock-out mouse that is prone to develop atherosclerosis. The role of annexin A5 in efferocytosis and migration of cells, and the expression of the protein in atherosclerotic lesions is discussed. Chapter $\mathbf{4}$ focuses on the effect of exogenous annexin A1 on atherosclerosis. Production of full-length functional protein was confirmed by measuring both physical and biological properties. The route of administration was determined by assessing biodistribution and blood clearance of intravenous and intra peritoneal injected annexin A1. The therapeutic potential of annexin A1 was further expanded in chapter $\mathbf{5}$. In this chapter treatment of reperfusion injury after an ischemic event was evaluated. Additionaly, a derivative of heparin that lacks anticoagulant activity was used to target NETs. Histological analysis and functionality tests are combined to determine treatment efficacy. Structural analysis of annexin A1 is the main theme of chapter 6. Annexin A1 was uniformly labeled using stable isotopes of hydrogen, carbon and nitrogen, which enables structural analysis by nuclear magnetic resonance (NMR). The general discussion of chapter 7 describes the most important findings of this thesis and discusses these in perspective with current literature. The thesis culminates with a summary, valorization, curriculum vitea, publication list and the acknowledgements as addendum. 


\section{References}

1. Borissoff JI, Spronk HM, ten Cate H. The hemostatic system as a modulator of atherosclerosis. $N$ Engl J Med. 2011;364:1746-1760.

2. Kusters DH, Tegtmeier J, Schurgers LJ, Reutelingsperger CP. Molecular imaging to identify the vulnerable plaque--from basic research to clinical practice. Mol Imaging Biol. 2012;14:523-533.

3. Mozaffarian D, Wilson PW, Kannel WB. Beyond established and novel risk factors: lifestyle risk factors for cardiovascular disease. Circulation. 2008;117:3031-3038.

4. $\quad$ Ross R. Atherosclerosis--an inflammatory disease. N Engl J Med. 1999;340:115-126.

5. Hansson GK. Inflammation, atherosclerosis, and coronary artery disease. $N$ Engl J Med. 2005;352:1685-1695.

6. Nigro P, Abe J, Berk BC. Flow shear stress and atherosclerosis: a matter of site specificity. Antioxid Redox Signal. 2011;15:1405-1414.

7. Halvorsen B, Otterdal K, Dahl TB, Skjelland M, Gullestad L, Oie E, Aukrust P. Atherosclerotic plaque stability--what determines the fate of a plaque? Prog Cardiovasc Dis. 2008;51:183-194.

8. Burke AP, Farb A, Kolodgie FD, Narula J, Virmani R. Atherosclerotic plaque morphology and coronary thrombi. J Nucl Cardiol. 2002;9:95-103.

9. Virmani R, Kolodgie FD, Burke AP, Farb A, Schwartz SM. Lessons from sudden coronary death: a comprehensive morphological classification scheme for atherosclerotic lesions. Arterioscler Thromb Vasc Biol. 2000;20:1262-1275.

10. Powers SK, Murlasits Z, Wu M, Kavazis AN. Ischemia-reperfusion-induced cardiac injury: a brief review. Med Sci Sports Exerc. 2007;39:1529-1536.

11. Weber C, Noels H. Atherosclerosis: current pathogenesis and therapeutic options. Nat Med. 2011;17:1410-1422.

12. Jordan JE, Zhao ZQ, Vinten-Johansen J. The role of neutrophils in myocardial ischemia-reperfusion injury. Cardiovasc Res. 1999;43:860-878.

13. Kaminski KA, Bonda TA, Korecki J, Musial WJ. Oxidative stress and neutrophil activation--the two keystones of ischemia/reperfusion injury. Int J Cardiol. 2002;86:41-59.

14. Goldmann O, Medina E. The expanding world of extracellular traps: not only neutrophils but much more. Front Immunol. 2012;3:420.

15. Gerke V, Moss SE. Annexins: from structure to function. Physiol Rev. 2002;82:331-371.

16. Creutz CE, Pazoles CJ, Pollard HB. Identification and purification of an adrenal medullary protein (synexin) that causes calcium-dependent aggregation of isolated chromaffin granules. J Biol Chem. 1978;253:2858-2866.

17. Flower RJ. Background and discovery of lipocortins. Agents Actions. 1986;17:255-262.

18. Glenney JR, Jr., Tack B, Powell MA. Calpactins: two distinct Ca++-regulated phospholipid- and actin-binding proteins isolated from lung and placenta. J Cell Biol. 1987;104:503-511.

19. Geisow MJ, Walker JH, Boustead C, Taylor W. Annexins--new family of Ca2+-regulated-phospholipid binding protein. Biosci Rep. 1987;7:289-298.

20. Rescher U, Gerke V. Annexins--unique membrane binding proteins with diverse functions. J Cell Sci. 2004;117:2631-2639.

21. Gerke V, Creutz CE, Moss SE. Annexins: linking Ca2+ signalling to membrane dynamics. Nat Rev Mol Cell Biol. 2005;6:449-461.

22. Gavins FN, Hickey MJ. Annexin A1 and the regulation of innate and adaptive immunity. Front Immunol. 2012;3:354.

23. Perretti M, D'Acquisto F. Annexin A1 and glucocorticoids as effectors of the resolution of inflammation. Nat Rev Immunol. 2009;9:62-70. 
24. Walther A, Riehemann K, Gerke V. A novel ligand of the formyl peptide receptor: annexin I regulates neutrophil extravasation by interacting with the FPR. Mol Cell. 2000;5:831-840.

25. Raynal P, Pollard HB. Annexins: the problem of assessing the biological role for a gene family of multifunctional calcium- and phospholipid-binding proteins. Biochim Biophys Acta. 1994;1197:63-93.

26. Perretti M. The annexin 1 receptor(s): is the plot unravelling? Trends Pharmacol Sci. 2003;24:574-579.

27. Rosengarth $\mathrm{A}$, Luecke $\mathrm{H}$. A calcium-driven conformational switch of the $\mathrm{N}$-terminal and core domains of annexin A1. J Mol Biol. 2003;326:1317-1325.

28. Bena S, Brancaleone V, Wang JM, Perretti M, Flower RJ. Annexin A1 interaction with the FPR2/ ALX receptor: identification of distinct domains and downstream associated signaling. J Biol Chem. 2012;287:24690-24697.

29. Arur S, Uche UE, Rezaul K, Fong M, Scranton V, Cowan AE, Mohler W, Han DK. Annexin I is an endogenous ligand that mediates apoptotic cell engulfment. Dev Cell. 2003;4:587-598.

30. Blume KE, Soeroes S, Waibel M, Keppeler H, Wesselborg S, Herrmann M, Schulze-Osthoff K, Lauber K. Cell surface externalization of annexin A1 as a failsafe mechanism preventing inflammatory responses during secondary necrosis. J Immunol. 2009;183:8138-8147.

31. Hannon R, Croxtall JD, Getting SJ, Roviezzo F, Yona S, Paul-Clark MJ, Gavins FN, Perretti M, Morris JF, Buckingham JC, Flower RJ. Aberrant inflammation and resistance to glucocorticoids in annexin 1-/- mouse. FASEB J. 2003;17:253-255.

32. Chatterjee BE, Yona S, Rosignoli G, Young RE, Nourshargh S, Flower RJ, Perretti M. Annexin 1-deficient neutrophils exhibit enhanced transmigration in vivo and increased responsiveness in vitro. J Leukoc Biol. 2005;78:639-646.

33. Sena A, Grishina I, Thai A, Goulart L, Macal M, Fenton A, Li J, Prindiville T, Oliani SM, Dandekar S, Sankaran-Walters S. Dysregulation of anti-inflammatory annexin A1 expression in progressive Crohns Disease. PLoS One. 2013;8:e76969.

34. Eke Gungor H, Tahan F, Gokahmetoglu S, Saraymen B. Decreased levels of lipoxin A4 and annexin A1 in wheezy infants. Int Arch Allergy Immunol. 2014;163:193-197.

35. Cheng TY, Wu MS, Lin JT, Lin MT, Shun CT, Huang HY, Hua KT, Kuo ML. Annexin A1 is associated with gastric cancer survival and promotes gastric cancer cell invasiveness through the formyl peptide receptor/extracellular signal-regulated kinase/integrin beta-1-binding protein 1 pathway. Cancer. 2012;118:5757-5767.

36. Perretti M, Ahluwalia A, Harris JG, Goulding NJ, Flower RJ. Lipocortin-1 fragments inhibit neutrophil accumulation and neutrophil-dependent edema in the mouse. A qualitative comparison with an antiCD11b monoclonal antibody. J Immunol. 1993;151:4306-4314.

37. D’Amico M, Di Filippo C, La M, Solito E, McLean PG, Flower RJ, Oliani SM, Perretti M. Lipocortin 1 reduces myocardial ischemia-reperfusion injury by affecting local leukocyte recruitment. FASEB J. 2000;14:1867-1869.

38. Dalli J, Consalvo AP, Ray V, Di Filippo C, D’Amico M, Mehta N, Perretti M. Proresolving and tissueprotective actions of annexin A1-based cleavage-resistant peptides are mediated by formyl peptide receptor 2/lipoxin A4 receptor. J Immunol. 2013;190:6478-6487.

39. Perretti M, Getting SJ, Solito E, Murphy PM, Gao JL. Involvement of the receptor for formylated peptides in the in vivo anti-migratory actions of annexin 1 and its mimetics. Am J Pathol. 2001;158:1969-1973.

40. Reutelingsperger CP, Hornstra G, Hemker HC. Isolation and partial purification of a novel anticoagulant from arteries of human umbilical cord. Eur J Biochem. 1985;151:625-629.

41. Andree HA, Stuart MC, Hermens WT, Reutelingsperger CP, Hemker HC, Frederik PM, Willems GM. Clustering of lipid-bound annexin V may explain its anticoagulant effect. J Biol Chem. 1992;267:17907-17912. 
42. Huber R, Romisch J, Paques EP. The crystal and molecular structure of human annexin V, an anticoagulant protein that binds to calcium and membranes. EMBO J. 1990;9:3867-3874.

43. Boersma HH, Kietselaer BL, Stolk LM, Bennaghmouch A, Hofstra L, Narula J, Heidendal GA, Reutelingsperger CP. Past, present, and future of annexin A5: from protein discovery to clinical applications. J Nucl Med. 2005;46:2035-2050.

44. De Saint-Hubert M, Bauwens M, Deckers N, Drummen M, Douma K, Granton P, Hendrikx G, Kusters D, Bucerius J, Reutelingsperger CP, Mottaghy FM. In Vivo Molecular Imaging of Apoptosisand Necrosis in Atherosclerotic PlaquesUsing MicroSPECT-CT and MicroPET-CT Imaging. Mol Imaging Biol. 2013.

45. Ewing MM, de Vries MR, Nordzell M, Pettersson K, de Boer HC, van Zonneveld AJ, Frostegard J, Jukema JW, Quax PH. Annexin A5 therapy attenuates vascular inflammation and remodeling and improves endothelial function in mice. Arterioscler Thromb Vasc Biol. 2011;31:95-101.

46. Ewing MM, Karper JC, Sampietro ML, de Vries MR, Pettersson K, Jukema JW, Quax PH. Annexin A5 prevents post-interventional accelerated atherosclerosis development in a dose-dependent fashion in mice. Atherosclerosis. 2012;221:333-340.

47. Domeij H, Hua X, Su J, Backlund A, Yan Z, Frostegard AG, Haeggstrom JZ, Modeer T, Frostegard J. Annexin A5 inhibits atherogenic and pro-inflammatory effects of lysophosphatidylcholine. Prostaglandins Other Lipid Mediat. 2013;106:72-78.

48. Wan M, Hua X, Su J, Thiagarajan D, Frostegard AG, Haeggstrom JZ, Frostegard J. Oxidized but not native cardiolipin has pro-inflammatory effects, which are inhibited by Annexin A5. Atherosclerosis. 2014;235:592-598.

49. Ghislat G, Aguado C, Knecht E. Annexin A5 stimulates autophagy and inhibits endocytosis. J Cell Sci. 2012;125:92-107.

50. New SE, Goettsch C, Aikawa M, Marchini JF, Shibasaki M, Yabusaki K, Libby P, Shanahan CM, Croce K, Aikawa E. Macrophage-derived matrix vesicles: an alternative novel mechanism for microcalcification in atherosclerotic plaques. Circ Res. 2013;113:72-77.

51. Yoshida S, Minematsu N, Chubachi S, Nakamura H, Miyazaki M, Tsuduki K, Takahashi S, Miyasho T, Iwabuchi T, Takamiya R, Tateno H, Mouded M, Shapiro SD, Asano K, Betsuyaku T. Annexin $\mathrm{V}$ decreases PS-mediated macrophage efferocytosis and deteriorates elastase-induced pulmonary emphysema in mice. Am J Physiol Lung Cell Mol Physiol. 2012;303:L852-860.

52. Ueki H, Mizushina T, Laoharatchatathanin T, Terashima R, Nishimura Y, Rieanrakwong D, Yonezawa T, Kurusu S, Hasegawa Y, Brachvogel B, Poschl E, Kawaminami M. Loss of maternal annexin A5 increases the likelihood of placental platelet thrombosis and foetal loss. Sci Rep. 2012;2:827.

53. Brachvogel B, Welzel H, Moch H, von der Mark K, Hofmann C, Poschl E. Sequential expression of annexin A5 in the vasculature and skeletal elements during mouse development. Mech Dev. 2001;109:389-393.

54. Brachvogel B, Dikschas J, Moch H, Welzel H, von der Mark K, Hofmann C, Poschl E. Annexin A5 is not essential for skeletal development. Mol Cell Biol. 2003;23:2907-2913.

55. Belluoccio D, Grskovic I, Niehoff A, Schlotzer-Schrehardt U, Rosenbaum S, Etich J, Frie C, Pausch F, Moss SE, Poschl E, Bateman JF, Brachvogel B. Deficiency of annexins A5 and A6 induces complex changes in the transcriptome of growth plate cartilage but does not inhibit the induction of mineralization. J Bone Miner Res. 2010;25:141-153.

56. Singh NK, Yadav DP, Gupta A, Singh U, Godara M. Role of anti-annexin A5 in pathogenesis of hypercoagulable state in patients with antiphospholipid syndrome. Int J Rheum Dis. 2013;16:325-330.

57. Schutters K, Reutelingsperger CPM. Phosphatidylserine targeting for diagnosis and treatment of human diseases. Apoptosis. 2010;15:1072-1082. 


\section{Chapter 1}

58. Kietselaer BL, Reutelingsperger CP, Heidendal GA, Daemen MJ, Mess WH, Hofstra L, Narula J. Noninvasive detection of plaque instability with use of radiolabeled annexin A5 in patients with carotid-artery atherosclerosis. $N$ Engl J Med. 2004;350:1472-1473. 


\section{Chapter 2}

\section{Molecular imaging to identify the vulnerable plaque - From basic research to clinical practice}

DHM Kusters, J Tegtmeier, LJ Schurgers and CPM Reutelingsperger

Mol Imaging Biol 2012 Oct;14(5):523-33

reprinted with permission 


\section{Abstract}

Cardiovascular disease (CVD) is still the leading cause of death in the Western World. Adverse outcomes of CVD include stroke, myocardial infarction and heart failure. Atherosclerosis is considered to be the major cause of CVD and is estimated to cause half of all deaths in developed countries. Atherosclerotic lesions of the vessel wall may obstruct blood flow mechanically through stenosis, but rupture of atherosclerotic plaques causing formation of occlusive thrombi is far more prevalent. Unfortunately, conventional diagnostic tools fail to assess whether a plaque is vulnerable to rupture. Research over the past decades identified the biological processes that are implicated in the course towards plaque rupture, like cell death and inflammation. Knowledge about plaque biology propelled the development of imaging techniques that target biologic processes in order to predict the vulnerable plaque. This review discusses novel and existing molecular imaging targets and addresses advantages and disadvantages of these targets and respective imaging techniques in respect of clinical application and socio-economic impact. 


\section{Introduction}

Despite great advances in diagnosis and therapy over the past decades, cardiovascular disease (CVD) remains the leading cause of death in developed countries ${ }^{1}$. Globalization of Western life-style is associated with a sharp increase in cardiovascular-related deaths in various emerging economies. Atherosclerosis is considered to be major cause of CVD 2. Atherosclerosis is a systemic inflammatory disease of arteries with focal manifestations of heterogeneous nature that develop over long periods of time ${ }^{3,4}$. The complete process of atherogenesis is described to great extent by Ross ${ }^{2}$, and will therefore not be subject of this review. Briefly, atherosclerosis is characterized by lesions of the intimal vessel wall that develop progressively. The immune and haemostatic system are key players in the progression towards an advanced lesion ${ }^{5}$. The major complication of atherosclerosis is formation of an occlusive thrombus after rupture of a plaque ${ }^{3,6}$.

In order to identify high risk patients prone to develop cardiovascular events, risk profiling such as the Framingham risk score is applied ${ }^{7}$. This score is based on information gathered by epidemiological studies and estimates the risk to develop acute myocardial infarction over a period of 10 years. Although this helps to visualize the risk of individual patients it only offers a rough estimation of a possible event over a long time frame. Moreover, even for high-risk patients, it is currently impossible to discriminate between stable and unstable plaques, and thus to identify patients in need for immediate intervention. Different characteristics of atherosclerotic plaques can be taken into account to assess the severity of the disease. Contrary to common beliefs, plaque size itself does not determine plaque vulnerability. In fact, it has been shown that most atherosclerotic plaques that undergo abrupt rupture showed only negligible levels of vessel stenosis and these patients are most often asymptomatic ${ }^{8,9}$.

Several diagnostic approaches have been employed to identify the patient at high risk for acute arterial events in the presymptomatic phase. One such approach comprises the quantitative measurement of circulating biomarkers. Despite great advances in understanding atherogenic processes on the molecular level, circulating biomarkers are still of limited value ${ }^{10}$. Other approaches comprise imaging techniques to visualize anatomy of atherosclerotic plaques including computed tomography (CT), intravascular ultrasound (IVUS), optical coherence tomography (OCT) and magnetic resonance imaging (MRI). As stipulated above these techniques fail to identify the vulnerable 
plaque because no unambiguous association exists between plaque morphology and stability. Therefore, recently focus has shifted towards molecular imaging in an attempt to identify the unstable plaque ${ }^{11,12}$. Several biological characteristics in humans have been associated with an unstable plaque phenotype e.g. pro-inflammatory status ${ }^{13-15}$, large (oxidized) lipid content ${ }^{16}$, thin fibrous cap ${ }^{17,18}$, presence of platelets/intra-plaque thrombi or hemorrhage ${ }^{19}$, low number of (viable) vascular smooth muscle cells, high content of activated matrix metalloproteases (MMPs) ${ }^{20-25}$, neovascularization ${ }^{26}$, (micro) calcification ${ }^{27,28}$, high shear ${ }^{29}$, large necrotic core ${ }^{16}$, high levels of apoptosis ${ }^{30}$ and impaired efferocytosis ${ }^{31-35}$. All these biological characteristics can be exploited for noninvasive molecular imaging of atherosclerosis in order to visualize the vulnerable plaque. This review focuses on existing and novel targets to image atherosclerosis non-invasively, and addresses which targets could possibly be translated from preclinic to clinic in order to filter out patients at risk for acute atherothrombotic events (Figure 1).

\section{Molecular imaging of inflammation}

\section{Preclinical}

The reader is referred to a recent review for details of inflammation and macrophages in atherosclerosis ${ }^{36}$. Cells participating in the inflammatory process use glucose as main energy source. An analogue of glucose, 2-deoxy-2- ${ }^{37}$ fluoro-D-glucose $\left({ }^{18} \mathrm{FDG}\right)$, can be used to visualize these cells using Positron Emission Tomography (PET) ${ }^{38}$. Although not the primary aim, it was first noted in cancer studies that also arterial walls showed uptake of ${ }^{18} \mathrm{FDG}$ and that this uptake was higher in older patients and patients with cardiovascular risk factors ${ }^{39}$. It was confirmed by several other studies that ${ }^{18} \mathrm{FDG}$ is taken up by the vessel wall, and that this uptake correlates with atherosclerosis ${ }^{40-42}$. Uptake of ${ }^{18} \mathrm{FDG}$ was higher in more advanced and unstable plaques and correlated with macrophages content inside the plaque ${ }^{43}, 44$.

Macrophages can also be targeted with antibodies against e.g. LOX-1, PBR (peripheral benzodiazepine receptor) or lactadherin (mfg-E8) ${ }^{15}$. LOX-1 has been suggested as an interesting target since it is upregulated in response to high levels of oxLDL, proinflammatory cytokines, or mechanical stress ${ }^{45}{ }^{46}$. For imaging purposes, a LOX-1 antibody was conjugated with ${ }^{99 \mathrm{~m}}$ Technetium $\left({ }^{99 \mathrm{~m}} \mathrm{Tc}\right)$, which can be visualized by Single Photon Emission Computed Tomography (SPECT). The efficacy of this antibody was 
first demonstrated in a rabbit model of atherosclerosis and evaluated by histological analysis ${ }^{47}$. Li et al. confirmed that this antibody reliably targets macrophages in vivo in ApoE ${ }^{-1}$ mice and $\mathrm{LDLR}^{--}\left(\mathrm{LOX1}^{--}\right)$mice ${ }^{48}$. The PBR (also known as translocator protein, TSPO) is minimally expressed in non-inflamed tissue and highly expressed on activated macrophages, and is therefore exploited as molecular imaging target ${ }^{49}$.

The most frequently used contrast agents for molecular imaging of macrophages in atherosclerotic plaques are (lipid-coated ultra) small superparamagnetic iron-oxide particles (LUSPIO/SPIO) or antibody coated micelles ${ }^{50-53}$. SPIOs are spontaneously engulfed by macrophages of animals and humans. Focal accumulation of SPIOs causes a signal decrease that can be detected by MRI. It has been shown that this decrease correlates with the level of intra-plaque inflammation ${ }^{54}$. These nanoparticles can also be conjugated to specific ligands targeting macrophages with high sensitivity and selectivity ${ }^{50}$. Monocrystalline iron oxide nanoparticles (MION) or cross-linked iron oxide nanoparticles (CLIO) have been coupled to a variety of unstable plaque-specific ligands targeting, adhesion molecules, lipoproteins, proteases and macrophages and offers the possibility to add fluorescent dyes for imaging in vivo and in vitro ${ }^{11,55-58}$.

Another target for imaging of inflammation is P-selectin, which is expressed on activated endothelial cells and platelets. This molecule mediates tethering and rolling of leukocytes prior to migration into the plaque and is associated with increased plaque instability 59 . A recently described nuclear tracer ( ${ }^{99 \mathrm{~m}} \mathrm{Tc}$-fucoidan) can be used to successfully image P-selectin overexpression in arterial thrombosis and endothelial cell activation after ischemia ${ }^{60}$. Using different imaging probes, the feasibility of P-selectin imaging in atherosclerotic settings has already been shown ${ }^{61,62}$. Another adhesion molecule, vascular cell adhesion molecule 1 (VCAM-1), is also exploited as potential imaging target. In a recent publication it is shown that a VCAM-1 targeted USPIO derivative (R832) shows specific plaque uptake in $\mathrm{ApoE}^{-/-}$mice, visualized by MRI within 30 minutes ${ }^{63}$. Specific uptake was confirmed by ex vivo histology. However, after 30 minutes also non-specific uptake was observed, which was probably caused by the enhanced permeability and retention (EPR) effect in the plaque. The authors show a possibility to identify features of unstable plaque phenotypes in these mice, which could potentially be translated to the clinic ${ }^{63}$. Besides adhesion molecules, activated endothelial cells also highly express the integrin $\alpha_{v} \beta_{3}$. Targeting this integrin has been done by a low molecular weight peptidomimetic of arginine-glycin-asparctic acid peptide (mimRGD) conjugated to 
gadolinium-diethylenetriaminepentaacetate (Gd-DTPA) ${ }^{64}$. Specific integrin binding and imaging of aortic plaques was confirmed by competition experiments and subsequent histological analysis. Increased uptake of the contrast agent is directly correlated with an enlarged neovascular network and thus plaque instability.

\section{Clinical}

Imaging of vascular inflammation by ${ }^{18} \mathrm{FDG}$ uptake with PET has been performed in several clinical trials which have recently been reviewed by Rudd et al. ${ }^{65}$. Menezes et al. performed a prospective study to determine the optimal time to image vascular inflammation using ${ }^{18} \mathrm{FDG}$ PET/CT amongst 17 asymptomatic patients undergoing routine surveillance for atherosclerotic abdominal aortic aneurysms ${ }^{66}$. There was no significant difference in Signal to Noise Ratio (SNR), despite a significant difference between aortic wall and lumen uptake in time ${ }^{66}$. More recently ${ }^{18} \mathrm{FDG}$ PET and CT angiography were performed in 21 patients undergoing endarterectomy in order to investigate plaque vulnerability. A positive correlation between plaque ${ }^{18} \mathrm{FDG}$ uptake and CD68/VEGF positivity was found. Furthermore an inverse relationship between ${ }^{18} \mathrm{FDG}$ plaque uptake and plaque percentage calcium composition on CT was observed ${ }^{67}$. Meyers et al. conducted a multicenter clinical trial to evaluate arterial ${ }^{18} \mathrm{FDG}$ uptake in peripheral artery disease. The researchers included 21 patients and measured ${ }^{18} \mathrm{FDG}$ uptake in carotid, aortic and femoral artery before atherectomy, and compared this uptake to immunohistochemical CD68 positivity. However, no significant correlation between lesion SNR and CD68 level was found ${ }^{68}$.

A recent clinical trial (dal-PLAQUE) that evaluates the efficacy and safety of dalcetrapib, assigned 64 patients to dalcetrapib or placebo for 24 months. Total vessel area was determined by MRI and found to be reduced in patients given dalcetrapib. However, PET/CT showed no evidence of increased or decreased vascular inflammation ${ }^{69,70}$.

Most of these clinical trials provide in vivo evidence that increased plaque metabolism is associated with increased biomarkers of inflammation. However the greater part fails to show a correlation between ${ }^{18} \mathrm{FDG}$ uptake and plaque vulnerability, particularly in the coronary arteries. Imaging of coronary arteries is complicated because of the movement of the heart and the small size. Moreover, the myocardium has a high background uptake of ${ }^{18} \mathrm{FDG}$ which compromises the SNR. Dietary measures can suppress the background uptake of ${ }^{18} \mathrm{FDG}$ by the myocardium to some extent ${ }^{71}$. 


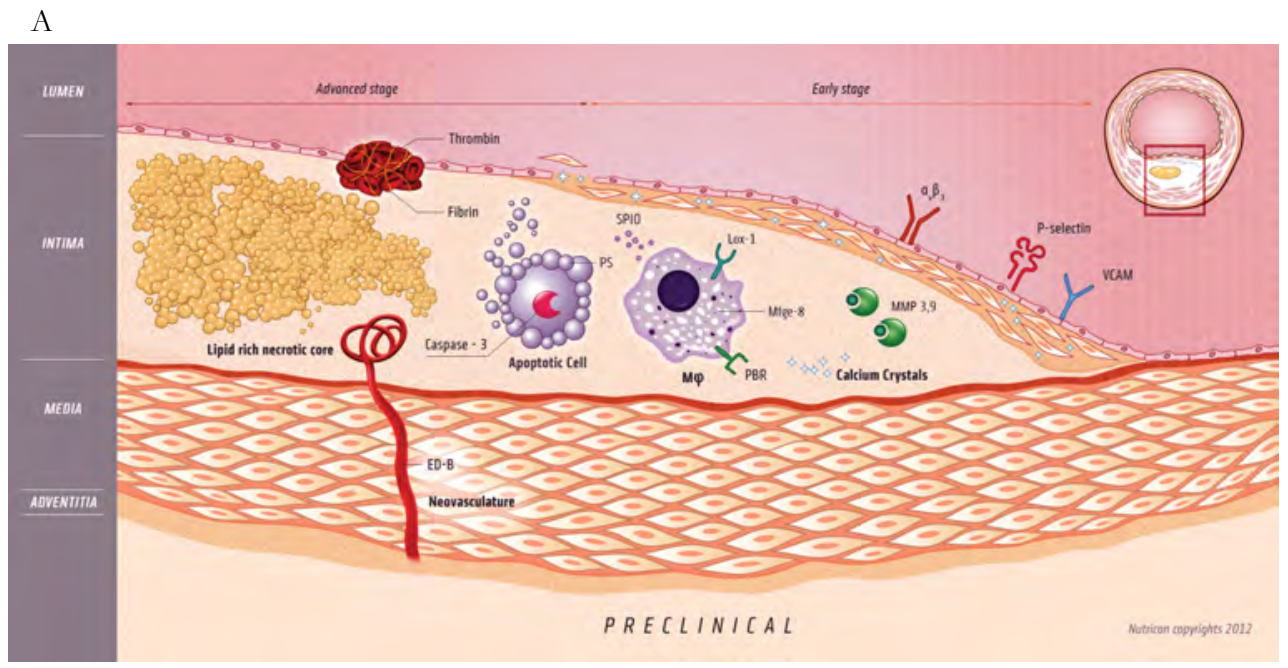

B

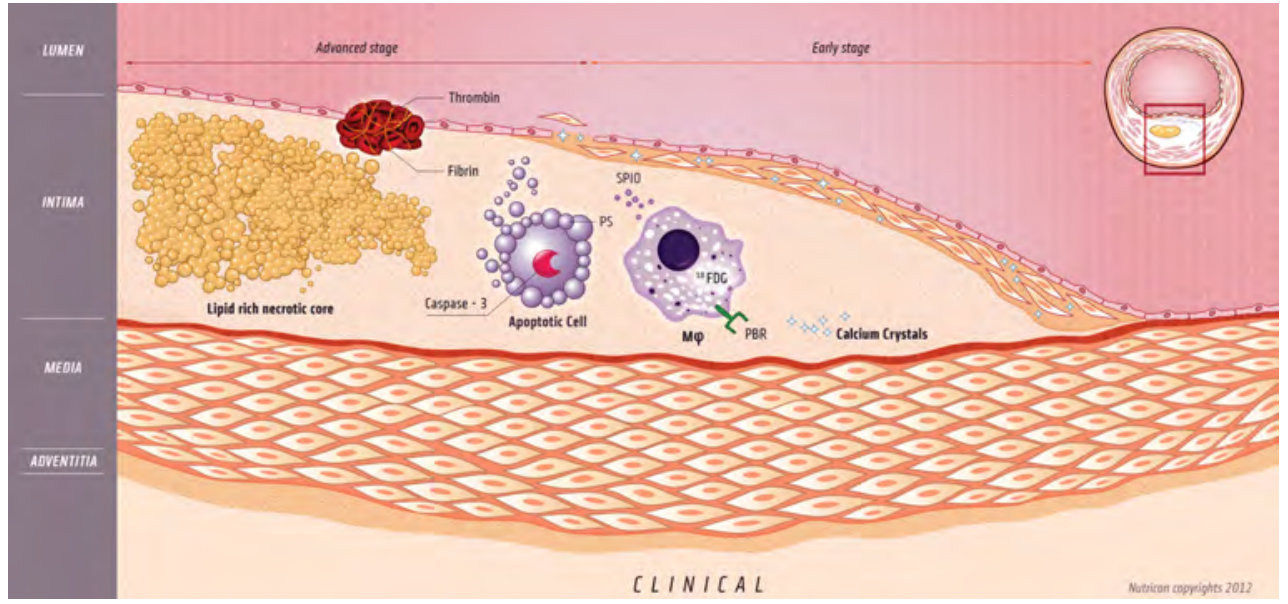

Figure 1-Molecular imaging targets for the detection of the vulnerable atherosclerotic plaque. The process of atherogenesis is shown with preclinical (A) and clinical (B) molecular imaging targets. Some targets have proven their potential in animal models but have not been validated in clinical trials. VCAM, vascular cell adhesion molecule 1; MMP, matrix metalloprotease; PBR, peripheral benzodiazepine receptor; $\mathrm{M} \varphi$, macrophage; SPIO, super paramagnetic iron oxide particle; PS, phosphatidylserine; ED-B, fibronectin extra-domain B. 
PET imaging of the peripheral benzodiazepine receptor (PBR) has also been performed. Although animal studies have yielded several promising tracers for PBR imaging (e.g. ${ }^{11} \mathrm{C}$ PK11195, ${ }^{11} \mathrm{C}-\mathrm{DAA} 1106,{ }^{11} \mathrm{C}-\mathrm{PBR} 28,{ }^{11} \mathrm{C}-\mathrm{DPA} 713,{ }^{11} \mathrm{C}$-CLINME and ${ }^{18} \mathrm{~F}$-FEDAA1106), hitherto only ${ }^{11} \mathrm{C}$-PK11195 (1-(2-chlorophenyl)- $N$-methyl- $N$-(1-methylpropyl)-3isoquinoline-carboxamide) has been investigated in clinical studies ${ }^{72}$. Recently ${ }^{11} \mathrm{CPK} 11195$ has been used in two small-scale clinical trials. Pugliese et al. imaged 6 patients with systemic inflammatory disorders and clinical suspicion of active vasculitis compared to 9 controls. Focal ${ }^{11} \mathrm{C}-\mathrm{PK} 11195$ uptake in the arterial wall of all symptomatic patients was noticed compared to no detectable uptake in the control group ${ }^{73}$. Gaemperli $e t$ al. imaged 32 patients with carotid stenosis (9 symptomatic / 23 asymptomatic) and compared ${ }^{11} \mathrm{C}-\mathrm{PK} 11195$ uptake into carotid plaques ${ }^{74}$. Both research groups concluded that ${ }^{11} \mathrm{C}$-PK11195 PET allows non-invasive detection and quantification of intra-plaque inflammation in patients. Moreover, the combination of ${ }^{11} \mathrm{C}-\mathrm{PK} 11195$ PET with contrastenhanced CT provides an integrated assessment of plaque structure, composition and biological activity, and allows the distinction between recently symptomatic vulnerable plaques and asymptomatic plaques with a high positive predictive value. Whether ${ }^{11} \mathrm{C}$ PK11195 is a Molecular Imaging agent to identify vulnerable plaque, also in coronary arteries, needs to be assessed by more clinical trials.

\section{Molecular imaging of cell death}

\section{Preclinical}

Apoptosis of macrophages and smooth muscle cells is associated with plaque instability, since this leads to a growing necrotic core, inflammation, the release of proteases and subsequently thinning of the fibrous cap ${ }^{17,31}$. Apoptosis can be imaged using either intracellular or membrane bound targets.

During apoptosis caspases are activated that degrade intracellular proteins and DNA in an orderly manner. Caspases are expressed as inactive zymogens in healthy cells, but cleave to their active form in response to apoptotic signals. This property makes targeting of activated caspases attractive. An inhibitor of caspase-3 and -7, radiolabeled isatin-5sulfonamide $\left({ }^{18} \mathrm{~F}-\mathrm{ICTM}-11\right)$ and several of its analogues, have been evaluated as imaging agent of apoptosis in vitro ${ }^{75}$, in vivo ${ }^{76}$, in a rat model of liver cell apoptosis ${ }^{77}$ and in tumor bearing mice ${ }^{78}$. All studies provide great evidence of the potential to use activated 
caspase specific imaging agents to find culprit lesions. However, thus far this has not been tested in animal models of atherosclerosis.

Another hallmark of apoptosis is, externalization of phosphatidylserine (PS), which is normally predominantly confined to the inner leaflet of the plasma membrane ${ }^{79}$. The protein annexin A5 (anxA5) has been shown to bind PS with nanomolar affinity. This discovery has led to the use of PS as target for molecular imaging of apoptosis in vitro and in vivo in myocardial infarction ${ }^{80}$, cancer $^{81,82}$ and atherosclerosis ${ }^{43}$. For this purpose, anxA5 was conjugated to radiotracers for nuclear imaging and fluorescent probes for histological analysis ${ }^{83-85}$. Pioneering studies of molecular imaging of apoptosis were performed with technetium-labeled anxA5 ( ${ }^{99 \mathrm{~m}} \mathrm{Tc}$-anxA5) and SPECT. One of the first approaches was to target apoptotic macrophages in animal models of atherosclerosis ${ }^{43,51,86,87}$. To verify the results of molecular imaging, histological analysis of the atherosclerotic plaques was performed. Atherosclerotic lesions showed increased uptake of ${ }^{99 \mathrm{~m}} \mathrm{Tc}-\mathrm{AnxA} 5$ compared to control animals. Furthermore a gradient of ${ }^{99 \mathrm{~m}} \mathrm{Tc}$-anxA5 uptake was observed which correlated to the grade of the atherosclerotic lesion. This level of ${ }^{99 \mathrm{~m}} \mathrm{Tc}$-anxA5 uptake could directly be linked to the level of macrophage infiltration ${ }^{87}$. Those in vivo results confirmed that ${ }^{99 \mathrm{~m}} \mathrm{Tc}$-anxA5 can target apoptosis in living animals and that uptake correlates with the severity of atherosclerosis ${ }^{43,87}$. An alternative to anxA5 to target PS is lactadherin (mfg-E8). Falborg et al. compared the biodistribution of lactadherin and anxA5, both conjugated to ${ }^{99 \mathrm{~m}} \mathrm{Tc}$-labeled hydrazinonicotinamide ( ${ }^{99 \mathrm{~m}} \mathrm{Tc}-\mathrm{HYNIC}$ ). Regarding biodistribution and blood clearance lactadherin is comparable to anxA5. However, anxA5 showed higher uptake in the kidneys, whereas lactadherin showed higher uptake in the liver ${ }^{88}$. Another alternative for detection of cell death is the $\mathrm{C} 2 \mathrm{~A}$ domain of synaptotagmin-I which also binds PS ${ }^{89}$. The C2A domain has been labeled with paramagnetic and radionuclide labels and used to detect apoptosis in vivo successfully. However, a proper quantification of conjugated label could not be performed, and affinity for PS decreased after labeling ${ }^{90}$. A recent study compared a mutated form of C2A and anxA5 in their ability to quantitatively image cell death ${ }^{91}$. The mutant described was fluorescently labeled and showed lower binding to viable cells than a similarly labeled anxA5, thus increasing its specificity. This could partly be explained by a slightly lower affinity for PS, which might be important when radionuclide derivatives of this protein will be used to detect cell death in vivo ${ }^{91}$. Confirmation of its ability to detect apoptosis in atherosclerotic plaques still has to be performed. 


\section{Clinical}

The first small scale clinical trial to image apoptosis with labelled anxA5 was done in 4 patients with either recent or remote history of a transient ischemic attack (TIA) ${ }^{92}$. These patients were scheduled for carotid endarterectomy (CEA), and imaging was done before removal of the carotid lesions. The patients with a recent TIA showed lucid uptake of ${ }^{99 \mathrm{~m}}$ Tc-AnxA5, whereas those with a remote TIA did not show any significant uptake. After CEA, plaque analysis from patients with recent TIA showed that unstable plaques stained anxA5 positive. In contrast, lesions of patients with remote TIA which had a stable phenotype, showed almost no anxA5 uptake. The researchers conclude that ${ }^{99 \mathrm{~m}} \mathrm{Tc}$-anxA5 imaging could help to identify unstable plaques in patients with carotid atherosclerosis ${ }^{92}$. Unfortunately, this clinical study involved only a very small number of patients, thus more and larger clinical cohort studies are needed to confirm these promising results. Although very promising, all other imaging tracers mentioned above for the imaging of cell death, have not been tested in a clinical trial thus far.

\section{Molecular imaging of remodeling}

\section{Preclinical}

As response to partial occlusion of a vessel, constrictive or expansive vascular remodeling can occur ${ }^{93}$. Vascular remodeling is associated with increasing plaque vulnerability and consists of several distinct processes. Two major processes are angiogenesis and hypertrophic compensation of the vessel ${ }^{94}$.

Key players and potential imaging target of vascular remodeling are vascular smooth muscle cells (VSMCs). In general, VSMCs can exhibit two phenotypes, contractile or synthetic ${ }^{95}$. Synthetic VSMCs are predominantly present in the intima, are more prone to calcify and become apoptotic, and therefore seen as detrimental ${ }^{96}$. Several groups targeted vascular remodeling in atherosclerosis with a labeled antibody (Z2D3) specific against synthetic VSMCs. They verified binding ex vivo in human atherosclerotic endarterectomy specimens ${ }^{97}$, in vivo by SPECT in a rabbit model ${ }^{98,99}$, a rat model ${ }^{100}$ and by scintillation gamma counting in a swine model ${ }^{101,102}$. All studies show the possibility to selectively image synthetic VSMCs to great extent in animals, but this still has to be established in clinical trials. 
Hypertrophic compensation is associated with the activation of several proteases (e.g. matrix metallo proteases (MMPs) or cathepsin $\mathrm{G}$ ). Besides their role in vascular remodeling and inflammation, these proteases have significant detrimental effects on cap thickness and therefore plaque stability ${ }^{20-22,24}$. Activated MMPs form an interesting target to identify unstable lesions, and have extensively been investigated using an antibody against activated MMPs (P947). This antibody was recently tested and validated in several in vivo studies $23,25,55,103$. Lancelot et al. show excellent delinearization of the plaque with strong signal intensity enhancement using non-invasive MRI. However, a limitation of imaging with P947 is that it does not discriminate between different activated MMPs and Johnson et al. found that MMP-3 and 9 could even exert a beneficial effect on plaque phenotype ${ }^{22}$. Another strategy for imaging of activated MMP's is using MMP2/9 specific substrate. Deguchi et al. show that labeling of a small substrate peptide with a near infra-red probe enables specific non-invasive optical molecular imaging of activated MMP2/9 in atherosclerotic plaques ${ }^{104}$. As an alternative for MMP imaging, Narula $e t$

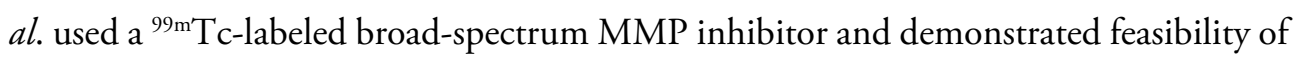
noninvasive detection of activated MMPs in atherosclerotic lesions ${ }^{105}$.

Another process in vascular remodeling is angiogenesis. Plaque and vasa vasorum neovascularization are associated with decreased plaque stability and offers several potential imaging targets that have been investigated; integrin $\alpha_{v} \beta_{3}{ }^{26,106,107}$, fibronectin extradomain B (ED-B) ${ }^{108}$ and vascular endothelial growth factor receptor (VEGFr). Winter et al. showed that in vivo imaging of neovascularization of atherosclerotic plaques using MRI targeting $\alpha_{\mathrm{v}} \beta_{3}$ is feasible and might provide a method for defining the burden and evolution of atherosclerosis ${ }^{26}$. Matter et al. showed that targeting of fibronectin with a labeled human recombinant antibody $\left({ }^{125} \mathrm{I}-\mathrm{SIP}^{108}\right)$, could selectively visualize atherosclerotic plaques in ApoE $E^{-/}$-mice with a high SNR and very high specificity ${ }^{108}$. Thus far no molecular imaging studies targeting VEGFr in atherosclerosis have been performed, nevertheless molecular imaging of VEGFr in cancer has been investigated and validated extensively ${ }^{109,110}$.

Taken together these preclinical studies indicate high potential for non-invasive molecular imaging of vascular remodeling, even though none of above mentioned probes has made it to clinical studies yet (table 1). 
Table 1: Molecular imaging targets for the vulnerable plaque

\begin{tabular}{|c|c|c|c|c|}
\hline Process & Target & Agent & $\begin{array}{l}\text { Imaging } \\
\text { Modality }\end{array}$ & Phase (ref) \\
\hline \multirow[t]{6}{*}{ Inflammation } & Macrophages & ${ }^{18} \mathrm{FDG}$ & PET or PET/CT & Clinical $40-44,66-70$ \\
\hline & & ${ }^{11} \mathrm{C}-\mathrm{PK} 11195$ & PET & Clinical ${ }^{72-74}$ \\
\hline & & 99mTc-anti- & SPECT & Preclinical 47,48 \\
\hline & & LOX-1 & & \\
\hline & & Nanoparticles & MRI & Preclinical 52,54 \\
\hline & P-Selectin & ${ }^{99 \mathrm{~m}} \mathrm{Tc}$-fucoiden & SPECT/MRI & Preclinical ${ }^{60-62}$ \\
\hline \multirow[t]{2}{*}{ Apoptosis } & VSMC, & ${ }^{99 m}$ Tc-anxA5 & SPECT & Clinical $^{43,84-86,92}$ \\
\hline & Macrophages & & & \\
\hline \multirow{4}{*}{$\begin{array}{l}\text { Vascular } \\
\text { remoddeling }\end{array}$} & VSMC & Z2D3 & SPECT & Preclinical 97-102 \\
\hline & MMP & P947 & MRI & $\begin{array}{l}\text { Preclinical 23, 25, } \\
55,103\end{array}$ \\
\hline & Integrin $\otimes_{\mathrm{v}} \bigotimes_{3}$ & Nanoparticles & MRI & Preclinical ${ }^{26}$ \\
\hline & ED-B & L19 & SPECT & Preclinical 108 \\
\hline
\end{tabular}

\section{Molecular imaging of thrombosis}

\section{Preclinical}

The haemostatic system is an important modulator of atherosclerosis and plays a key role in plaque rupture and subsequent thrombus formation ${ }^{111}$. Therefore, partakers of the coagulation cascade might be an interesting target for molecular imaging to identify the vulnerable plaque ${ }^{112}$. Inflamed endothelium and cells participating in the development of the necrotic core show high levels of fibrin and thrombin expression. Abundance of fibrin on the surface or within atherosclerotic plaques has thus been associated with vulnerable plaques ${ }^{113,114}$. The fibrin-targeted-contrast-agent (FTCA) uses gadolinium contrast and can be visualized by MRI. Besides its various applications in animal studies, FTCA has also been used in a clinical trial to detect thrombi in the heart and blood vessels ${ }^{115-118}$. A recent study showed that FTCA can be successfully applied to image endothelial and intraplaque fibrin in a mouse model of atherosclerosis ${ }^{119}$. Despite the ubiquitous distribution of fibrin, FTCA in atherosclerotic plaques could be visualized with a good SNR. FTCA uptake and signal enhancement was strongest in culprit lesions, 
as confirmed by immunohistochemistry. This is in concordance with recent findings from autopsy studies that indicate that advanced lesions express high levels of fibrin ${ }^{113}$. Additionally, it was found that fibrin is a key component of plaque erosion ${ }^{114,120}$ and can be applied to image eroding plaques which can cause thrombosis without plaque rupture 119 . Although less common in general, plaque erosion is estimated to cause up to $25 \%$ of coronary thrombosis leading to $\mathrm{MI}$ and is especially important in women ${ }^{121}$. Even though molecular imaging of thrombosis has not yet been applied in clinical studies of atherosclerosis, it still represents a promising target. Given that fibrin is associated with two important characteristics of vulnerable plaques and FTCA has been successfully used to detect thrombi in the heart and blood vessels of patients. Therefore, the future clinical use of thrombosis imaging to identify vulnerable plaques is highly probable.

\section{Molecular imaging of (micro) calcification}

\section{Preclinical}

Calcification has long been associated with the process of atherosclerosis and acute cardiovascular events ${ }^{120}$. Although large calcifications inside the plaque have been shown to promote plaque stability ${ }^{122}$, spotty calcifications - especially inside the fibrous cap - are suggested to cause plaque rupture and thrombotic events ${ }^{28,123}$. It is postulated that those micro-calcifications, which are undetectable by conventional imaging, increase the local stress inside the thin fibrous cap by 2 -fold and thus increase the likelihood of rupture ${ }^{28}$. It is assumed that calcification is a product of osteogenic action by osteocytic- and chondrocytic-like cells inside the plaque. The work of Aikawa and colleagues provided substantial insights in the course of micro-calcification and possibilities to visualize this process ${ }^{124}$. In a mouse model of atherosclerosis they showed that macrophage infiltration in early atherosclerotic plaques precedes calcification. Later, those events occur in temporal and spatial overlap. Conventional histological and CT imaging failed to visualize early micro-calcifications. Using intravital fluorescence microscopy with a nanoparticle-based contrast agent to visualize macrophages and a bisphosphonate-bases agent to detect calcifications, the authors were able to properly detect inflammation and micro-calcifications in early atherosclerotic plaques. Due to the time at which these micro-calcifications take place and their implications in destabilizing the plaque, molecular imaging would be able to detect rupture-prone plaques at a very early stage. Asymptomatic high-risk patients would benefit from this application. Additionally, molecular imaging 
of micro-calcification provides an opportunity to monitor and evaluate the early success of therapeutic interventions.

\section{Clinical}

The association of vascular ${ }^{18} \mathrm{FDG}$ uptake and vascular calcification detected by contemporaneous CT was investigated. The researchers evaluated PET/CT images of 78 patients that were referred for tumor staging. These images were analyzed for the presence of vascular ${ }^{18} \mathrm{FDG}$ uptake and vascular calcification. They found that vascular calcification and vascular metabolic activity rarely $(<2 \%)$ overlapped. This suggests that these findings represent different phases of atherosclerosis ${ }^{125}$. These findings were confirmed by Rudd $e t$ $a l$. who investigated the relationship between inflammation and arterial calcification. The researchers imaged inflammation in 41 patients with ${ }^{18} \mathrm{FDG}$ PET/CT and scored calcium by CT analysis. Additionally, from 33 of these patients a collection of biomarkers was determined. The authors suggested that ${ }^{18}$ FDG PET imaging can be used as a surrogate marker of both atherosclerotic disease activity and drug effectiveness ${ }^{41}$.

Calcification status can also be visualized by ${ }^{18} \mathrm{~F}$-sodium fluoride with PET. In a retrospective study, arterial ${ }^{18} \mathrm{~F}$-sodium fluoride uptake and calcification was evaluated. When spatial correlation between vascular ${ }^{18} \mathrm{~F}$-sodium fluoride uptake and calcification sites were analyzed per-lesion, $12 \%$ of lesions with marked arterial wall ${ }^{18} \mathrm{~F}$-sodium fluoride uptake did not show concordant calcification. This study shows the feasibility of using ${ }^{18} \mathrm{~F}$-sodium fluoride for in vivo functional imaging of atherosclerotic lesions ${ }^{126}$. Hitherto, locating microcalcification in the vessel wall with ${ }^{18} \mathrm{~F}$-sodium fluoride has not been demonstrated, in order to find these minute alterations OCT might be more feasible.

\section{Socio-economic impact of molecular imaging}

As major cause of cardio- and cerebrovascular morbidity and mortality, atherosclerosis puts a significant strain on healthcare budgets. The following numbers serve as an example of the costs that originate from atherosclerosis and underline the need for new diagnostic tools and treatments. The total expenses for stroke in the Netherlands summed up to more than 1.6 billion euros in the year 2007, making stroke one of the ten most expensive conditions ${ }^{127}$. The costs for stroke made up 2,2\% of total healthcare costs in the Netherlands. A comparable situation is found in Germany (3.4\% of total costs) ${ }^{128}$. 
Acute coronary syndromes (mostly unstable angina and acute MI) are also within the top ten of the most expensive diseases in the Netherlands. The total expenses in 2007 summed up to 1.807 billion euros ${ }^{127}$. In other European countries like the UK, France, Germany, Italy and Spain costs range from 1 to 3 billion euros yearly ${ }^{129}$. These values represent between $1 \%$ and $3 \%$ of total healthcare costs in those countries. In the US, total annual costs for CVD and stroke are estimated at 297.7 billion dollar, accounting for $16 \%$ of total healthcare expenditures in $2008{ }^{130}$.

These numbers demonstrate the enormous expenses for the healthcare system. Therefore any improvement in the diagnosis of atherosclerosis, and thus prevention of its adverse outcomes, would lower financial burden significantly.

Support for this approach comes from the SHAPE Guideline by Naghavi and colleagues ${ }^{131}$. In an extensive work the SHAPE task force proposed protocols to identify the vulnerable patient with a high risk of MI or stroke. The report underlines the shortcomings of current risk stratification as the Framingham Risk Score and the System Coronary Risk Evaluation (SCORE). These tools assign most people to a group with intermediate risk for adverse outcomes. The power to predict an acute event is especially low in this group; yet the incidence of $\mathrm{MI}$ is the highest. To improve risk profiling the authors propose two non-invasive tests namely carotid intima-media thickness (CIMT) and coronary artery calcification (CACS) to be applied to the population at risk. Based on initial screening with CIMT or CACS patients are categorized and treated if necessary. Large studies demonstrated predictive power and cost-effectiveness of this approach. All current nonmolecular imaging modalities are able to find vascular stenosis but fail to discriminate reliably between vulnerable and stable lesions in patients ${ }^{132}$. Newer imaging techniques can increase the accuracy of this risk stratification. In this regard, molecular imaging of the vulnerable plaque offers great potential. Once established, molecular imaging can be added to the SHAPE Guideline to strengthen the power of diagnostics in preventive cardiology. Another beneficial aspect is that molecular imaging uses probes specific for targets on (unstable) atherosclerotic plaques, which could potentially be used as theranostic. 


\section{Conclusion and Future Perspectives}

Molecular imaging of atherosclerosis bears potential as a powerful diagnostic tool to screen and select patients prone to develop CVD morbidity and mortality and, hence, to contribute to a personalized and more cost-effective treatment of atherosclerotic disease. This review has highlighted molecular imaging targets that have been studied in vitro and in vivo in experimental animal models of atherosclerosis and that have potential to be translated to clinical practice. Most promising targets are found in the process of apoptosis, vascular remodelling and inflammation (Figure 1, Table 1). Additionally, we suggest that efferocytosis of apoptotic cells might be added as an interesting molecular imaging target, since impairment of efferocytosis is associated with an increase of necrotic core and consequently with an increased vulnerability $31,32,34,133,134$. Ligands specific for non-invasive imaging of efferocytosis still need to be explored; potential targets might be C1q, MfgE-8, LRP-1 and Gas6.

Translation of molecular imaging ligands from preclinical research to clinical practice faces important scientific as well as financial challenges to be overcome. Although animal models can reflect human vulnerable plaque phenotype, results of preclinical research cannot simply be extrapolated to the human situation, since spontaneous rupture of a plaque without manipulation so far has not been observed in animal models. In addition, molecular imaging remains relatively expensive and time-consuming, both of which limit large clinical studies to validate targets and ligands.

Further scientific research into pathobiology of the vulnerable plaque, and technological development of imaging equipment that increases sensitivity and specificity are required if we wish to uphold the promise of molecular imaging to reduce health care costs. Successful translation of targets and ligands to clinical molecular imaging of the vulnerable plaque may also offer novel therapeutic avenues to treat the vulnerable plaque employing strategies such as targeted drug delivery. 


\section{References}

1. Borissoff JI, Spronk HM, ten Cate H. The hemostatic system as a modulator of atherosclerosis. The New England journal of medicine. 2011;364:1746-1760.

2. Ross R. Atherosclerosis--an inflammatory disease. The New England journal of medicine. 1999;340:115-126.

3. Libby P. Molecular bases of the acute coronary syndromes. Circulation. 1995;91:2844-2850.

4. Virmani R, Burke AP, Kolodgie FD, Farb A. Vulnerable plaque: the pathology of unstable coronary lesions. J Intervent Cardiol. 2002;15:439-446.

5. Libby P, Ridker PM, Hansson GK. Progress and challenges in translating the biology of atherosclerosis. Nature. 2011;473:317-325.

6. Libby P, Sukhova G, Lee RT, Galis ZS. Cytokines regulate vascular functions related to stability of the atherosclerotic plaque. J Cardiovasc Pharmacol. 1995;25 Suppl 2:S9-12.

7. Tzoulaki I, Liberopoulos G, Ioannidis JP. Assessment of claims of improved prediction beyond the Framingham risk score. JAMA : the journal of the American Medical Association. 2009;302:2345-2352.

8. Davies MJ. A macro and micro view of coronary vascular insult in ischemic heart disease. Circulation. 1990;82:II38-46.

9. Hansson GK. Inflammation, atherosclerosis, and coronary artery disease. $N$ Engl J Med. 2005;352:1685-1695.

10. Wang TJ, Gona P, Larson MG, Tofler GH, Levy D, Newton-Cheh C, Jacques PF, Rifai N, Selhub J, Robins SJ, Benjamin EJ, D’Agostino RB, Vasan RS. Multiple biomarkers for the prediction of first major cardiovascular events and death. NEngl J Med. 2006;355:2631-2639.

11. Matter CM, Stuber M, Nahrendorf M. Imaging of the unstable plaque: how far have we got? Eur Heart J. 2009;30:2566-2574.

12. Yuan C, Hatsukami TS, Cai J. MRI plaque tissue characterization and assessment of plaque stability. Stud Health Technol Inform. 2005;113:55-74.

13. Bouki KP, Katsafados MG, Chatzopoulos DN, Psychari SN, Toutouzas KP, Charalampopoulos AF, Sakkali EN, Koudouri AA, Liakos GK, Apostolou TS. Inflammatory markers and plaque morphology: an optical coherence tomography study. Int J Cardiol. 2012;154:287-292.

14. Kerwin WS, O'Brien KD, Ferguson MS, Polissar N, Hatsukami TS, Yuan C. Inflammation in carotid atherosclerotic plaque: a dynamic contrast-enhanced MR imaging study. Radiology. 2006;241:459-468.

15. Tabas I. Macrophage death and defective inflammation resolution in atherosclerosis. Nature reviews. Immunology. 2010;10:36-46.

16. Gao T, Zhang Z, Yu W, Wang Y. Atherosclerotic carotid vulnerable plaque and subsequent stroke: a high-resolution MRI study. Cerebrovasc Dis. 2009;27:345-352.

17. Kolodgie FD, Narula J, Haider N, Virmani R. Apoptosis in atherosclerosis. Does it contribute to plaque instability? Cardiol Clin. 2001;19:127-139, ix.

18. Tabas I. Pulling down the plug on atherosclerosis: finding the culprit in your heart. Nat Med. 2011;17:791-793.

19. Derksen WJ, Peeters W, van Lammeren GW, Tersteeg C, de Vries JP, de Kleijn DP, Moll FL, van der Wal AC, Pasterkamp G, Vink A. Different stages of intraplaque hemorrhage are associated with different plaque phenotypes: a large histopathological study in 794 carotid and 276 femoral endarterectomy specimens. Atherosclerosis. 2011;218:369-377.

20. Bazeli R, Coutard M, Duport BD, Lancelot E, Corot C, Laissy JP, Letourneur D, Michel JB, Serfaty JM. In vivo evaluation of a new magnetic resonance imaging contrast agent (P947) to target matrix metalloproteinases in expanding experimental abdominal aortic aneurysms. Invest Radiol. 2010;45:662-668. 
21. Galis ZS, Sukhova GK, Lark MW, Libby P. Increased expression of matrix metalloproteinases and matrix degrading activity in vulnerable regions of human atherosclerotic plaques. The Journal of clinical investigation. 1994;94:2493-2503.

22. Johnson JL, George SJ, Newby AC, Jackson CL. Divergent effects of matrix metalloproteinases 3, 7, 9, and 12 on atherosclerotic plaque stability in mouse brachiocephalic arteries. Proc Natl Acad Sci U S A. 2005;102:15575-15580.

23. Lancelot E, Amirbekian V, Brigger I, Raynaud JS, Ballet S, David C, Rousseaux O, Le Greneur S, Port M, Lijnen HR, Bruneval P, Michel JB, Ouimet T, Roques B, Amirbekian S, Hyafil F, Vucic E, Aguinaldo JG, Corot C, Fayad ZA. Evaluation of matrix metalloproteinases in atherosclerosis using a novel noninvasive imaging approach. Arterioscler Thromb Vasc Biol. 2008;28:425-432.

24. Loftus IM, Naylor AR, Bell PR, Thompson MM. Matrix metalloproteinases and atherosclerotic plaque instability. The British journal of surgery. 2002;89:680-694.

25. Ouimet T, Lancelot E, Hyafil F, Rienzo M, Deux F, Lemaitre M, Duquesnoy S, Garot J, Roques BP, Michel JB, Corot C, Ballet S. Molecular and cellular targets of the MRI contrast agent p947 for atherosclerosis imaging. Molecular pharmaceutics. 2012;9:850-861.

26. Winter PM, Morawski AM, Caruthers SD, Fuhrhop RW, Zhang H, Williams TA, Allen JS, Lacy EK, Robertson JD, Lanza GM, Wickline SA. Molecular imaging of angiogenesis in early-stage atherosclerosis with alpha(v)beta3-integrin-targeted nanoparticles. Circulation. 2003;108:2270-2274.

27. Vengrenyuk Y, Cardoso L, Weinbaum S. Micro-CT based analysis of a new paradigm for vulnerable plaque rupture: cellular microcalcifications in fibrous caps. Molecular \& cellular biomechanics : MCB. 2008;5:37-47.

28. Vengrenyuk Y, Carlier S, Xanthos S, Cardoso L, Ganatos P, Virmani R, Einav S, Gilchrist L, Weinbaum S. A hypothesis for vulnerable plaque rupture due to stress-induced debonding around cellular microcalcifications in thin fibrous caps. Proc Natl Acad Sci U S A. 2006;103:14678-14683.

29. Slager CJ, Wentzel JJ, Gijsen FJ, Schuurbiers JC, van der Wal AC, van der Steen AF, Serruys PW. The role of shear stress in the generation of rupture-prone vulnerable plaques. Nature clinical practice. Cardiovascular medicine. 2005;2:401-407.

30. Bennett MR. Life and death in the atherosclerotic plaque. Curr Opin Lipidol. 2010;21:422-426.

31. Van Vre EA, Ait-Oufella H, Tedgui A, Mallat Z. Apoptotic cell death and efferocytosis in atherosclerosis. Arterioscler Thromb Vasc Biol. 2012;32:887-893.

32. Thorp E, Tabas I. Mechanisms and consequences of efferocytosis in advanced atherosclerosis. J Leukoc Biol. 2009;86:1089-1095.

33. Tabas I. Macrophage apoptosis in atherosclerosis: consequences on plaque progression and the role of endoplasmic reticulum stress. Antioxid Redox Signal. 2009;11:2333-2339.

34. Schrijvers DM, De Meyer GR, Kockx MM, Herman AG, Martinet W. Phagocytosis of apoptotic cells by macrophages is impaired in atherosclerosis. Arterioscler Thromb Vasc Biol. 2005;25:1256-1261.

35. Schoenenberger AW, Urbanek N, Bergner M, Toggweiler S, Resink TJ, Erne P. Associations of Reactive Hyperemia Index and Intravascular Ultrasound-Assessed Coronary Plaque Morphology in Patients With Coronary Artery Disease. The American journal of cardiology. 2012;109:1711-1716.

36. Moore KJ, Tabas I. Macrophages in the pathogenesis of atherosclerosis. Cell. 2011;145:341-355.

37. Bannas P, Weber C, Derlin T, Lambert J, Leypoldt F, Adam G, Mester J, Klutmann S. 18F-FDG-PET/ CT in the diagnosis of paraneoplastic neurological syndromes: a retrospective analysis. Eur Radiol. 2010;20:923-930.

38. Visioni A, Kim J. Positron emission tomography for benign and malignant disease. Surg Clin North Am. 2011;91:249-266.

39. Yun M, Yeh D, Araujo LI, Jang S, Newberg A, Alavi A. F-18 FDG uptake in the large arteries: a new observation. Clin Nucl Med. 2001;26:314-319. 
40. Rudd JH, Myers KS, Bansilal S, Machac J, Rafique A, Farkouh M, Fuster V, Fayad ZA. (18) Fluorodeoxyglucose positron emission tomography imaging of atherosclerotic plaque inflammation is highly reproducible: implications for atherosclerosis therapy trials. J Am Coll Cardiol. 2007;50:892-896.

41. Rudd JH, Myers KS, Bansilal S, Machac J, Woodward M, Fuster V, Farkouh ME, Fayad ZA. Relationships among regional arterial inflammation, calcification, risk factors, and biomarkers: a prospective fluorodeoxyglucose positron-emission tomography/computed tomography imaging study. Circulation. Cardiovascular imaging. 2009;2:107-115.

42. Tawakol A, Migrino RQ, Bashian GG, Bedri S, Vermylen D, Cury RC, Yates D, LaMuraglia GM, Furie K, Houser S, Gewirtz H, Muller JE, Brady TJ, Fischman AJ. In vivo 18F-fluorodeoxyglucose positron emission tomography imaging provides a noninvasive measure of carotid plaque inflammation in patients. J Am Coll Cardiol. 2006;48:1818-1824.

43. Laufer EM, Winkens HM, Corsten MF, Reutelingsperger CP, Narula J, Hofstra L. PET and SPECT imaging of apoptosis in vulnerable atherosclerotic plaques with radiolabeled Annexin A5. QJ Nucl Med Mol Imaging. 2009;53:26-34.

44. Paulmier B, Duet M, Khayat R, Pierquet-Ghazzar N, Laissy JP, Maunoury C, Hugonnet F, Sauvaget E, Trinquart L, Faraggi M. Arterial wall uptake of fluorodeoxyglucose on PET imaging in stable cancer disease patients indicates higher risk for cardiovascular events. J Nucl Cardiol. 2008;15:209-217.

45. Goyal T, Mitra S, Khaidakov M, Wang X, Singla S, Ding Z, Liu S, Mehta JL. Current Concepts of the Role of Oxidized LDL Receptors in Atherosclerosis. Current atherosclerosis reports. 2012;14:150-159.

46. Reiss AB, Anwar K, Wirkowski P. Lectin-like oxidized low density lipoprotein receptor 1 (LOX-1) in atherogenesis: a brief review. Curr Med Chem. 2009;16:2641-2652.

47. Ishino S, Mukai T, Kuge Y, Kume N, Ogawa M, Takai N, Kamihashi J, Shiomi M, Minami M, Kita T, Saji H. Targeting of lectinlike oxidized low-density lipoprotein receptor 1 (LOX-1) with 99mTclabeled anti-LOX-1 antibody: potential agent for imaging of vulnerable plaque. Journal of nuclear medicine : official publication, Society of Nuclear Medicine. 2008;49:1677-1685.

48. Li D, Patel AR, Klibanov AL, Kramer CM, Ruiz M, Kang BY, Mehta JL, Beller GA, Glover DK, Meyer $\mathrm{CH}$. Molecular imaging of atherosclerotic plaques targeted to oxidized LDL receptor LOX-1 by SPECT/CT and magnetic resonance. Circ Cardiovasc Imaging. 2010;3:464-472.

49. Canat X, Guillaumont A, Bouaboula M, Poinot-Chazel C, Derocq JM, Carayon P, LeFur G, Casellas P. Peripheral benzodiazepine receptor modulation with phagocyte differentiation. Biochem Pharmacol. 1993;46:551-554.

50. Chen W, Cormode DP, Fayad ZA, Mulder WJ. Nanoparticles as magnetic resonance imaging contrast agents for vascular and cardiac diseases. Wiley Interdiscip Rev Nanomed Nanobiotechnol. 2010;3:146-161.

51. Sadeghi MM, Glover DK, Lanza GM, Fayad ZA, Johnson LL. Imaging atherosclerosis and vulnerable plaque. J Nucl Med. 2010;51 Suppl 1:51S-65S.

52. Schmitz SA, Coupland SE, Gust R, Winterhalter S, Wagner S, Kresse M, Semmler W, Wolf KJ. Superparamagnetic iron oxide-enhanced MRI of atherosclerotic plaques in Watanabe hereditable hyperlipidemic rabbits. Invest Radiol. 2000;35:460-471.

53. Sanz J, Fayad ZA. Imaging of atherosclerotic cardiovascular disease. Nature. 2008;451:953-957.

54. Trivedi RA, Mallawarachi C, JM UK-I, Graves MJ, Horsley J, Goddard MJ, Brown A, Wang L, Kirkpatrick PJ, Brown J, Gillard JH. Identifying inflamed carotid plaques using in vivo USPIOenhanced MR imaging to label plaque macrophages. Arterioscler Thromb Vasc Biol. 2006;26:1601-1606.

55. Amirbekian V, Aguinaldo JG, Amirbekian S, Hyafil F, Vucic E, Sirol M, Weinreb DB, Le Greneur S, Lancelot E, Corot C, Fisher EA, Galis ZS, Fayad ZA. Atherosclerosis and matrix metalloproteinases: experimental molecular MR imaging in vivo. Radiology. 2009;251:429-438.

56. Frias JC, Williams KJ, Fisher EA, Fayad ZA. Recombinant HDL-like nanoparticles: a specific contrast agent for MRI of atherosclerotic plaques. J Am Chem Soc. 2004;126:16316-16317. 
57. Kooi ME, Cappendijk VC, Cleutjens KB, Kessels AG, Kitslaar PJ, Borgers M, Frederik PM, Daemen MJ, van Engelshoven JM. Accumulation of ultrasmall superparamagnetic particles of iron oxide in human atherosclerotic plaques can be detected by in vivo magnetic resonance imaging. Circulation. 2003;107:2453-2458.

58. Lipinski MJ, Frias JC, Amirbekian V, Briley-Saebo KC, Mani V, Samber D, Abbate A, Aguinaldo JG, Massey D, Fuster V, Vetrovec GW, Fayad ZA. Macrophage-specific lipid-based nanoparticles improve cardiac magnetic resonance detection and characterization of human atherosclerosis. JACC Cardiovasc Imaging. 2009;2:637-647.

59. Blann AD, Nadar SK, Lip GY. The adhesion molecule P-selectin and cardiovascular disease. Eur Heart J. 2003;24:2166-2179.

60. Rouzet F, Bachelet-Violette L, Alsac JM, Suzuki M, Meulemans A, Louedec L, Petiet A, JandrotPerrus M, Chaubet F, Michel JB, Le Guludec D, Letourneur D. Radiolabeled fucoidan as a p-selectin targeting agent for in vivo imaging of platelet-rich thrombus and endothelial activation. Journal of nuclear medicine : official publication, Society of Nuclear Medicine. 2011;52:1433-1440.

61. Jacobin-Valat MJ, Deramchia K, Mornet S, Hagemeyer CE, Bonetto S, Robert R, Biran M, Massot P, Miraux S, Sanchez S, Bouzier-Sore AK, Franconi JM, Duguet E, Clofent-Sanchez G. MRI of inducible P-selectin expression in human activated platelets involved in the early stages of atherosclerosis. NMR Biomed. 2010;24:413-424.

62. McAteer MA, Schneider JE, Ali ZA, Warrick N, Bursill CA, von zur Muhlen C, Greaves DR, Neubauer $S$, Channon KM, Choudhury RP. Magnetic resonance imaging of endothelial adhesion molecules in mouse atherosclerosis using dual-targeted microparticles of iron oxide. Arterioscler Thromb Vasc Biol. 2008;28:77-83.

63. Burtea C, Ballet S, Laurent S, Rousseaux O, Dencausse A, Gonzalez W, Port M, Corot C, Elst LV, Muller RN. Development of a magnetic resonance imaging protocol for the characterization of atherosclerotic plaque by using vascular cell adhesion molecule- 1 and apoptosis-targeted ultrasmall superparamagnetic iron oxide derivatives. Arterioscler Thromb Vasc Biol. 2012;32:e36-48.

64. Burtea C, Laurent S, Murariu O, Rattat D, Toubeau G, Verbruggen A, Vansthertem D, Vander Elst $\mathrm{L}$, Muller RN. Molecular imaging of alpha $\mathrm{v}$ beta3 integrin expression in atherosclerotic plaques with a mimetic of RGD peptide grafted to Gd-DTPA. Cardiovasc Res. 2008;78:148-157.

65. Rudd JH, Narula J, Strauss HW, Virmani R, Machac J, Klimas M, Tahara N, Fuster V, Warburton EA, Fayad ZA, Tawakol AA. Imaging atherosclerotic plaque inflammation by fluorodeoxyglucose with positron emission tomography: ready for prime time? J Am Coll Cardiol. 2010;55:2527-2535.

66. Menezes LJ, Kotze CW, Hutton BF, Endozo R, Dickson JC, Cullum I, Yusuf SW, Ell PJ, Groves AM. Vascular inflammation imaging with 18F-FDG PET/CT: when to image? Journal of nuclear medicine : official publication, Society of Nuclear Medicine. 2009;50:854-857.

67. Menezes LJ, Kotze CW, Agu O, Richards T, Brookes J, Goh VJ, Rodriguez-Justo M, Endozo R, Harvey R, Yusuf SW, Ell PJ, Groves AM. Investigating vulnerable atheroma using combined (18)F-FDG PET/ $\mathrm{CT}$ angiography of carotid plaque with immunohistochemical validation. Journal of nuclear medicine : official publication, Society of Nuclear Medicine. 2011;52:1698-1703.

68. Myers KS, Rudd JH, Hailman EP, Bolognese JA, Burke J, Pinto CA, Klimas M, Hargreaves R, Dansky HM, Fayad ZA. Correlation between arterial FDG uptake and biomarkers in peripheral artery disease. JACC. Cardiovascular imaging. 2012;5:38-45.

69. Fayad ZA, Mani V, Woodward M, Kallend D, Abt M, Burgess T, Fuster V, Ballantyne CM, Stein EA, Tardif JC, Rudd JH, Farkouh ME, Tawakol A. Safety and efficacy of dalcetrapib on atherosclerotic disease using novel non-invasive multimodality imaging (dal-PLAQUE): a randomised clinical trial. Lancet. 2011;378:1547-1559. 
70. Fayad ZA, Mani V, Woodward M, Kallend D, Bansilal S, Pozza J, Burgess T, Fuster V, Rudd JH, Tawakol A, Farkouh ME. Rationale and design of dal-PLAQUE: a study assessing efficacy and safety of dalcetrapib on progression or regression of atherosclerosis using magnetic resonance imaging and $18 \mathrm{~F}$-fluorodeoxyglucose positron emission tomography/computed tomography. Am Heart J. 2011;162:214-221 e212.

71. Wykrzykowska J, Lehman S, Williams G, Parker JA, Palmer MR, Varkey S, Kolodny G, Laham R. Imaging of inflamed and vulnerable plaque in coronary arteries with 18F-FDG PET/CT in patients with suppression of myocardial uptake using a low-carbohydrate, high-fat preparation. J Nucl Med. 2009;50:563-568.

72. Debruyne JC, Versijpt J, Van Laere KJ, De Vos F, Keppens J, Strijckmans K, Achten E, Slegers G, Dierckx RA, Korf J, De Reuck JL. PET visualization of microglia in multiple sclerosis patients using [11C]PK11195. European journal of neurology : the official journal of the European Federation of Neurological Societies. 2003;10:257-264.

73. Pugliese F, Gaemperli O, Kinderlerer AR, Lamare F, Shalhoub J, Davies AH, Rimoldi OE, Mason JC, Camici PG. Imaging of vascular inflammation with [11C]-PK11195 and positron emission tomography/computed tomography angiography. J Am Coll Cardiol. 2010;56:653-661.

74. Gaemperli O, Shalhoub J, Owen DR, Lamare F, Johansson S, Fouladi N, Davies AH, Rimoldi OE, Camici PG. Imaging intraplaque inflammation in carotid atherosclerosis with 11C-PK11195 positron emission tomography/computed tomography. Eur Heart J. 2011;doi: 10.1093/eurheartj/ehr367.

75. Kopka K, Faust A, Keul P, Wagner S, Breyholz HJ, Holtke C, Schober O, Schafers M, Levkau B. 5-pyrrolidinylsulfonyl isatins as a potential tool for the molecular imaging of caspases in apoptosis. $J$ Med Chem. 2006;49:6704-6715.

76. Chen DL, Zhou D, Chu W, Herrbrich P, Engle JT, Griffin E, Jones LA, Rothfuss JM, Geraci M, Hotchkiss RS, Mach RH. Radiolabeled isatin binding to caspase-3 activation induced by anti-Fas antibody. Nucl Med Biol. 2012;39:137-144.

77. Zhou D, Chu W, Rothfuss J, Zeng C, Xu J, Jones L, Welch MJ, Mach RH. Synthesis, radiolabeling, and in vivo evaluation of an 18F-labeled isatin analog for imaging caspase-3 activation in apoptosis. Bioorg Med Chem Lett. 2006;16:5041-5046.

78. Nguyen QD, Smith G, Glaser M, Perumal M, Arstad E, Aboagye EO. Positron emission tomography imaging of drug-induced tumor apoptosis with a caspase-3/7 specific [18F]-labeled isatin sulfonamide. Proc Natl Acad Sci U S A. 2009;106:16375-16380.

79. Schutters K, Reutelingsperger C. Phosphatidylserine targeting for diagnosis and treatment of human diseases. Apoptosis : an international journal on programmed cell death. 2010;15:1072-1082.

80. Taki J, Higuchi T, Kawashima A, Tait JF, Kinuya S, Muramori A, Matsunari I, Nakajima K, Tonami $\mathrm{N}$, Strauss HW. Detection of cardiomyocyte death in a rat model of ischemia and reperfusion using 99mTc-labeled annexin V. Journal of nuclear medicine : official publication, Society of Nuclear Medicine. 2004; $45: 1536-1541$.

81. Takei T, Kuge Y, Zhao S, Sato M, Strauss HW, Blankenberg FG, Tait JF, Tamaki N. Enhanced apoptotic reaction correlates with suppressed tumor glucose utilization after cytotoxic chemotherapy: use of 99mTc-Annexin V, 18F-FDG, and histologic evaluation. Journal of nuclear medicine : official publication, Society of Nuclear Medicine. 2005;46:794-799.

82. Belhocine T, Steinmetz N, Hustinx R, Bartsch P, Jerusalem G, Seidel L, Rigo P, Green A. Increased uptake of the apoptosis-imaging agent $(99 \mathrm{~m}) \mathrm{Tc}$ recombinant human Annexin V in human tumors after one course of chemotherapy as a predictor of tumor response and patient prognosis. Clinical cancer research : an official journal of the American Association for Cancer Research. 2002;8:2766-2774. 
83. Blankenberg FG, Katsikis PD, Tait JF, Davis RE, Naumovski L, Ohtsuki K, Kopiwoda S, Abrams MJ, Darkes M, Robbins RC, Maecker HT, Strauss HW. In vivo detection and imaging of phosphatidylserine expression during programmed cell death. Proc Natl Acad Sci US A. 1998;95:6349-6354.

84. Dumont EA, Reutelingsperger CP, Smits JF, Daemen MJ, Doevendans PA, Wellens HJ, Hofstra L. Real-time imaging of apoptotic cell-membrane changes at the single-cell level in the beating murine heart. Nat Med. 2001;7:1352-1355.

85. Hofstra L, Liem IH, Dumont EA, Boersma HH, van Heerde WL, Doevendans PA, De Muinck E, Wellens HJ, Kemerink GJ, Reutelingsperger CP, Heidendal GA. Visualisation of cell death in vivo in patients with acute myocardial infarction. Lancet. 2000;356:209-212.

86. Kolodgie FD, Petrov A, Virmani R, Narula N, Verjans JW, Weber DK, Hartung D, Steinmetz N, Vanderheyden JL, Vannan MA, Gold HK, Reutelingsperger CP, Hofstra L, Narula J. Targeting of apoptotic macrophages and experimental atheroma with radiolabeled annexin V: a technique with potential for noninvasive imaging of vulnerable plaque. Circulation. 2003;108:3134-3139.

87. Laufer EM, Reutelingsperger CP, Narula J, Hofstra L. Annexin A5: an imaging biomarker of cardiovascular risk. Basic Res Cardiol. 2008;103:95-104.

88. Falborg L, Waehrens LN, Alsner J, Bluhme H, Frokiaer J, Heegaard CW, Horsman MR, Rasmussen JT, Rehling M. Biodistribution of 99mTc-HYNIC-lactadherin in mice--a potential tracer for visualizing apoptosis in vivo. Scand J Clin Lab Invest. 2010;70:209-216.

89. Davletov BA, Sudhof TC. A single C2 domain from synaptotagmin I is sufficient for high affinity Ca2+/phospholipid binding. The Journal of biological chemistry. 1993;268:26386-26390.

90. Krishnan AS, Neves AA, de Backer MM, Hu DE, Davletov B, Kettunen MI, Brindle KM. Detection of cell death in tumors by using MR imaging and a gadolinium-based targeted contrast agent. Radiology. 2008;246:854-862.

91. Alam IS, Neves AA, Witney TH, Boren J, Brindle KM. Comparison of the C2A domain of synaptotagmin-I and annexin-V as probes for detecting cell death. Bioconjug Chem. 2010;21:884-891.

92. Kietselaer BL, Reutelingsperger CP, Heidendal GA, Daemen MJ, Mess WH, Hofstra L, Narula J. Noninvasive detection of plaque instability with use of radiolabeled annexin A5 in patients with carotid-artery atherosclerosis. $N$ Engl J Med. 2004;350:1472-1473.

93. Takeuchi H, Morino Y, Matsukage T, Masuda N, Kawamura Y, Kasai S, Hashida T, Fujibayashi D, Tanabe T, Ikari Y. Impact of vascular remodeling on the coronary plaque compositions: an investigation with in vivo tissue characterization using integrated backscatter-intravascular ultrasound. Atherosclerosis. 2009;202:476-482.

94. Pasterkamp G, Fitzgerald PF, de Kleijn DP. Atherosclerotic expansive remodeled plaques: a wolf in sheep's clothing. J Vasc Res. 2002;39:514-523.

95. Iyemere VP, Proudfoot D, Weissberg PL, Shanahan CM. Vascular smooth muscle cell phenotypic plasticity and the regulation of vascular calcification. J Intern Med. 2006;260:192-210.

96. Shanahan CM, Weissberg PL. Smooth muscle cell phenotypes in atherosclerotic lesions. Curr Opin Lipidol. 1999;10:507-513.

97. Carrio I, Pieri PL, Narula J, Prat L, Riva P, Pedrini L, Pretolani E, Caruso G, Sarti G, Estorch M, Berna L, Riambau V, Matias-Guiu X, Pak C, Ditlow C, Chen F, Khaw BA. Noninvasive localization of human atherosclerotic lesions with indium 111-labeled monoclonal Z2D3 antibody specific for proliferating smooth muscle cells. Journal of nuclear cardiology : official publication of the American Society of Nuclear Cardiology. 1998;5:551-557.

98. Narula J, Petrov A, Bianchi C, Ditlow CC, Lister BC, Dilley J, Pieslak I, Chen FW, Torchilin VP, Khaw BA. Noninvasive localization of experimental atherosclerotic lesions with mouse/human chimeric Z2D3 F(ab')2 specific for the proliferating smooth muscle cells of human atheroma. Imaging with conventional and negative charge-modified antibody fragments. Circulation. 1995;92:474-484. 
99. Narula J, Petrov A, Pak KY, Ditlow C, Chen F, Khaw BA. Noninvasive detection of atherosclerotic lesions by $99 \mathrm{mTc}$-based immunoscintigraphic targeting of proliferating smooth muscle cells. Chest. 1997;111:1684-1690.

100. Tekabe Y, Einstein AJ, Johnson LL, Khaw BA. Targeting very small model lesions pretargeted with bispecific antibody with 99mTc-labeled high-specific radioactivity polymers. Nucl Med Commun. 2010;31:320-327.

101. Jimenez J, Donahay T, Schofield L, Khaw BA, Johnson LL. Smooth muscle cell proliferation index correlates with 111 In-labeled antibody Z2D3 uptake in a transplant vasculopathy swine model. Journal of nuclear medicine : official publication, Society of Nuclear Medicine. 2005;46:514-519.

102. Johnson LL, Schofield LM, Verdesca SA, Sharaf BL, Jones RM, Virmani R, Khaw BA. In vivo uptake of radiolabeled antibody to proliferating smooth muscle cells in a swine model of coronary stent restenosis. Journal of nuclear medicine : official publication, Society of Nuclear Medicine. 2000;41:1535-1540.

103. Hyafil F, Vucic E, Cornily JC, Sharma R, Amirbekian V, Blackwell F, Lancelot E, Corot C, Fuster V, Galis ZS, Feldman LJ, Fayad ZA. Monitoring of arterial wall remodelling in atherosclerotic rabbits with a magnetic resonance imaging contrast agent binding to matrix metalloproteinases. Eur Heart J. 2011;32:1561-1571.

104. Deguchi JO, Aikawa M, Tung CH, Aikawa E, Kim DE, Ntziachristos V, Weissleder R, Libby P. Inflammation in atherosclerosis: visualizing matrix metalloproteinase action in macrophages in vivo. Circulation. 2006;114:55-62.

105. Ohshima S, Petrov A, Fujimoto S, Zhou J, Azure M, Edwards DS, Murohara T, Narula N, Tsimikas $S$, Narula J. Molecular imaging of matrix metalloproteinase expression in atherosclerotic plaques of mice deficient in apolipoprotein e or low-density-lipoprotein receptor. Journal of nuclear medicine: official publication, Society of Nuclear Medicine. 2009;50:612-617.

106. ten Kate GL, Sijbrands EJ, Valkema R, ten Cate FJ, Feinstein SB, van der Steen AF, Daemen MJ, Schinkel AF. Molecular imaging of inflammation and intraplaque vasa vasorum: a step forward to identification of vulnerable plaques? Journal of nuclear cardiology : official publication of the American Society of Nuclear Cardiology. 2010;17:897-912.

107. Moulton KS. Angiogenesis in atherosclerosis: gathering evidence beyond speculation. Curr Opin Lipidol. 2006;17:548-555.

108. Matter CM, Schuler PK, Alessi P, Meier P, Ricci R, Zhang D, Halin C, Castellani P, Zardi L, Hofer CK, Montani M, Neri D, Luscher TF. Molecular imaging of atherosclerotic plaques using a human antibody against the extra-domain B of fibronectin. Circ Res. 2004;95:1225-1233.

109. Cai W, Chen K, Mohamedali KA, Cao Q, Gambhir SS, Rosenblum MG, Chen X. PET of vascular endothelial growth factor receptor expression. Journal of nuclear medicine : official publication, Society of Nuclear Medicine. 2006;47:2048-2056.

110. Rodriguez-Porcel M. Non-invasive Monitoring of Angiogenesis in Cardiology. Current cardiovascular imaging reports. 2009;2:59-66.

111. Borissoff JI, Spronk HM, ten Cate H. The hemostatic system as a modulator of atherosclerosis. $N$ Engl J Med. 2011;364:1746-1760.

112. Clofent-Sanchez G, Jacobin-Valat MJ, Laroche-Traineau J. The growing interest of fibrin imaging in atherosclerosis. Atherosclerosis. 2012;222:22-25.

113. Tavora F, Cresswell N, Li L, Ripple M, Burke A. Immunolocalisation of fibrin in coronary atherosclerosis: implications for necrotic core development. Pathology (Phila). 2010;42:15-22.

114. Sato Y, Hatakeyama K, Yamashita A, Marutsuka K, Sumiyoshi A, Asada Y. Proportion of fibrin and platelets differs in thrombi on ruptured and eroded coronary atherosclerotic plaques in humans. Heart. 2005;91:526-530. 
115. Botnar RM, Buecker A, Wiethoff AJ, Parsons EC, Jr., Katoh M, Katsimaglis G, Weisskoff RM, Lauffer RB, Graham PB, Gunther RW, Manning WJ, Spuentrup E. In vivo magnetic resonance imaging of coronary thrombosis using a fibrin-binding molecular magnetic resonance contrast agent. Circulation. 2004;110:1463-1466.

116. Spuentrup E, Buecker A, Katoh M, Wiethoff AJ, Parsons EC, Jr., Botnar RM, Weisskoff RM, Graham $\mathrm{PB}$, Manning WJ, Gunther RW. Molecular magnetic resonance imaging of coronary thrombosis and pulmonary emboli with a novel fibrin-targeted contrast agent. Circulation. 2005;111:1377-1382.

117. Spuentrup E, Botnar RM, Wiethoff AJ, Ibrahim T, Kelle S, Katoh M, Ozgun M, Nagel E, Vymazal J, Graham PB, Gunther RW, Maintz D. MR imaging of thrombi using EP-2104R, a fibrin-specific contrast agent: initial results in patients. Eur Radiol. 2008;18:1995-2005.

118. Spuentrup E, Katoh M, Buecker A, Fausten B, Wiethoff AJ, Wildberger JE, Haage P, Parsons EC, Jr., Botnar RM, Graham PB, Vettelschoss M, Gunther RW. Molecular MR imaging of human thrombi in a swine model of pulmonary embolism using a fibrin-specific contrast agent. Invest Radiol. 2007;42:586-595.

119. Makowski MR, Forbes SC, Blume U, Warley A, Jansen CH, Schuster A, Wiethoff AJ, Botnar RM. In vivo assessment of intraplaque and endothelial fibrin in ApoE(-/-) mice by molecular MRI. Atherosclerosis. 2012;222:43-49.

120. Virmani R, Burke AP, Farb A, Kolodgie FD. Pathology of the vulnerable plaque. J Am Coll Cardiol. 2006; $47:$ C13-18.

121. Arbustini E, Dal Bello B, Morbini P, Burke AP, Bocciarelli M, Specchia G, Virmani R. Plaque erosion is a major substrate for coronary thrombosis in acute myocardial infarction. Heart. 1999;82:269-272.

122. Huang H, Virmani R, Younis H, Burke AP, Kamm RD, Lee RT. The impact of calcification on the biomechanical stability of atherosclerotic plaques. Circulation. 2001;103:1051-1056.

123. Ehara S, Kobayashi Y, Yoshiyama M, Shimada K, Shimada Y, Fukuda D, Nakamura Y, Yamashita H, Yamagishi H, Takeuchi K, Naruko T, Haze K, Becker AE, Yoshikawa J, Ueda M. Spotty calcification typifies the culprit plaque in patients with acute myocardial infarction: an intravascular ultrasound study. Circulation. 2004;110:3424-3429.

124. Aikawa E, Nahrendorf M, Figueiredo JL, Swirski FK, Shtatland T, Kohler RH, Jaffer FA, Aikawa M, Weissleder R. Osteogenesis associates with inflammation in early-stage atherosclerosis evaluated by molecular imaging in vivo. Circulation. 2007;116:2841-2850.

125. Dunphy MP, Freiman A, Larson SM, Strauss HW. Association of vascular 18F-FDG uptake with vascular calcification. Journal of nuclear medicine : offcial publication, Society of Nuclear Medicine. 2005;46:1278-1284.

126. Derlin T, Richter U, Bannas P, Begemann P, Buchert R, Mester J, Klutmann S. Feasibility of 18F-sodium fluoride PET/CT for imaging of atherosclerotic plaque. Journal of nuclear medicine : official publication, Society of Nuclear Medicine. 2010;51:862-865.

127. Slobbe LCJ SJ, Groen J, Poos MJJC, Kommer GJ. Cost of Illness in the Netherlands 2007 : Trends in healthcare expenditure 1999-2010 RIVM rapport: Rijksinstituut voor Volksgezondheid en Milieu RIVM Centraal Bureau voor de Statistiek CBS; 2011.

128. Koch-Institut R. Krankheitskosten Krankheitskosten [Gesundheitsberichterstattung - Themenhefte]; 2009.

129. Taylor MJ, Scuffham PA, McCollam PL, Newby DE. Acute coronary syndromes in Europe: 1-year costs and outcomes. Curr Med Res Opin. 2007;23:495-503.

130. Roger VL, Go AS, Lloyd-Jones DM, Benjamin EJ, Berry JD, Borden WB, Bravata DM, Dai S, Ford ES, Fox CS, Lackland DT, Lichtman JH, Lisabeth LD, Makuc DM, Marcus GM, Marelli A, Matchar DB, Moy CS, Mozaffarian D, Mussolino ME, Nichol G, Paynter NP, Soliman EZ, Sorlie PD, Sotoodehnia N, Turan TN, Virani SS, Wong ND, Woo D, Turner MB. Heart disease and stroke statistics--2012 update: a report from the American Heart Association. Circulation. 2012;125:e2-e220. 
131. Naghavi M, Falk E, Hecht HS, Jamieson MJ, Kaul S, Berman D, Fayad Z, Budoff MJ, Rumberger J, Naqvi TZ, Shaw LJ, Faergeman O, Cohn J, Bahr R, Koenig W, Demirovic J, Arking D, Herrera VL, Badimon J, Goldstein JA, Rudy Y, Airaksinen J, Schwartz RS, Riley WA, Mendes RA, Douglas P, Shah PK. From vulnerable plaque to vulnerable patient--Part III: Executive summary of the Screening for Heart Attack Prevention and Education (SHAPE) Task Force report. The American journal of cardiology. 2006;98:2H-15H.

132. Chan $\mathrm{KH}, \mathrm{Ng} \mathrm{MK}$. Is there a role for coronary angiography in the early detection of the vulnerable plaque? Int J Cardiol. 2012; doi:10.1016/j.ijcard.2012.01.027.

133. Ait-Oufella H, Kinugawa K, Zoll J, Simon T, Boddaert J, Heeneman S, Blanc-Brude O, Barateau V, Potteaux S, Merval R, Esposito B, Teissier E, Daemen MJ, Leseche G, Boulanger C, Tedgui A, Mallat Z. Lactadherin deficiency leads to apoptotic cell accumulation and accelerated atherosclerosis in mice. Circulation. 2007;115:2168-2177.

134. Aprahamian T, Rifkin I, Bonegio R, Hugel B, Freyssinet JM, Sato K, Castellot JJ, Jr., Walsh K. Impaired clearance of apoptotic cells promotes synergy between atherogenesis and autoimmune disease. The Journal of experimental medicine. 2004;199:1121-1131. 
Chapter 2 


\section{Chapter 3}

\section{Annexin A5-deficiency in ApoE ${ }^{-/-}$mice promotes efferocytosis and inhibits atherosclerosis}

DHM Kusters, ML Chatrou, BAG Willems, K Schutters, E Marsch, M Gijbels, B Brachvogel, LJ Schurgers, CPM Reutelingsperger 


\section{Abstract}

Background and purpose - Efferocytosis, the process by which apoptotic cells are engulfed by phagocytes, plays a crucial role in atherosclerosis. Exogenous annexin A5 (anxA5) binds apoptotic cells and inhibits efferocytosis. Here we investigate the role of endogenous anxA5 in efferocytosis and development of atherosclerosis.

Experimental approach - ApoE--1/anxA5--1 double knock-out $(\mathrm{DKO})$ and $\mathrm{ApoE}^{-/-}$mice were fed normal chow diet and sacrificed at 14, 20 and 26 weeks of age. Plaque size and phenotype were analyzed. In vivo efferocytosis by resident peritoneal macrophages was measured. Bone marrow derived macrophages were used to measure migration.

Key results - DKO mice were slightly lower in body weight and had increased levels of circulating triglycerides and total cholesterol. Levels of circulating Ly6 $\mathrm{C}^{\text {high }}$ monocytes were higher in DKO mice. DKO mice of 26 weeks had smaller plaques with less apoptotic cells. In contrast to ApoE $\mathrm{E}^{-/-}$mice there was no large necrotic core development in DKO mice. DKO macrophages expressed higher efferocytotic activity. No difference in migration was observed between $\mathrm{DKO}$ and $\mathrm{ApoE}^{-1-}$ macrophages.

Conclusion and implications - Endogenous anxA5 inhibits efferocytosis and promotes atherosclerosis. Targeted inhibition of anxA5 may be a therapeutic avenue to attenuate plaque progression 


\section{Introduction}

Atherosclerosis is the major cause of cardiovascular disease, of which adverse outcomes include stroke, myocardial infarction and heart failure ${ }^{1-3}$. Atherosclerosis is a chronic inflammatory disease of the arterial vessel wall in which macrophages play a crucial role 4, 5 . Macrophages are the most important phagocyte in atherosclerotic lesions and can limit formation of a necrotic core through phagocytosis of apoptotic cells (this process is termed efferocytosis) which otherwise would become secondary necrotic ${ }^{6,7}$. Efferocytosis is preceded by tethering and tickling of macrophage receptors by so-called "eat me" signals on the surface of the apoptotic cell ${ }^{8}$. The negatively charged aminophospholipid phosphatidylserine (PS) is an important "eat me" signal that is ubiquitously expressed by apoptotic cells regardless of cell type and cell death trigger 9,10 .

Annexin A5 (anxA5) is a member of the multigene annexin family ${ }^{11}$ that binds cell surface expressed PS with high affinity ${ }^{12}$. Human recombinant anxA5 (hr-anxA5) is employed as Molecular Imaging agent to visualize the unstable atherosclerotic plaque (Chapter 2), the PS content of which increases with increasing vulnerability ${ }^{13}$, 14 . In addition, hr-anxA5 acts pharmacodynamically by suppressing inflammation ${ }^{15}$ and inhibiting atherosclerosis in the $\mathrm{ApoE}^{-1-}$ mouse model ${ }^{16}$. Hr-anxA5 reduces inflammation by acting on activated endothelium ${ }^{15}$ and targeting pro-inflammatory mediators ${ }^{17,}{ }^{18}$. Interestingly, hr-anxA5 inhibits efferocytosis in vitro by binding PS of the apoptotic cell ${ }^{19,20}$ and the macrophage ${ }^{21}$. In contrast to the wealth of published data on hr-anxA5 and its interaction with atherosclerosis, the (patho)physiological role of endogenous anxA5 in atherosclerosis is unknown. Therefore we have generated anxA5 ${ }^{-1 /} / \mathrm{ApoE}^{-/}$- double knock-out mice (DKO) and studied atherogenesis in DKO mice on chow diet compared to $\mathrm{ApoE}^{-/-}$mice. Mice were put on normal chow diet to induce minor atherogenic pressure. We demonstrate that anxA5 deficiency increases efferocytosis by macrophages and consequently reduce progression of atherosclerotic plaque development.

\section{Methods}

Animal welfare and ethical statement - All animal experiments have been conducted under a protocol approved by the ethics committee for animal experiments of Maastricht University (DEC 2010-152) and comply with ARRIVE (Animal Research: Reporting In Vivo Experiments) guidelines and followed the European Union Directive (2010/63/ 
EU). All procedures used were performed as humane as possible. A total of 160 animals were used in the experiments described here. Mice were kept at a constant temperature $\left(21^{\circ} \mathrm{C}\right)$ and a regular light (06:30-19:30h) and dark (19:30-06:30h) cycle, with normal chow diet and water provided ad libitum.

Mouse strain - The anxA5 ${ }^{-1-} \mathrm{C} 57 / \mathrm{Bl6} / \mathrm{J}$ mice have been generated by Brachvogel et al. as described previously ${ }^{22}$. These mice were back-crossed for at least 5 generations with ApoE ${ }^{-1-} \mathrm{B} 16.129 \mathrm{P} 2-\mathrm{ApoEtm} 1 \mathrm{Unc} / \mathrm{J}$ mice before inclusion into the experiment. Complete knock-out of anxA5 was confirmed by genotyping and western blotting with a specific rabbit- $\alpha$-anxA5 antibody. AnxA5 heterozygous ApoE knock-out mice were used for crossbreeding; AnxA5-WT/apoE $E^{-/}\left(\mathrm{ApoE}^{-/}\right)$and anxA5 $5^{-/} / \mathrm{ApoE}^{-/-}(\mathrm{DKO})$ male littermates of indicated ages were used for experiments. $\mathrm{ApoE}^{-{ }^{-}}$and $\mathrm{DKO}$ were co-housed during the entire experiment.

Genotyping - Genotyping of mice was performed by PCR detecting the wild type allele with primers Exon4-dw (5'-GAAGCAATGCTCAGCGCCGGA-3') and Intron4-up (5'-CTGTACTCTATCACTATCACTGACTGTTTAATC-3’) and the mutated allele with primers Exon3-dw (5'-CGAGAGGCACTGTGACTGACTTCCCTGGAT-3') and LacZup (5'-GCCAGTTTGAGGGGACGACGACAG-3 ${ }^{\circ}$ ) as described previously ${ }^{22}$. Genotyping for ApoE was performed using primers: ApoE-up (5'-CATAGTGTCCTCCATCAGTGC-3’) and ApoE-low (5'-GCCTAGCCGAGGGAGAGCCG-3’).

Atherosclerosis experiments - Mice were fed normal chow diet for 14, 20 or 26 weeks before sacrifice. Blood was collected in $3.2 \%$ sodium citrate by vena cava puncture. Residual cells were removed by perfusion with $10 \mathrm{ml}$ binding buffer (BB, containing 40mM HEPES, $150 \mathrm{mM} \mathrm{NaCl}, 5 \mathrm{mM} \mathrm{KCl}, 1 \mathrm{mM} \mathrm{MgCl}_{2}$ and $2.5 \mathrm{mM} \mathrm{CaCl}_{2}$ ) supplemented with $100 \mu \mathrm{M}$ sodium nitroprusside via the left ventricle. The aortic arch and main branch points (brachiocephalic, carotid and subclavian artery) were dissected and either fixed in 1\% paraformaldehyde (PFA) in BB o/n and paraffin embedded ( $5 \mu \mathrm{m}$ sections), or directly frozen in TissueTek O.C.T. Compound for cryosectioning ( $7 \mu \mathrm{m}$ sections).

Endogenous thrombin potential - ETP was determined in plasma containing $3.3 \mu \mathrm{M}$ corn trypsin inhibitor (CTI) using $7 \mathrm{pM}$ of tissue factor, $60 \mu \mathrm{M}$ of phospholipids $(20 \% \mathrm{PS} / 60 \% \mathrm{PC} / 20 \% \mathrm{PE})$ and $8.2 \mathrm{mM} \mathrm{Ca}^{2+}$ as discribed previously ${ }^{23}$. 
Cholesterol and triglyceride measurements - Total plasma cholesterol and triglycerides were determined according to manufacturer's protocol (Precimat glycerol and GPO-PAP, Boehringer-Manheim).

Flow cytometry analysis of blood and bone marrow - Blood was collected via vena cava puncture in $3.2 \%$ sodium citrate. After erythrocyte lysis, blood cell composition was determined using anti-bodies against CD11b (BD Biosciences), Ly6G (BD Biosciences), Ly6C (Miltenyi Biotec), CD3e (eBioscience), B220 (BD Biosciences), NK1.1 (eBioscience), $\mathrm{CD} 4$ (BD Biosciences) and CD8a (eBioscience). Bone marrow composition was determined using antibodies against B220, CD3e, NK1.1, CD11b, Ly6G, Ly6C and CD115 (eBioscience). Flow cytometry was analyzed using FACSDiva Software (V6.1.3), gate settings for blood analysis are shown in Supplemental Figure 1. Values are expressed as percentage of viable cells.

Histology - Plaque sizes were determined using standard Hematoxylin and Eosin (H\&E) staining on every fifth section and analyzing total aortic plaque burden with ImageJ Software (V1.45). Total plaque area was determined for the entire arch and major branchpoints. Sizes of every two consecutive sections are averaged, multiplied by $20 \mu \mathrm{m}$ (the distance in between) and summed up to obtain total plaque burden. Plaque progression was scored on the following parameters: neutrophil and macrophage content, apoptosis and necrosis, cap thickness and calcification status as is summarized in Supplemental Tables 1 and 2. Additional plaque features were determined using a Sirius red staining for collagen, terminal deoxynucleotidyl transferase dUTP nick-end labeling (TUNEL) for apoptosis and immunohistochemistry using antibodies against MAC-3 (BD Biosciences, clone M3/84) for all macrophages, iNOS (Abcam, AB3523) for M1-polarized macrophages and $\alpha$-SMa (Abcam) for vascular smooth muscle cells. Size and cross-linking of the collagen fibers is determined by the color distribution of polarized light as described previously ${ }^{24}$. AnxA5 promoter activity was determined by $\beta$-galactosidase (lac Z) staining of cryostat sections as described previously ${ }^{25}$.

Cells - Primary bone marrow derived monocytes were isolated as described before ${ }^{26}$. At least 6 femurs and 6 tibias were dissected, rinsed with 70\% ethanol and flushed with RPMI1640. Bone marrow plugs were collected, and disrupted by passing through a 19 gauge needle twice. Cell suspension was filtered using a $70 \mu \mathrm{m}$ cell strainer, and collected by centrifugation $(400 \mathrm{~g}, 5 \mathrm{~min})$. Cells were resuspended and differentiated for 8 days in 
RPMI1640 containing 10mM HEPES, 10\% heat inactivated FBS (Gibco-BRL), 15\% L929 conditioned medium and 100U.ml ${ }^{-1}$ penicillin (Gibco-BRL) and $100 \mu \mathrm{g} \cdot \mathrm{ml}^{-1}$ streptomycin (Gibco-BRL). Macrophages were polarized using vehicle, $100 \mathrm{U} \cdot \mathrm{ml}^{-1} \mathrm{IFN}-\gamma$, 20ng. $\mathrm{ml}^{-1}$ IL-4 and 10ng. $\mathrm{ml}^{-1}$ IL-10 (all Peprotech, UK) to obtain M0, M1, M2a and M2c macrophages respectively. Migration of bone marrow derived macrophages was assessed in a label free Real-Time Cell Analysis platform on CIM plates of the xCELLigence (Roche) according to manufacturer's protocol.

Jurkat cells were cultured in RPMI1640 containing 10\% heat inactivated FBS (GibcoBRL), 100U.ml-1 penicillin (Gibco-BRL) and 100 $\mu \mathrm{g} \cdot \mathrm{ml}^{-1}$ streptomycin (Gibco-BRL).

In vivo phagocytosis - In vivo phagocytosis was adapted from Taylor et al. ${ }^{27}$. In short, Jurkat cells were labeled with $2.5 \mu \mathrm{M}$ CFSE, resuspended to $2.10^{6}$ cells. $\mathrm{ml}^{-1}$ and irradiated for 10 minutes with UV-B (290-320nm). After 3 hours of incubation, about $80 \%$ of cells were apoptotic (Supplemental Figure 2) as determined by flow cytometry ${ }^{28} \cdot 10.10^{6}$ cells were injected intraperitoneally in temperature controlled, isoflurane anesthetized, paired $\mathrm{ApoE}^{-1-}$ and DKO mice. Phagocytosis was allowed for 30 minutes before collection of cells by peritoneal lavage with ice cold PBS. After isolation, Fc-receptors were blocked (CD16/32, eBioSceince) and macrophages were stained with F4/80 (F4/80-APC, ITK diagnostics) and analyzed by flow cytometry.

Statistical analysis - All values are shown as mean \pm SEM. Statistical significance between two groups was checked for normal distribution using the Shapiro-Wilk normality test and tested on significance by unpaired (or paired if stated) student's $t$-test using Graphpad Prism 5.0 software. A two tailed value of $\mathrm{p}<0.05$ was considered statistically significant. $P$-values are indicated in the table and figures by asterisks representing: ${ }^{*} \mathrm{p}<0.05,{ }^{* *} \mathrm{p}<0.005$, ${ }^{* * *} \mathrm{p}<0.001$

\section{Results}

\section{Comparison of baseline characteristics of DKO and ApoE $E^{-1}$}

In order to study the role of endogenous anxA5 in atherogenesis, anxA $5^{-1-} / \mathrm{ApoE}^{-/-}$double knock-out mice $(\mathrm{DKO})$ were generated. First we compared $\mathrm{DKO}$ and $\mathrm{ApoE}^{-/-}$mice for a selection of parameters. Body weights did not differ significantly between DKO and ApoE $^{-/-}$(Table 1). Blood triglycerides and total cholesterol were significantly higher in 
20 and 26 weeks old DKO mice (Table 1). AnxA5-deficiency did not cause a change in coagulability of blood plasma as determined by the endogenous thrombin potential (ETP) (Table 1). Total body section did not reveal any organ abnormalities or other differences between both strains as assessed by an animal pathologist. Analyses of circulating leukocyte populations revealed that 26 weeks old DKO mice had a circulating leukocyte profile with a significantly lower fraction of B-cells ( $\mathrm{p}=0.047$ ) (Table 2 and supplemental Figure 1). Within the monocyte population there was a shift towards pro-inflammatory Ly6C $\mathrm{C}^{\text {high }}$ monocytes $(\mathrm{p}=0.018$ ) (Table 2). Analyses of bone marrow leukocytes showed no differences between $\mathrm{DKO}$ and $\mathrm{ApoE}^{-1-}$ (Table 2).

\section{AnxA5 deficiency slows down atherogenesis}

At 14 weeks of age neither $\mathrm{ApoE}^{-/-}$nor DKO mice showed lesion formation in the arch, whereas both developed single cell adhesion (SCA) in the brachiocephalic artery (BCA) indicating initiation of plaque formation (Figure $1 \mathrm{~A}$ ). At 20 weeks of age $\mathrm{ApoE}^{-1-}$ and DKO showed SCA and intimal xanthoma (IX) formation in aortic arch. BCA lesion development progressed towards intermediate lesions (IL) and advanced lesions (AL) (Figure 1B). At 26 weeks both strains had developed plaques in aortic arch and BCA. Plaques of DKO mice were smaller and less advanced compared to plaques of $\mathrm{ApoE}^{-/-}$mice (Figure 1C). Quantification showed a significant reduction of plaque size in DKO at 26 weeks of age in the arch (Figure 2A) and BCA (Figure 2B). While both strains have IL and $\mathrm{AL}$ in the $\mathrm{BCA}$, the progression of the lesion development in the arch of DKO mice was delayed (Figure 2C). Only 2 out 13 DKO mice developed a plaque with a necrotic core in the arch after 26 weeks, while in $\mathrm{ApoE}^{-/}$mice this was 10 out of 12 (Figure 2D). No difference in necrotic core development was observed in BCA (Figure 2D).

Cellularity of the plaques was equal between both strains at 20 and 26 weeks of age and predominantly consisted of macrophages and VSMC (Figure $3 \mathrm{~A}-\mathrm{D}$ ). Cell death as determined by TUNEL-staining was less in plaques of DKO mice as compared to plaques of ApoE ${ }^{-1}$ mice at 26 weeks of age (Figure 3E, F). AnxA5 deficiency affected neither total collagen content nor cross-linking of collagen fibers at 26 weeks (Figure 2G-J). 
Table 1 Baseline characteristics of ApoE-/- and DKO mouse strains.

\begin{tabular}{lllllll} 
& 14 weeks & \multicolumn{3}{c}{20 weeks } & \multicolumn{3}{c}{26 weeks } \\
& DKO & ApoE ${ }^{-/-}$ & DKO & ApoE $^{-/-}$ & DKO & ApoE $^{-/-}$ \\
Weight (g) & $26 \pm 3$ & $27 \pm 2$ & $27 \pm 2$ & $28 \pm 2$ & $28 \pm 2$ & $31 \pm 2$ \\
$\begin{array}{l}\text { Lipids (nM) } \\
\text { Cholesterol }\end{array}$ & $n . d$. & $n . d$. & $13 \pm 3$ & $12 \pm 4$ & $14 \pm 4^{* * *}$ & $11 \pm 3$ \\
Triglycerides & $n . d$. & $n . d$. & $1.5 \pm 0.6^{*}$ & $1.1 \pm 0.4$ & $1.6 \pm 0.6^{*}$ & $1.1 \pm 0.6$ \\
Coagulation & & & & & & \\
ETP (nM.min) & $556 \pm 124$ & $680 \pm 34$ & $713 \pm 189$ & $651 \pm 153$ & $523 \pm 72$ & $706 \pm 243$ \\
Peak height (nM) & $137 \pm 15$ & $123 \pm 13$ & $149 \pm 22$ & $162 \pm 19$ & $129 \pm 29$ & $141 \pm 8$
\end{tabular}

Table 2 Flow cytometric analysis of blood and bone marrow at 26 weeks of age

$\begin{array}{lllll}\text { Parameter } & \text { Subpopulation } & \text { DKO }(n=16) & \operatorname{ApoE}^{-1 /}(n=17) & P\end{array}$

Blood

Leukocytes $\left(10^{9} \cdot \mathrm{L}^{-1}\right)$

Erythrocytes $\left(10^{12} \cdot \mathrm{L}^{-1}\right)$

Hemoglobin $(\mathrm{mM})$

Hematoctit (\%)

B-cells (\%viable)

NK-cells (\%viable)

Granulocytes (\%viable)

Monocytes (\%viable)

T-cells (\%viable)
$6.8 \pm 0.7$

$7.9 \pm 0.2$

$7.2 \pm 0.2$

$40.0 \pm 7.0$

$26.6 \pm 15.0^{*}$

$3.1 \pm 1.4$

$41.2 \pm 21.4$

$12.4 \pm 5.8$

$63.5 \pm 25.5^{*}$

$5.4 \pm 0.5$

$30.9 \pm 26.5$

$12.0 \pm 5.8$

$\mathrm{CD}^{+}$(\%parent)

CD8 ${ }^{+}$(\%parent)
$55.8 \pm 27.4$

$40.0 \pm 19.7$
$5.7 \pm 1.8$

$8.1 \pm 0.3$

$7.6 \pm 0.6$

$40.1 \pm 15.2$

$37.6 \pm 15.6$

$4.1 \pm 1.4$

$28.4 \pm 16.5$

$9.5 \pm 5.2$

$45.9 \pm 14.9$

$7.7 \pm 1.7$

$41.5 \pm 20.7$

$15.5 \pm 5.7$

$41.4 \pm 13.7$

$54.3 \pm 22.2$ n.s.

n.s.

n.s.

n.s.

0.047

n.s.

n.s.

n.s.

0.018

n.s.

n.s.

n.s.

n.s.

n.s.

\section{Bonemarrow}

B-cell (\%viable)

NK-cell (\%viable)

Granulocytes (\%viable)

Monocytes (\%viable)

Ly6C
hygh (\%parent)
Ly6C
Lyed
(\%parent)

$13.4 \pm 8.5$

$13.5 \pm 4.3$

n.s.

$0.4 \pm 0.2$

$0.6 \pm 0.2$

n.s.

$36.7 \pm 9.7$

$33.8 \pm 8.4$

n.s.

$6.6 \pm 2.5$

$7.1 \pm 3.5$

n.s.

$40.9 \pm 32.6$

$45.5 \pm 37.4$

n.s.

$20.9 \pm 7.9$

$42.2 \pm 17.0$

n.s.

$45.2 \pm 30.8$

$14.1 \pm 10.2$

n.s.

T-cells(\%viable)

$2.3 \pm 1.1$

$2.0 \pm 0.6$

n.s. 
A
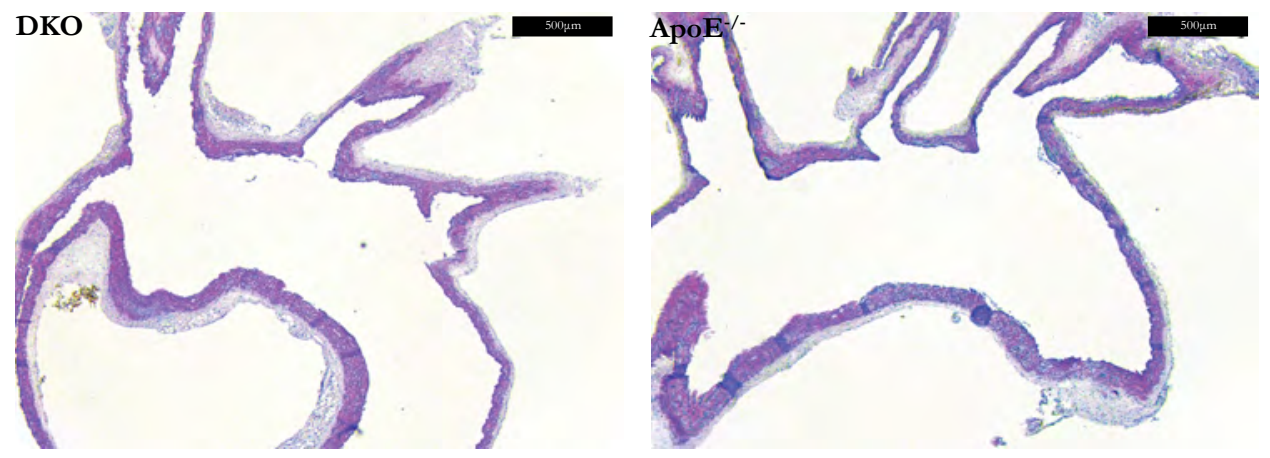

B
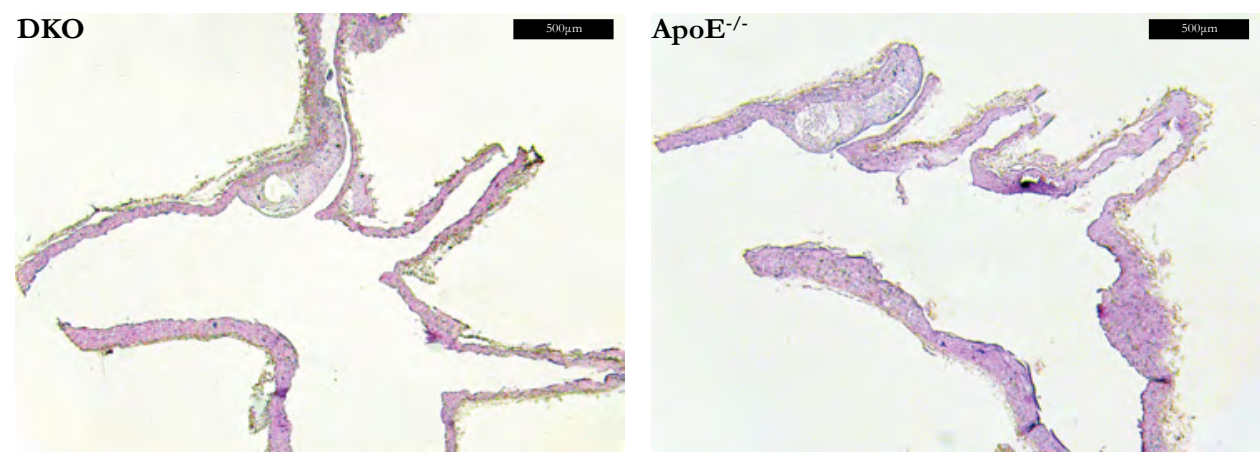

C
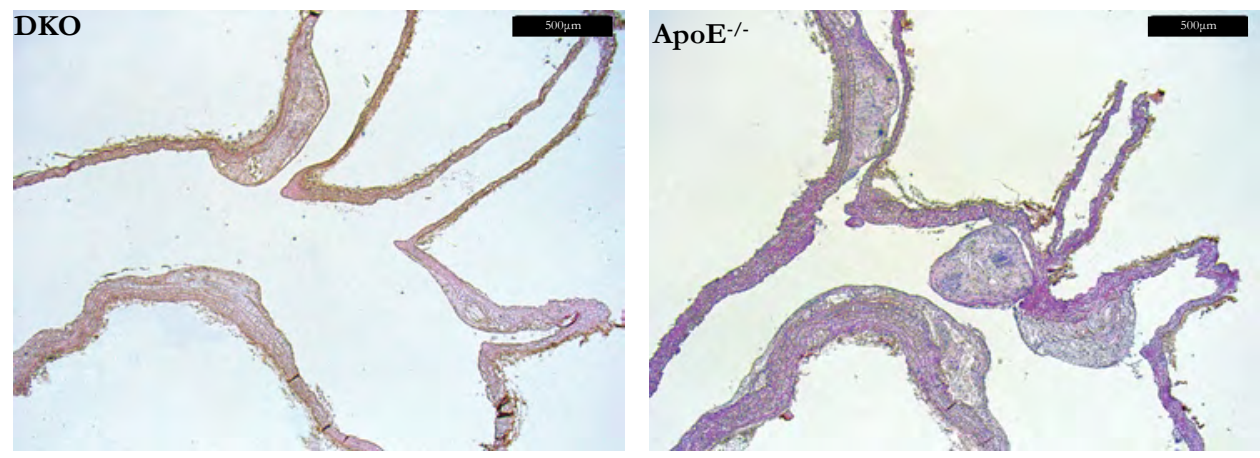

Figure 1 - Hematoxylin and eosin stained aortic arches. Representative images of H\&E stained sections of (A) 14 weeks (B) 20 weeks and (C) 26 weeks old apoE ${ }^{-/-}$and DKO mice fed normal chow diet. Showing initial plaque development starts in the BCA and is followed by development in the arch. $40 \mathrm{x}$ magnification, scale bar $500 \mu \mathrm{m} . \mathrm{n} \geq 10 /$ group. 
A

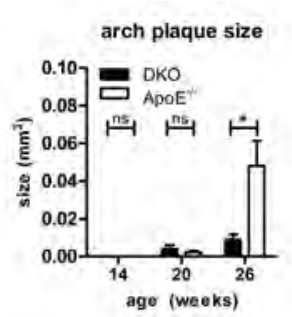

B

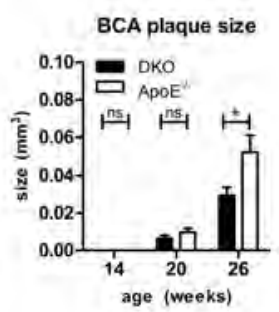

C

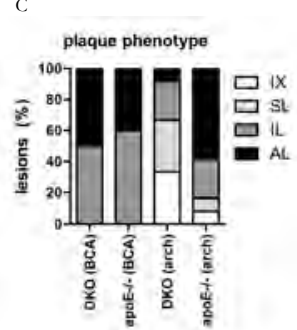

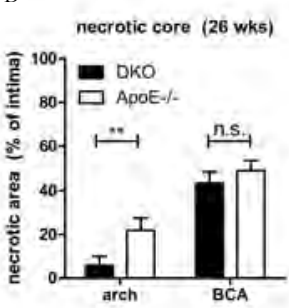

Figure 2 - AnxA5 deficiency slows down atherogenesis. At 14 weeks of age there is only single cell adhesion; measurable plaque development starts from 20 weeks of age. (A) Plaque size was measured in the aortic arch, DKO show decreased plaque development at 26 weeks. (B) Plaque size was measured in the brachiocephalic artery (BCA), DKO show decreased plaque development at 26 weeks. (C) Plaque phenotype was scored at 26 weeks of age, DKO has decreased progression towards advanced lesions in the arch and equal plaque development in the BCA. (D) Necrotic core size and number were measured at 26 weeks. DKO had only a necrotic core in $2 / 13$ (15\%) of cases in the arch and 11/13 (85\%) in the BCA, while the $\mathrm{ApoE}^{-/-}$had developed a necrotic core in 10/12 (83\%) in the arch and 12/12 (100\%) in the BCA. When mice developed a necrotic core, the size was equal. Values are represented as mean $+/$ - SEM, $n \geq 12 /$ group. SCA $=$ single cell adhesion; IX = intimal xanthoma; IL = intermediate lesion; $\mathrm{AL}=$ advanced lesion.

\section{ANXA5 gene promoter activity is increased in macrophages around the necrotic core}

In order to study ANXA5 gene promoter activity in atherosclerotic plaques we performed a LacZ staining for $\beta$-galactosidase on cryosections of 26 weeks DKO aortas. The atherosclerotic plaque contained cells that stained blue, reflecting ANXA5 gene promoter activity (Figure 4A, B). Cells around the core stained intense blue whereas cells in the shoulders of the plaque had a faint blue staining. Blue cells were predominantly MAC-3 positive macrophages, indicating that MAC-3 positive macrophages can regulate ANXA5 gene promoter activity locally (Figure 4C, D). Staining of the M1 macrophage specific marker iNOS, shows an evenly distribution of M1 macrophages in the shoulder and around the necrotic core (Figure $4 \mathrm{E}$ ). There was no difference in total M1 macrophage content between $\mathrm{ApoE}^{-/-}$and DKO (data not shown). In order to investigate whether ANXA5 gene promoter activity is regulated by polarization of macrophages, bone marrow derived macrophages were differentiated towards M0, M1 and M2 phenotype. Figure $4 \mathrm{~F}$ demonstrates that differentiation per se did not affect anxA5 mRNA levels. However, stimulation with LPS caused an upregulation of anxA5 mRNA expression only in M1 macrophages. 


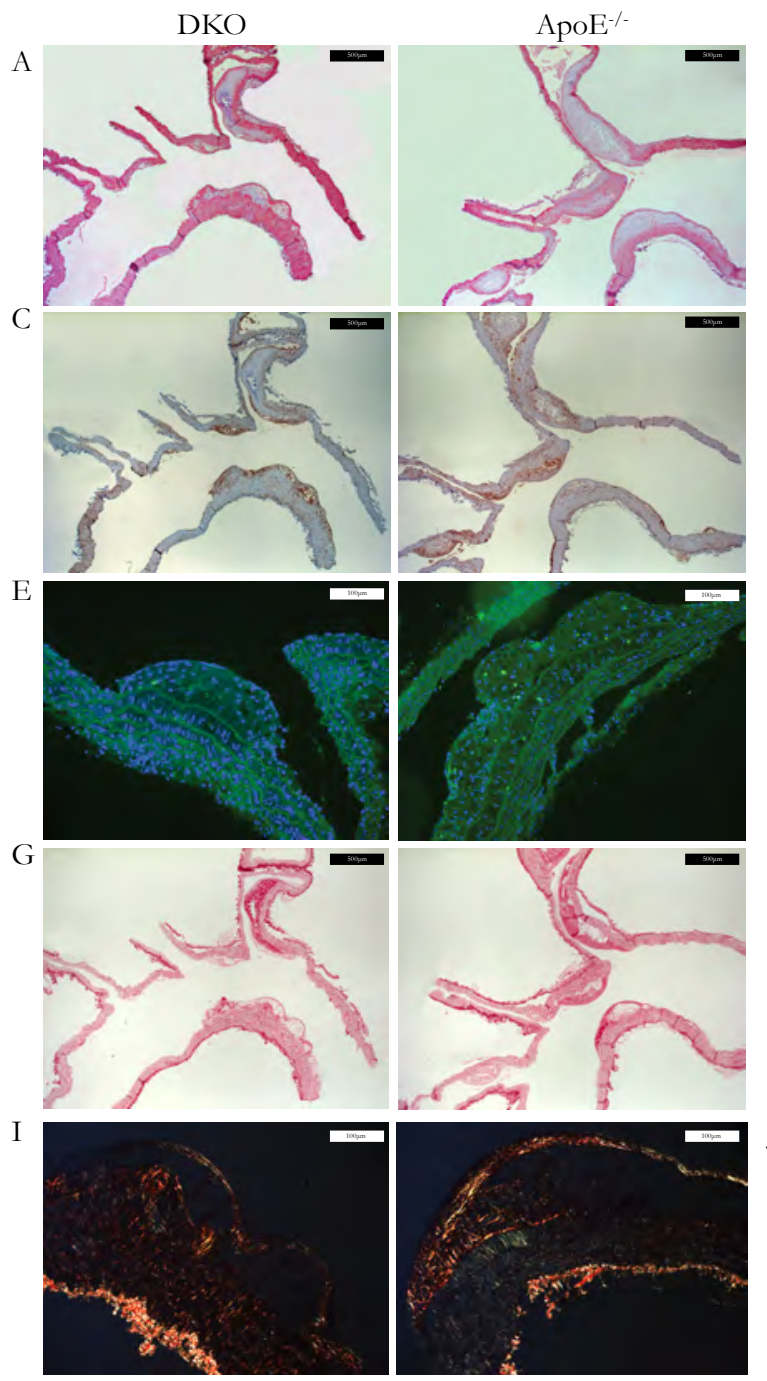

B

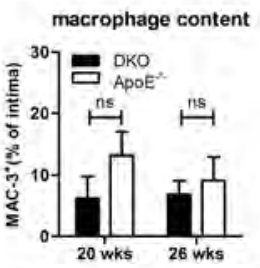

D
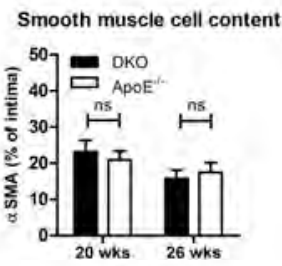

F

Apoptosis

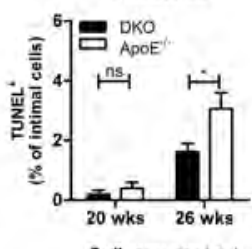

Collagen content
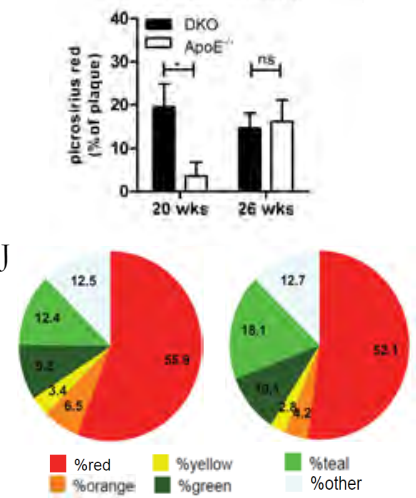

Figure 3 - Anx $A 5$ deficiency results in more stable lesion development. All sections shown are representative images of $26 \mathrm{wks}$ old fed normal chow diet ApoE ${ }^{-/}$and DKO mice. (A,B) MAC-3 staining (brown) for total macrophage content, MAC3 macrophage positive area is equal between ApoE $\mathrm{E}^{-/}$and $\mathrm{DKO}$, quantified as percentage of MAC3+ area of total intima (40x, scale bar $500 \mu \mathrm{m})$. (C,D) $\alpha \mathrm{SMA}$ staining (red) for total vascular smooth muscle cells shows no difference between apoE ${ }^{-/}$ and DKO, quantified as percentage of $\alpha \mathrm{SMA}^{+}$area of total intimal area $(40 \mathrm{x}$, scale bar $500 \mu \mathrm{m})$. (E,F) TUNEL staining for apoptosis (green) and DAPI staining for nucleus (blue), show less apoptotic cells in DKO at 26 weeks of age, quantified as percentage of TUNEL ${ }^{+}$cells of total

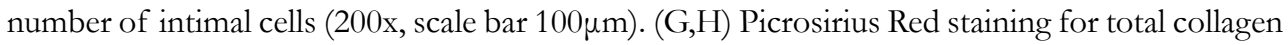
content in bright-field shows higher collagen content at 20 weeks of age in DKO (200x, scale bar $100 \mu \mathrm{m})$. (I,J) Picrosirius Red staining visualized by polarized light for collagen birefringence, shows no difference in age or cross-linking between apoE ${ }^{-/-}$and DKO $(200 \mathrm{x}$, scale bar $100 \mu \mathrm{m})$. All quantifications are represented as mean \pm SEM, $n \geq 12$. 
A

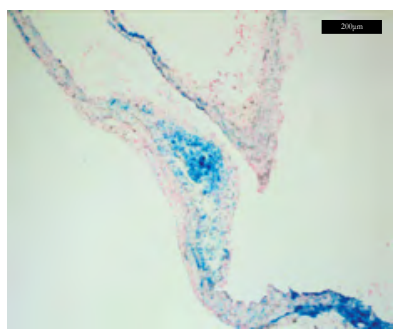

$\mathrm{D}$

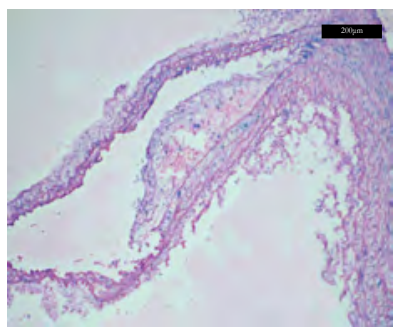

B

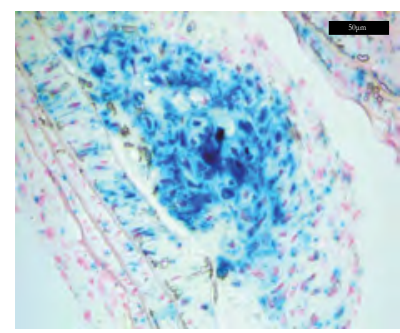

$\mathrm{E}$

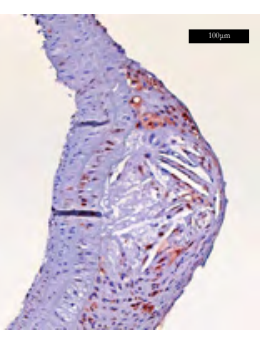

C

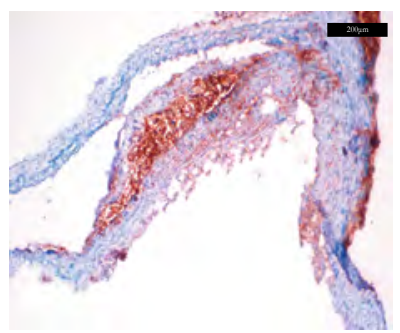

F

anxA5 expression in polarized macrophages

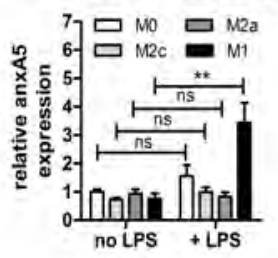

Figure 4 - ANXA5 gene promoter activity is increased in macrophages around the necrotic core. (A,B) LacZ staining for $\beta$-galactosidase activity as a measure of ANXA5 gene promoter activity of BCA plaque shows increased activity around the core (100x and 400x, scale bar $200 \mu \mathrm{m}$ and $50 \mu \mathrm{m}$ respectively). (C) MAC-3/LacZ staining of BCA plaque for macrophages and anxA5 promoter activity, shows that the core and shoulders of the plaque contain MAC-3 positive macrophages (100x, scale bar $200 \mu \mathrm{m})(\mathrm{D})$ LacZ staining of consecutive section shows that not all MAC-3+ macrophages of figure 4C stained equally blue positive (100x, scale bar represents $200 \mu \mathrm{m})$. (E) iNOS staining for M1 polarized macrophages indicates that M1 macrophages are evenly distributed throughout the lesion. (F) qPCR analysis of polarized macrophages, corrected for GAPDH expression and normalized to M0 without LPS stimulation, shows that polarization by itself does not affect anxA5 promoter activity, but activation with LPS causes an upregulation of anxA5 in the M1 polarized macrophages only. Values are presented as mean \pm SEM, $n=4$ mice measured in triplicate.

\section{DKO macrophages exhibit increased efferocytosis in vivo}

Resident peritoneal macrophages were exposed to fluorescently labeled apoptotic Jurkat cells in vivo. Flow cytometry analysis of collected peritoneal macrophages revealed that DKO macrophages phagocytosed apoptotic cells significantly better than ApoE1- macrophages (Figure $5 \mathrm{~A}-\mathrm{C}$ ). Since peritoneal macrophages egress from peritoneum after efferocytosis we excluded that the observed enhanced efferocytosis results from impairment in migration as a result of anxA5 deficiency. $\mathrm{DKO}$ and $\mathrm{ApoE}^{-/-}$macrophages display similar migratory activity with a tendency that $\mathrm{DKO}$ macrophages migrate better than $\mathrm{ApoE}^{-/-}$macrophages (Figure $5 \mathrm{D}$ ). 

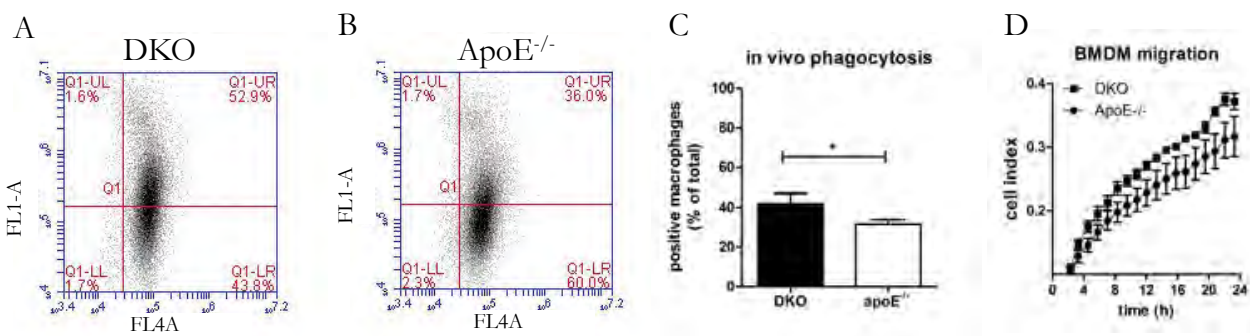

Figure 5-DKO macrophages exhibit increased efferocytosis in vivo. (A,B) Representative dot plot of the uptake of CFSE-labeled apoptotic Jurkat cells by residential peritoneal macrophages of DKO and ApoE-/- mice. Upper right corner of the FL-1/FL-4 image represent double positive cells for CFSE (apoptotic cells) and F4/80-APC (macrophages). Parameters are set using unlabeled and single labeled control conditions. (C) Quantification of in vivo phagocytosis shows increased phagocytosis by DKO ( $\mathrm{n}=8 \mathrm{mice} /$ group, analysis was performed using paired $t$-test). (D) Migration of bone marrow derived macrophages in a label free Real-Time Cell Analysis platform (xCELLigence), indicates that the migratory ability between $\mathrm{DKO}$ and apoE-/- is equal, with a tendency of higher migration by $\mathrm{DKO}$ macrophages.

\section{Discussion}

In this paper we investigated the role of anxA5 in atherosclerosis by anxA5 knockout on an $\mathrm{ApoE}^{-/-}$background. AnxA5 is broadly known as imaging tool to visualize apoptosis in vitro ${ }^{29}$, and in vivo in animal models ${ }^{30}$ and patients ${ }^{13}$. Imaging studies revealed that anxA5 accumulates in atherosclerotic plaques and that extent of its accumulation reflects plaque vulnerability ${ }^{14,31-33}$. Recently it was also shown that exogenously administered hr-anxA5 reduces plaque inflammation and shifts plaques towards a more stable phenotype $^{16}$ (Burgmaier et al. J Cell Mol Med 2014 accepted for publication). The pharmacodynamics of hr-anxA5 were explained by its ability to reduce pro-inflammatory effects of phosphatidylserine, lysophosphatidylcholine, oxidated LDL and oxidated cardiolipin ${ }^{12,17,18}$.

We were interested whether endogenous anxA5 would serve a similar protective function in atherosclerosis. Knocking out anxA5 was associated with a significant increase in plasma triglycerides, total cholesterol and a shift towards circulating Ly- $6 \mathrm{C}^{\text {high }}$ monocytes. There was a tendency towards an increase of circulating granulocytes. All these factors have previously been associated with increased atherogenic pressure ${ }^{34-38}$ and therefore, would suggest an aggravation of atherosclerosis in the DKO mice. Surprisingly, our study shows that anxA5 deficiency results in inhibition of atherogenesis in mice on normal chow diet. Differences in plaque burden became significant at the age of 26 weeks. DKO had smaller and less advanced plaques both in aortic arch and BCA. The effect of anxA5-deficiency 
on atherogenesis was more pronounced in the arch. The speed of plaque development was slower in the arch suggesting that anxA5-deficiency causes subtle differences in processes underlying plaque formation. After 26 weeks plaques of the arch of DKO mice had a lower frequency of cell death and were almost devoid of a necrotic core. This indicates that either fewer cells execute apoptosis and progress towards secondary necrosis, or apoptotic cells are more efficiently removed by efferocytosis in DKO plaques.

It has been shown before that increased apoptotic and necrotic cell accumulation leads to increased plaque development ${ }^{39-41}$. Apoptosis is an important process with dual impact on atherogenesis, as it impedes development of early plaques and accelerates progression of late plaques ${ }^{42}$. Our findings that anxA5 deficiency does not accelerate early plaque development, suggests that apoptosis is not affected. Therefore we reasoned that depletion of anxA5 affects efficiency of efferocytosis by plaque macrophages. Our in vivo experiments indeed show that anxA5 deficiency improves efferocytosis by macrophages. Others showed that anxA5 deficiency increased engulfment of necrotic cells by peritoneal macrophages 43. How endogenous anxA5 suppresses efferocytosis remains to be elucidated. Possibly the macrophage externalizes anxA5 ${ }^{44,45}$ which subsequently shields PS on the apoptotic prey and phagocyte and suppresses efferocytosis ${ }^{19-21}$. Alternatively, intracellular anxA5 is involved in phagolysosome formation ${ }^{46}$. Interestingly we observed that plaque macrophages, and especially macrophages located in the core of the plaque where necrotic debris coalesces, have increased promoter activity of the ANXA5 gene. Atherosclerotic plaques of ApoE $\mathrm{E}^{-/-}$mice contain predominantly the classically activated and pro-inflammatory M1 macrophage ${ }^{38}$. The differential regulation of ANXA5 gene promoter activity by plaque macrophages was not associated with skewing of polarization towards the alternatively activated and anti-inflammatory M2 phenotype. Apparently, the micro-environment of macrophages determines ANXA5 gene promoter activity without affecting polarization. This notion is supported by our findings that M0, M1 and M2 have comparable ANXA5 gene promoter activity and that only M1 macrophages respond to LPS by upregulating anxA5 mRNA expression. It is tempting to speculate that the plaque core environment induces M1 macrophages to upregulate anxA5 expression with subsequently suppression of phagocytic activity and necrotic core development.

In conclusion, our results demonstrate that endogenous anxA5 plays a role in atherogenesis and that targeted inhibition of anxA5 may be a therapeutic avenue to attenuate plaque progression. 


\section{References}

1. Borissoff JI, Spronk HM, ten Cate H. The hemostatic system as a modulator of atherosclerosis. $N$ Engl J Med. 2011;364:1746-1760.

2. Virmani R, Burke AP, Kolodgie FD, Farb A. Vulnerable plaque: the pathology of unstable coronary lesions. J Interv Cardiol. 2002;15:439-446.

3. Ross R. Atherosclerosis--an inflammatory disease. N Engl J Med. 1999;340:115-126.

4. Virmani R, Kolodgie FD, Burke AP, Farb A, Schwartz SM. Lessons from sudden coronary death: a comprehensive morphological classification scheme for atherosclerotic lesions. Arterioscler Thromb Vasc Biol. 2000;20:1262-1275.

5. Hansson GK. Inflammation, atherosclerosis, and coronary artery disease. $N$ Engl J Med. 2005;352:1685-1695.

6. Thorp E, Tabas I. Mechanisms and consequences of efferocytosis in advanced atherosclerosis. J Leukoc Biol. 2009;86:1089-1095.

7. Heo KS, Cushman HJ, Akaike M, Woo CH, Wang X, Qiu X, Fujiwara K, Abe J. ERK5 Activation in Macrophages Promotes Efferocytosis and Inhibits Atherosclerosis. Circulation. 2014;130:180-191.

8. Poon IK, Lucas CD, Rossi AG, Ravichandran KS. Apoptotic cell clearance: basic biology and therapeutic potential. Nat Rev Immunol. 2014;14:166-180.

9. Martin SJ, Reutelingsperger CP, McGahon AJ, Rader JA, van Schie RC, LaFace DM, Green DR. Early redistribution of plasma membrane phosphatidylserine is a general feature of apoptosis regardless of the initiating stimulus: inhibition by overexpression of Bcl-2 and Abl. J Exp Med. 1995;182:1545-1556.

10. Wu Y, Tibrewal N, Birge RB. Phosphatidylserine recognition by phagocytes: a view to a kill. Trends Cell Biol. 2006;16:189-197.

11. Gerke V, Creutz CE, Moss SE. Annexins: linking Ca2+ signalling to membrane dynamics. Nat Rev Mol Cell Biol. 2005;6:449-461.

12. van Genderen HO, Kenis H, Hofstra L, Narula J, Reutelingsperger CP. Extracellular annexin A5: functions of phosphatidylserine-binding and two-dimensional crystallization. Biochim Biophys Acta. 2008; 1783:953-963.

13. Boersma HH, Kietselaer BL, Stolk LM, Bennaghmouch A, Hofstra L, Narula J, Heidendal GA, Reutelingsperger CP. Past, present, and future of annexin A5: from protein discovery to clinical applications. J Nucl Med. 2005;46:2035-2050.

14. Kusters DH, Tegtmeier J, Schurgers LJ, Reutelingsperger CP. Molecular imaging to identify the vulnerable plaque--from basic research to clinical practice. Mol Imaging Biol. 2012;14:523-533.

15. Ewing MM, de Vries MR, Nordzell M, Pettersson K, de Boer HC, van Zonneveld AJ, Frostegard J, Jukema JW, Quax PH. Annexin A5 therapy attenuates vascular inflammation and remodeling and improves endothelial function in mice. Arterioscler Thromb Vasc Biol. 2011;31:95-101.

16. Ewing MM, Karper JC, Sampietro ML, de Vries MR, Pettersson K, Jukema JW, Quax PH. Annexin A5 prevents post-interventional accelerated atherosclerosis development in a dose-dependent fashion in mice. Atherosclerosis. 2012;221:333-340.

17. Domeij H, Hua X, Su J, Backlund A, Yan Z, Frostegard AG, Haeggstrom JZ, Modeer T, Frostegard J. Annexin A5 inhibits atherogenic and pro-inflammatory effects of lysophosphatidylcholine. Prostaglandins Other Lipid Mediat. 2013;106:72-78.

18. Wan M, Hua X, Su J, Thiagarajan D, Frostegard AG, Haeggstrom JZ, Frostegard J. Oxidized but not native cardiolipin has pro-inflammatory effects, which are inhibited by Annexin A5. Atherosclerosis. 2014;235:592-598. 
19. Yoshida S, Minematsu N, Chubachi S, Nakamura H, Miyazaki M, Tsuduki K, Takahashi S, Miyasho T, Iwabuchi T, Takamiya R, Tateno H, Mouded M, Shapiro SD, Asano K, Betsuyaku T. Annexin $\mathrm{V}$ decreases PS-mediated macrophage efferocytosis and deteriorates elastase-induced pulmonary emphysema in mice. Am J Physiol Lung Cell Mol Physiol. 2012;303:L852-860.

20. Schutters K, Kusters DH, Chatrou ML, Montero-Melendez T, Donners M, Deckers NM, Krysko DV, Vandenabeele P, Perretti M, Schurgers LJ, Reutelingsperger CP. Cell surface-expressed phosphatidylserine as therapeutic target to enhance phagocytosis of apoptotic cells. Cell Death Differ. 2013;20:49-56.

21. Callahan MK, Williamson P, Schlegel RA. Surface expression of phosphatidylserine on macrophages is required for phagocytosis of apoptotic thymocytes. Cell Death Differ. 2000;7:645-653.

22. Brachvogel B, Dikschas J, Moch H, Welzel H, von der Mark K, Hofmann C, Poschl E. Annexin A5 is not essential for skeletal development. Mol Cell Biol. 2003;23:2907-2913.

23. Hemker HC, Giesen P, Al Dieri R, Regnault V, de Smedt E, Wagenvoord R, Lecompte T, Beguin S. Calibrated automated thrombin generation measurement in clotting plasma. Pathophysiol Haemost Thromb. 2003;33:4-15.

24. MacKenna DA, Omens JH, Covell JW. Left ventricular perimysial collagen fibers uncoil rather than stretch during diastolic filling. Basic Res Cardiol. 1996;91:111-122.

25. Logan C, Khoo WK, Cado D, Joyner AL. Two enhancer regions in the mouse En-2 locus direct expression to the mid/hindbrain region and mandibular myoblasts. Development. 1993;117:905-916.

26. Davies JQ, Gordon S. Isolation and culture of murine macrophages. Methods Mol Biol. 2005;290:91-103.

27. Taylor PR, Carugati A, Fadok VA, Cook HT, Andrews M, Carroll MC, Savill JS, Henson PM, Botto M, Walport MJ. A hierarchical role for classical pathway complement proteins in the clearance of apoptotic cells in vivo. J Exp Med. 2000;192:359-366.

28. van Genderen H, Kenis H, Lux P, Ungeth L, Maassen C, Deckers N, Narula J, Hofstra L, Reutelingsperger C. In vitro measurement of cell death with the annexin A5 affinity assay. Nat Protoc. 2006;1:363-367.

29. Vermes I, Haanen C, Steffens-Nakken H, Reutelingsperger C. A novel assay for apoptosis. Flow cytometric detection of phosphatidylserine expression on early apoptotic cells using fluorescein labelled Annexin V. J Immunol Methods. 1995;184:39-51.

30. Belhocine TZ, Blankenberg FG. The imaging of apoptosis with the radiolabelled annexin A5: a new tool in translational research. Curr Clin Pharmacol. 2006;1:129-137.

31. De Saint-Hubert M, Bauwens M, Deckers N, Drummen M, Douma K, Granton P, Hendrikx G, Kusters D, Bucerius J, Reutelingsperger CP, Mottaghy FM. In Vivo Molecular Imaging of Apoptosisand Necrosis in Atherosclerotic PlaquesUsing MicroSPECT-CT and MicroPET-CT Imaging. Mol Imaging Biol. 2013.

32. Kolodgie FD, Petrov A, Virmani R, Narula N, Verjans JW, Weber DK, Hartung D, Steinmetz N, Vanderheyden JL, Vannan MA, Gold HK, Reutelingsperger CP, Hofstra L, Narula J. Targeting of apoptotic macrophages and experimental atheroma with radiolabeled annexin V: a technique with potential for noninvasive imaging of vulnerable plaque. Circulation. 2003;108:3134-3139.

33. Kietselaer BL, Reutelingsperger CP, Heidendal GA, Daemen MJ, Mess WH, Hofstra L, Narula J. Noninvasive detection of plaque instability with use of radiolabeled annexin A5 in patients with carotid-artery atherosclerosis. $N$ Engl J Med. 2004;350:1472-1473.

34. Swirski FK, Libby P, Aikawa E, Alcaide P, Luscinskas FW, Weissleder R, Pittet MJ. Ly-6Chi monocytes dominate hypercholesterolemia-associated monocytosis and give rise to macrophages in atheromata. J Clin Invest. 2007;117:195-205.

35. Murphy AJ, Akhtari M, Tolani S, Pagler T, Bijl N, Kuo CL, Wang M, Sanson M, Abramowicz S, Welch C, Bochem AE, Kuivenhoven JA, Yvan-Charvet L, Tall AR. ApoE regulates hematopoietic stem cell proliferation, monocytosis, and monocyte accumulation in atherosclerotic lesions in mice. J Clin Invest. 2011;121:4138-4149. 
36. Swirski FK. Monocyte recruitment and macrophage proliferation in atherosclerosis. Kardiol Pol. 2014;72:311-314.

37. Soehnlein O, Swirski FK. Hypercholesterolemia links hematopoiesis with atherosclerosis. Trends Endocrinol Metab. 2013;24:129-136.

38. Moore KJ, Sheedy FJ, Fisher EA. Macrophages in atherosclerosis: a dynamic balance. Nat Rev Immunol. 2013;13:709-721.

39. Ait-Oufella H, Kinugawa K, Zoll J, Simon T, Boddaert J, Heeneman S, Blanc-Brude O, Barateau V, Potteaux S, Merval R, Esposito B, Teissier E, Daemen MJ, Leseche G, Boulanger C, Tedgui A, Mallat Z. Lactadherin deficiency leads to apoptotic cell accumulation and accelerated atherosclerosis in mice. Circulation. 2007;115:2168-2177.

40. Ait-Oufella H, Pouresmail V, Simon T, Blanc-Brude O, Kinugawa K, Merval R, Offenstadt G, Leseche G, Cohen PL, Tedgui A, Mallat Z. Defective mer receptor tyrosine kinase signaling in bone marrow cells promotes apoptotic cell accumulation and accelerates atherosclerosis. Arterioscler Thromb Vasc Biol. 2008;28:1429-1431.

41. Thorp E, Cui D, Schrijvers DM, Kuriakose G, Tabas I. Mertk receptor mutation reduces efferocytosis efficiency and promotes apoptotic cell accumulation and plaque necrosis in atherosclerotic lesions of apoe-/- mice. Arterioscler Thromb Vasc Biol. 2008;28:1421-1428.

42. Tabas I. Consequences and therapeutic implications of macrophage apoptosis in atherosclerosis: the importance of lesion stage and phagocytic efficiency. Arterioscler Thromb Vasc Biol. 2005;25:2255-2264.

43. Frey B, Munoz LE, Pausch F, Sieber R, Franz S, Brachvogel B, Poschl E, Schneider H, Rodel F, Sauer R, Fietkau R, Herrmann M, Gaipl US. The immune reaction against allogeneic necrotic cells is reduced in Annexin A5 knock out mice whose macrophages display an anti-inflammatory phenotype. J Cell Mol Med. 2009;13:1391-1399.

44. Callahan MK, Halleck MS, Krahling S, Henderson AJ, Williamson P, Schlegel RA. Phosphatidylserine expression and phagocytosis of apoptotic thymocytes during differentiation of monocytic cells. $J$ Leukoc Biol. 2003;74:846-856.

45. Ravassa S, Bennaghmouch A, Kenis H, Lindhout T, Hackeng T, Narula J, Hofstra L, Reutelingsperger C. Annexin A5 down-regulates surface expression of tissue factor: a novel mechanism of regulating the membrane receptor repertoir. J Biol Chem. 2005;280:6028-6035.

46. Diakonova M, Gerke V, Ernst J, Liautard JP, van der Vusse G, Griffiths G. Localization of five annexins in J774 macrophages and on isolated phagosomes. J Cell Sci. 1997;110 ( Pt 10):1199-1213. 

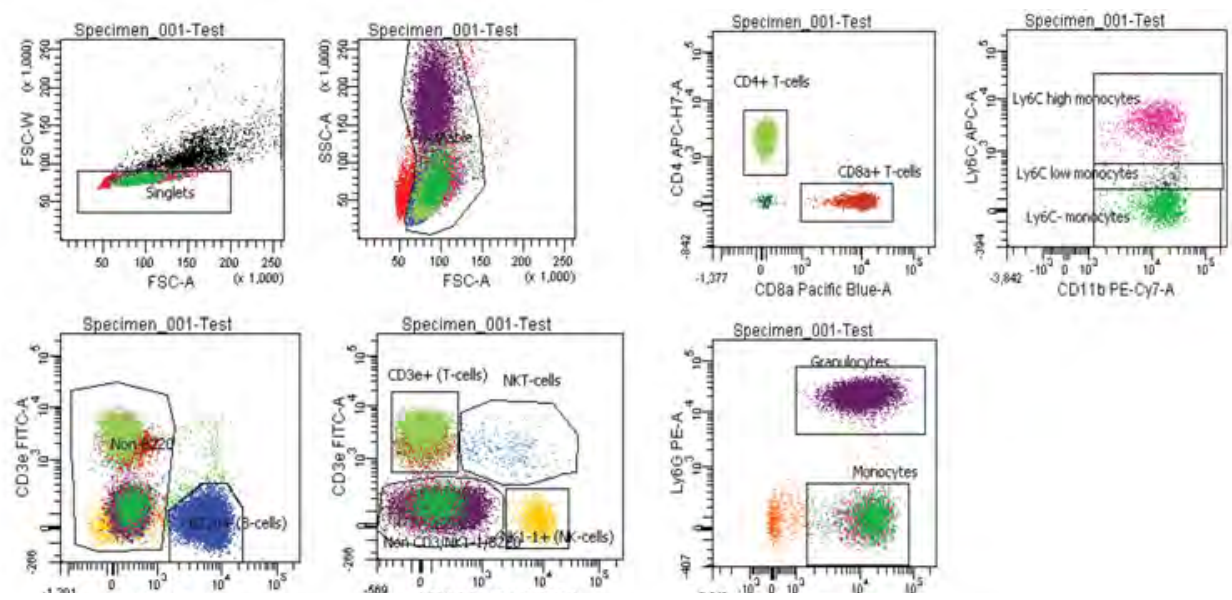

Supplemental figure 1 - Gate settings for blood analysis. Flow cytometry analysis of blood on FACS Canto. First single cells are selected. Viable cells are selected from the single cells and further classified using antibodies against CD11b (monocytes+granulocytes), Ly-6G (granulocytes), Ly6C (monocytes), CD3e (T-cells), B220 (B-cells), NK1.1 (NK-cells), CD4 (T-helper cell) and CD8a (cytotoxic T-cell).
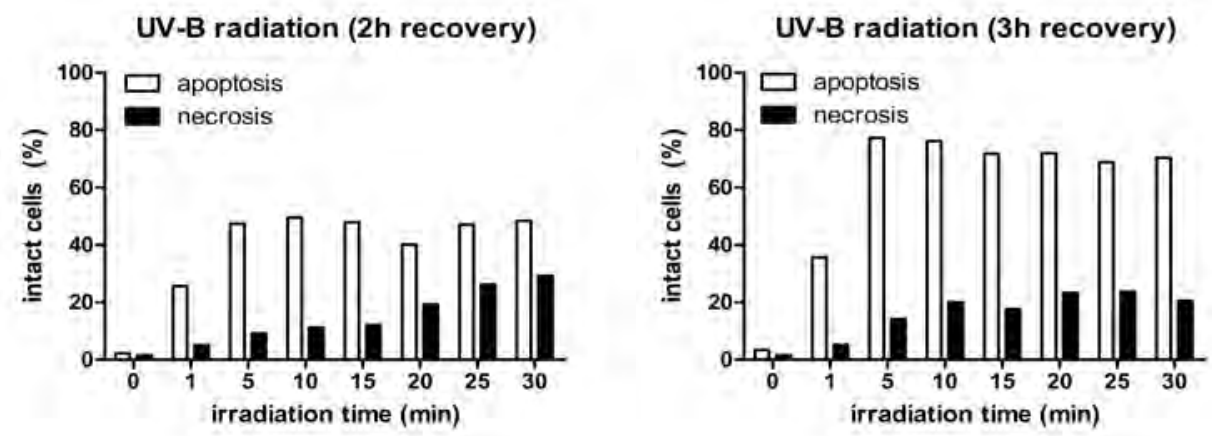

Supplemental figure 2 - the effect of $U V-B$ radiation and incubation time on apoptosis and necrosis of Jurkat cells. After 10 minutes of UV-B irradiation and 3 hours incubation, about $75 \%$ of cells are apoptotic with minor necrosis present. This is the condition we selected for the in vivo phagocytosis assay. 


\section{Supplemental Table 1 - quantification of plaque progression.}

$\begin{array}{llll}\text { Subject } & \text { Amount } & \text { Score } \\ \text { Neutrophils (\#) } & 0 & 0 \\ & 1,2 & 1 \\ \text { Macrophages (\% intima) } & \geq 3 & 2 \\ & 0-10 & 0 \\ & 11-20 & 1 \\ & 21-30 & 2 \\ \text { Apoptosis (yes/no) } & \geq 31 & 3 \\ \text { Necrotic core size (\% intima) } & \text { negative } & 0 \\ & \text { positive } & 1 \\ \text { Cap thickness (cell layers) } & <20 & 0 \\ & \geq 20 & 1 \\ \text { Calcification (status) } & 0-1 & 2 \\ & 2-3 & 0 \\ & >3 & 1 \\ & \text { absent } & 2 \\ & \text { osteochondrocytic cells } & 1 \\ & \text { calcification } & 2\end{array}$

Supplemental Table 2 - Classification of plaque progression score.

$\begin{array}{lll}\text { Total score } & \text { Definition } & \text { Abbreviation } \\ 0-3 & \text { Intimal Xanthoma } & \text { IX } \\ 4-5 & \text { Small Lesion } & \text { SL } \\ 6-7 & \text { Intermediate Lesion } & \text { IL } \\ \geq 8 & \text { Advanced Lesion } & \text { AL }\end{array}$


Chapter 3 


\section{Chapter 4}

\section{Exogenous annexin A1 attenuates athero- genesis in $\mathrm{LDLR}^{-1-}$ mice on Western Type Diet}

DHM Kusters, ML Chatrou, BAG Willems, M De Saint-Hubert, M Bauwens, E van der Vorst, S Bena, EAL Biessen, M Perretti, LJ Schurgers, CPM Reutelingsperger

Resubmitted to Cardiovasc Res 


\section{Abstract}

Objective: To investigate effects of anxA1 administration on atherogenesis in $\mathrm{LDLR}^{-1-}$ mice.

Methods: In vivo, biodistribution of human recombinant annexin A1 (hr-anxA1) was determined in $\mathrm{C} 57 \mathrm{Bl} / 6 \mathrm{~J}$ mice after intravenous and intraperitoneal administration. For atherosclerosis, Western Type Diet fed $\mathrm{LDLR}^{-/-}$mice were treated 3 times per week for a period of 6 weeks. Total plaque burden and phenotype were analyzed using immunohistochemistry. In vitro, effects of hr-anxA1 on leukocyte adherence and rolling on activated endothelial cells are studied in a flow chamber model.

Results: In vivo, intravenously administered hr-anxA1 had blood clearance with $\mathrm{t}_{1 / 2}<10$ minutes. Intraperitoneal administered hr-anxA1 peaked in circulation 50 minutes postinjection and had $0.5 \%$ of injected dose per gram circulating after 24 hours. Administration of hr-anxA1 did not affect initiation of plaque formation $(-33 \% ; \mathrm{P}=0.21)$ but significantly inhibited progression of plaque size $(-50 \% ; \mathrm{P}=0.005)$ and necrotic core size $(-76 \%$, $\mathrm{P}=0.015)$. In vitro, hr-anxA1 inhibited rolling and adherence of neutrophils but not monocytes to activated endothelial cells.

Conclusion: Annexin A1 attenuates atherogenesis by reducing plaque inflammation 


\section{Introduction}

Atherosclerosis is a systemic chronic inflammatory disease affecting the vascular wall of arteries and is the major cause of morbidity and mortality in both developed and developing countries. The disease is characterized by confined manifestations of atherosclerotic lesions in the arterial vessel wall that may develop into unstable plaques causing adverse outcomes over time ${ }^{1-3}$. Unstable plaques are characterized by abundant presence of inflammatory cells, a large necrotic core and a thin fibrous cap ${ }^{4}$. Inflammatory cells are considered key players in initiation of- and progression to an unstable plaque ${ }^{5,6}$. Activated neutrophils act as important effectors and regulators of inflammation through their ability to produce a myriad of effector molecules including cytokines, chemokines and angiogenic factors ${ }^{7}$. Reducing recruitment of neutrophils to the inflamed arterial vessel wall by neutrophilspecific antibodies and gene-deletions of chemokines and their receptors, suppresses arterial lesion development in mouse models of atherosclerosis ${ }^{8-10}$.

Annexin A1 (anxA1) is a member of the multigene annexin family ${ }^{11}$ with potent antiinflammatory activity ${ }^{12}$. The polypeptide chain of anxA1 comprises a C-terminal core domain, which is conserved amongst all members of the family and harbors the $\mathrm{Ca}^{2+}$ and phospholipid binding sites, and an $\mathrm{N}$-terminal tail that varies between annexin members. The N-terminal tail of anxA1 can interact with the receptor for formylated peptides (FPR-2/ALXR) ${ }^{11,13-16}$. In the absence of calcium and a phospholipid surface, the tail is concealed within the core domain. However, upon membrane binding anxA1 changes conformation and exposes its $\mathrm{N}$-terminus at the surface enabling interaction with FPR-2 ${ }^{15}$. AnxA1-FPR-2 interaction results in inhibition of neutrophil recruitment to inflamed sites ${ }^{17}$. Alternatively, proteolysis can cause release of the $\mathrm{N}$-terminal peptide ${ }^{18}$, which then can interact with FPR-1 and 2 evoking anti-inflammatory activity ${ }^{19}$. Pharmacological treatment of inflammation using anxA1 and its $\mathrm{N}$-terminal peptide has been studied in mouse models of neutrophil-dependent edema ${ }^{20}$, cardiac ischemia-reperfusion injury ${ }^{21}$, ${ }^{22}$ and acute peritonitis ${ }^{23}$, however, hitherto not in atherosclerosis.

In this paper we studied pharmacological effects of human recombinant anxA1 (hr-anxA1) on the initiation of atherosclerosis and the progression of established atherosclerotic plaques in an LDLR ${ }^{-1}$ mouse model. We demonstrate that hr-anxA1 has no effect on initiation of early plaque development, but significantly attenuates progression of existing lesions to unstable plaques. 


\section{Methods}

Design, production and purification of human recombinant (hr)-anxA1- cDNA coding for hr-anxAl was amplified by polymerase chain reaction (PCR) using primers: 5'-GGTATCGAGGGAAGGGCAATGGTATCAGAATTC-3' and 5'-GCTCAGCTAATTAAGCTTTAGTTTCCTCCACAAAGAGC-3'. The primers introduced Stu-I and Hind-III restriction sites, required for the ligation into the expression vector $\mathrm{pQE} 30 \mathrm{Xa}$ (Qiagen). His-tagged hr-anxA1 was produced according to previously published protocol for anxA5 24. In short, E. Coli (SG13009[pREP4]) (Novagen) were fermented in Luria-Bertani broth (LB) medium supplemented with Ampicillin (50ug/ml, Roche), Kanamycin (30ug/ml, Gibco) and $0.5 \%$ glycerol. At $\mathrm{OD}_{450}$ of $>6$, over-expression of the protein was initiated by addition of $5 \mathrm{mM}$ isopropyl $\beta$-D-1-thiogalactopyranoside (IPTG, Eurogentec). Proteins were purified by immobilized metal affinity chromatography (IMAC) using nickel. Purity and homogeneity were assessed by silver-stained SDS-PAGE, western blotting and MALDI-TOF/TOF analysis.

Endotoxin determination - Endotoxin was determined with the Endosafe-PTS (CharlesRiver) according to manufacturer's protocol. Purified protein preparations containing $<1$ unit $/ \mathrm{ml}$ endotoxin were used for experiments.

Ellipsometry - PS-binding property of purified hr-anxA1 was determined by ellipsometry using a bilayer of 20 mole\% dioleoyl-phosphatidylserine / 80 mole\% dioleoyl-phosphatidylcholine (20 mole\% DOPS/80 mole\% DOPC; Avanti Polar Lipids, Alabaster, AL, USA) as described previously ${ }^{25}$.

Cell culture - Primary bone marrow derived monocytes were isolated as described before ${ }^{26}$. Mice are anesthetized with 5\% isoflurane before sacrifice by cervical dislocation. Cells were grown for 8 days in RPMI 1640 containing $10 \mathrm{mM}$ Hepes, $10 \%$ heat inactivated fetal bovine serum (FBS, Gibco-BRL), 15\% L-cell conditioned medium, 100U/ml Penicillin (Gibco-BRL) and $100 \mu \mathrm{g} / \mathrm{ml}$ Streptomycin (Gibco-BRL). The human monocytic cell line THP-1 (ATCC, Manassas, USA), was cultured in RPMI 1640 without color indicator (Gibco-BRL, Invitrogen, USA) supplemented with $2 \mathrm{mM}$ glutamine (Gibco-BRL, Invitrogen), 10\% heat-inactivated FBS, 100 units/ml penicillin and $100 \mu \mathrm{g} / \mathrm{ml}$ streptomycin. Polymorphonuclear leukocytes (PMN) were isolated from blood collected into 3.2\% sodium citrate, diluted 1:1 in RPMI 1640 (Sigma-Aldrich) before separation through 
a double-density gradient as described previously ${ }^{19}$. Confluent human umbilical vein endothelial cells (HUVEC, PromoCell, C12203) were grown to a monolayer in a $\mu$-slide (Ibidi, 80666, Germany) before flow experiments.

Calcium mobilization and flow-chamber assay - Receptor binding studies were performed on FPR-2 transfected HEK293 cells as described previously ${ }^{27}$. Leukocyte rolling and adhesion flow chamber experiments were performed as described previously ${ }^{19}$. Each flow experiment consisted in total of a 10 second recording at 1 frame per 0.3 second. Cells of all 32 frames were counted: adhering cells were stationary in all frames, while rolling cells were defined as all interacting non-stationary cells.

In vitro internalization of $h r$-anxA1 - Binding and internalization of fluorescently labeled hr-anxA1 by apoptotic Jurkat cells was visualized with confocal laser scanning microscopy (CLSM) as described previously ${ }^{28}$ and by flow cytometry.

Animals - The investigation conforms to the Guide for the Care and Use of Laboratory Animals published by the US National Institute of Health (NIH Publication NO. 8523, revised 2011). All animal studies were conducted under a protocol approved by the ethics committee for animal experiments of Maastricht University. For pharmacological treatment with hr-anxA1, 12 weeks old $\mathrm{LDLR}^{-1-}$ mice were fed a Western type diet (WTD, $0.15 \%$ cholesterol) ( $\mathrm{AB}$ diets 4021.13 ) for 6 weeks (group I, $\mathrm{n}=12$ ) or 12 weeks (group $\mathrm{P}, \mathrm{n}=12$ ). Group I received either $1 \mathrm{mg} / \mathrm{kg} \mathrm{hr}$-anxA1 or PBS (control) 3 times per week via intraperitoneal (IP) injection starting at day 0 for 6 weeks. Group P received either 1 $\mathrm{mg} / \mathrm{kg} \mathrm{hr}$-anxA1 or PBS 3 times per week via IP injection starting 6 weeks after initiation of WTD for 6 weeks. Mice were treated with $0.1 \mathrm{mg} / \mathrm{kg}$ Buprenorphine (Temgesic) subcutaneously and anesthetized with $5 \%$ isoflurane, before sacrifice by vena cava puncture. Aortic arches with all major branch points were dissected, fixed in $1 \% \mathrm{PFA} o / \mathrm{n}$, paraffin embedded and sectioned at $4 \mu \mathrm{m}$ thickness. Total plaque area was determined for the entire arch and the brachiocephalic, carotid and subclavian arteries using standard hematoxylin/ eosin (H\&E) staining on every fifth section, and analyzed with ImageJ Software (v1.45). Plaque progression was scored on the following parameters: neutrophil and macrophage content, apoptosis and necrosis, cap thickness and calcification status as is summarized in supplemental Tables 1 and 2. 
Nuclear imaging, biodistribution and blood clearance - Purified His-tagged hr-anxA1 was radiolabeled with technetium-99m $\left({ }^{99 \mathrm{~m}} \mathrm{Tc}(\mathrm{CO})_{3}\right.$-His-anxA1) using the IsoLink tricarbonyl labeling method (Covidien, Petten, The Netherlands) as described previously for HisanxA5 ${ }^{29}$. Nuclear imaging, blood clearance and biodistribution were performed using 12 weeks old $\mathrm{LDLR}^{-1-}$ mice (Charles-River). Biodistribution and blood clearance of IP and intravenous (IV) injection of $100 \mathrm{MBq}^{99 \mathrm{~m}} \mathrm{Tc}(\mathrm{CO})_{3}$-His-anxA1 were determined. To exclude any dietary effect on the biodistribution or blood clearance, the mice were put on WTD 2 weeks prior to the experiment. Total body single photon emission tomography (SPECT) imaging was performed 45 minutes post-injection as previously described ${ }^{30}$.

Flow cytometric analysis of blood and bone marrow - Single cell suspensions were prepared and stained with anti-CD3, -CD4, -CD8a, -CD11b, -CD115, -Ly6C, -Ly6G, -B220, -NK1.1, or isotype control IgG. Antibodies conjugated to FITC, PE, APC, Cy7, eFluo450, or PerCP (all BD Biosciences) were used and cells were analyzed using a FACS-Canto II and FACSDiva Software (V6.1.3, BD Biosciences).

Anti-hr-anxA1 antibody formation - Blood was collected in 3.2\% sodium citrate, plasma was collected by 5 minutes centrifugation at $10.000 \mathrm{~g}$. A 96-well plate was coated with 5 $\mu \mathrm{g} / \mathrm{ml}$ hr-anxA1 in $0.1 \mathrm{M}$ carbonate buffer $(\mathrm{pH} 9.5) \mathrm{o} / \mathrm{n}$, washed with PBS and blocked with $3 \%$ non-fat dry milk in phosphate buffered saline (PBS). Ten times diluted plasma was added and incubated $1 \mathrm{~h}$ at $37^{\circ} \mathrm{C}$, rabbit- $\alpha$-human anxA1 antibody was used as positive control. HRP-labeled rat- $\alpha$-mouse-IgG (Dako, P0161) was added and incubated $1 \mathrm{~h}$ at $37^{\circ} \mathrm{C}$. Chromogenic substrate tetramethyl benzidine (TMB) was measured at $450 \mathrm{~nm}$.

Endogenous thrombin potential (ETP) - ETP was determined in plasma containing $3.3 \mu \mathrm{M}$ corn trypsin inhibitor (CTI) using $7 \mathrm{pM}$ of tissue factor, $60 \mu \mathrm{M}$ of phospholipids (20\%PS/60\%PC/20\%PE), $420 \mu \mathrm{M}$ fluorogenic substrate and $8.2 \mathrm{mM} \mathrm{Ca}^{2+}$ as described previously ${ }^{31}$.

Immunohistochemistry - Immunohistochemistry was performed using antibodies against MAC-3 (BD Biosciences, clone M3/84, 553322) for all macrophages, iNOS (Abcam, AB3523) for M1-polarized and Ym1 (kind gift from professor Christoph Binder, Vienna, Austria) and CD206 (ITK diagnostics, 141702) for M2-polarized macrophages. 
Statistical analysis - All data is presented as mean \pm SEM. Normality was tested using the Shapiro-Wilk normality test with GraphPad Prism 5.0 software. Statistical significance between two groups was tested by unpaired two tailed student's $t$-test. A value of $\mathrm{P}<0.05$ was considered statistically significant. $P$-values are indicated in the tables and figures by asterisks as follows ${ }^{*} P<0.05,{ }^{* *} P<0.005,{ }^{* * *} P<0.001$.

\section{Results}

\section{Physical and biological characterization of hr-anxA1}

The $\mathrm{N}$-terminal tail mediates anti-inflammatory activities of anxA1 and contains proteasesensitive sites ${ }^{27}$. We used the expression vector pQE30Xa that introduced a His-tag upstream of the N-terminal tail, which was cleaved off after purification by FXa. In order to verify that our procedure yielded full length recombinant product, purified hranxA1 was subjected to structural analyses including MALDITOF/TOF (Supplemental Figure 1A), silver stained SDS-PAGE and Western blotting (Supplemental Figure 1B) and tryptic digestion. These analyses confirmed the production and purification of full-length hr-anxA1 with a purity of $>95 \%$. Hr-anxA1 was stable for at least 1 year if stored in $\mathrm{HEPES} / \mathrm{NaCl} \mathrm{pH} 7.4$ at $4^{\circ} \mathrm{C}$. Biological functionality of the $\mathrm{N}$-terminal tail and $\mathrm{Ca}^{2+}$-dependent PS-binding of the $\mathrm{C}$-terminal core were intact as assessed by the calcium flux induced in FPR-2 transfected HEK-293 cells and ellipsometry respectively (Figure 1A, B and supplemental Figure 2A-C). Furthermore, hr-anxA1 was internalized by Jurkat cells in the early phase of apoptosis in an PS-binding and FPR-dependent manner. This was demonstrated with FPR-inhibitors cyclosporine $\mathrm{H}(\mathrm{CsH})$ and WRW4 using flow cytometry (Figure 1C) and confocal microsopy (Figure 1D) and underscored by absence of internalization if hr-anxA1 lacks its $\mathrm{N}$-terminus (Supplemental Figure 3). AnxA5 internalization, which depends on PS-binding and trimerization ${ }^{32,33}$ was affected by neither inhibitor (Figure 1C). Finally, hr-anxA1 significantly inhibited rolling and adhesion of polymorphonuclear cells (50\% and 63\%, respectively) over a monolayer of TNF $\alpha$-activated HUVECs (Figure 1E) while it had no effect on rolling and adhesion of THP-1 monocytes (Figure 1G). 
A

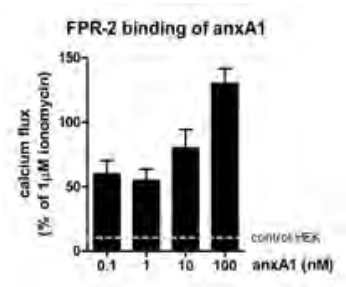

B

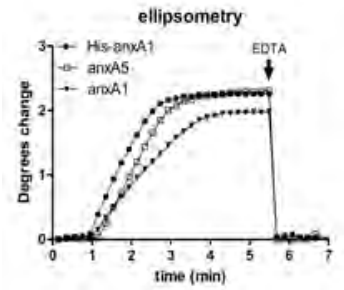

C

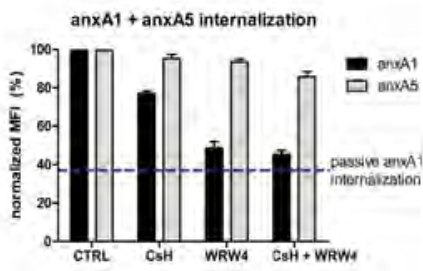

$\mathrm{D}$

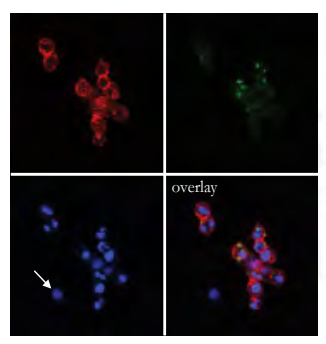

E

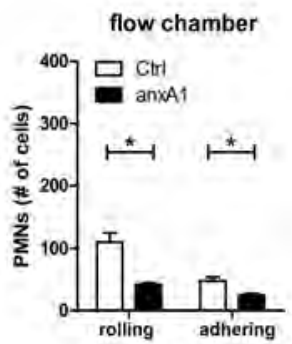

F

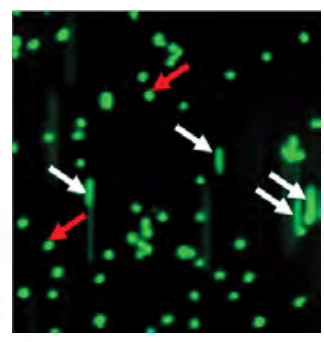

G

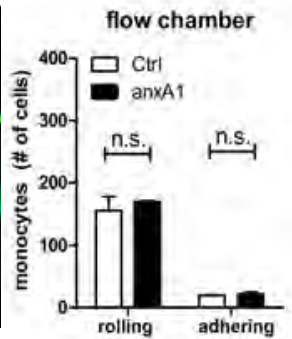

Figure 1 - Physical and biological characterization of hr-anxA1. $\mathrm{Hr}$-anxA1 induced concentration dependent calcium flux in FPR-2 transfected HEK-293 cells, $1 \mu \mathrm{M}$ ionomycin is taken as reference value (100\%) (A). Ellipsometry analysis shows calcium dependent binding of $1 \mu \mathrm{g} / \mathrm{ml}$ purified annexin to a $20 / 80 \mathrm{~mol} \% \mathrm{PS} / \mathrm{PC}$ bilayer (B). Internalization of fluorescent annexin by apoptotic Jurkat cells in presence and absence of inhibitors of FPR-1 (cyclosporin H, 1 $\mu \mathrm{M}$ ) and FPR-2/3 (WRW, $10 \mu \mathrm{M}$ ) as analyzed by flow cytometry (C). Mean fluorescence intensity (MFI) is normalized to MFI of annexin internalization on ice. Hr-anxA1 internalization (green) as visualized by fluorescent confocal laser scanning microscopy (CLSM) (D). Nuclei are stained with DAPI (blue) and PS-expression is stained with anxA5-AF568 (red). PS negative cells (indicated by arrow) did not internalize hr-anxA1. Pretreatment of PMN with 10nM rh-anxA1 inhibited both rolling and adhesion of PMN on a TNF- $\alpha$ activated HUVEC monolayer $(\mathrm{G})$. One frame out of 32 is shown of a flow chamber model with rolling and adhering fluorescent THP-1 monocytes, flowing over TNF- $\alpha$ activated HUVEC monolayer. Flowing and adhering THP-1 monocytes are indicated by white and red arrows respectively (F). Pretreatment of THP-1 cells with 10nM hr-anxA1 has effect on neither rolling nor adhesion of THP-1 cells $(\mathrm{G})$. All values are represented as mean \pm SEM of 3 independent experiments.

\section{Determination of in vivo administration route of $h r$-anxAl}

In order to establish the preferred route of administration, biodistribution and blood clearance were determined for intravenously (IV) and intraperitoneally (IP) administered technetium labeled anxA1 $\left({ }^{99 \mathrm{~m}} \mathrm{Tc}(\mathrm{CO})_{3}\right.$-His-anxA1). ${ }^{99 \mathrm{~m}} \mathrm{Tc}(\mathrm{CO})_{3}$-His-anxA1 had radiochemical purity of approximately $90 \%$ and eluted as a single peak on RP-HPLC (Supplemental Figure 4A). IV administered ${ }^{99 \mathrm{~m}} \mathrm{Tc}(\mathrm{CO})_{3}$-His-anxA1 was cleared by the kidneys, liver and lungs. IP administered ${ }^{99 \mathrm{~m}} \mathrm{Tc}(\mathrm{CO})_{3}$-His-anxA1 was gradually released 
into the blood circulation, peaked at $50 \mathrm{~min}$ post injection and then gradually decreased through clearance by the kidneys and liver (Supplemental Figure 4B-D) with $\mathrm{t}_{1 / 2}$ of approximately 6 hours. About $0.5 \%$ of injected dose per gram (ID/g) anxA1 remained in the circulation 24 hours post injection. On basis of pharmacokinetics we decided to administer hr-anxA1 three times per week IP as treatment.

\section{Administration of hr-anxA1 does not alter baseline characteristics of LDLR-/-mice}

Treatment of LDLR $^{-1-}$ mice on WTD with hr-anxA1 had no effect on body weight, circulating cholesterol and triglyceride levels and procoagulant activity of blood plasma (Table 1). Sustained treatment did not cause generation of antibodies against hr-anxA1 (data not shown). Heart rate and blood pressure were not affected by anxA1 administration.

Table 1 - Baseline characteristics of control and hr-anxA1 treated mice.

\begin{tabular}{lllll} 
& \multicolumn{2}{l}{ Initial plaques (I) } & \multicolumn{2}{l}{ Existing plaques (P) } \\
& Ctrl & AnxA1 & Ctrl & AnxA1 \\
\hline Age (weeks) & $18.0 \pm 0.5$ & $18.0 \pm 0.5$ & $24.0 \pm 0.5$ & $24.0 \pm 0.5$ \\
Weight (g) & $26.2 \pm 1.9$ & $25.8 \pm 1.6$ & $29.2 \pm 2.4$ & $27.9 \pm 1.5$ \\
Cholesterol (mM) & $25.2 \pm 2.9$ & $24.6 \pm 3.9$ & $28.3 \pm 2.7$ & $26.9 \pm 2.9$ \\
Triglycerides (mM) & $3.3 \pm 0.6$ & $3.2 \pm 0.8$ & $3.3 \pm 0.6$ & $3.6 \pm 0.5$ \\
Coagulation & & & & \\
ETP (nM.min) & $1376.1 \pm 104.0$ & $1312.3 \pm 46.3$ & $1342.2 \pm 78$ & $1325.4 \pm 59.8$ \\
Peak Height (nM) & $185.3 \pm 6.7$ & $190.8 \pm 11.0$ & $180.1 \pm 7.3$ & $188.6 \pm 8.9$
\end{tabular}

Hr-anxA1 has no significant effect on early plaque development

Administration of hr-anxA1, starting with initiation WTD, failed to effect plaque initiation (total plaque size $0.024 \pm 0.019 \mathrm{~mm}^{3}$ versus $0.016 \pm 0.010 \mathrm{~mm}^{3}$, control versus hr-anxA1, $-33 \%, P=0.21$ ). Analysis of plaque development at different anatomical sites did not reveal site-specific effects of hr-anxA1 on plaque size (Figure 2A, B). Vehicle and hr-anxA1 treated animals both showed intimal xanthoma (IX) formation and small foam cell lesions (SL) (Figure 2C) with infiltrated macrophages in comparable proportion, suggesting that hr-anxA1 affects neither onset of IX formation nor their transition into $\mathrm{SL}$ in $\mathrm{LDLR}^{-1-}$ mice under atherogenic pressure. $70 \%$ to $80 \%$ of the endothelium of the aortic arch was activated as evidenced by ICAM-1 expression. Treatment with hr-anxA1 had no significant effect on ICAM-1 expression (Figure 2D, E). 


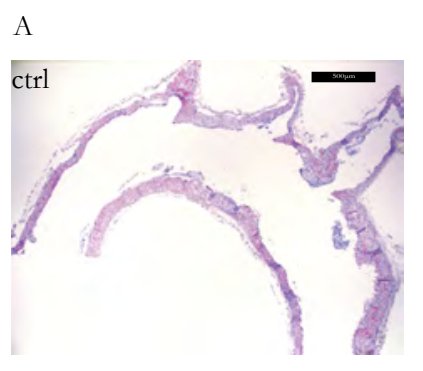

C

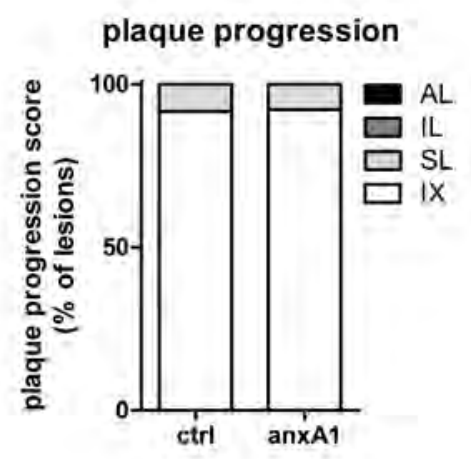

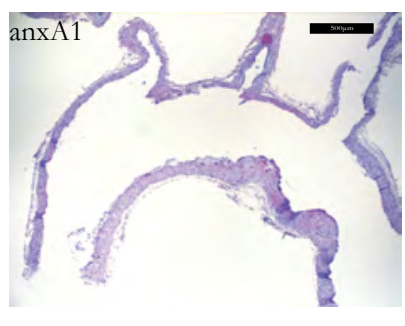

D

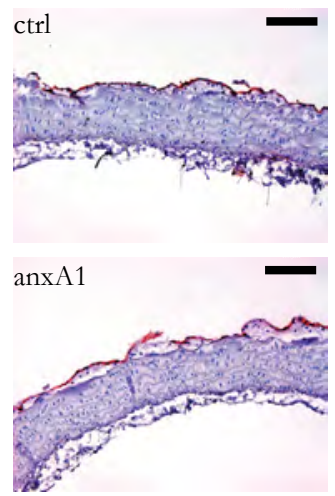

B

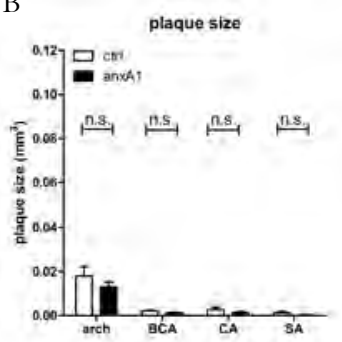

E

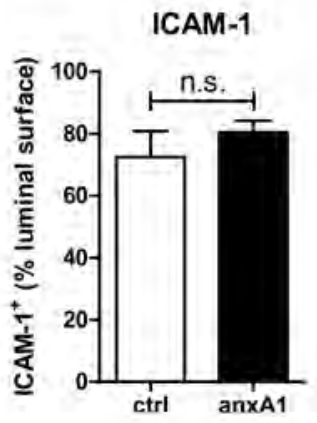

Figure 2 - Hr-anxA1 has no significant effect on early plaque development. 12 weeks old mice were fed WTD during 6 weeks. Hr-anxA1 treatment started at the initiation of WTD. Representative $\mathrm{H} \& \mathrm{E}$ staining of aortic arches after 6 weeks of treatment (A). Treatment with hr-anxA1 significantly reduced total plaque burden in the arch and subclavian artery (SA) but not in brachiocephalic (BCA) and left common carotid artery (CA) (B). Individual plaque progression was scored on following parameters: neutrophil and macrophage content, apoptosis and necrosis, cap thickness and calcification status (see Supplemental Tables 1 and 2). Hr-anxA1 treatment had no effect on early plaque progression (C). Hr-anxA1 treatment had no effect on endothelial ICAM-1 expression (D, E). IX: intimal xanthoma; SL: small lesion; IL: intermediate lesion; AL: advanced lesion. All values are represented as mean \pm SEM, $n=12$ per group. Panel A: 40x magnification, scale bar represents 500 $\mu \mathrm{m}$. Panel D: 200x magnification, scale bar represents $100 \mu \mathrm{m}$.

\section{$H r$-anxA1 attenuates progression into advanced plaques}

Hr-anxA1 treatment of mice with established plaques caused a significant inhibition of total plaque growth $\left(0.131 \pm 0.080 \mathrm{~mm}^{3}\right.$ versus $0.065 \pm 0.031 \mathrm{~mm}^{3}$, control versus hr-anxA1, $-50 \%, \mathrm{P}=0.005)$, which was most pronounced in the arch and subclavian artery (Figure 3A, B). Necrotic core development was suppressed by hr-anxA1 treatment (Figure 3C). As a measure of plaque size we determined plaque volume and plaque surface area at maximal stenosis. These two parameters showed a very high correlation 
$\left(\mathrm{R}^{2}=0.84\right)$ (Supplemental Figure 5), indicating that a single 2-dimensional measurement at maximal stenosis is sufficient for plaque size determination. All lesions of control and hr-anxA1 treated mice contained comparable amount of infiltrating macrophages and smooth muscle cells as further evaluated by MAC-3 (Figure 3D, E) and $\alpha \mathrm{SMa}$ (Figure 3F, G) staining, respectively. Furthermore there was no difference in endothelial ICAM-1 expression (Figure 3H, I). Individual plaque progression was further scored as described by Supplemental Tables 1 and 2. This classification showed that hr-anxA1 treated mice predominantly developed IX and SL, while the control treated mice predominantly had already intermediate lesion (IL) and advanced lesion (AL) development (Figure 3J). In addition, blood analysis revealed significant increase in proportion of granulocytes of circulating leukocytes, while bone marrow showed no differences in leukocyte composition between control and hr-anxA1 treated mice (Table 2).

Table 2 - Flow cytometric analysis of blood and bone marrow.

\begin{tabular}{|c|c|c|c|c|}
\hline Parameter & Subpopulation & $\operatorname{ctrl}(\mathrm{n}=7)$ & hr-anxA1 $(n=6)$ & $\mathrm{P}$ \\
\hline Blood (\% of viable) & (\% of parent) & & & \\
\hline B-cells & & $46.9 \pm 9.5$ & $33.8 \pm 15.8$ & n.s. \\
\hline NK-cells & & $4.1 \pm 0.4$ & $4.0 \pm 0.3$ & n.s. \\
\hline Granulocytes & & $18.2 \pm 7.1$ & $35.0 \pm 18.8^{*}$ & 0.039 \\
\hline \multirow[t]{4}{*}{ Monocytes } & & $9.9 \pm 4.5$ & $10.6 \pm 2.5$ & n.s. \\
\hline & Ly6C $C^{\text {neg/low }}$ & $22.1 \pm 4.2$ & $18.5 \pm 10.0$ & n.s. \\
\hline & Ly6C $\mathrm{C}^{\text {medium }}$ & $10.7 \pm 2.0$ & $9.7 \pm 1.8$ & n.s. \\
\hline & Ly6C $C^{\text {high }}$ & $67.2 \pm 5.6$ & $71.8 \pm 8.3$ & n.s. \\
\hline \multirow[t]{3}{*}{ T-cells } & & $14.2 \pm 1.8$ & $12.1 \pm 4.9$ & n.s. \\
\hline & $\mathrm{CD}^{+}$ & $41.9 \pm 1.6$ & $45.3 \pm 6.4$ & n.s. \\
\hline & $\mathrm{CD}^{+}$ & $58.1 \pm 1.6$ & $54.7 \pm 6.4$ & n.s. \\
\hline Bone marrow & & & & n.s. \\
\hline B-cells & & $17.8 \pm 1.4$ & $19.6 \pm 5.2$ & n.s. \\
\hline NK-cells & & $1.1 \pm 0.2$ & $1.0 \pm 0.2$ & n.s. \\
\hline Granulocytes & & $36.7 \pm 2.0$ & $30.2 \pm 9.1$ & n.s. \\
\hline \multirow[t]{4}{*}{ Monocytes } & & $14.8 \pm 1.5$ & $14.3 \pm 2.0$ & n.s. \\
\hline & Ly6C $6 C^{\text {neg/low }}$ & $10.6 \pm 2.5$ & $9.9 \pm 2.8$ & n.s. \\
\hline & Ly6C $\mathrm{C}^{\text {medium }}$ & $51.1 \pm 6.2$ & $46.2 \pm 9.4$ & n.s. \\
\hline & Ly6C high & $38.2 \pm 7.8$ & $43.8 \pm 10.6$ & n.s. \\
\hline T-cells & & $0.5 \pm 0.2$ & $0.7 \pm 0.3$ & n.s. \\
\hline Undefined & & $25.6 \pm 1.8$ & $30.1 \pm 5.0$ & n.s. \\
\hline
\end{tabular}




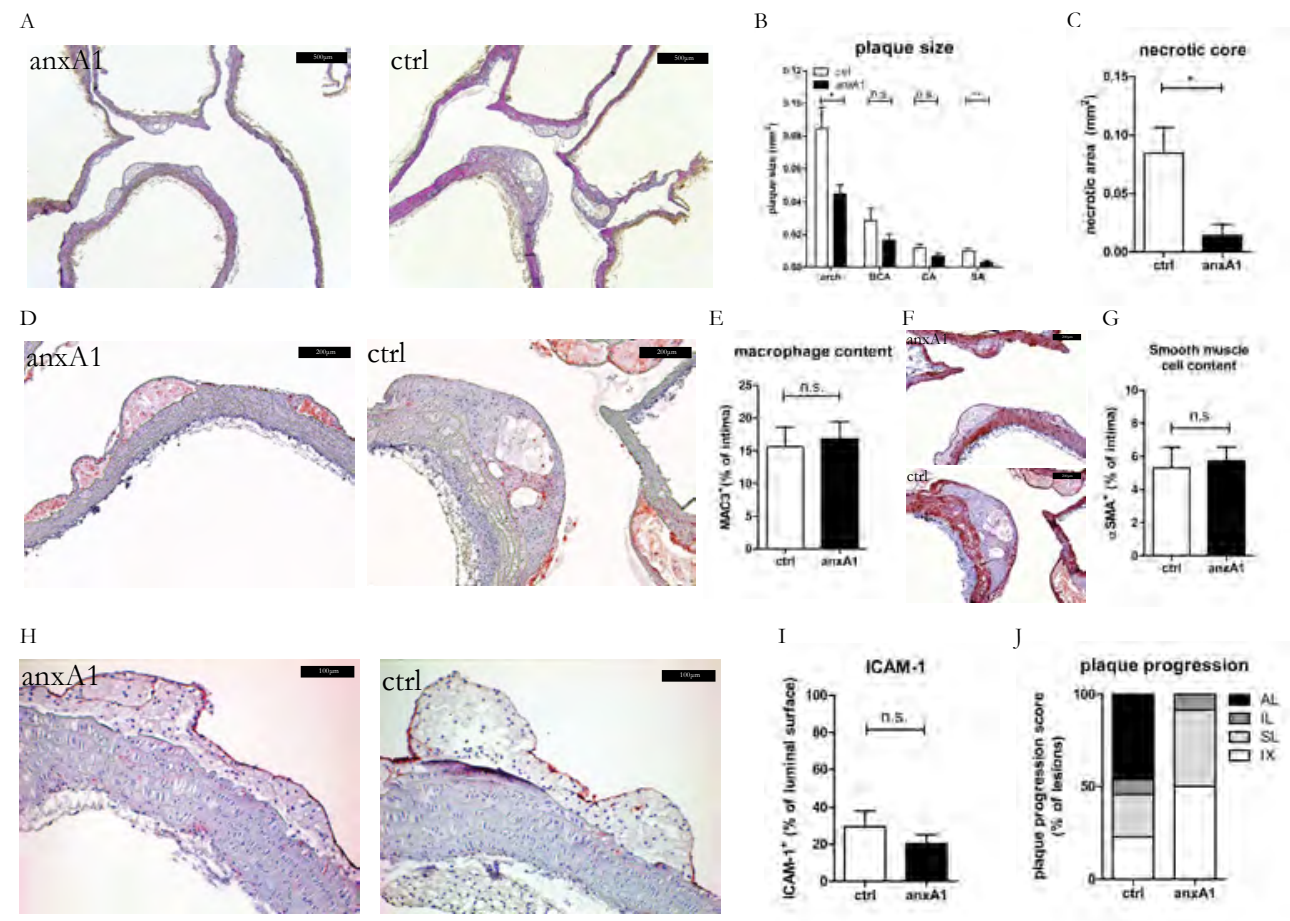

Figure 3 - Hr-anxA1 attenuates progression into advanced plaques. 12 weeks old mice were fed WTD 6 weeks before start of treatment with hr-anxA1. Representative H\&E staining of aortic arches (A). Treatment with hr-anxA1 significantly reduced total plaque burden in the arch and subclavian artery (SA) but not in the brachiocephalic (BCA) and left carotid artery (CA) (B). Total necrotic core size was smaller after treatment $(\mathrm{C})$. Macrophage (D, E) and smooth muscle cell (F, G) content and endothelial ICAM-1 expression (H, I) were not changed by treatment. Individual plaque progression was scored on following parameters: neutrophil and macrophage content, apoptosis and necrosis, cap thickness and calcification status (see Supplemental Tables 1 and 2). Hr-anxA1 treatment caused inhibition of plaque progression (J). IX: intimal xanthoma; SL: small lesion; IL: intermediate lesion; AL: advanced lesion. All values are represented as mean \pm SEM, n=12 per group. Panel A: 40x magnification, scale bar represents 500 $\mu \mathrm{m}$; Panel D,F: 100x magnification, scale bar represents $200 \mu \mathrm{m}$; Panel H: 200x magnification, scale bar represents $100 \mu \mathrm{m}$. 


\section{Hr-anxA1 does not affect macrophage polarization in atherosclerotic plaque}

Recently we demonstrated that endogenous anxA1 contributes to resolution of chronic inflammation in a mouse model of nonalcoholic steatohepatitis (NASH) through stimulation of IL-10 production and down-modulation of M1 polarization ${ }^{34}$. Therefore we studied whether hr-anxA1 could influence polarization of macrophages in the atherosclerotic plaque. Quantification of M1 polarization marker iNOS (Figure 4A, B) showed no differences between control and anxA1 treated plaques. Staining was diffuse throughout the entire lesion, whereas the non-immune immunoglobulin staining was negative (data not shown). We did not detect any marker of M2 polarization in the atherosclerotic lesions of both groups using antibodies against Ym1 (Figure 4C, D) and CD206 (data not shown). This indicates that the lesions are predominantly occupied by M1 macrophages. Treatment of bone marrow-derived macrophages (BMDM) with hr-anxA1 in vitro did neither affect IL-12 and TNF- $\alpha$ mRNA expression nor NO production as compared to control (see Supplemental Figure 6). IL-10 mRNA expression was below detection limit in hr-anxA1 teated and untreated BMDM.

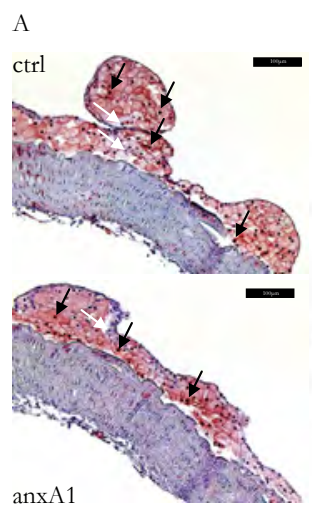

B

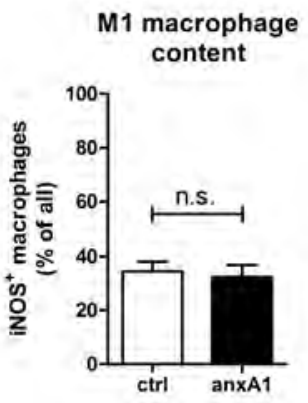

C

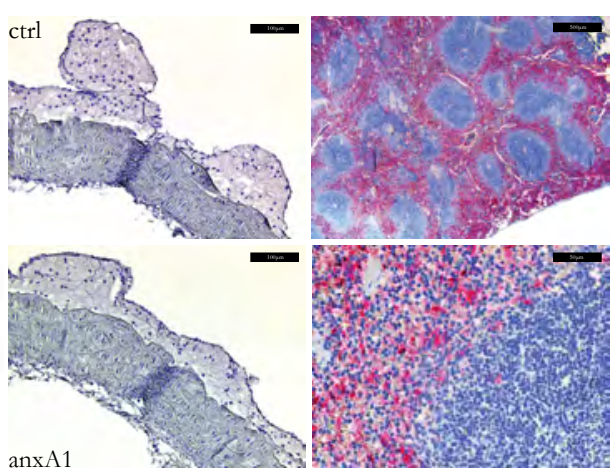

Figure 4-Rh-anxA1 does not affect macrophage polarization in atherosclerotic plaque. Representative staining for M1 macrophage specific marker iNOS. Black arrows indicate fully commited M1 macrophages, white arrows indicate iNOS negative macrophages (A). Quantification of iNOSstaining indicates no difference between control and anxA1 treated animals (B). Representative staining of M2 specific marker $\mathrm{Ym} 1$. Both control and rh-anxA1 treated mice were negative for Ym1 (C). Staining of Ym1 positive cells in the spleen indicating functionality of anti-Ym1 antibody (D). Panel A: 200x magnification, scale bar represents 100 $\mathrm{m}$; panel D: 40x and 400x magnification, scale bar represent $500 \mu \mathrm{m}$ and $50 \mu \mathrm{m}$ respectively. 


\section{Discussion}

AnxA1 has anti-inflammatory and pro-resolving properties causing dampening of inflammation in several animal models of acute and chronic inflammation ${ }^{34-36}$. We hypothesized that exogenously administered anxA1 would reduce atherogenesis. In order to explore pharmacodynamics of anxA1 on atherogenesis we produced recombinant human anxA1 (hr-anxA1) and thoroughly inspected integrity and functional properties of the $\mathrm{N}$-terminal tail and $\mathrm{C}$-terminal core. Both are essential to the anti-inflammatory properties of anxA1, since this requires both interaction with FPR-2 and binding to PS, respectively ${ }^{22}$. Hr-anxA1 possessed both functional properties with sufficient shelf-stability to perform series of in vivo experiments. Secondly, pharmacokinetics and biodistribution of hr-anxA1 were determined to select the preferred route of administration. Intravenous administered hr-anxA1 was cleared rapidly from circulation with $t_{1 / 2}$ of $<10 \mathrm{~min}$. This rapid pharmacokinetic is comparable with half-life reported for anxA5, another member of the annexin family ${ }^{37}$. Biodistribution showed accumulation of hr-anxA1 in kidneys but also in liver and lungs. Currently we have no explanation for the latter phenomenon but this could indicate clearance via the reticula-endothelial system. Pharmacokinetics and biodistribution of intraperitoneal administered $\mathrm{hr}$-anxA1 revealed release of hr-anxA1 into circulation during a longer period of time with a peak at $50 \mathrm{~min}$ post administration. Here, clearance from circulation occurred predominantly by kidneys. Based on the pharmacokinetics we decided to administer hr-anxA1 by IP injection, 3 times per week as treatment regimen.

In our experiments hr-anxA1 did not affect the formation of intimal xanthoma lesions or the transition to small lesions, but treatment significantly attenuated the transition from small lesions to intermediate and advanced lesions. This was most pronounced in the inner curvature of the arch and in the subclavian artery. Neutrophils are considered as the primary target of anxA1 for its anti-inflammatory action ${ }^{12}$ and neutrophils can modulate initiation and progression of atherosclerosis ${ }^{38,39}$. ICAM-1 is a strong regulator of neutrophil adhesion and transmigration ${ }^{40}$. Endothelial ICAM-1 expression was not altered by anxA1 in our experiments. AnxA1 inhibits adhesion of neutrophils to endothelial cells ${ }^{19,41}$ and diminishes their transmigration across the endothelium ${ }^{42}$ by engaging via its $\mathrm{N}$-terminal tail with the FPR-2/AXLR ${ }^{14,43}$. Concordant with a previous report ${ }^{42}$ we observed that hr-anxA1 induced a relative increase of circulating granulocytes, which is an indication for $\mathrm{hr}$-anxA1 induced neutrophil demargination and inactivation. A similar effect has been reported for treatment with glucocorticoids ${ }^{44}$, of which anxA1 is 
considered to be a down-stream effector ${ }^{12}$. Interestingly, our in vivo results show that hranxA1 treatment did not affect intimal xanthoma and small lesion formation but afforded substantial inhibitory effects on progression of small lesions towards advanced lesions. Recent observations showed that hyperactivation and life prolongation of neutrophils through knocking out CXCR4 affect progression rather than initiation of atherosclerosis 39. Together our findings strongly indicate that the neutrophil is likely to be the main target for inhibition afforded by hr-anxA1 on experimental atherosclerosis.

$\mathrm{Hr}$-anxA1 may attenuate atherosclerosis also by acting on the plaque macrophage. We reported recently that anxA1 can polarize liver macrophages towards the antiinflammatory M2 phenotype ${ }^{34}$. Macrophage polarization is an important contributor to atherogenesis ${ }^{45}, 46$. M2 polarized macrophages diminish plaque inflammation and inhibit plaque progression ${ }^{47}$. However, we found no evidence of macrophage skewing in the atherosclerotic lesions of our mice. We cannot exclude hr-anxA1 might modulate macrophage functions. Indeed, hr-anxA1 may also affect removal of apoptotic cells by enhancing efferocytosis by macrophages. Apoptosis and efferocytosis determine rate of plaque progression and plaque phenotype ${ }^{48,49}$. $\mathrm{Hr}$-anxA1 is known to act as opsonin for apoptotic cells and in this way it stimulates efferocytosis ${ }^{22,50,51}$, and subsequently reduces release of pro-inflammatory cytokines IL- 6 and TNF- $\alpha{ }^{52}$. Atherosclerotic plaques that were treated with hr-anxA1 had smaller necrotic cores, suggestive of a stimulated efferocytotic machinery within the plaque.

We conclude that established atherosclerosis can be treated with hr-anxA1 in a murine model of atherosclerosis. These findings may open novel avenues to treat chronic inflammatory diseases such as atherosclerosis. 


\section{References}

1. Virmani R, Burke AP, Kolodgie FD, Farb A. Vulnerable plaque: the pathology of unstable coronary lesions. J Interv Cardiol. 2002;15:439-446.

2. $\quad$ Ross R. Atherosclerosis--an inflammatory disease. N Engl J Med. 1999;340:115-126.

3. Kusters DH, Tegtmeier J, Schurgers LJ, Reutelingsperger CP. Molecular imaging to identify the vulnerable plaque--from basic research to clinical practice. Mol Imaging Biol. 2012;14:523-533.

4. Falk E, Nakano M, Bentzon JF, Finn AV, Virmani R. Update on acute coronary syndromes: the pathologists' view. Eur Heart J. 2013;34:719-728.

5. Moore KJ, Tabas I. Macrophages in the pathogenesis of atherosclerosis. Cell. 2011;145:341-355.

6. Mocsai A. Diverse novel functions of neutrophils in immunity, inflammation, and beyond. J Exp Med. 2013;210:1283-1299.

7. Mantovani A, Cassatella MA, Costantini C, Jaillon S. Neutrophils in the activation and regulation of innate and adaptive immunity. Nat Rev Immunol. 2011;11:519-531.

8. Drechsler M, Megens RT, van Zandvoort M, Weber C, Soehnlein O. Hyperlipidemia-triggered neutrophilia promotes early atherosclerosis. Circulation. 2010;122:1837-1845.

9. de Jager SC, Bot I, Kraaijeveld AO, Korporaal SJ, Bot M, van Santbrink PJ, van Berkel TJ, Kuiper J, Biessen EA. Leukocyte-specific CCL3 deficiency inhibits atherosclerotic lesion development by affecting neutrophil accumulation. Arterioscler Thromb Vasc Biol. 2013;33:e75-83.

10. Zernecke A, Bot I, Djalali-Talab Y, Shagdarsuren E, Bidzhekov K, Meiler S, Krohn R, Schober A, Sperandio M, Soehnlein O, Bornemann J, Tacke F, Biessen EA, Weber C. Protective role of CXC receptor 4/CXC ligand 12 unveils the importance of neutrophils in atherosclerosis. Circ Res. 2008;102:209-217.

11. Gerke V, Creutz CE, Moss SE. Annexins: linking Ca2+ signalling to membrane dynamics. Nat Rev Mol Cell Biol. 2005;6:449-461.

12. Perretti M, D’Acquisto F. Annexin A1 and glucocorticoids as effectors of the resolution of inflammation. Nat Rev Immunol. 2009;9:62-70.

13. Raynal P, Pollard HB. Annexins: the problem of assessing the biological role for a gene family of multifunctional calcium- and phospholipid-binding proteins. Biochim Biophys Acta. 1994;1197:63-93.

14. Bena S, Brancaleone V, Wang JM, Perretti M, Flower RJ. Annexin A1 interaction with the FPR2/ ALX receptor: identification of distinct domains and downstream associated signaling. J Biol Chem. 2012;287:24690-24697.

15. Rosengarth $\mathrm{A}$, Luecke $\mathrm{H}$. A calcium-driven conformational switch of the $\mathrm{N}$-terminal and core domains of annexin A1. J Mol Biol. 2003;326:1317-1325.

16. Perretti M. The annexin 1 receptor(s): is the plot unravelling? Trends Pharmacol Sci. 2003;24:574-579.

17. Babbin BA, Lee WY, Parkos CA, Winfree LM, Akyildiz A, Perretti M, Nusrat A. Annexin I regulates SKCO15 cell invasion by signaling through formyl peptide receptors. J Biol Chem. 2006;281:19588-19599.

18. Vong L, D’Acquisto F, Pederzoli-Ribeil M, Lavagno L, Flower RJ, Witko-Sarsat V, Perretti M. Annexin 1 cleavage in activated neutrophils: a pivotal role for proteinase 3.J Biol Chem. 2007;282:29998-30004.

19. Hayhoe RP, Kamal AM, Solito E, Flower RJ, Cooper D, Perretti M. Annexin 1 and its bioactive peptide inhibit neutrophil-endothelium interactions under flow: indication of distinct receptor involvement. Blood. 2006;107:2123-2130.

20. Perretti M, Ahluwalia A, Harris JG, Goulding NJ, Flower RJ. Lipocortin-1 fragments inhibit neutrophil accumulation and neutrophil-dependent edema in the mouse. A qualitative comparison with an antiCD11b monoclonal antibody. J Immunol. 1993;151:4306-4314. 
21. D’Amico M, Di Filippo C, La M, Solito E, McLean PG, Flower RJ, Oliani SM, Perretti M. Lipocortin 1 reduces myocardial ischemia-reperfusion injury by affecting local leukocyte recruitment. FASEB J. 2000;14:1867-1869.

22. Dalli J, Consalvo AP, Ray V, Di Filippo C, D’Amico M, Mehta N, Perretti M. Proresolving and tissueprotective actions of annexin A1-based cleavage-resistant peptides are mediated by formyl peptide receptor 2/lipoxin A4 receptor. J Immunol. 2013;190:6478-6487.

23. Perretti M, Getting SJ, Solito E, Murphy PM, Gao JL. Involvement of the receptor for formylated peptides in the in vivo anti-migratory actions of annexin 1 and its mimetics. Am J Pathol. 2001;158:1969-1973.

24. Schutters K, Kusters DH, Chatrou ML, Montero-Melendez T, Donners M, Deckers NM, Krysko DV, Vandenabeele P, Perretti M, Schurgers LJ, Reutelingsperger CP. Cell surface-expressed phosphatidylserine as therapeutic target to enhance phagocytosis of apoptotic cells. Cell Death Differ. 2013;20:49-56.

25. Cuypers PA, Corsel JW, Janssen MP, Kop JM, Hermens WT, Hemker HC. The adsorption of prothrombin to phosphatidylserine multilayers quantitated by ellipsometry. J Biol Chem. 1983;258:2426-2431.

26. Davies JQ, Gordon S. Isolation and culture of murine macrophages. Methods Mol Biol. 2005;290:91-103.

27. Pederzoli-Ribeil M, Maione F, Cooper D, Al-Kashi A, Dalli J, Perretti M, D’Acquisto F. Design and characterization of a cleavage-resistant Annexin A1 mutant to control inflammation in the microvasculature. Blood. 2010;116:4288-4296.

28. van Genderen H, Kenis H, Lux P, Ungeth L, Maassen C, Deckers N, Narula J, Hofstra L, Reutelingsperger C. In vitro measurement of cell death with the annexin A5 affinity assay. Nat Protoc. 2006;1:363-367.

29. De Saint-Hubert M, Mottaghy FM, Vunckx K, Nuyts J, Fonge H, Prinsen K, Stroobants S, Mortelmans L, Deckers N, Hofstra L, Reutelingsperger CP, Verbruggen A, Rattat D. Site-specific labeling of 'second generation' annexin $\mathrm{V}$ with $99 \mathrm{mTc}(\mathrm{CO}) 3$ for improved imaging of apoptosis in vivo. Bioorg Med Chem. 2010;18:1356-1363.

30. De Saint-Hubert M, Bauwens M, Deckers N, Drummen M, Douma K, Granton P, Hendrikx G, Kusters D, Bucerius J, Reutelingsperger CP, Mottaghy FM. In Vivo Molecular Imaging of Apoptosisand Necrosis in Atherosclerotic PlaquesUsing MicroSPECT-CT and MicroPET-CT Imaging. Mol Imaging Biol. 2013.

31. Tchaikovski SN, BJ VANV, Rosing J, Tans G. Development of a calibrated automated thrombography based thrombin generation test in mouse plasma. J Thromb Haemost. 2007;5:2079-2086.

32. Kenis H, van Genderen H, Bennaghmouch A, Rinia HA, Frederik P, Narula J, Hofstra L, Reutelingsperger CP. Cell surface-expressed phosphatidylserine and annexin A5 open a novel portal of cell entry. J Biol Chem. 2004;279:52623-52629.

33. Ungethum L, Kenis H, Nicolaes GA, Autin L, Stoilova-McPhie S, Reutelingsperger CP. Engineered annexin A5 variants have impaired cell entry for molecular imaging of apoptosis using pretargeting strategies. J Biol Chem. 2011;286:1903-1910.

34. Locatelli I, Sutti S, Jindal A, Vacchiano M, Bozzola C, Reutelingsperger C, Kusters D, Bena S, Parola M, Paternostro C, Bugianesi E, McArthur S, Albano E, Perretti M. Endogenous annexin A1 IS a novel protective determinant in nonalcoholic steatohepatitis (NASH). Hepatology. 2014.

35. Girol AP, Mimura KK, Drewes CC, Bolonheis SM, Solito E, Farsky SH, Gil CD, Oliani SM. Antiinflammatory mechanisms of the annexin A1 protein and its mimetic peptide Ac2-26 in models of ocular inflammation in vivo and in vitro. J Immunol. 2013;190:5689-5701.

36. Leoni G, Alam A, Neumann PA, Lambeth JD, Cheng G, McCoy J, Hilgarth RS, Kundu K, Murthy N, Kusters D, Reutelingsperger C, Perretti M, Parkos CA, Neish AS, Nusrat A. Annexin A1, formyl peptide receptor, and NOX1 orchestrate epithelial repair. J Clin Invest. 2013;123:443-454. 
37. Vangestel C, Peeters M, Oltenfreiter R, D’Asseler Y, Staelens S, Van Steenkiste M, Philippe J, Kusters D, Reutelingsperger C, Van Damme N, Van de Wiele C. In vitro and in vivo evaluation of [99mTc]-labeled tricarbonyl His-annexin A5 as an imaging agent for the detection of phosphatidylserine-expressing cells. Nucl Med Biol. 2010;37:965-975.

38. Soehnlein O. Multiple roles for neutrophils in atherosclerosis. Circ Res. 2012;110:875-888.

39. Bot I, Daissormont IT, Zernecke A, van Puijvelde GH, Kramp B, de Jager SC, Sluimer JC, Manca M, Herias V, Westra MM, Bot M, van Santbrink PJ, van Berkel TJ, Su L, Skjelland M, Gullestad L, Kuiper J, Halvorsen B, Aukrust P, Koenen RR, Weber C, Biessen EA. CXCR4 blockade induces atherosclerosis by affecting neutrophil function. J Mol Cell Cardiol. 2014;74C:44-52.

40. Yang L, Froio RM, Sciuto TE, Dvorak AM, Alon R, Luscinskas FW. ICAM-1 regulates neutrophil adhesion and transcellular migration of TNF-alpha-activated vascular endothelium under flow. Blood. 2005;106:584-592.

41. Vago JP, Nogueira CR, Tavares LP, Soriani FM, Lopes F, Russo RC, Pinho V, Teixeira MM, Sousa LP. Annexin A1 modulates natural and glucocorticoid-induced resolution of inflammation by enhancing neutrophil apoptosis. J Leukoc Biol. 2012;92:249-258.

42. Lim LH, Solito E, Russo-Marie F, Flower RJ, Perretti M. Promoting detachment of neutrophils adherent to murine postcapillary venules to control inflammation: effect of lipocortin 1. Proc Natl Acad Sci U S A. 1998;95:14535-14539.

43. Walther A, Riehemann K, Gerke V. A novel ligand of the formyl peptide receptor: annexin I regulates neutrophil extravasation by interacting with the FPR. Mol Cell. 2000;5:831-840.

44. Nakagawa M, Terashima T, D’Yachkova Y, Bondy GP, Hogg JC, van Eeden SF. Glucocorticoid-induced granulocytosis: contribution of marrow release and demargination of intravascular granulocytes. Circulation. 1998;98:2307-2313.

45. Libby P, Lichtman AH, Hansson GK. Immune effector mechanisms implicated in atherosclerosis: from mice to humans. Immunity. 2013;38:1092-1104.

46. Stoger JL, Gijbels MJ, van der Velden S, Manca M, van der Loos CM, Biessen EA, Daemen MJ, Lutgens E, de Winther MP. Distribution of macrophage polarization markers in human atherosclerosis. Atherosclerosis. 2012;225:461-468.

47. Cardilo-Reis L, Gruber S, Schreier SM, Drechsler M, Papac-Milicevic N, Weber C, Wagner O, Stangl $\mathrm{H}$, Soehnlein O, Binder CJ. Interleukin-13 protects from atherosclerosis and modulates plaque composition by skewing the macrophage phenotype. EMBO Mol Med. 2012;4:1072-1086.

48. Tabas I. Consequences and therapeutic implications of macrophage apoptosis in atherosclerosis: the importance of lesion stage and phagocytic efficiency. Arterioscler Thromb Vasc Biol. 2005;25:2255-2264.

49. Tabas I, Tall A, Accili D. The impact of macrophage insulin resistance on advanced atherosclerotic plaque progression. Circ Res. 2010;106:58-67.

50. Scannell M, Flanagan MB, deStefani A, Wynne KJ, Cagney G, Godson C, Maderna P. Annexin-1 and peptide derivatives are released by apoptotic cells and stimulate phagocytosis of apoptotic neutrophils by macrophages. J Immunol. 2007;178:4595-4605.

51. Blume KE, Soeroes S, Keppeler H, Stevanovic S, Kretschmer D, Rautenberg M, Wesselborg S, Lauber K. Cleavage of annexin A1 by ADAM10 during secondary necrosis generates a monocytic "find-me" signal. J Immunol. 2012;188:135-145.

52. Yang YH, Aeberli D, Dacumos A, Xue JR, Morand EF. Annexin-1 regulates macrophage IL-6 and TNF via glucocorticoid-induced leucine zipper. J Immunol. 2009;183:1435-1445. 


\section{Supplemental Figures and Tables}

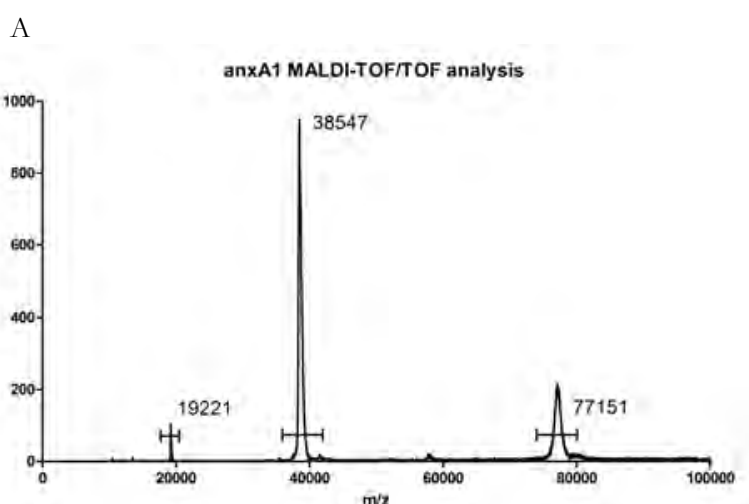

B

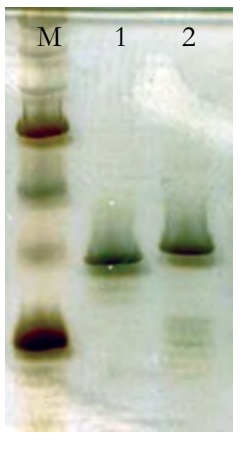

C

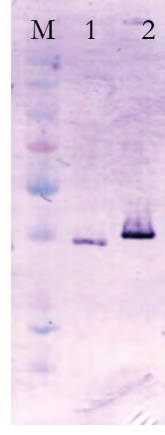

Supplemental Figure 1 - Production and purification of $h r$-anxA1. MALDI-TOF/TOF analysis shows a molecular weight of $38.5 \mathrm{kDa}$ for purified hr-anxA1, which is in concordance with the theoretical molecular weight of full-length anxA1 (A). Bis-protonated hr-anxA1 and hr-anxA1 dimers are represented on the spectrum as peaks of $19.2 \mathrm{kDa}$ and $77.2 \mathrm{kDa}$ respectively. Representative image of 50ng purified hr-anxA1 (1) and His-anxA1 (2) on silver-stained SDS-PAGE for total protein (B) and Western blotting with an $\alpha$-anxA1-antibody (C) ( $\mathrm{n} \geq 5$ purifications) $M=$ broad range protein marker.

A

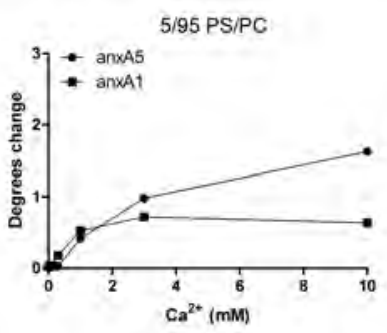

$5 / 95 \mathrm{PS} / \mathrm{PC}$

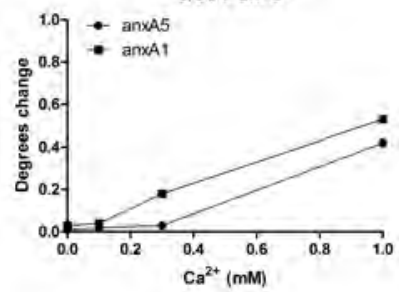

B

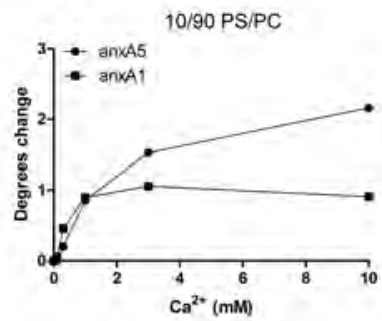

$10 / 90 \mathrm{PS} / \mathrm{PC}$

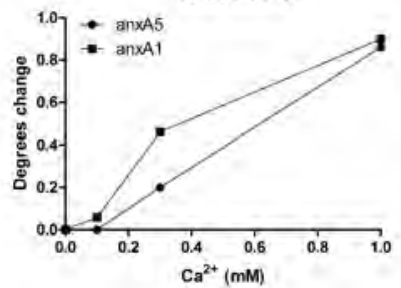

C
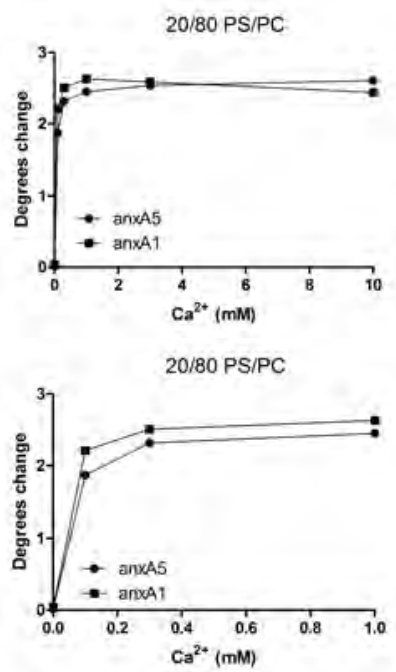

Supplemental Figure 2 - Ellipsometry analysis of phospholipid binding properties. $\mathrm{Ca}^{2+}$-dependent binding curves of $1 \mu \mathrm{g} / \mathrm{ml} \mathrm{hr}$-anxA1 and $1 \mu \mathrm{g} / \mathrm{ml}$ anxA5 binding to 5/95 (A), 10/90 (B) and 20/80 mol\% PS/PC bilayer (C) as measured by ellipsometry. 


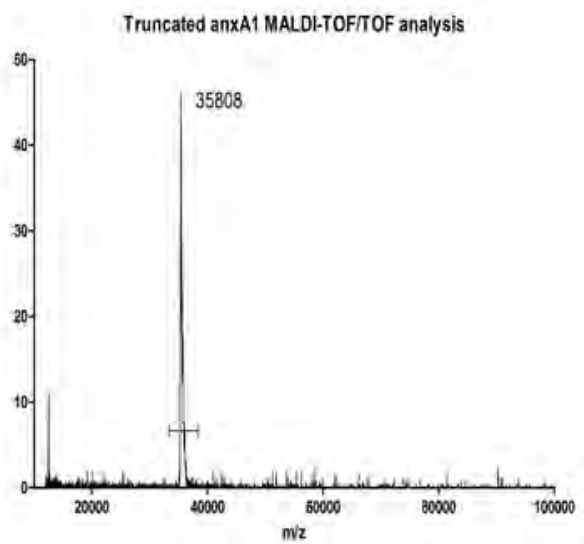

Supplemental figure 3 - MALDI-TOF/TOF analysis of truncated hr-anxA1. Mass spectrometry analysis of truncated hr-anxA1 shows a molecular weight of $35.8 \mathrm{kDa}$, which means truncation occurred between Thr23 en Val24.

A

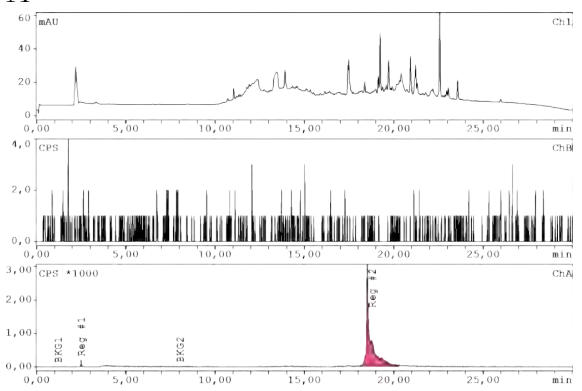

C

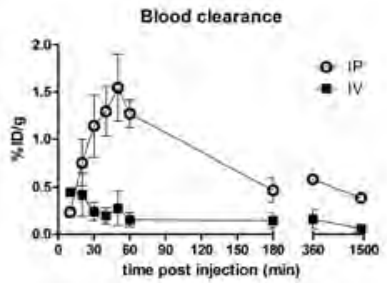

$\mathrm{B}$
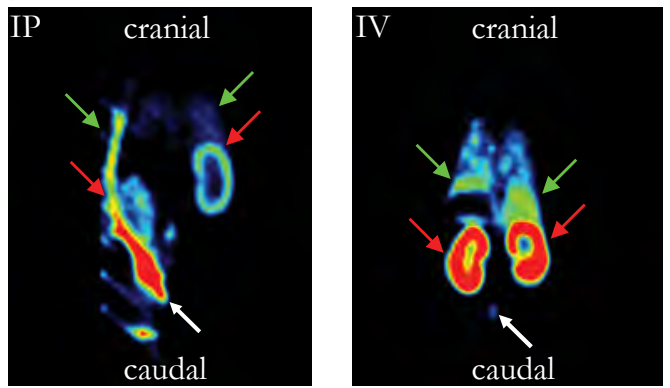

E

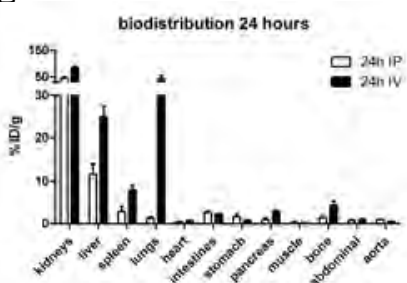

Supplemental Figure 4 - Determination of in vivo administration route of hr-anxA1. HPLC analysis of radio-labeled His-anxA1 ( ${ }^{99 \mathrm{~m}} \mathrm{Tc}(\mathrm{CO}) 3$-His-anxA1) shows a radiochemical purity of $>95 \%$ and specific retention time of approximately 18 minutes (A). SPECT image 45 minutes after intraperitoneal (IP) and intravenous (IV) injection of ${ }^{99 \mathrm{~m}} \mathrm{Tc}(\mathrm{CO}) 3$-His-anxA1 (B). White arrows indicate site of injection, red arrows indicate kidneys and green arrows indicate lungs. Rapid renal clearance and uptake in the lungs was observed in the IV injected mice, whereas IP injection mice show peritoneal localization. Time courses of blood levels of ${ }^{99 \mathrm{~m}} \mathrm{Tc}(\mathrm{CO}) 3$-HisanxA1 were determined by $\gamma$-counting $(\mathrm{C})$. Biodistribution was determined by weighing and $\gamma$-counting of organs dissected 3 (D) and 24 hours (E) post-injection. All values are represented as mean \pm SEM ( $n=6$ per group). 


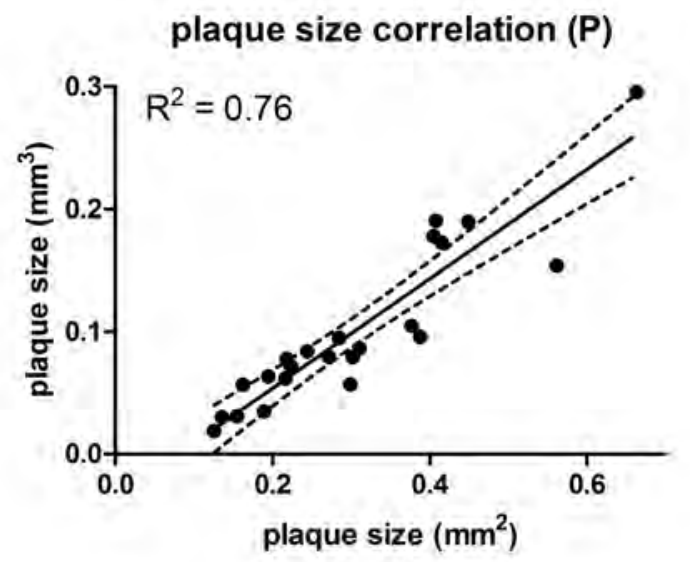

Supplemental Figure 5 - Correlation of 2 and 3 dimensional plaque sizes. Plaque volumes were determined and correlated with plaque areas of the section having the largest plaque area.

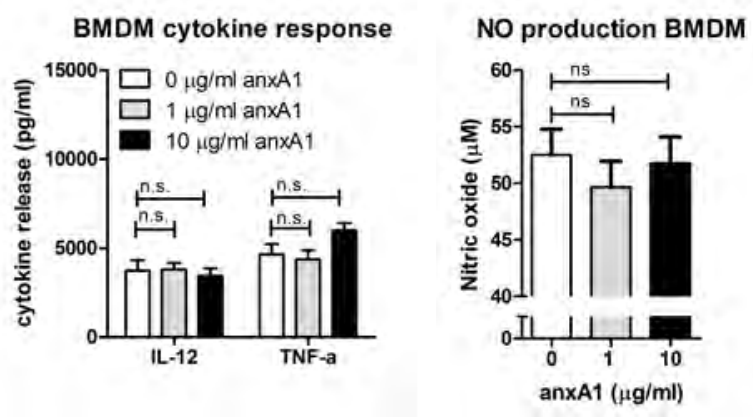

Supplemental Figure 6 - Response of bone marrow derived macrophages to anxA1. IL-12 and TNF- $\alpha$ release are not affected by 1 or $10 \mu \mathrm{g} / \mathrm{ml}$ anxA1 (A). Nitric oxide release is not altered by anxA1 stimulation. 
Supplemental Table 1 - quantification of plaque progression.

\begin{tabular}{|c|c|c|}
\hline Subject & Amount & Score \\
\hline \multirow[t]{3}{*}{ Neutrophils (\#) } & 0 & 0 \\
\hline & 1,2 & 1 \\
\hline & $\geq 3$ & 2 \\
\hline \multirow{4}{*}{ Macrophages (\% intima) } & $0-10$ & 0 \\
\hline & $11-20$ & 1 \\
\hline & $21-30$ & 2 \\
\hline & $\geq 31$ & 3 \\
\hline \multirow[t]{2}{*}{ Apoptosis (yes/no) } & negative & 0 \\
\hline & positive & 1 \\
\hline \multirow[t]{3}{*}{ Necrotic core size ( $\%$ intima) } & 0 & 0 \\
\hline & $<20$ & 1 \\
\hline & $\geq 20$ & 2 \\
\hline \multirow[t]{3}{*}{ Cap thickness (cell layers) } & $0-1$ & 0 \\
\hline & $2-3$ & 1 \\
\hline & $>3$ & 2 \\
\hline \multirow[t]{3}{*}{ Calcification (status) } & absent & 0 \\
\hline & osteochondrocytic cells & 1 \\
\hline & calcification & 2 \\
\hline
\end{tabular}

Supplemental Table 2 - Classification of plaque progression score.

$\begin{array}{lll}\text { Total score } & \text { Definition } & \text { Abbreviation } \\ 0-3 & \text { Intimal Xanthoma } & \text { IX } \\ 4-5 & \text { Small Lesion } & \text { SL } \\ 6-7 & \text { Intermediate Lesion } & \text { IL } \\ \geq 8 & \text { Advanced Lesion } & \text { AL }\end{array}$




\section{Chapter 5}

\section{Annexin A1 ameliorates infarct size and LV systolic function following myocardial ischemia/reperfusion injury}

DHM Kusters, LJ Schurgers, P Leenders, R Schrijver, GA Nicolaes, CPM Reutelingsperger 


\section{Abstract}

Background - Neutrophils play a detrimental role in myocardial ischemia/reperfusion (I/R) injury. Citrullinated histones released by activated neutrophils are cytotoxic. Annexin A1 (anxA1) inhibits neutrophil recruitment and function. Low-anticoagulant heparin $(\mathrm{AADH})$ neutralizes cytotoxic activity of histones.

Aim - The aim is to determine effects of administration of anxA1 and AADH on the extent of ischemic area and cardiac function after 24 hours of reperfusion.

Methods - 12 weeks old C57Bl.6J mice were subjected to 30 minutes ischemia by left anterior descending artery occlusion followed by 24 hours of reperfusion. Mice were treated with $1 \mathrm{mg} / \mathrm{kg}$ annexin $\mathrm{A} 1$ or $18 \mathrm{mg} / \mathrm{kg}$ AADH 30 minutes before onset of ischemia and directly at start of reperfusion.

Results - Treatment with anxA1 and AADH significantly reduced infarcted area as compared to vehicle. Neither anxA1 nor AADH reduced influx of neutrophils into the area at risk after 24 hours of reperfusion. However, anxA1 administration caused a significant reduction in loss of ventricular contractility. AADH had no effect on I/Raffected ventricular contractility.

Conclusion - Both anxA1 and $\mathrm{AADH}$ reduce the infarcted area after ischemia-reperfusion, however only anxA1 improves ventricular contractility. 


\section{Introduction}

Restoring myocardial reperfusion after an ischemic attack is considered essential for cardiac functionality, but initiates a second phase of myocardial injury termed reperfusion injury ${ }^{1}$. The initial ischemia, followed by reperfusion (IR) induces a complex cascade of events that ultimately leads to cardiomyocyte apoptosis and necrosis. Reperfusion injuries share many characteristics with the normal inflammatory response, where neutrophils are the most prevalent leukocyte the first day after injury. The impact neutrophils have in reperfusion injury became apparent over time ${ }^{1-3}$. Complete or partial neutrophil depletion in animals undergoing IR resulted in a marked decrease in infarct size, demonstrating that a significant amount of myocardial injury is neutrophil dependent ${ }^{4}$. Neutrophils release reactive oxygen species, proinflammatory cytokines and chemokines activating the endothelium, resulting in recruitment and activation of additional neutrophils. Upon activation, neutrophils have the possibility to excrete neutrophil extracellular traps (NETs) in a specialized form of cell death named NETosis ${ }^{5}$. NETs consist of a complex network that contains DNA and proteins like histones and neutrophil elastase ${ }^{6,7}$. Histones in particular exhibit cytotoxic activity towards host cells ${ }^{8}$.

Annexin A1 (anxA1), is a member of the multigene annexin family ${ }^{9}$ with potent antiinflammatory activity ${ }^{10}$. The $\mathrm{N}$-terminal tail of anxA1 can interact with the receptor for formylated peptides present on all leukocytes (FPR-2/ALXR) 9, 11-14. AnxA1-FPR-2 interaction results primarily in inhibition of neutrophil recruitment to inflamed sites ${ }^{15}$, but also affects neutrophil survival ${ }^{16-18}$ and clearance ${ }^{19}$. Administration of anxA1 to rats undergoing I/R has shown to reduce infarction size ${ }^{20}$. However, its effect on the important clinical marker of post ischemic heart function has so far not been studied. Antithrombin affinity depleted heparin $(\mathrm{AADH})$, is a strong negatively charged polysaccharide with the ability to neutralize positively charged histones. Using this ability, AADH prevents histone-mediated cytotoxicity thus improving overall survival in a murine sepsis model ${ }^{6}$.

In this paper we study the potential of anxA1 and $\mathrm{AADH}$ to inhibit neutrophil cytotoxicity after ischemia-reperfusion. We study the effect of treatment at 24 hours of reperfusion and show that anxA1 and $\mathrm{AADH}$ treatment reduce infarct size. In addition, anxA1 was able to reduce the loss of ventricular contractile force. Both anxA1 and AADH treatment did not affect neutrophil infiltration at 24 hours of reperfusion, which suggests that the cardioprotective effect of both treatments occurred earlier or was neutrophil independent. 


\section{Materials and methods}

Animals - Male 12 week old out bred C57bl6/J mice were purchased from Charles River (Someren, the Netherlands). All animal experiments were conducted according to a protocol approved by the ethics committee for animal experiments of Maastricht University. (After surgery, animals were housed individually with unlimited access to food and water).

Ischemia-reperfusion - Ischemia Reperfusion injury was performed as described previously ${ }^{22}$. In short, mice received subcutaneous analgesia $0.1 \mathrm{mg} / \mathrm{kg}$ buprenorphine $\mathrm{HCl}$ (Temgesic) before being anesthetized with $4 \%$ isoflurane. After intubation and mechanical ventilation (tidal volume of $250 \mu \mathrm{l}$ and 210 breaths/min anesthesia was maintained with $2 \%$ isoflurane. First a canula was placed into the vena jugularis for injection of PBS, $1 \mathrm{mg} / \mathrm{kg}$ anxA1 or $18 \mathrm{mg} / \mathrm{kg} \mathrm{AADH}$. Then, an incision was made in the left fourth intercostal space $2 \mathrm{~mm}$ from the sternum. Ligature of the left anterior descending (LAD) coronary artery at the inferior edge of the left atrium was performed using a 6-0 prolene suture (Surgipro, Chicago, USA). A small piece of polyethylene tube (PE-10) was used to secure the ligature without damaging the artery. After 30 minutes of ischemia the tube was removed and reperfusion occurred. Reperfusion was confirmed by visible restoration of color to the ischemic tissue. After surgery, the chest was closed and respiration was returned to normal. Mice received another dose of analgesia $(0.1 \mathrm{mg} / \mathrm{kg})$ buprenorphine before sacrifice the next day.

Area at risk and infarct size assessment - To assess area at risk (AAR) and infarcted area (IA) in an in vivo I/R model, mice were anesthetized and sacrificed after 24 hours of reperfusion. The left anterior coronary artery was re-occluded and Evan's blue dye (2\%; Sigma) was injected into the vena cava inferior to delineate the AAR. The heart was rapidly excised, directly rinsed in $0.9 \% \mathrm{NaCl}$ and atria were removed. Hearts were frozen for 10 minutes and sectioned into $1 \mathrm{~mm}$ transverse sections from the apex to the base (10-12 slices/heart). The sections were incubated with preheated $2 \%$ triphenyltetrazolium chloride (TTC) in phosphate buffer ( $\mathrm{pH} 7.4$ ) for $10 \mathrm{~min}$ at $37^{\circ} \mathrm{C}$. Sections were photographed with a digital microscope eyepiece camera (Dino-lite, Naarden, The Netherlands) to distinguish the area not at risk (AnAR) in blue, stained ischemic viable tissue in red, and unstained necrotic tissue in white ${ }^{21}$. Planimetry was performed using Image J software (v1.45). AAR was expressed as percentage of total heart size; IA was expressed as percentage of AAR. 
Left ventricular function - Left ventricular function was evaluated $24 \mathrm{~h}$ after reperfusion as described before ${ }^{22}$. In short, mice were anaesthetized with $2.5 \mathrm{mg} / \mathrm{g}$ body weight urethane (Sigma). A high-fidelity catheter tip micromanometer (Mikro-tip 1.4F; SPR-671, Millar Instruments, USA) was inserted through the right carotid artery into the left ventricular cavity. Ventricular pressure was measured and sampled at a rate of $2 \mathrm{kHz}$. Maximal positive pressure development $(+\mathrm{dP} / \mathrm{dt})$ and heart rate were determined on a beat-tobeat basis and $1 \mathrm{~s}$ averages were stored. The heart was then stimulated with increasing concentration of dobutamine (Sigma) administered intravenously into the jugular vein using a microinjection pump (model 200 Series, KdScientific, USA). Maximal values of $+\mathrm{dP} / \mathrm{dt}$ were recorded and the changes of $+\mathrm{dP} / \mathrm{dt}$ values from baseline were calculated. At the end of the experiment heart was excised and embedded in OCT compound for histochemical staining.

Echocardiography - Cardiac function and heart dimensions were evaluated by twodimensional echocardiography using a Visual Sonics Vevo 2100 Ultrasound (Visual Sonics, Canada) with MicroScan-400 probe (18-38MHz) under isoflurane anesthesia. B-mode echocardiograms were captured to measure anterior and posterior wall thicknesses at end diastole and end systole. Left ventricular (LV) internal diameter (LVID) was measured as the largest anteroposterior diameter in either diastole (LVIDd) or systole (LVIDs). A single observer blinded to mouse groups performed echocardiography and data analysis. Fractional shortening was calculated by: FS(\%) $=(($ LVIDd - LVIDs $) /$ LVIDd $\times 100$. Ejection fraction was calculated by: EF $=\mathrm{EDV}-\mathrm{ESV} / \mathrm{EDV}$ where ESV is end systolic volume and EDV is end diastolic volume. LV mass was calculated by use of an uncorrected cube assumption as LVmass $=\left((\text { LVIDd }+ \text { LVPWd }+ \text { IVSd })^{3}-(\text { LVIDd })^{3}\right)$ $\mathrm{x} 1000$, as described previously ${ }^{23}$.

Immunohistochemistry - Hearts were frozen in OCT and cut serially in $7 \mu \mathrm{m}$ sections $200 \mu \mathrm{m}$ from the occlusion locus towards the apex (8 series of 20 sections). Between each series $100 \mu \mathrm{m}$ was removed. Immunohistochemic staining for neutrophils (rat- $\alpha$-mouse Ly6G, 1:250 clone RB6-8C5, Abcam) and citrullinated histone H3 (H3Cit)(Abcam, ab5103) was performed. Quantification was done with ImageJ (v1.45) on 3 fields within the area at risk at 40x magnification. Neutrophils were expressed as number of infiltrating cells per $\mathrm{mm}^{2}$ and $\mathrm{H} 3 \mathrm{Cit}$ as positive $\%$ of the area at risk. 
Antithrombin affinity depleted heparin - Antithrombin affinity depleted heparin (AADH) was prepared as described previously ${ }^{6}$.

Endogenous thrombin potential - ETP was determined of citrated plasma using 7pM of tissue factor (TF), $60 \mu \mathrm{M}$ of phospholipids $(20 \% \mathrm{PS} / 60 \% \mathrm{PC} / 20 \% \mathrm{PE})$ and $8.2 \mathrm{mM} \mathrm{Ca}^{2+}$, supplemented with $3.3 \mu \mathrm{M}$ corn trypsin inhibitor (CTI) to inhibit thrombin formation from contact activation (FXIIa) ${ }^{24}$.

\section{Results}

\section{AnxAI and $A A D H$ reduce IR injury}

Age and body weight of control and experimental groups were comparable (Table 1). Administration of anxA1 and AADH did not cause significant changes in blood coagulability as determined by the endogenous thrombin potential (Table 1). After twenty-four hours of reperfusion the area at risk (AAR) of the left ventricle was comparable for all groups, indicating no significant variation in positioning of the ligature around the $\mathrm{LAD}$ (Figure 1A-C). Infarcted area (IA) within the AAR was significantly smaller for anxA1 (36.4\%) and AADH (28\%) treatment compared to vehicle treated controls (Figure 1D).

Table 1 - baseline characteristics

\begin{tabular}{|c|c|c|c|c|}
\hline Category & control $(n=12)$ & $\operatorname{anx} A 1(n=12)$ & $\mathrm{AADH}(\mathrm{n}=12)$ & $\mathrm{P}$ \\
\hline \multicolumn{5}{|c|}{ baseline characteristics } \\
\hline Age (weeks) & $12 \pm 0.5$ & $12 \pm 0.5$ & $12 \pm 0.5$ & n.s. \\
\hline Body weight (g) & $25.5 \pm 0.1$ & $26.1 \pm 1.7$ & $26.0 \pm 1.2$ & n.s. \\
\hline \multicolumn{5}{|l|}{ Coagulation } \\
\hline ETP (nM.min) & $415.9 \pm 49.7$ & $394.7 \pm 69.7$ & $389.1 \pm 106.0$ & n.s. \\
\hline
\end{tabular}

AnxA1 but not AADH reduces loss of left ventricular contractility

Echocardiography showed that neither treatment affected physical parameters of the beating heart (Table 2). At unstressed conditions heart rate was lower in the AADH treated group (Figure 1E). Even though there is no difference in ejection fraction at baseline, dobutamine stimulation showed that ventricular contractility was significantly better after anxA1 treatment compared to the control (Figure 1F). Systolic pressure and lusitropy were comparable between the three groups (Figure 1G, H). 
A

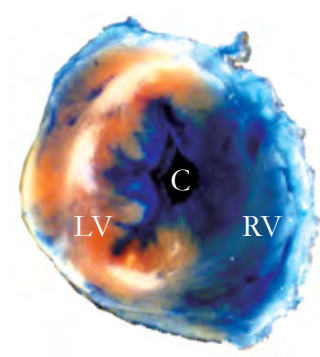

$\mathrm{E}$

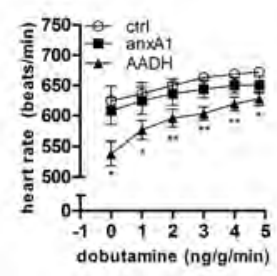

B

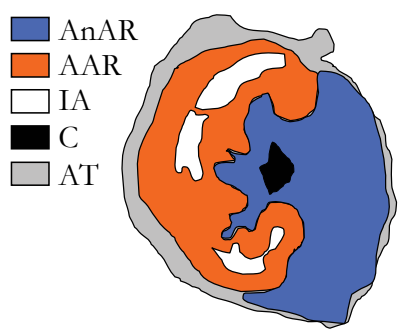

F

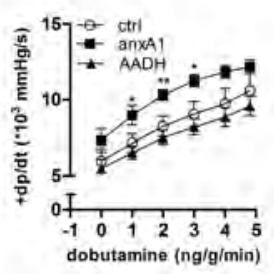

C

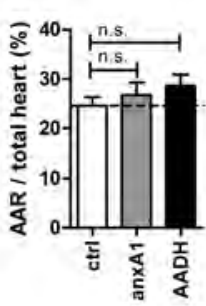

$\mathrm{D}$

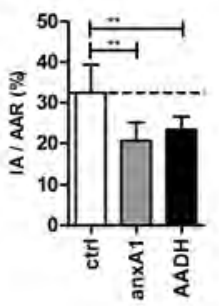

Figure 1 - Effects of anxA1 and AADH on infarct size and ventricular function after 24 hours of reperfusion. Mice were submitted to $30 \mathrm{~min}$ of ischemia and 24 hours of reperfusion. At the start of reperfusion mice were either treated with vehicle (ctrl), anxA1 or AADH. Macroscopic view of the ischemia/reperfusion injured heart $24 \mathrm{~h}$ after reperfusion (A). The heart was perfused with $2 \%$ Evans Blue (blue) and stained with triphenyltetrazolium chloride (TTC, red). LV, left ventricle; $\mathrm{C}$, left ventricular cavity; RV, right ventricle. Color coded representation of the heart of panel A showing the area not at risk (AnAR, blue), the area at risk (AAR, red) and the infarcted area (IA, white) within the AAR (B). Left ventricular cavity (C, black) and adipose tissue (AT, grey) complete the heart. Enumeration of color-coded area was employed to measure AAR as \% of total heart area (C) and IA as \% of AAR (D). After 24 hours of reperfusion heart rate (E), contractility (F), systolic pressure $(\mathrm{G})$ and lusitropy $(\mathrm{H})$ were measured as function of administration of increasing amounts of dobutamine. $\mathrm{n}=7$ per group; ns, non-significant; * $\mathrm{p}<0.05$; ${ }^{* *} \mathrm{p}<0.01$. 
Tabel 2 - echocardiographic parameters of unconscious animals after 24 hours of reperfusion.

\begin{tabular}{llllll} 
Category & Name & ctrl $(\mathrm{n}=6)$ & $\operatorname{anxA1}(\mathrm{n}=6)$ & AADH $(\mathrm{n}=8)$ & $\mathrm{P}$ \\
\hline $\begin{array}{l}\text { Long axis derived parameters } \\
\text { End diastolic volume }(\mu \mathrm{l})\end{array}$ & EDV & $72.5 \pm 8.6$ & $73.7 \pm 7.4$ & $71.2 \pm 17.0$ & n.s. \\
$\begin{array}{l}\text { End systolic volume }(\mu \mathrm{l}) \\
\text { Ejaction fraction }(\%)\end{array}$ & ESV & $42.9 \pm 14.5$ & $45.4 \pm 2.8$ & $46.9 \pm 20.1$ & n.s. \\
Short axis derived parameters & EF & $41.0 \pm 15.0$ & $38.0 \pm 5.0$ & $37.0 \pm 14.0$ & n.s. \\
Diastolic dimensions $(\mathrm{mm})$ & LVIDd & $4.1 \pm 0.3$ & $4.3 \pm 0.4$ & $4.2 \pm 0.3$ & n.s. \\
& PWTd & $0.7 \pm 0.1$ & $0.9 \pm 0.3$ & $0.7 \pm 0.1$ & n.s. \\
& AWTd & $0.8 \pm 0.1$ & $0.8 \pm 0.1$ & $0.7 \pm 0.1$ & n.s. \\
Systolic dimensions $(\mathrm{mm})$ & LVIDs & $3.3 \pm 0.3$ & $3.5 \pm 0.5$ & $3.3 \pm 0.7$ & n.s. \\
& PWTs & $1.1 \pm 0.2$ & $1,2 \pm 0.4$ & $1.0 \pm 0.2$ & n.s. \\
& AWTs & $1.1 \pm 0.1$ & $1.0 \pm 0.2$ & $1.0 \pm 0.2$ & n.s. \\
Left ventricle mass $(\mathrm{mg})$ & LVmass & $108.7 \pm 3.7$ & $109.6 \pm 10.0$ & $109.2 \pm 21.4$ & n.s. \\
Fractional shortening $(\%)$ & FS & $21.0 \pm 7.0$ & $19.0 \pm 6.0$ & $23.0 \pm 11.0$ & n.s.
\end{tabular}

AnxA1 and $A A D H$ do not affect neutrophil infltration at 24 hours of reperfusion

AnxA1 and AADH treatment had no effects on infiltration of $\mathrm{CD}^{4} 5^{+}$leukocytes (Figure $2 \mathrm{~A}, \mathrm{~B})$ or $\mathrm{ly} 6 \mathrm{G}^{\text {high }}$ neutrophils in the AAR after 24 hours of reperfusion (Figure $2 \mathrm{C}, \mathrm{D}$ ). Neutrophils executing NETosis are known to citrullinate histone H3. H3Cit-positive staining colocalized with neutrophil positive regions in the AAR (Figure 2E). AnxA1 and $\mathrm{AADH}$ treatment had no effects on the amount of $\mathrm{H} 3 \mathrm{Cit}$-positivity in the AAR (Figure 2F). Interestingly, we found H3Cit-positive/Ly6G-negative microvasculature in the AnAR that were present in all groups (Figure 2G). Plasma nucleosome levels as determined with measurement of histone/DNA concentration were not significantly different between the groups (Figure $2 \mathrm{H}$ ). 


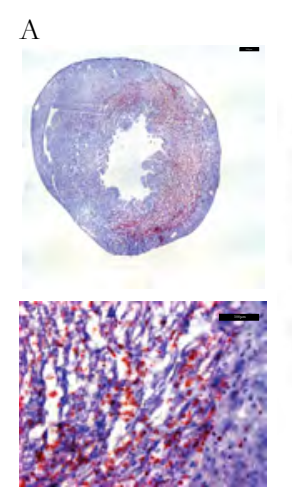

$\mathrm{E}$

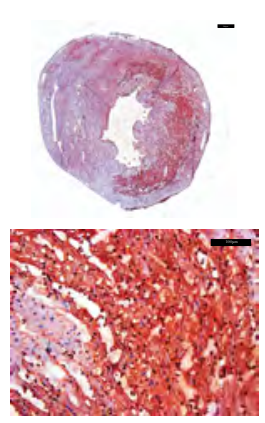

B

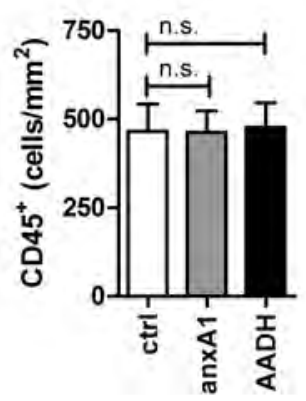

$\mathrm{F}$

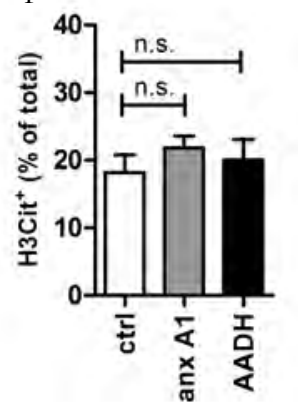

C

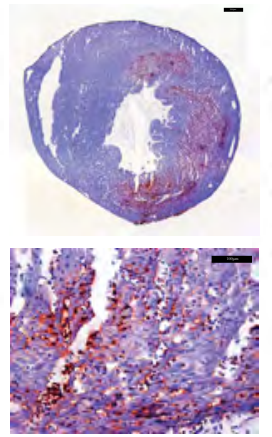

G

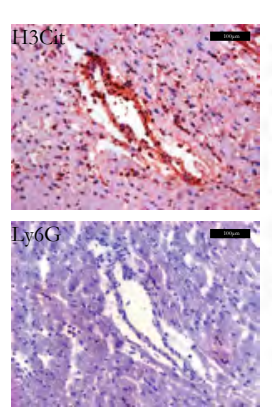

$\mathrm{D}$

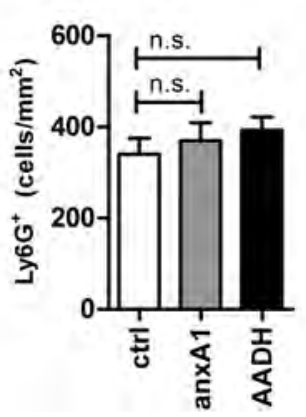

$\mathrm{H}$

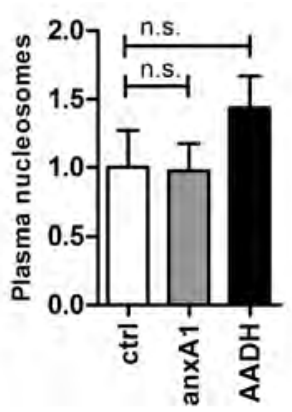

Figure 2 - Effects of anxA1 and AADH on neutrophil infiltration and H3 citrullination after 24 hours of reperfusion. Mice were submitted to $30 \mathrm{~min}$ of ischemia and 24 hours of reperfusion. At start of reperfusion mice were either untreated (ctrl) or treated with anxA1 and AADH. After 24 hours of reperfusion hearts were excised, sectioned and immunohistochemically stained with anti-CD45 (A, B), anti-Ly6G antibody (C, D) and anti-H3Cit antibody (E, F). Panel G shows a representative image of an $\mathrm{H} 3 \mathrm{Cit}$-positive/Ly6G-negative micro vessel in the AnAR. Plasma nucleosomes were quantified to assess free histone and DNA content in plasma $(\mathrm{H})$. Panels $\mathrm{A}, \mathrm{C}$ and $E$ show representative images. Scale bar upper panels A, C and E $500 \mu \mathrm{m}$, scale bar of lower panels $A, C, E$ and $G 100 \mu \mathrm{m}$. $n=6$ per group, n.s. is non-significant.

\section{Discussion}

Annexin A1 (anxA1) has anti-inflammatory and pro-resolving properties causing dampening of inflammation in several animal models of acute and chronic inflammation ${ }^{25-27}$. Lowanticoagulant heparin (AADH) has been shown to prevent histone-mediated cytotoxicity and improve overall survival in sepsis ${ }^{6}$. We hypothesized that treatment with anxA1 and AADH can reduce ischemia-reperfusion injury by inhibiting neutrophil infiltration and neutrophil extracellular trap (NET) formation. Indeed, the results of the current study show that anxA1 and AADH both reduce infarcted area. Interestingly, we found that in addition to reducing infarct size, anxA1 alone improves functional outcome. 
Although beneficial to limit ischemic damage, reperfusion itself causes myocardial injury and a large body of evidence suggests a predominant role for neutrophils ${ }^{1,28-30}$. Ischemic damage leads to influx of neutrophils and formation of granulation tissue, deposition of collagen-based matrix, complement activation and free radical generation, followed by a complex cytokine cascade and upregulation of chemokines ${ }^{31}$. This causes endothelial dysfunction, microvascular collapse and blood flow defects resulting in apoptosis and myocardial infarction which lead to further deterioration of the damaged heart ${ }^{3}$. Strategies aimed at total removal of neutrophils from perfusing blood in humans, reduce the amount of cardiac edema formation and total damage ${ }^{32,33}$. Neutrophil influx and ROS formation are directly correlated in infarcted hearts ${ }^{34}$ and attempts to inhibit neutrophil recruitment or activity appeared very successful in reducing damage ${ }^{34-36}$, but its impact on heart function remains to be elucidated.

Previously it has been shown that treatment with full-length anxA1 or anxA1 mimetic peptide (Ac2-26) leads to a dose-dependent decrease of leukocyte influx in a rat model of ischemia/reperfusion. This resulted in $50 \%$ reduction of infarct size at 2 hours of reperfusion 20,37. A longer anxA1 mimetic peptide (Ac2-50) resulted in 50-70\% reduction of infarct size at 2 hours of reperfusion in a mouse model ${ }^{38}$. Using full-length protein instead of mimetic peptides may increase the potency even further due to higher binding affinity to the anxA1 receptor and increased receptor specificity ${ }^{39}$. We show that treatment with full-length anxA1 reduces infarct size with $35 \%$ after 24 hours of reperfusion. We did not observe a reduction of neutrophil influx at this point in time and therefore suggest that the cardioprotective effect of anxA1 is most likely due to an earlier effect on neutrophil infiltration or a direct effect of anxA1 on the survival of cardiomyocytes ${ }^{40}$. Qin et al. have proposed that the anxA1 mimetic peptide Ac2-26 prevents cardiomyocyte injury by enhanced activation of cardioprotective signaling and/or improved intracellular calcium re-uptake by the sarcoplasmic reticulum ${ }^{41}$.

In conclusion, we show that full-length anxA1 and $\mathrm{AADH}$ have the ability to limit myocardial damage 24 hours after reperfusion without reducing neutrophil influx after 24 hours of reperfusion. Our results also demonstrate that a therapeutic strategy aiming at limitting infarct size will not necessarily result in improved cardiac function after reperfusion. 


\section{References}

1. Kaminski KA, Bonda TA, Korecki J, Musial WJ. Oxidative stress and neutrophil activation--the two keystones of ischemia/reperfusion injury. Int J Cardiol. 2002;86:41-59.

2. Smith EF, 3rd, Egan JW, Bugelski PJ, Hillegass LM, Hill DE, Griswold DE. Temporal relation between neutrophil accumulation and myocardial reperfusion injury. Am J Physiol. 1988;255:H1060-1068.

3. Jordan JE, Zhao ZQ, Vinten-Johansen J. The role of neutrophils in myocardial ischemia-reperfusion injury. Cardiovasc Res. 1999;43:860-878.

4. Romson JL, Hook BG, Kunkel SL, Abrams GD, Schork MA, Lucchesi BR. Reduction of the extent of ischemic myocardial injury by neutrophil depletion in the dog. Circulation. 1983;67:1016-1023.

5. Goldmann O, Medina E. The expanding world of extracellular traps: not only neutrophils but much more. Front Immunol. 2012;3:420.

6. Wildhagen KC, Garcia de Frutos P, Reutelingsperger CP, Schrijver R, Areste C, Ortega-Gomez A, Deckers NM, Hemker HC, Soehnlein O, Nicolaes GA. Nonanticoagulant heparin prevents histonemediated cytotoxicity in vitro and improves survival in sepsis. Blood. 2014;123:1098-1101.

7. Fuchs TA, Abed U, Goosmann C, Hurwitz R, Schulze I, Wahn V, Weinrauch Y, Brinkmann V, Zychlinsky A. Novel cell death program leads to neutrophil extracellular traps. J Cell Biol. 2007;176:231-241.

8. Saffarzadeh M, Juenemann C, Queisser MA, Lochnit G, Barreto G, Galuska SP, Lohmeyer J, Preissner KT. Neutrophil extracellular traps directly induce epithelial and endothelial cell death: a predominant role of histones. PLoS One. 2012;7:e32366.

9. Gerke V, Creutz CE, Moss SE. Annexins: linking Ca2+ signalling to membrane dynamics. Nat Rev Mol Cell Biol. 2005;6:449-461.

10. Perretti M, D’Acquisto F. Annexin A1 and glucocorticoids as effectors of the resolution of inflammation. Nat Rev Immunol. 2009;9:62-70.

11. Raynal P, Pollard HB. Annexins: the problem of assessing the biological role for a gene family of multifunctional calcium- and phospholipid-binding proteins. Biochim Biophys Acta. 1994;1197:63-93.

12. Bena S, Brancaleone V, Wang JM, Perretti M, Flower RJ. Annexin A1 interaction with the FPR2/ ALX receptor: identification of distinct domains and downstream associated signaling. J Biol Chem. 2012;287:24690-24697.

13. Rosengarth A, Luecke $\mathrm{H}$. A calcium-driven conformational switch of the $\mathrm{N}$-terminal and core domains of annexin A1. J Mol Biol. 2003;326:1317-1325.

14. Perretti M. The annexin 1 receptor(s): is the plot unravelling? Trends Pharmacol Sci. 2003;24:574-579.

15. Babbin BA, Lee WY, Parkos CA, Winfree LM, Akyildiz A, Perretti M, Nusrat A. Annexin I regulates SKCO15 cell invasion by signaling through formyl peptide receptors. J Biol Chem. 2006;281:19588-19599.

16. Solito E, Kamal A, Russo-Marie F, Buckingham JC, Marullo S, Perretti M. A novel calcium-dependent proapoptotic effect of annexin 1 on human neutrophils. FASEB J. 2003;17:1544-1546.

17. El Kebir D, Jozsef L, Filep JG. Opposing regulation of neutrophil apoptosis through the formyl peptide receptor-like 1/lipoxin A4 receptor: implications for resolution of inflammation. J Leukoc Biol. 2008;84:600-606.

18. Vago JP, Nogueira CR, Tavares LP, Soriani FM, Lopes F, Russo RC, Pinho V, Teixeira MM, Sousa LP. Annexin A1 modulates natural and glucocorticoid-induced resolution of inflammation by enhancing neutrophil apoptosis. J Leukoc Biol. 2012;92:249-258.

19. Arur S, Uche UE, Rezaul K, Fong M, Scranton V, Cowan AE, Mohler W, Han DK. Annexin I is an endogenous ligand that mediates apoptotic cell engulfment. Dev Cell. 2003;4:587-598.

20. D’Amico M, Di Filippo C, La M, Solito E, McLean PG, Flower RJ, Oliani SM, Perretti M. Lipocortin 1 reduces myocardial ischemia-reperfusion injury by affecting local leukocyte recruitment. FASEB J. 2000;14:1867-1869. 
21. Vivaldi MT, Kloner RA, Schoen FJ. Triphenyltetrazolium staining of irreversible ischemic injury following coronary artery occlusion in rats. Am J Pathol. 1985;121:522-530.

22. De Celle T, Cleutjens JP, Blankesteijn WM, Debets JJ, Smits JF, Janssen BJ. Long-term structural and functional consequences of cardiac ischaemia-reperfusion injury in vivo in mice. Exp Physiol. 2004;89:605-615.

23. van Empel VP, Bertrand AT, van der Nagel R, Kostin S, Doevendans PA, Crijns HJ, de Wit E, Sluiter W, Ackerman SL, De Windt LJ. Downregulation of apoptosis-inducing factor in harlequin mutant mice sensitizes the myocardium to oxidative stress-related cell death and pressure overload-induced decompensation. Circ Res. 2005;96:e92-e101.

24. Tchaikovski SN, BJ VANV, Rosing J, Tans G. Development of a calibrated automated thrombography based thrombin generation test in mouse plasma. J Thromb Haemost. 2007;5:2079-2086.

25. Locatelli I, Sutti S, Jindal A, Vacchiano M, Bozzola C, Reutelingsperger C, Kusters D, Bena S, Parola M, Paternostro C, Bugianesi E, McArthur S, Albano E, Perretti M. Endogenous annexin A1 IS a novel protective determinant in nonalcoholic steatohepatitis (NASH). Hepatology. 2014.

26. Girol AP, Mimura KK, Drewes CC, Bolonheis SM, Solito E, Farsky SH, Gil CD, Oliani SM. Antiinflammatory mechanisms of the annexin A1 protein and its mimetic peptide Ac2-26 in models of ocular inflammation in vivo and in vitro. J Immunol. 2013;190:5689-5701.

27. Leoni G, Alam A, Neumann PA, Lambeth JD, Cheng G, McCoy J, Hilgarth RS, Kundu K, Murthy N, Kusters D, Reutelingsperger C, Perretti M, Parkos CA, Neish AS, Nusrat A. Annexin A1, formyl peptide receptor, and NOX1 orchestrate epithelial repair. J Clin Invest. 2013;123:443-454.

28. Steffens S, Montecucco F, Mach F. The inflammatory response as a target to reduce myocardial ischaemia and reperfusion injury. Thromb Haemost. 2009;102:240-247.

29. Carbone F, Nencioni A, Mach F, Vuilleumier N, Montecucco F. Pathophysiological role of neutrophils in acute myocardial infarction. Thromb Haemost. 2013;110:501-514.

30. Ma Y, Yabluchanskiy A, Lindsey ML. Neutrophil roles in left ventricular remodeling following myocardial infarction. Fibrogenesis Tissue Repair. 2013;6:11.

31. Blankesteijn WM, Creemers E, Lutgens E, Cleutjens JP, Daemen MJ, Smits JF. Dynamics of cardiac wound healing following myocardial infarction: observations in genetically altered mice. Acta Physiol Scand. 2001;173:75-82.

32. Engler RL, Dahlgren MD, Morris DD, Peterson MA, Schmid-Schonbein GW. Role of leukocytes in response to acute myocardial ischemia and reflow in dogs. Am J Physiol. 1986;251:H314-323.

33. Palatianos GM, Balentine G, Papadakis EG, Triantafillou CD, Vassili MI, Lidoriki A, Dinopoulos A, Astras GM. Neutrophil depletion reduces myocardial reperfusion morbidity. Ann Thorac Surg. 2004;77:956-961.

34. Montecucco F, Bauer I, Braunersreuther V, Bruzzone S, Akhmedov A, Luscher TF, Speer T, Poggi A, Mannino E, Pelli G, Galan K, Bertolotto M, Lenglet S, Garuti A, Montessuit C, Lerch R, Pellieux C, Vuilleumier N, Dallegri F, Mage J, Sebastian C, Mostoslavsky R, Gayet-Ageron A, Patrone F, Mach F, Nencioni A. Inhibition of nicotinamide phosphoribosyltransferase reduces neutrophil-mediated injury in myocardial infarction. Antioxid Redox Signal. 2013;18:630-641.

35. Montecucco F, Lenglet S, Braunersreuther V, Pelli G, Pellieux C, Montessuit C, Lerch R, Deruaz M, Proudfoot AE, Mach F. Single administration of the CXC chemokine-binding protein Evasin-3 during ischemia prevents myocardial reperfusion injury in mice. Arterioscler Thromb Vasc Biol. 2010;30:1371-1377.

36. Braunersreuther V, Pellieux C, Pelli G, Burger F, Steffens S, Montessuit C, Weber C, Proudfoot A, Mach F, Arnaud C. Chemokine CCL5/RANTES inhibition reduces myocardial reperfusion injury in atherosclerotic mice. J Mol Cell Cardiol. 2010;48:789-798. 
37. La M, Tailor A, D’Amico M, Flower RJ, Perretti M. Analysis of the protection afforded by annexin 1 in ischaemia-reperfusion injury: focus on neutrophil recruitment. Eur J Pharmacol. 2001;429:263-278.

38. Dalli J, Consalvo AP, Ray V, Di Filippo C, D’Amico M, Mehta N, Perretti M. Proresolving and tissueprotective actions of annexin A1-based cleavage-resistant peptides are mediated by formyl peptide receptor 2/lipoxin A4 receptor. J Immunol. 2013;190:6478-6487.

39. Perretti M, Dalli J. Exploiting the Annexin A1 pathway for the development of novel anti-inflammatory therapeutics. Br J Pharmacol. 2009;158:936-946.

40. Ritchie RH, Gordon JM, Woodman OL, Cao AH, Dusting GJ. Annexin-1 peptide Anx-1(2-26) protects adult rat cardiac myocytes from cellular injury induced by simulated ischaemia. BrJ Pharmacol. 2005;145:495-502.

41. Qin C, Buxton KD, Pepe S, Cao AH, Venardos K, Love JE, Kaye DM, Yang YH, Morand EF, Ritchie $\mathrm{RH}$. Reperfusion-induced myocardial dysfunction is prevented by endogenous annexin-A1 and its N-terminal-derived peptide Ac-ANX-A1(2-26). Br J Pharmacol. 2013;168:238-252. 
Chapter 5 


\section{Chapter 6}

\section{Synthesis and NMR spectroscopic characterization of recombinant human annexin A1}

DHM Kusters, LJ Schurgers, TM Hackeng, CPM Reutelingsperger, H Ippel 


\section{Abstract}

Background - AnnexinA1 (anxA1) is a relatively large, anti-inflammatory protein that binds formyl peptide receptor 2 (FPR-2) via its N-terminal domain. Although an X-ray crystal structure of anxA1 and an NMR structure of Domain I are known, NMR structural and dynamic information on full-length anxA1 is lacking.

Aim - To investigate structural changes of human recombinant anxA1 in presence and absence of calcium and phospholipids by using NMR spectroscopy.

Materials and methods - AnxA1 was recombinantly expressed in normal and deuterated M9 minimal media containing ${ }^{13} \mathrm{C}$-glucose and ${ }^{15} \mathrm{~N}$-ammoniumchloride as sole carbon and nitrogen source. Double and triple isotopically labeled proteins were purified using IMAC. Purity and homogeneity were assessed by MALDI-TOF/TOF analysis and Western blotting. Structural analysis was performed by NMR spectroscopy.

Results - The N-terminal domain of anxA1 is sensitive to degradation and its conformation is strongly dependent on the calcium concentration. Calcium binding to one pocket changes the affinity of the other calcium-binding pockets. AnxA1 has three stable, closed conformations in the absence of calcium, whereas in the presence of calcium anxA1 has one single stable open conformation with the $\mathrm{N}$-terminal domain exposed for interaction. In the presence of a phospholipid surface, calcium promotes aggregation of anxA1 that leads to co-precipitation of anxA1 with phospholipid vesicles.

Conclusion - The calcium concentration determines the conformation of anxA1 and causes substantial changes solely to the $\mathrm{N}$-terminal domain, leaving the other domains relatively unaffected. Thus, calcium may be an important regulator of anxA1 function. 


\section{Introduction}

Annexin A1 (anxA1) belongs to the annexin superfamily of proteins that share a common organizational structure with a highly conserved core domain and a variable $\mathrm{N}$-terminal region. The core domain is composed of four annexin repeats, each of which consists of five $\alpha$-helices and the calcium/phospholipid binding pockets ${ }^{1,2}$ (Figure 1A, B). The $\mathrm{N}$-terminal domain contains a number of phosphorylation sites ${ }^{3}$ and the binding site for S100A $11^{4}$ and formyl peptide receptor 2 (FPR-2) ${ }^{5,6}$. AnxA1 is particularly well-known as a potent anti-inflammatory protein operating on the glucocorticoid axis ${ }^{7,8}$. By binding both phosphatidylserine (PS) and FPR-2, anxA1 bridges apoptotic cells to phagocytes thereby facilitating phagocytosis ${ }^{9,10}$. In addition, anxA1 can be cleaved and function as a local mediator of inflammation ${ }^{11}$. The structure of the protein (and consequently the availability of cleavage and binding sites) is essential for its function. Structural analysis of full-length anxA1 has hitherto only been performed by using X-ray crystallography ${ }^{12}$, which proposed that different conformations of anxA1 possess mechanistic and regulatory functions. It has also been suggested that anxA1 undergoes a conformational change following calcium-dependent phospholipid binding, thereby exposing a second membrane binding site ${ }^{13,14}$ and the $\mathrm{N}$-terminal domain that is normally sequestered within the annexin core domains ${ }^{13}$, 14 . Even though NMR studies on anxA1 have been performed previously, only part of the first domain was structurally defined ${ }^{15,16}$. NMR studies on the single, isolated subdomains of anxA1 have shown that subdomain D1 can fold autonomously ${ }^{16}$. In contrast, subdomains D2 to D4 are poorly soluble and do not fold properly without the presence of neighboring subdomains of the tetradomain arrangement. In other words, to gain insight into the biologically relevant structure of anxA1 in solution, analysis of the full-length anxA1 is required. To this end, we have employed NMR spectroscopy to study the structure and internal dynamics of anxA1, along with the effects of calcium and phospholipid binding. 
A

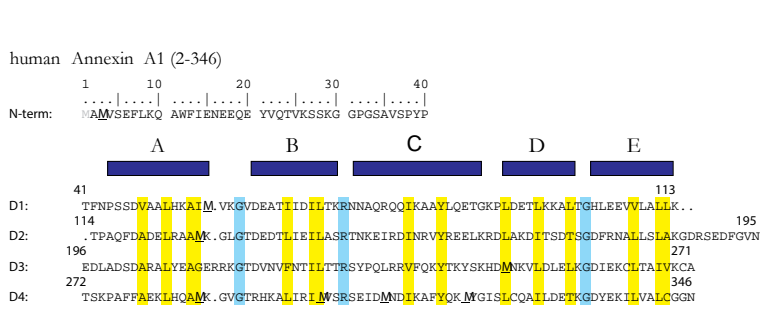

B

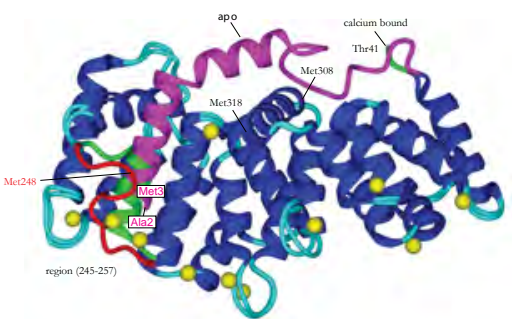

Figure 1 - Structural properties of anxA1. AnxA1 consists of an N-terminal domain and four annexin repeats that each consist of five $\alpha$-helices and contain the calcium/phospholipid binding pockets (A). In the presence of calcium the $\mathrm{N}$-terminal domain becomes available for interaction with FPR-2 and electron density is no longer visible with crystallography (B).

\section{Materials and methods}

Production of ${ }^{13} C^{15} N$-anx $A 1$ and ${ }^{2} H^{13} C^{15} N$-anx $A 1$ - For double isotopically labeled ${ }^{13} \mathrm{C}^{15} \mathrm{~N}$-anxA1 milliQ water was used, for triple labeled ${ }^{2} \mathrm{H}^{13} \mathrm{C}^{15} \mathrm{~N}$-anxA1 milliQ water was replaced with $99.9 \%$ deuterated water ( $\mathrm{D}_{2} \mathrm{O}$, CIL Isotopes). Fermentation of cDNA transformed E. Coli was performed as described in Chapter 4. SG13009[pREP4] bacteria were inoculated in $5 \mathrm{ml}$ Luria-Bertani broth (LB) medium supplemented with Ampicilin (50ug/ml, Roche) and kanamycin (30ug/ml, Gibco). After 8 hours, the culture was diluted $1 / 100$ in $50 \mathrm{ml} \mathrm{LB}$ and grown $\mathrm{o} / \mathrm{n}$. The next day, the culture was diluted $1 / 20$ in $50 \mathrm{ml} \mathrm{M} 9$ minimal growth medium (M9) supplemented with glucose $(6 \mathrm{~g} / \mathrm{L})$ and ${ }^{15} \mathrm{NH}_{4} \mathrm{Cl}(2 \mathrm{~g} / \mathrm{L})$. Following 8 hours, the culture was diluted $1 / 20$ to $500 \mathrm{ml} \mathrm{M9}$ supplemented with glucose $(2 \mathrm{~g} / \mathrm{L})$ and ${ }^{15} \mathrm{NH}_{4} \mathrm{Cl}(2 \mathrm{~g} / \mathrm{L})$ and grown again $\mathrm{o} / \mathrm{n}$. The next day, the $500 \mathrm{ml}$ culture was fermented in 3 liter M9 supplemented with ${ }^{15} \mathrm{NH}_{4} \mathrm{Cl}(2 \mathrm{~g} / \mathrm{L})$, oxygen saturation and glucose were constantly monitored. Induction of protein production was initiated when ${ }^{12} \mathrm{C}$-glucose was depleted using $1 \mathrm{mM}$ isopropyl- $\beta$-D-1-thiogalactopyranoside (IPTG, Eurogentec). Directly after induction $2 \mathrm{~g} / \mathrm{L}{ }^{13} \mathrm{C}$-glucose for double and [U- $\left.{ }^{13} \mathrm{C}-\mathrm{d} 7-{ }^{2} \mathrm{H}\right]-$ deuterated glucose (CIL Isotopes) for triple labeled anxA1 was added and cultured until the glucose was depleted. The bacterial pellet was collected by centrifugation, and the proteins were purified by IMAC (GE Healthcare) to homogeneity as determined by silver-stained SDS-PAGE and MALDI-TOF/TOF analysis. The His-tag was removed from His-anxA1 by Factor Xa-cleavage as also discribed in Chapter 4.

NMR spectroscopy - NMR spectra were recorded on a Bruker Avance III HD $700 \mathrm{MHz}$ spectrometer operating at a ${ }^{1} \mathrm{H}$ frequency of $700 \mathrm{MHz}$ and equipped with a triple channel 
TCI cryoprobe. Stock solutions of expressed and uniformly labeled ${ }^{13} \mathrm{C}^{15} \mathrm{~N}$-His-anxA1 (2.8 $\mathrm{mg} / \mathrm{ml}),{ }^{13} \mathrm{C}^{15} \mathrm{~N}$-anxA1 $(1.7 \mathrm{mg} / \mathrm{ml})$ and ${ }^{2} \mathrm{H}^{13} \mathrm{C}^{15} \mathrm{~N}$-anxA1 $(0.2 \mathrm{mg} / \mathrm{ml})$ were kept in $50 \mathrm{mM}$ Tris and $140 \mathrm{mM} \mathrm{NaCl}$ buffer $(\mathrm{pH} 7.4)$ at $4^{\circ} \mathrm{C}$. Stock solutions were concentrated using ultra-centrifugal filter units with a $10 \mathrm{kDa}$ cut-off (Millipore). For assignment purposes, ${ }^{13} \mathrm{C}^{15} \mathrm{~N}$-anxA1 $(30 \mathrm{mg} / \mathrm{ml})$ and ${ }^{2} \mathrm{H}^{13} \mathrm{C}^{15} \mathrm{~N}$-anxA1 $(12.3 \mathrm{mg} / \mathrm{ml})$ were prepared in $3 \mathrm{~mm}$ NMR tubes (Wilmad) in sample buffer $\left(50 \mathrm{mM}\right.$ Tris, $140 \mathrm{mM} \mathrm{NaCl}, 10 \mathrm{mM} \mathrm{Ca}^{2+}, \mathrm{pH}$ 7.40). The deuterium lock was obtained by adding $5-7 \%(\mathrm{v} / \mathrm{v})$ of $\mathrm{D}_{2} \mathrm{O}$ to $152 \mu \mathrm{l}$ sample volume and $1 \mu \mathrm{l}$ of $1 \mathrm{mM} 4,4$,dimethyl-4-silapentane-1-sulfonic acid solution (DSS, Sigma) was added to the NMR sample to act as internal chemical shift reference for ${ }^{1} \mathrm{H}$ of $0 \mathrm{ppm}$ to a total volume of $160 \mu \mathrm{l}$. Removal of $\mathrm{Ca}^{2+}$ ions in the apo-anxA1 control NMR samples was achieved by addition of $0.1 \mathrm{mM}$ EDTA during ultracentrifugation. NMR pulse sequences of acquisition spectra were taken from the standard Bruker pulse sequence library. Conventional NMR spectra were recorded with selective suppression of water using excitation sculpting techniques. Two dimensional (2D) heteronuclear single quantum coherence (HSQC) ${ }^{15} \mathrm{~N}-{ }^{1} \mathrm{H}, 2 \mathrm{D}$ transverse relaxation optimized spectroscopy (TROSY) ${ }^{15} \mathrm{~N}-{ }^{1} \mathrm{H}$ and $2 \mathrm{D}$ HSQC constant-time ${ }^{13} \mathrm{C}-{ }^{1} \mathrm{H}$ were acquired using sensitivity enhancement and gradient pulses. For resonance assignment purposes, backbone triple resonance spectra were TROSY variants of the following three-dimensional (3D) pulse sequences: HNCO, HN(CA)CO, HNCA, HN(CO)CA, HNCACB, HN(CO)CACB. Additional NMR spectra were acquired using 3D HCCH-DIPSI, carbon-detected 2D C_CON and C_CAN spectra $\left({ }^{13} \mathrm{C}^{15} \mathrm{~N}\right.$ samples), 3D TROSY-NOESY, and 3D HN(CO) CANNH and 3D HNCANNH triple resonance spectra $\left({ }^{2} \mathrm{H}^{13} \mathrm{C}^{15} \mathrm{~N}\right.$ sample $){ }^{17}$. Typically, NMR free induction decays were apodized with cosine square window functions and zero-filled once or twice prior to Fourier transformation. The resolution in the indirect proton, carbon or nitrogen dimensions of 2D and 3D spectra were normally enhanced by applying forward linear prediction up to twice the original digital resolution. Acquisition of spectra was performed using the Bruker program Topspin (v3.2), and analysis (peakpicking and integration) of processed NMR data was done using the program Sparky (version 3.114).

Calcium and sodium titrations - Specificity of calcium binding was investigated by performing a calcium titration of a highly concentrated sample of ${ }^{13} \mathrm{C}^{15} \mathrm{~N}$-anxA1 $(30 \mathrm{mg} / \mathrm{ml})$ buffered in Tris $50 \mathrm{mM}$ (pH 7.4). NMR spectra were acquired at 30 and $140 \mathrm{mM} \mathrm{NaCl}$ and 0.5 , $1.2,2.8$ and $10 \mathrm{mM}$ calcium. For titration with sodium up to $500 \mathrm{mM} \mathrm{Na}^{+}$, the buffer was exchanged with $\mathrm{NaCl}$-free, $50 \mathrm{mM} \mathrm{K}_{3} \mathrm{PO}_{4}(\mathrm{pH} 7.4)$ supplemented with 0.1 mM EDTA. 
NMR spectra acquired on anxA1 with small unilamilar vesicles - NMR samples of anxA1 in small, phospholipid unilaminar vesicles (SUV) were prepared by mixing the protein solution with a freshly prepared stock solution of $30 \mathrm{mM}$ SUV particles $(80 \% \mathrm{DOPC} / 20 \%$ DOPS in Tris $50 \mathrm{mM}, 140 \mathrm{mM} \mathrm{NaCl}, 0.1 \mathrm{mM}$ EDTA). The phospholipid stock solution was sonicated for 10 minutes to obtain SUV particles of roughly $20 \mathrm{~nm}$ in diameter, and the $\mathrm{pH}$ was adjusted to $\mathrm{pH} 7.4$. All SUV solutions were characterized by collecting and analyzing ${ }^{1} \mathrm{H}$ and natural abundance ${ }^{13} \mathrm{C}$ NMR spectra. A concentrated stock solution (9.9 $\mathrm{mg} / \mathrm{ml}$ ) of ${ }^{13} \mathrm{C}^{15} \mathrm{~N}$-labeled apo-anxA1 (12-346) was used with calcium being rigorously removed from solution by EDTA chelation and diluted to a final protein concentration of $1.6 \mathrm{mg} / \mathrm{ml}$ protein and $24 \mathrm{mM}$ of total phospholipid. Calcium-mediated anxA1-lipid complexation was made by adding concentrated $\mathrm{CaCl}_{2}$ (up to $2.5 \mathrm{mM} \mathrm{Ca}^{2+}$ ) to the apoprotein-lipid mixture.

\section{Results}

\section{Production of ${ }^{13} C^{15} \mathrm{~N}$-anxA1 and ${ }^{2} H^{13} C^{15} \mathrm{~N}$-anxA1 for $N M R$ analysis}

Isotopically enriched anxA1 was produced recombinantly. Bacterial oxygen consumption was greatly reduced when ${ }^{12} \mathrm{C}$-glucose was depleted. At that point, ${ }^{13} \mathrm{C}$-glucose and IPTG were added to induce expression of isotopically-labeled His-tagged anxA1 (HisanxA1) (supplementary Figure S1). Purity and homogeneity were checked on silverstained SDS-PAGE (Figure 2A), Western blotting (Figure 2B) and MALDI-TOF/TOF analysis (Figure 2C). Theoretical and empirical molecular weights for double and triple isotopically-labeled His-anxA1 and anxA1 were $42.9 \mathrm{kDa}$ and $40.5 \mathrm{kDa}$ for double-labeled protein, and $45.8 \mathrm{kDa}$ and $43.3 \mathrm{kDa}$ for triple labeled protein, respectively, as determined by MALDI-TOF/TOF mass spectrometry. Purity was $>95 \%$ as determined by silverstained SDS-PAGE (supplementary Figure S2). Maximum solubility of anxA1 at room temperature was found to be approximately $24 \mathrm{mg} / \mathrm{ml}$ in Tris/ $\mathrm{NaCl}(\mathrm{pH} 7.4)$. 
A

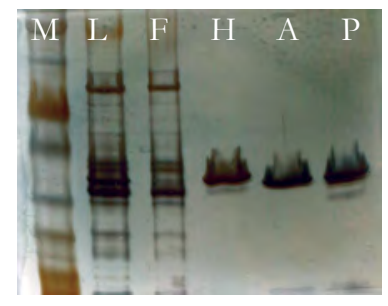

B

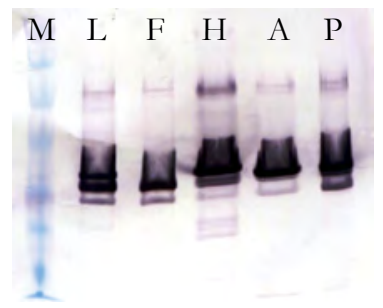

C

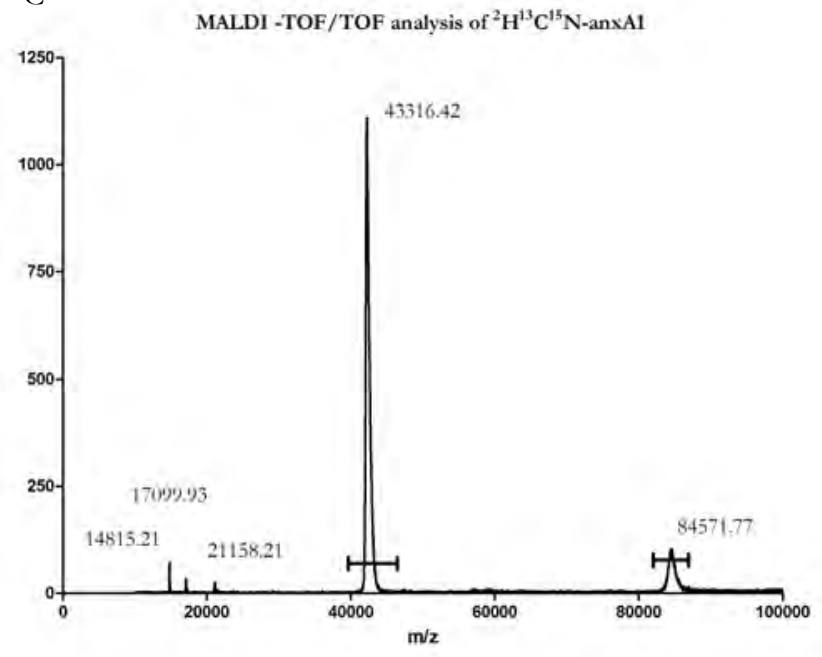

Figure 2 - Purification of anxA1 for NMR spectroscopy. Silver stained SDS-PAGE (A), Western blotting (B) and MALDI-TOF/TOF analysis (C) of the purification of ${ }^{2} \mathrm{H}^{13} \mathrm{C}^{15} \mathrm{~N}$-anxA1. Silverstained SDS-PAGE indicates purity $>95 \%$ and MALDI-TOF/TOF analysis confirms theoretical molecular weight of $42.3 \mathrm{kDa}$ for ${ }^{2} \mathrm{H}^{13} \mathrm{C}^{15} \mathrm{~N}$-anxA1. M-broad range protein marker; L-bacterial lysate; F-flow-through; $\mathrm{H}-^{2} \mathrm{H}^{13} \mathrm{C}^{15} \mathrm{~N}$-His-anxA1 peak fraction; $\mathrm{A}_{-}{ }^{2} \mathrm{H}^{13} \mathrm{C}^{15} \mathrm{~N}$-anxA1; $\mathrm{P}$-anxA1 (positive control).

Spontaneous $N$-terminal truncation of ${ }^{13} C^{15} N$-His-anx $A 1$ and ${ }^{13} C^{15} N$-anxA1

NMR measurements for complete backbone resonance assignments required about three weeks of acquisition time. To assess $\mathrm{N}$-terminal cleavage susceptibility of long-term incubations, we performed NMR spectroscopy, mass spectrometry, and gel-electrophoresis. All three methodologies demonstrated that the first eleven amino acids were susceptible to degradation, whereas Trp-12 remained unaffected. In the $2 \mathrm{D}{ }^{15} \mathrm{~N}-\mathrm{HSQC}$ spectrum, the readily identifiable side chain $\mathrm{H} \varepsilon$ proton of Trp-12 appeared as two well-resolved resonances, one corresponding to intact anxA1 and the other to $(\Delta 2-11)$ truncated anxA1(12-346). Based on the ratio between the two peaks, complete conversion would take months at $4^{\circ} \mathrm{C}$. The formation of truncated anxA1(12-346) was also observed for His-anxA1. Silver stained SDS-PAGE and MALDI-TOF/TOF analyses on these NMR samples confirmed the loss of amino acids 2-11 (Supplementary Figure S2). 


\section{AnxA1 has two calcium dependent conformations.}

To assess helix insertion as function of calcium binding, two NMR constructs of anxA1 were investigated: N-terminally His-anxA1 and full-length anxA1(2-346) (Figure 3A, B). Preliminary data on unlabeled protein showed that anxA1 may be kept in various buffers to a maximum concentration of $15 \mathrm{mg} / \mathrm{ml}$ at $37^{\circ} \mathrm{C}$. NMR spectra recorded at low $(1.7 \mathrm{mg} / \mathrm{ml})$ and saturated $(\geq 24 \mathrm{mg} / \mathrm{ml}$, partially precipitated) protein concentration appeared to be essentially the same. Therefore, most samples used for 3D-NMR backbone assignments were recorded using saturated protein solutions. Comparison of the ${ }^{15} \mathrm{~N}^{1} \mathrm{H}$ HSQC spectrum of double- and triple-labeled anxA1 showed comparable spectral patterns and similar peak intensities, indicating that all amide deuterons were back-exchanged to protons in the folded protein of the triple labeled sample. N-terminal degradation had negligible effects on NMR spectra of calcium bound anxA1. Because more backbone $\mathrm{N}-\mathrm{H}$ resonances were observed than expected, we concluded that several conformations of apo-anxA1 were present in the sample. Several amide peaks were separated into two slightly offset signals exhibiting a constant intensity ratio of estimated 2:1. This ratio was not affected by N-terminal cleavage at Trp-12, and appears to be independent of the protein concentration and method of isotope labeling.

\section{The NMR spectrum of anxA1 closely resembles the crystal structure}

Figure $2 \mathrm{~A}$ shows the $2 \mathrm{D}$ TROSY ${ }^{15} \mathrm{~N}-1 \mathrm{H}$ spectra of triple-labeled, back-exchanged anxA1(2$346)$ in the absence (grey cross peaks) and presence (black cross peaks) of calcium. Note that these spectra differ considerably. Focusing on Trp-12, it is apparent that there are three broad signals in the apo-form (Figures $3 \mathrm{~B}$ and $4 \mathrm{~A}$ ), yet only a single, sharp peak in the calcium bound state (Figures $3 \mathrm{~B}$ and $4 \mathrm{~A}$ ). Tripling of peaks is also detected in other areas of the spectrum, implying the presence of three slowly exchanging states of apo anxA1 and one stable, calcium-bound state. In apo-His-anxA1, the Trp-12 He-group appears as a single resonance at the identical position as that in the calcium bound state in anxA1 (Figure 3B), indicating similar structural environments. The calcium-bound His-anxA1 and calcium-bound anxA1 yield very similar spectra, indicating analogous structures over this shared sequence. In ${ }^{13} \mathrm{C}-{ }^{1} \mathrm{H}$ HSQC spectra, there are only minor differences between calcium-bound His-anxA1 and calcium-bound anxA1 (Figures 4A and $4 \mathrm{~B}$ ). This spectral region mainly contains peaks of hydrophobic amino acid residues (Met, Ala, Val, Ile and Leu). With His-anxA1, there are some additional resonances 
arising from linker residues Met(-21) and Ile(-4). Differences in chemical shifts of some of the remaining resonances are consistent with perturbations induced by the linker on the $\mathrm{N}$-terminus, which results in a rather large displacement in the position of the Ala-2 methyl group (see arrow in Figure 5B).

A

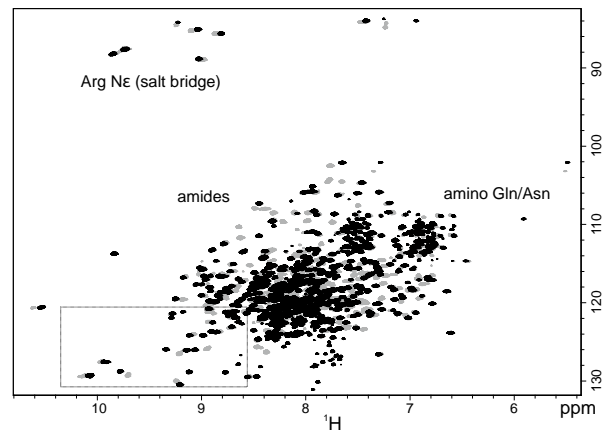

B

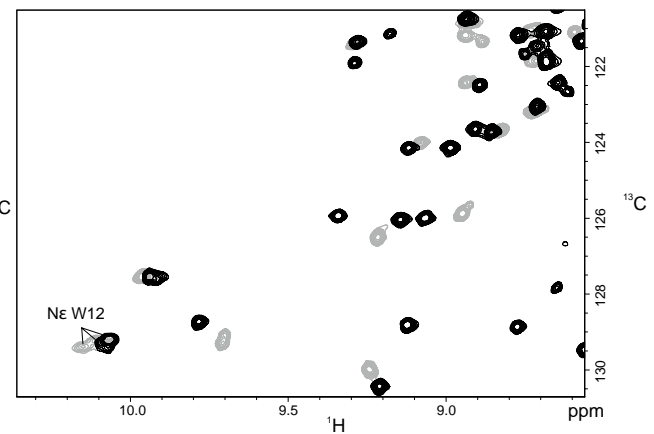

Figure $3-{ }^{15} N-{ }^{1} H H S Q C$ spectrum of ${ }^{13} C^{15} N$-anxA1 in an overlay of apo-anx $A 1$ (grey) and calcium bound anxA1 (black). Overview spectrum (A) and an expanded zoom view (B) of the rectangled region in the left spectrum. Backbone amino groups belonging to Asn, Gln or Arg and $\mathrm{N} \varepsilon$ amides of the sidechain can be determined based on chemical shifts alone and are and indicated in the plot (A). Of interest are the sharp downfield shifted $N \varepsilon$ amino signals of arginines, which are a strong indicator for the presence of salt bridges between Arg side-chains and Glu or Asp carboxyl groups. The salt bridges are preserved after calcium binding, since the number of peaks remains equal and only minute chemical shifts occur.

A

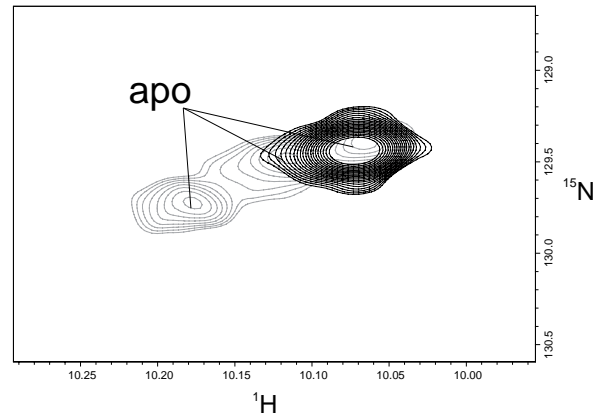

B

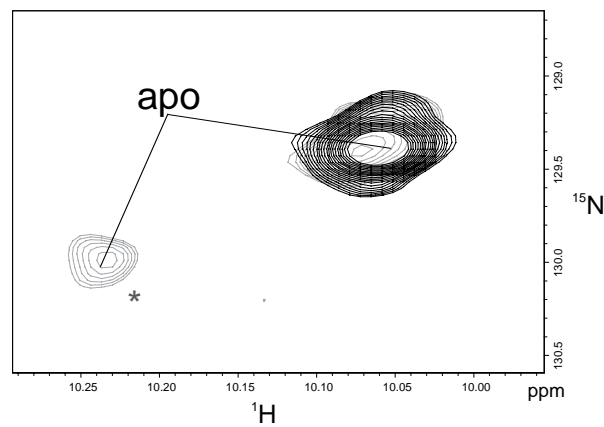

Figure $4-{ }^{15} \mathrm{~N}-{ }^{1} \mathrm{H}$ HSQC spectrum of ${ }^{13} \mathrm{C}^{15} \mathrm{~N}$-His-anxA1 and ${ }^{13} \mathrm{C}^{15} \mathrm{~N}$-anxA1 containing $\mathrm{H} \varepsilon$ Trp-12 at high protein concentrations. The apo-form of anxA1(2-346) shows three broad peaks (grey) of which only one state is promoted in the presence of excess calcium (black peak) (A). The His-anxA1 shows one major peak for $\mathrm{H} \varepsilon$ Trp-12 in the apo form (grey) at the identical position of the calcium bound form of anxA1 (black). *The grey peak on the left is assigned to a small percentage of truncated apo-anxA1(12-346) (B). 
A
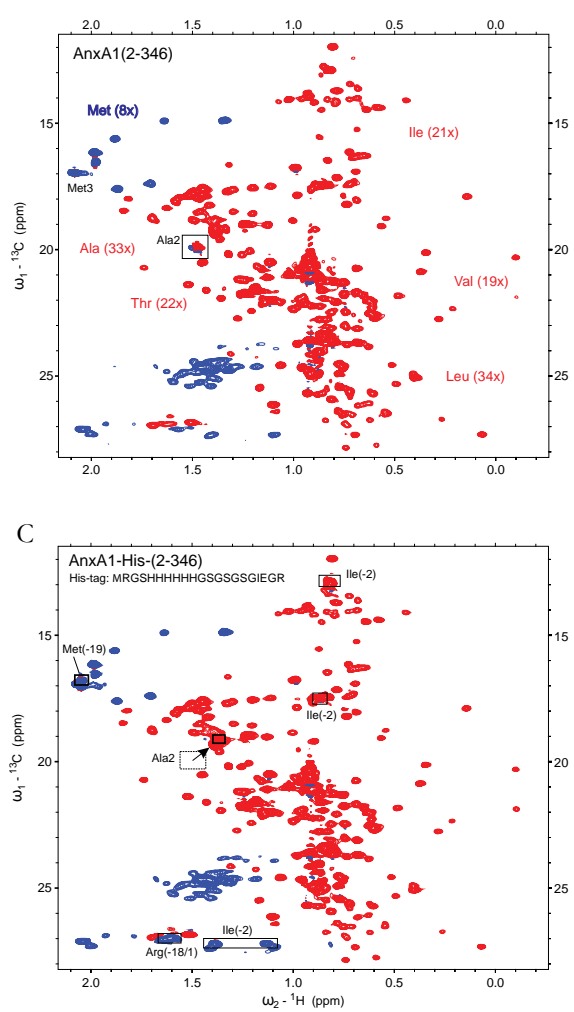

B
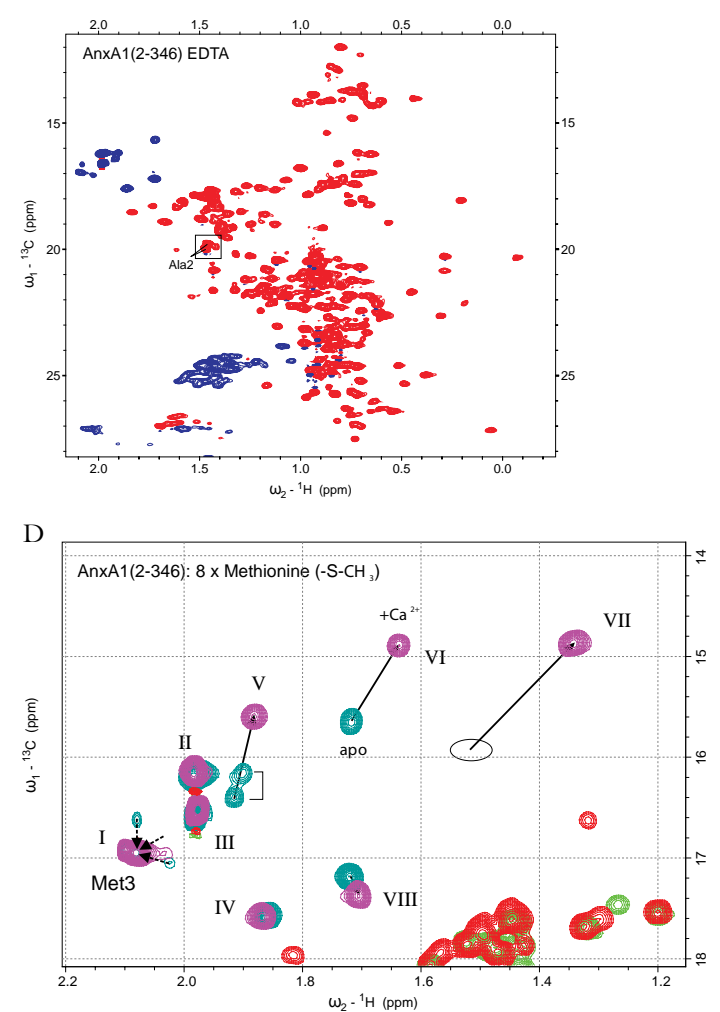

Figure $5-{ }^{13} \mathrm{C}-{ }^{1} \mathrm{H}$ HSQC spectra of His-tagged and full-length anxA1. Comparison between ${ }^{13} \mathrm{C}^{15} \mathrm{~N}$-anxA1(2-346) (A) and His-tagged ${ }^{13} \mathrm{C}^{15} \mathrm{~N}$-anxA1 (-21-346) (B) in saturated calcium and of AnxA1 (2-346) in the presence of EDTA (C). Chemical shifts between the apo and the calcium bound form of anxA1(2-346) with focus on the methionines (arbitrarily numbered I-VIII) (D).

Sodium causes chemical shift profiles comparable to calcium in the absence of calcium

In the ${ }^{13} \mathrm{C}^{1} \mathrm{H}$ HSQC spectrum, chemical shifts of side chain methyl resonances are greatly influenced by the binding of calcium. Note the changes in calcium bound anxA1 (Figure 5A) and His-anxA1 (Figure 5B) compared to the apo state (Figure 5C). It is most interesting to focus on the eight well-resolved methionine methyl groups in anxA1 (Figure 5D). The addition of increasing amounts of calcium or sodium induces chemical shift changes in at least three out of these eight methionine resonances (labeled V, VI and VII in Figure 6). In absence of calcium and at low sodium salt resonances are split up in two components, indicated "a" and "b", and that merge into a single peak at higher salt conditions. AnxA1 in the presence of $140 \mathrm{mM} \mathrm{NaCl}$ is comparable to anxA1 in $50 \mathrm{mM}$ $\mathrm{K}_{3} \mathrm{PO}_{4}$ and $0.5 \mathrm{mM}$ calcium, indicating that $\mathrm{NaCl}$ can induce overall structural changes 
that are normally associated with calcium binding. Met-VII shows the highest affinity for calcium with a $\mathrm{K}_{\mathrm{d}}$ value below $0.5 \mathrm{mM}$, whereas Met-IV must be distant from the calcium binding site because its resonance is not chemically shifted during the titration.

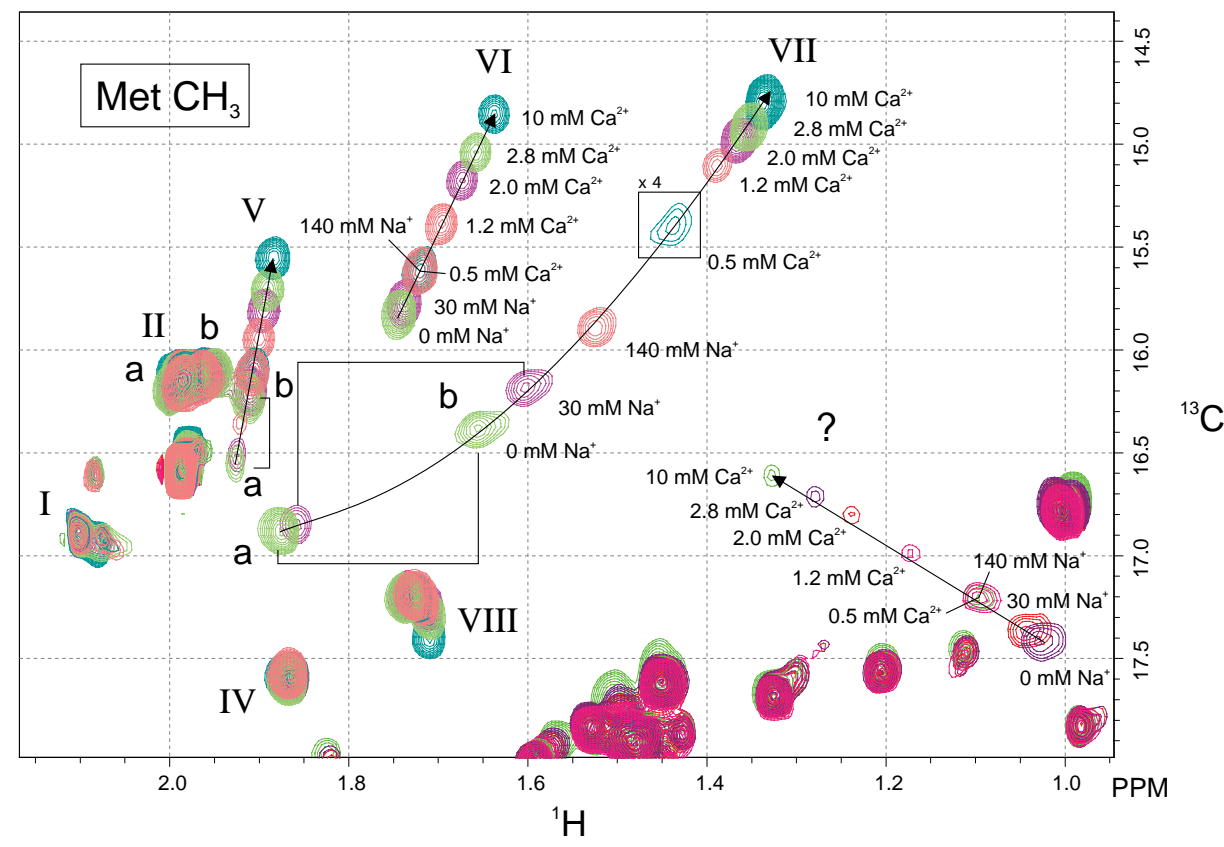

Figure $6-{ }^{13} \mathrm{C}-{ }^{1} \mathrm{H}$ HSQC spectrum showing the effect of sodium and calcium on the methionines of anxA1. The methyl group of Met-3 is too broad to detect in the absence of calcium, but appears and sharpens with increasing calcium concentrations. Met VII (and to lesser extent II and V) display two clear signals in the spectra recorded with no added $\mathrm{Na}^{+}$and low concentration of $30 \mathrm{mM} \mathrm{NaCl}$ (denoted 'a' and 'b'). Above $100 \mathrm{mM} \mathrm{NaCl}$ the two peaks of Met VII signal start to merge into a broad peak, confirming the presence of a dynamic conformational switch in the apo form induced by calcium binding. The peak of Met VII is most broadened at $0.5 \mathrm{mM} \mathrm{Ca}^{2+}$ and for that reason the lowest contour level has been set four times lower (indicated in the squared box). The peak labeled with a question mark is unassigned for now, but most likely corresponds to a methyl group of an Ala in close proximity to one of the calcium binding loops. 


\section{Calcium induced anxA1 phospholipid binding causes temperature dependent precipitation}

Although solutions of SUV without protein are very stable, the mixture of cleaved apo ${ }^{13} \mathrm{C}^{15} \mathrm{~N}$ anxA1(12-346) and SUV is observed to precipitate slowly at $37^{\circ} \mathrm{C}$ (Figure $7 \mathrm{~A}$ ). On the other hand, the signals from phospholipid also decrease over time (Figure $7 \mathrm{~B}$ ), suggesting formation of insoluble complexes between particles of SUV and the protein. Precipitation is completely blocked at room temperature (Figure 7C), and addition of calcium promotes rapid precipitation under all conditions. Analysis of a conventional 1D NMR spectrum indicates the loss of at least $80 \%$ of the protein (lower panels Figure 7A-C), but then the sample remains unchanged for days. Increasing the calcium concentration and lowering the incubation temperature yields similar results (Figure 7C). AnxA1 resonances that remain in the HSQC spectrum are in fact a subset of minor peaks already present in the original spectrum (Figure 7D). This fraction of the protein is not considered capable of binding DOPS phospholipids in the presence of calcium.

\section{Discussion}

Currently, there are no solution structures of native, full-length human anxA1, and most of our knowledge about the structure of anxA1 comes from crystallographic studies of porcine anxA1 ${ }^{6,12}$ or of truncated ( $\left.\triangle 1-32\right)$ human anxA1 ${ }^{15}$. Human and porcine anxA1 have $89 \%$ sequence identity, therefore many of their structural features should be conserved. More recently, the high-resolution crystal structure of annexin B22 from the malaria parasite Schistosoma mansoni ${ }^{18}$ has become available. This structure also has the highly conserved annexin folding motif. By analysis of our NMR data, we have been able to partially assign backbone and side chain resonances for human anxA1. Based on these preliminary results, it appears that in solution anxA1 is a quite dynamic molecule that exploits the binding of calcium as a structural switch to modulate its biological function and binding to cell membranes.

Each of the four annexin domain repeats (D1 to D4) can bind up to two calcium ions ${ }^{6}$, 19. This significantly affects the position of the $\mathrm{N}$-terminal tail (2-32) and therefore the possibility of the protein to interact with FPR-2. Based on our NMR data, the structures of calcium bound His-anxA1 and anxA1 are very comparable. However, residues at the $\mathrm{N}$-terminus of apo-anxA1 (Ala-2, Met-3 and Trp-12) exist in multiple conformations, a feature that is not found in apo His-anxA1. If the His-tag itself sterically hinders insertion 
A

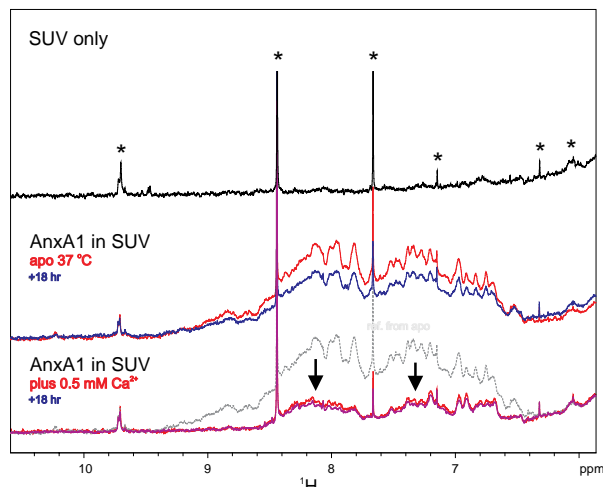

C

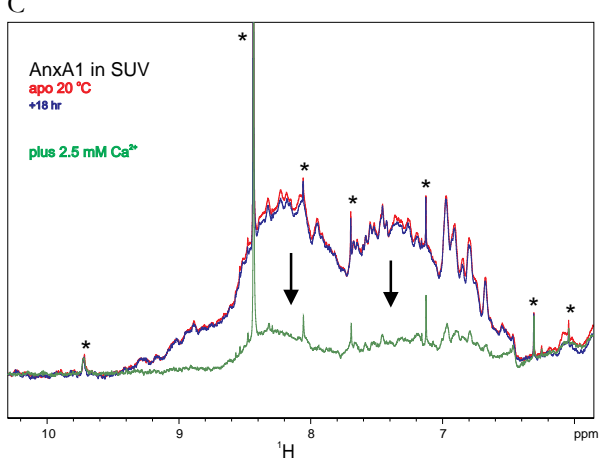

$\mathrm{B}$

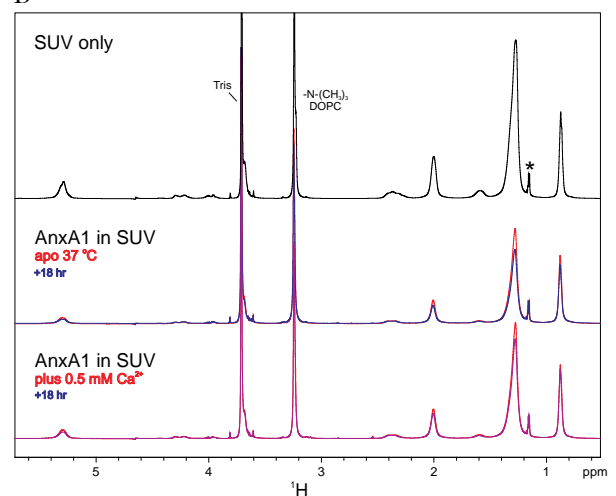

$\mathrm{D}$

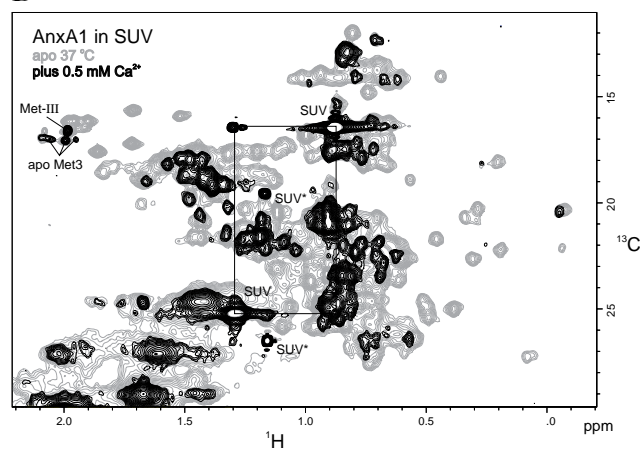

Figure 7 - The effect of calcium dependent lipid binding of anxA1 in solution. The top spectrum shows the reference SUV spectrum. Incubation of SUV with apo-anxA1(12-246) is followed for 18 hours at $37^{\circ} \mathrm{C}(\mathrm{A}, \mathrm{B}$, middle spectrum $)$ and $20^{\circ} \mathrm{C}(\mathrm{C})$, showing a small loss of protein signal (A) and phospholipid signal (B) but not at $20^{\circ} \mathrm{C}(\mathrm{C})$. Small impurities like chloroform are indicated with asterisks. The bottom two spectra show the loss of proton signal immediately after addition of calcium at 0 and 18 hours. Arrows indicated downward movement of complete spectrum. Overlay of ${ }^{13} \mathrm{C}-{ }^{1} \mathrm{H}$ HSQC of ${ }^{13} \mathrm{C}^{15} \mathrm{~N}$-AnxA1(12-346) in the absence of calcium (grey) and after addition of an excess of calcium (black) at $37^{\circ} \mathrm{C}(\mathrm{D})$. Addition of calcium caused a removal of most native anxA1 resonances. The proton signals of the natural occurring ${ }^{13} \mathrm{C}$ atoms $(1.1 \%)$ of the phospholipids are relatively large and prominently present in the spectra (indicated as 'SUV').

of the N-terminal tail into the protein, then the N-terminal helix, as hypothesized, should be preferentially inserted into the core of the protein in absence of calcium. The non-linear, curved nature of chemical shift trends of anxA1 Met-VII and VIII resonances during the calcium titration strongly suggests the presence of a multi-state equilibrium that includes various intermediate states, each having a different calcium binding affinity. Moreover, this suggests the presence of a cooperative process in which calcium binding to one binding site influences the affinity of calcium binding to another site. The conformation and functionality of anxA1 are highly dependent on the sodium concentration. We 
have demonstrated that anxA1 is only active at a physiological salt concentration. This salt-stabilized form should be considered the initial state for the calcium-specific switch, although the same state can also be reached at low calcium concentration. The lower affinity binding sites have apparent dissociation constants of about 1 to $2 \mathrm{mM}$. Saturation of all calcium binding sites occurs at $10 \mathrm{mM}$ calcium. Even at $30 \mathrm{mg} / \mathrm{ml}$ anxA1, calcium binding has its saturation point near $20 \mathrm{mM}$ calcium. Thus, in absence of lipid, the fully calcium-bound state of anxA1 is attained at a calcium:protein molar ratio of about 25:1.

Furthermore, our NMR data demonstrate that in the absence of calcium or another divalent cations, anxA1 interacts only weakly with a lipid bilayer comprised of small, unilaminar phospholipid vesicles (SUV). In fact, our NMR spectra of apo-anxA1 in the presence and absence of SUV vesicles are virtually indistinguishable, indicating the absence of any significant structural changes to the protein in the phospholipid environment. On the other hand, we observed a relatively strong association between anxA1 and DOPSphospholipids even at low levels of calcium. At higher levels of calcium, however, SUVanxA1 complexes precipitate and NMR signals are lost. This supports previous findings that anxA1 promotes aggregation of phospholipid vesicles in a calcium-dependent manner ${ }^{20}$. AnxA1-mediated vesicle aggregation, which probably involves homotypic dimerization ${ }^{21}$, is dependent on the presence of its $\mathrm{N}$-terminal tail ${ }^{22}$. This phenomenon precludes NMR-based structural analysis of the influence of calcium and phospholipids on the topology of the N-terminal tail in full-length anxA1. 


\section{References}

1. Raynal P, Pollard HB. Annexins: the problem of assessing the biological role for a gene family of multifunctional calcium- and phospholipid-binding proteins. Biochim Biophys Acta. 1994;1197:63-93.

2. Gerke V, Creutz CE, Moss SE. Annexins: linking Ca2+ signalling to membrane dynamics. Nat Rev Mol Cell Biol. 2005;6:449-461.

3. D'Acunto CW, Gbelcova H, Festa M, Ruml T. The complex understanding of Annexin A1 phosphorylation. Cell Signal. 2014;26:173-178.

4. Seemann J, Weber K, Gerke V. Structural requirements for annexin I-S100C complex-formation. Biochem J. 1996;319 ( Pt 1):123-129.

5. Bena S, Brancaleone V, Wang JM, Perretti M, Flower RJ. Annexin A1 interaction with the FPR2/ ALX receptor: identification of distinct domains and downstream associated signaling. J Biol Chem. 2012;287:24690-24697.

6. Rosengarth A, Luecke $\mathrm{H}$. A calcium-driven conformational switch of the $\mathrm{N}$-terminal and core domains of annexin A1. J Mol Biol. 2003;326:1317-1325.

7. Parente L, Solito E. Annexin 1: more than an anti-phospholipase protein. Inflamm Res. 2004;53:125-132.

8. Gavins FN, Hickey MJ. Annexin A1 and the regulation of innate and adaptive immunity. Front Immunol. 2012;3:354.

9. Arur S, Uche UE, Rezaul K, Fong M, Scranton V, Cowan AE, Mohler W, Han DK. Annexin I is an endogenous ligand that mediates apoptotic cell engulfment. Dev Cell. 2003;4:587-598.

10. Blume KE, Soeroes S, Waibel M, Keppeler H, Wesselborg S, Herrmann M, Schulze-Osthoff K, Lauber K. Cell surface externalization of annexin A1 as a failsafe mechanism preventing inflammatory responses during secondary necrosis. J Immunol. 2009;183:8138-8147.

11. Vong L, D’Acquisto F, Pederzoli-Ribeil M, Lavagno L, Flower RJ, Witko-Sarsat V, Perretti M. Annexin 1 cleavage in activated neutrophils: a pivotal role for proteinase 3.J Biol Chem. 2007;282:29998-30004.

12. Rosengarth A, Gerke V, Luecke H. X-ray structure of full-length annexin 1 and implications for membrane aggregation. J Mol Biol. 2001;306:489-498.

13. de la Fuente M, Ossa CG. Binding to phosphatidyl serine membranes causes a conformational change in the concave face of annexin I. Biophys J. 1997;72:383-387.

14. Gerke V, Moss SE. Annexins: from structure to function. Physiol Rev. 2002;82:331-371.

15. Weng X, Luecke H, Song IS, Kang DS, Kim SH, Huber R. Crystal structure of human annexin I at 2.5 A resolution. Protein Sci. 1993;2:448-458.

16. Gao J, Li Y, Yan H. NMR solution structure of domain 1 of human annexin I shows an autonomous folding unit. J Biol Chem. 1999;274:2971-2977.

17. Sattler M, Schleucher Jr, Griesinger C. Heteronuclear multidimensional NMR experiments for the structure determination of proteins in solution employing pulsed field gradients. Progress in Nuclear Magnetic Resonance Spectroscopy. 1999;34:93-158.

18. Leow CY, Willis C, Osman A, Mason L, Simon A, Smith BJ, Gasser RB, Jones MK, Hofmann A. Crystal structure and immunological properties of the first annexin from Schistosoma mansoni: insights into the structural integrity of the schistosomal tegument. FEBS J. 2013.

19. Simpkins B, Donohue MP, Li Y. Molecular dynamic studies on the impact of mutations on the structure, stability, and $\mathrm{N}$-terminal orientation of annexin A1: Implications for membrane aggregation. Proteins. 2014.

20. Drust DS, Creutz CE. Aggregation of chromaffin granules by calpactin at micromolar levels of calcium. Nature. 1988;331:88-91.

21. Lambert O, Gerke V, Bader MF, Porte F, Brisson A. Structural analysis of junctions formed between lipid membranes and several annexins by cryo-electron microscopy. J Mol Biol. 1997;272:42-55. 
22. Hoekstra D, Buist-Arkema R, Klappe K, Reutelingsperger CP. Interaction of annexins with membranes: the $\mathrm{N}$-terminus as a governing parameter as revealed with a chimeric annexin. Biochemistry. 1993;32:14194-14202.

\section{Supplemental Figures}

Fermentation anxA1 M9 minimal medium

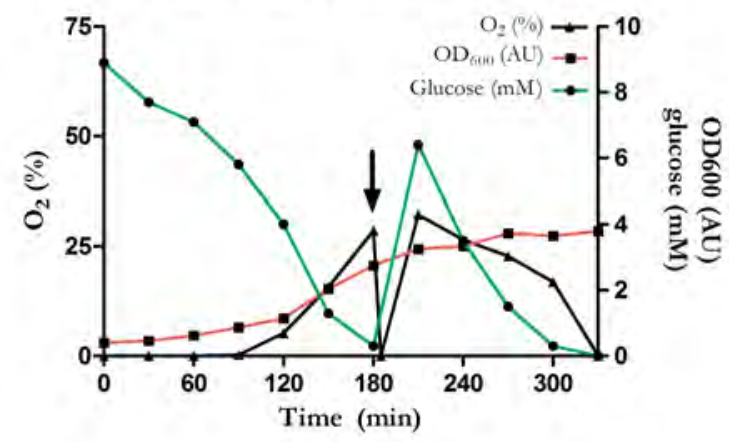

Supplemental Figure S1 - Oxygen saturation and glucose consumption of anxA1 fermentation in time. Oxygen and glucose consumption were continuously monitored, bacteria completely stopped oxygen consumption when glucose was depleted. At this point ${ }^{13} \mathrm{C}$-glucose was added together with IPTG to induce protein production.

A

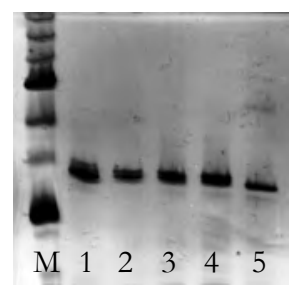

B

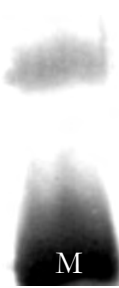

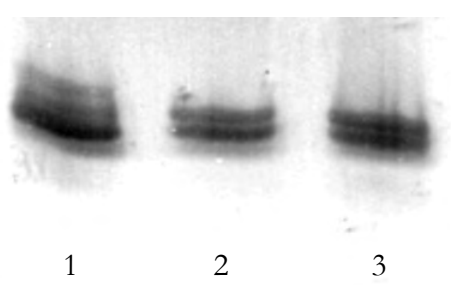
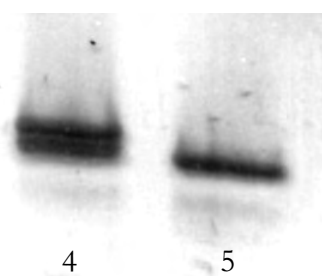

Supplemental Figure S2 - Silver-stained SDS-PAGE after NMR analysis. Silver-stained SDSPAGE gel (A) enlarged (B) of 50ng protein demonstrates partial degradation ${ }^{13} \mathrm{C}^{15} \mathrm{~N}$-anxA1 and His-tagged ${ }^{13} \mathrm{C}^{15} \mathrm{~N}$-anxA1 after diverse NMR measurements. $\mathrm{M}$ ) broad range protein marker; 1) His-tagged ${ }^{13} \mathrm{C}^{15} \mathrm{~N}$-anxA1; 2) ${ }^{13} \mathrm{C}^{15} \mathrm{~N}$-anxA1; 3) Tris-NaCl-EDTA-NMR ${ }^{13} \mathrm{C}^{15} \mathrm{~N}$-anxA1; 4) $\mathrm{K}_{3} \mathrm{PO}_{4}-\mathrm{NaCl}$-EDTA-NMR ${ }^{13} \mathrm{C}^{15} \mathrm{~N}$-anxA1; 5) His-tagged ${ }^{13} \mathrm{C}^{15} \mathrm{~N}$-AnxA1 completely truncated 


\section{Chapter 7}

\section{General discussion}


Cardiovascular disease (CVD) is the leading cause of death in the Western societies and accounts for over 17 million deaths world-wide annually ${ }^{1}$. Atherosclerosis is the predominant underlying pathology for CVD and contributes most to the morbidity and mortality ${ }^{2}$. Cell death by apoptosis contributes largely to the growth and progression of atherosclerotic lesions. One of the first hallmarks of cell death is the externalization of the phospholipid phosphatidylserine (PS). Annexins are calcium and phospholipid binding proteins that belong to an evolutionary well conserved multigene family, with members of the family being expressed throughout animal and plant kingdoms ${ }^{3}$. All annexins bind calcium dependently and reversibly to negatively charged phospholipids thereby regulating membrane-associated processes. This thesis centers around two members of the annexin family, annexin A1 and A5. Annexin A1 (anxA1) is involved in intracellular vesicle trafficking as well as in regulation of neutrophil activity through binding the extracellular domain of members of the formyl peptide receptors (FPR ${ }^{4}$ and is a wellknown anti-inflammatory protein that operates on the glucocorticoid axis. AnxA5 is most famous as (molecular) imaging agent to visualize cell surface expressed PS ${ }^{5}$. The (patho)physiology of anxA5 is less apparent, it is known that anxA5 inhibits the activity of prothrombinase ${ }^{6}$ and is linked to the antiphospholipid syndrome ${ }^{7}$.

This thesis focused on the role of anxA1 and anxA5 in cardiovascular disease. We have investigated the role of endogenous anxA5 in atherogenesis (I). Furthermore we have studied the effect of exogenous anxA1 on atherosclerosis (II) and ischemia-reperfusion injury (III). Additionally, we have investigated the efficacy of low-anticoagulant heparin $(\mathrm{AADH})$ on ischemia-reperfusion injury (IV). Finally, we performed a structural NMR analysis of anxA1 in order to obtain more insight in the structure-function relationship of this protein $(\mathrm{V})$.

The key findings of this thesis are:

(I) Endogenous anxA5 inhibits efferocytosis of apoptotic cells and aggravates plaque development (chapter 3).

(II) Exogenous anxA1 reduces plaque progression and increases plaque stability (chapter 4).

(III) Exogenous anxA1 reduces ischemia-reperfusion injury and improves cardiac function (chapter 5). 
(IV) $\mathrm{AADH}$ reduces ischemia-reperfusion injury without improving cardiac function (chapter 5).

(V) AnxA1 has a single closed conformation with a concealed N-terminal tail in absence of calcium ions; the presence of calcium ions induces a conformational change towards two stable open conformations (chapter 6).

\section{Impaired efferocytosis promotes plaque progression.}

Histological analysis of advanced atherosclerotic lesions demonstrates the presence of large necrotic and acellular regions ${ }^{8}$. Even though necrosis is involved, consensus is that the vast majority of dying cells in the lesion execute apoptosis ${ }^{9}$. This is supported by the detection of terminal deoxynucleotidyl transferase dUTP nick-end labeling (TUNEL) and active caspase-3 in atherosclerotic lesions ${ }^{10}$. Whereas in histological sections of healthy tissues apoptosis is only rarely observed, due to swift clearance mechanisms such as efferocytosis ${ }^{11}$. Several phases of efferocytosis can be distinguished; attraction of phagocytes, recognition, engulfment and post-engulfment responses ${ }^{12}$. Cells executing apoptosis release soluble attractants or "find me" signals to recruit phagocytes. Examples are an ATP gradient and lysophosphatidylcholine (LPC) ${ }^{13}$. After attraction, exposure of PS on the exoplasmic leaflet of the plasma membrane of apoptotic cells is the most prominent "eat me" signal for phagocytes ${ }^{14}$. Therefore, cell surface expressed PS is an ideal target for molecular imaging of vulnerable atherosclerotic plaques (chapter 2). The balance between positive ("eat me") and negative ("don't eat me") signals determine whether efferocytosis is initiated or not ${ }^{11}$. Exposure of PS on the apoptotic cell as well as on the phagocyte is necessary for proper efferocytosis ${ }^{15}$. However, PS by itself does not suffice for adequate efferocytosis; certain bridging molecules facilitate/opsonize the interaction between apoptotic cell and phagocyte ${ }^{16}$. Molecules like complement factor $\mathrm{C} 1 \mathrm{q}$, anxA1, pentraxin and thrombospondin-1 have been shown to opsonize apoptotic cells and facilitate clearance ${ }^{17,18}$. However, the phagocytic function is impaired in atherosclerosis, which results in accumulation of extracellular apoptotic debris and high numbers of apoptotic cells ${ }^{19}$. This impaired phagocytic function is explained by several factors. First there is competition of apoptotic cells and oxidized lipids for phagocytes ${ }^{19}$, ${ }^{20}$. Furthermore, direct oxidative stress and the uptake of oxidized lipids by macrophages leading to foam cell formation, impairs their ability to engulf apoptotic debris ${ }^{12,19}$. 


\section{Efferocytosis as target in atherosclerosis}

The importance of proper efferocytosis is shown by aggravation of atherosclerosis when clearance of apoptotic cells is impaired ${ }^{19}$. Individual deficiency of opsonins such as lactadherin, MERTK or C1q lead to impaired efferocytosis, and thus enhanced accumulation of apoptotic cells and subsequent increased necrotic core and plaque development ${ }^{21-23}$. Therefore, enhancing efferocytosis would be a feasible approach to treat atherosclerosis ${ }^{24}$. This thesis focuses on two less obvious proteins involved in efferocytosis: anxA1 and anxA5. Intraperitoneal injection of anxA5 has shown to reduce plaque formation by suppressing inflammation. This suppression results from the effect of anxA5 on endothelial cells and inhibition of proinflammatory mediators like oxidized cardiolipin and LPC ${ }^{25-28}$. We have shown that anxA5 deficiency results in a significant attenuation of plaque formation (chapter 3). Moreover, plaques had features of a more stable phenotype as deduced from decreased TUNEL positivity and a smaller necrotic core. In order to determine whether this reduced detection of apoptotic cells is a result of anxA5 mediated diminished susceptibility to apoptosis or an increased clearance of apoptotic cells, we have performed additional experiments. We showed that anxA5 deficiency does not result in reduced susceptibility to apoptosis as a result of oxidative stress. In addition, we demonstrated that anxA5 deficient peritoneal macrophages display increased phagocytosis of apoptotic cells. Frey et al. showed that anxA5 deficient macrophages have increased capacity to phagocytose secondary necrotic cells and exhibit an anti-inflammatory cytokine profile ${ }^{29}$. We hypothesized that this anti-inflammatory response could induce a difference in macrophage polarization. Polarization of atherosclerotic macrophages towards an anti-inflammatory phenotype is important for the stability of the lesion ${ }^{30}$. However, we could not confirm that macrophage polarization was affected in the atherosclerotic lesions between anxA5 deficient and wild-type mice. Interestingly, we did find a difference in anxA5 expression of polarized macrophages in vitro. Stimulation of M1 polarized macrophages with LPS caused a significant upregulation of anxA5 promoter activity. We hypothesize that anxA5 exhibits an intracellular function in the regulation or maintenance of macrophage polarization after activation. Our hypothesis is supported by the finding that expression of anxA5 is more pronounced in macrophages located in the center of the lesions or at the edges of the necrotic core of more advanced lesions. Since this location is subjected to high numbers of apoptotic and necrotic cells and thus macrophage activation ${ }^{31}$ it is temping to speculate that this may influence macrophage polarization. However, we did not find a link between anxA5 expression and macrophage polarization in the atherosclerotic lesions. 


\section{Neutrophils as target in atherosclerosis}

Standard treatment of atherosclerosis is lowering LDL cholesterol and triglyceride levels and reducing blood pressure by statins (HMG-CoA reductase inhibitors) and antihypertensive medication, respectively ${ }^{32,33}$. Additional or alternative targets have been subject of intense research, examples are myeloperoxidase (MPO) ${ }^{34}$ and phospholipase A2 (PLA2) ${ }^{35,} 36$. Both PLA2 and MPO are profoundly linked to neutrophils. PLA2 activates neutrophils and MPO is a major part of the neutrophils granule proteins and causes the generation of reactive oxygen species (ROS). The role of neutrophils in atherosclerosis has been subject of serious debate for years, particularly because the detection in atherosclerotic lesions is minute ${ }^{37,38}$. Nevertheless, there is current scientific consensus that neutrophils are involved during all stages of atherosclerotic plaque development ${ }^{37,39}$. AnxA1 is known to exert its anti-inflammatory effect predominantly by direct inhibition of neutrophil activity ${ }^{40}$. Additionally, anxA1 is known to inhibit PLA2 activity ${ }^{17}$. AnxA1 exerts direct anti-inflammatory functions by binding to the receptor for formylated peptides (FPR) on neutrophils and can serve as opsonin by binding PS on the apoptotic cells and bridging them to phagocytes ${ }^{41-43}$. Both routes of action result in an anti-inflammatory response 44-46. Because of these anti-inflammatory properties, we treated atherosclerosis prone mice with endogenous anxA1 and investigated the effect on atherogenesis (chapter 4). We showed that anxA1 treatment reduces total plaque size in $\mathrm{LDLR}^{-/}$mice. Moreover, anxA1 treatment attenuated plaque progression, predominantly in the later stages of plaque development. we hypothesized that these effects are caused by a combination of enhanced opsonization of apoptotic debris and the direct anti-inflammatory effect of anxA1 on neutrophils. Supporting this premise is the significantly smaller necrotic core in anxA1 treated animals. In concordance with previous reports, we observed a relative increase in circulating granulocytes resulting from prolonged anxA1 treatment, without affecting bone marrow composition ${ }^{42}$. The increase in circulating neutrophils is most likely caused by an influx of neutrophils from the margins of the blood vessel rather than reduced apoptosis or increased release from the bone marrow, an effect that has previously been observed after corticosteroid treatment ${ }^{47}$.

\section{Neutrophils as target in ischemia-reperfusion injury}

Restoring myocardial reperfusion after an ischemic attack is essential for cardiac functionality, however may initiate a second phase of myocardial injury called reperfusion injury ${ }^{48}$. Reperfusion injury is predominantly caused by neutrophil derived reactive oxygen species 
(ROS), the excretion of proteases and the production of proinflammatory chemokines and cytokines ${ }^{4851}$. Neutrophil extracellular traps (NETs) are put forward as major contributors of hind-limb reperfusion injury ${ }^{52}$. However, their contribution to reperfusion injury of the heart is hitherto not proven. NETs are composed of a complex network of DNA and proteins such as histones and neutrophil elastase ${ }^{53}$. Histones in particular exhibit cytotoxic activity towards host cells ${ }^{54}$. Because of their strong positive charge, they form an apposite target for treatment with a strong negatively charged moiety like antithrombin affinity depleted heparin $(\mathrm{AADH})$. We treated mice with anxA1 to target neutrophil infiltration and with AADH to neutralize neutrophil derived histones (chapter 5). Since it is known that anxA1 and AADH interact with each other ${ }^{55,56}$, the combination of both was not performed. The capacity of anxA1 to reduce neutrophil influx and activity has already been shown in several animal models of both acute and chronic inflammation ${ }^{57-59}$. Additionaly, anxA1 and the anxA1 N-terminal peptidomimetic (Ac2-26) are able to reduce neutrophil dependent damage to cardiomyocytes within the first few hours of reperfusion ${ }^{60,61}$. We investigated whether anxA1 treatment could reduce cardiomyocyte damage 24 hours after start of reperfusion and subsequently diminish loss of cardiac function. Our results show that treatment with a bolus injection of anxA1 indeed significantly reduced infarcted area at 24 hours of reperfusion. This protective effect was less than seen for data published at 2 hours of reperfusion ${ }^{60}$. Whether multiple injections of anxA1 during the first 24 hours of reperfusion can improve the protective effect needs to be determined. Moreover, we are the first to show that a bolus injection of anxA1 reduces loss of cardiac function after 24 hours of reperfusion treatment, both at baseline and in response to dobutamin stimulation. Interestingly, the amount of infiltrated neutrophils 24 hours after start of reperfusion was equal to untreated controls, suggesting that reduction in damage occurred at an earlier time point. There is evidence that neutrophils are required for anxA1 to be cardioprotective, even if anxA1 does not reduce the influx of neutrophils in the area at risk. However, the exact mechanism remains to be elucidated ${ }^{62}$. Ritchie et al. hypothesized that Ac2-26 has a direct protective effect on cardiomyocytes ${ }^{63}$ and recently proposed that this protective effect is caused by enhanced activation of cardioprotective signaling and/ or improved intracellular calcium re-uptake by the sarcoplasmic reticulum ${ }^{61,63}$. Whether this cardioprotective effect is FPR-mediated is still subject of discussion, since blocking FPR with antagonists partly abolishes the protective effect of anxA1 and its $\mathrm{N}$-terminal peptidomimetic ${ }^{61,64}$ whereas FPR gene deletion does not alter the cardioprotective effect afforded by the $\mathrm{N}$-terminal peptidomimetic ${ }^{62}$. However, it might also be that the improvement we have measured in cardiac function is not merely dependent on 
neutrophils. Nevertheless, our results further support the hypothesis that anxA1 exerts a direct protective effect on cardiomyocytes. In addition to a possible direct protection of anxA1 on the cardiomyocytes, we have investigated whether AADH treatment would reduce histone-mediated cardiomyocyte damage. It has been shown in a murine model of sepsis that neutralizing histones with AADH improves survival by decreasing cytotoxicity ${ }^{53}$. We show that treatment with AADH successfully reduces infarct size, but fails to improve cardiac function. The mechanism of protection by AADH remains to be elucidated, but may be linked to the reduction heart rate, which decreases the cardiac energy requirement and thus oxygen consumption. Since actual damage by neutrophil derived histones may take longer than 24 hours, prolonged treatment with $\mathrm{AADH}$ possibly leads to improved function. This has to be tested in future experiments.

\section{Structural analysis of anxA1}

The structure and availability of cleavage or binding sites is essential for functionality of anxA1. Structural analysis of full-length anxA1 thus far has only been performed using $\mathrm{X}$-ray crystallography ${ }^{65}$. AnxA1 undergoes a conformational change after calcium dependent phospholipid binding, exposing a secondary membrane binding site ${ }^{3,66}$. This secondary binding site consists of 4 consecutive amino acids and form the basis for the interaction between anxA1 and FPR ${ }^{67}$. Although structural nuclear magnetic resonance (NMR) studies on anxA1 were initiated over 2 decades ago ${ }^{68}$, thus far only the first domain has been defined ${ }^{69}$. This NMR analysis was performed on double isotopically labeled isolated anxA1 domain 1. We have produced full-length AnxA1 protein triple isotopically labeled and focused on the $\mathrm{N}$-terminal domain (chapter 6). We show that anxA1 has a single closed conformation in the absence of calcium, but has two stable open conformations in the presence of calcium, in a 2:1 ratio. Even in the absence of a phospholipid membrane there is motion of the AnxA1 N-terminus, suggesting that the interaction with the FPR might be possible even without a phospholipid surface. Currently we are further defining the structure and conformation in presence and absence of phospholipid vesicles and with or without competition of the $\mathrm{N}$-terminal peptidomimetic Ac2-26. Future research includes NMR measurements in the presence of FPR-transfected cells in order to advance knowledge on the interaction between anxA1 and FPR. 


\section{Clinical implications and future perspectives}

Basic medical science aims to elucidate novel molecular pathways or targets to reveal innovative treatments. The search for innovative theranostics and personalized medicine will continue in decades to come. Our research on the role of anxA1 and anxA5 in cardiovascular disease has identified novel targets for development of innovative new medication. The immune system is key in many diseases involving injury/wounding, infection, transplantation and auto-immunity. Efferocytosis is unequivocally linked to the immune system, and we show important roles for annexins. AnxA5 exhibits inhibitory whereas anxA1 has stimulatory properties. Further research should identify whether administration of anxA5 or stimulation of anxA5 gene activity is a target in e.g. graftversus-host immune responses in order to reduce organ rejection after transplantation. Alternatively, inhibition of anxA5 activity by e.g. morpholinos potentially forms a target for chronic inflammatory diseases like rheumatoid arthritis or lupus erythematosus. For anxA1 similar treatment avenues are paved. Our research has led to the large-scale production and augmentation of anxA1, which offers a great opportunity to test and further expand this research both in vitro and in vivo. 


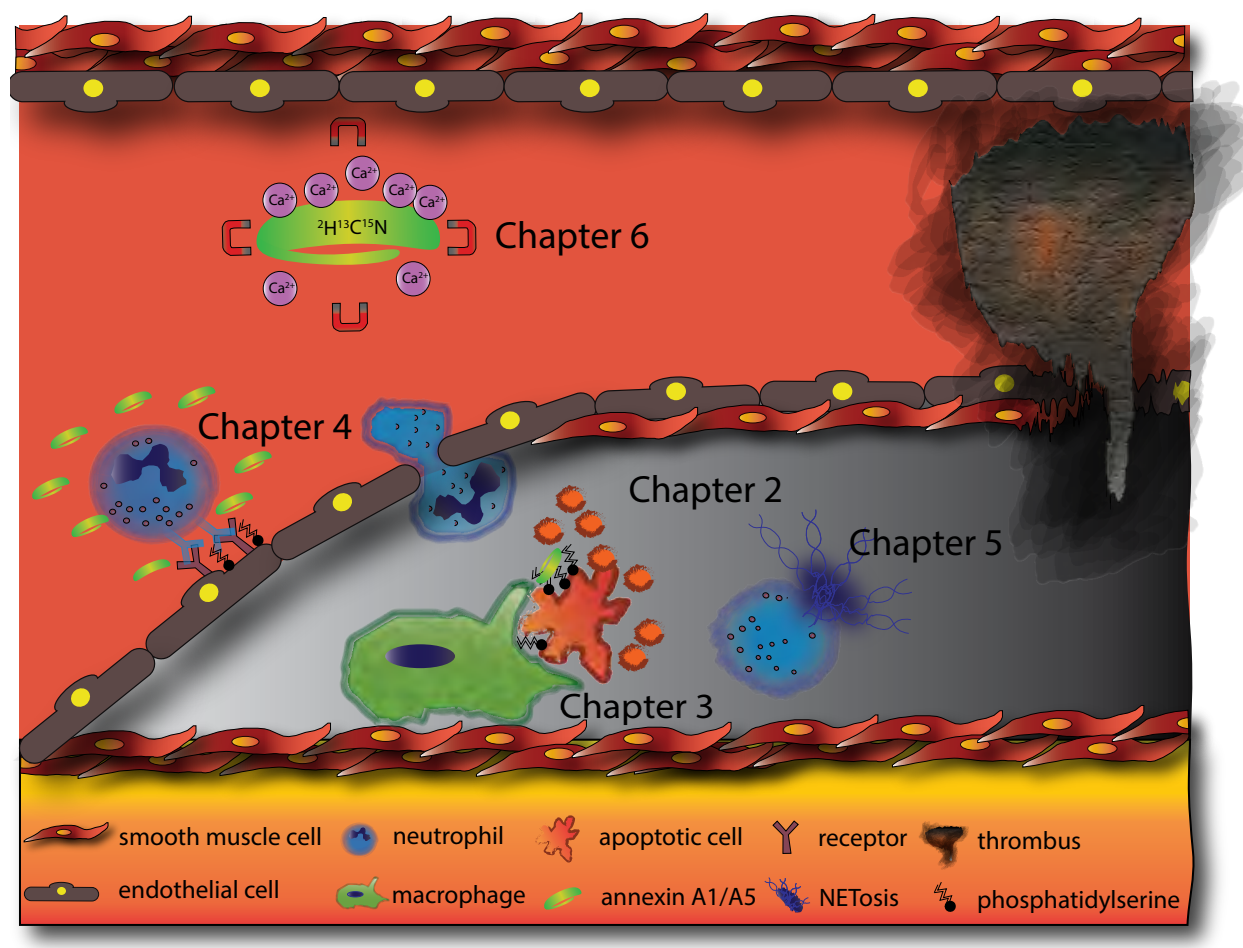

Figure 1 - overview of the research chapters in this thesis. After an introductory chapter, current molecular imaging modalities of the vulnerable plaque are evaluated in chapter 2 . One of the targets for molecular imaging is phosphatidylserine (PS) imaging with annexin A5 (anxA5). The role of endogenous anxA5 in the development of atherosclerosis is subject of chapter 3 . The role of anxA5 in the process of efferocytosis is emphasized. Another member of the annexin family, annexin A1 (anxA1), is known to have potnent anti-inflammatory properties. Treatment of atherosclerosis prone mice with anxA1 is the subject of chapter 4. Without treatment, plaque progression continues and may lead to plaque rupture over time. This rupture causes occlusion of a blood vessel, which in turn causes ischemia to downstream tissue. Chapter $\mathbf{5}$ discusses treatment of ischemia-reperfusion injury of the heart by inhibition of neutrophil infiltration and neutrophil extracellular trap (NET) formation. Finally, nuclear magnetic resonance analysis of isotopically labeled anxA1 is discussed in chapter $\mathbf{6}$. 


\section{References}

1. Kusters DH, Tegtmeier J, Schurgers LJ, Reutelingsperger CP. Molecular imaging to identify the vulnerable plaque--from basic research to clinical practice. Mol Imaging Biol. 2012;14:523-533.

2. Borissoff JI, Spronk HM, ten Cate H. The hemostatic system as a modulator of atherosclerosis. $N$ Engl J Med. 2011;364:1746-1760.

3. Gerke V, Moss SE. Annexins: from structure to function. Physiol Rev. 2002;82:331-371.

4. Perretti M. The annexin 1 receptor(s): is the plot unravelling? Trends Pharmacol Sci. 2003;24:574-579.

5. Kietselaer BL, Reutelingsperger CP, Heidendal GA, Daemen MJ, Mess WH, Hofstra L, Narula J. Noninvasive detection of plaque instability with use of radiolabeled annexin A5 in patients with carotid-artery atherosclerosis. N Engl J Med. 2004;350:1472-1473.

6. Andree HA, Stuart MC, Hermens WT, Reutelingsperger CP, Hemker HC, Frederik PM, Willems GM. Clustering of lipid-bound annexin V may explain its anticoagulant effect. $J$ Biol Chem. 1992;267:17907-17912.

7. Rand JH, Wu XX, Quinn AS, Taatjes DJ. The annexin A5-mediated pathogenic mechanism in the antiphospholipid syndrome: role in pregnancy losses and thrombosis. Lupus. 2010;19:460-469.

8. Virmani R, Kolodgie FD, Burke AP, Farb A, Schwartz SM. Lessons from sudden coronary death: a comprehensive morphological classification scheme for atherosclerotic lesions. Arterioscler Thromb Vasc Biol. 2000;20:1262-1275.

9. Kolodgie FD, Narula J, Guillo P, Virmani R. Apoptosis in human atherosclerotic plaques. Apoptosis. 1999;4:5-10.

10. Mallat Z, Tedgui A. Apoptosis in the vasculature: mechanisms and functional importance. $\mathrm{Br} \mathrm{J}$ Pharmacol. 2000;130:947-962.

11. Ravichandran KS, Lorenz U. Engulfment of apoptotic cells: signals for a good meal. Nat Rev Immunol. 2007;7:964-974.

12. Van Vre EA, Ait-Oufella H, Tedgui A, Mallat Z. Apoptotic cell death and efferocytosis in atherosclerosis. Arterioscler Thromb Vasc Biol. 2012;32:887-893.

13. Peter C, Wesselborg S, Herrmann M, Lauber K. Dangerous attraction: phagocyte recruitment and danger signals of apoptotic and necrotic cells. Apoptosis. 2010;15:1007-1028.

14. Schutters K, Kusters DH, Chatrou ML, Montero-Melendez T, Donners M, Deckers NM, Krysko DV, Vandenabeele P, Perretti M, Schurgers LJ, Reutelingsperger CP. Cell surface-expressed phosphatidylserine as therapeutic target to enhance phagocytosis of apoptotic cells. Cell Death Differ. 2013;20:49-56.

15. Callahan MK, Williamson P, Schlegel RA. Surface expression of phosphatidylserine on macrophages is required for phagocytosis of apoptotic thymocytes. Cell Death Differ. 2000;7:645-653.

16. Segawa K, Suzuki J, Nagata S. Constitutive exposure of phosphatidylserine on viable cells. Proc Natl Acad Sci U S A. 2011;108:19246-19251.

17. Perretti M, D'Acquisto F. Annexin A1 and glucocorticoids as effectors of the resolution of inflammation. Nat Rev Immunol. 2009;9:62-70.

18. Poon IK, Hulett MD, Parish CR. Molecular mechanisms of late apoptotic/necrotic cell clearance. Cell Death Differ. 2010;17:381-397.

19. Schrijvers DM, De Meyer GR, Kockx MM, Herman AG, Martinet W. Phagocytosis of apoptotic cells by macrophages is impaired in atherosclerosis. Arterioscler Thromb Vasc Biol. 2005;25:1256-1261.

20. Chang MK, Bergmark C, Laurila A, Horkko S, Han KH, Friedman P, Dennis EA, Witztum JL. Monoclonal antibodies against oxidized low-density lipoprotein bind to apoptotic cells and inhibit their phagocytosis by elicited macrophages: evidence that oxidation-specific epitopes mediate macrophage recognition. Proc Natl Acad Sci US A. 1999;96:6353-6358. 
21. Ait-Oufella H, Kinugawa K, Zoll J, Simon T, Boddaert J, Heeneman S, Blanc-Brude O, Barateau V, Potteaux S, Merval R, Esposito B, Teissier E, Daemen MJ, Leseche G, Boulanger C, Tedgui A, Mallat Z. Lactadherin deficiency leads to apoptotic cell accumulation and accelerated atherosclerosis in mice. Circulation. 2007;115:2168-2177.

22. Thorp E, Cui D, Schrijvers DM, Kuriakose G, Tabas I. Mertk receptor mutation reduces efferocytosis efficiency and promotes apoptotic cell accumulation and plaque necrosis in atherosclerotic lesions of apoe-/- mice. Arterioscler Thromb Vasc Biol. 2008;28:1421-1428.

23. Bhatia VK, Yun S, Leung V, Grimsditch DC, Benson GM, Botto MB, Boyle JJ, Haskard DO. Complement $\mathrm{C} 1 \mathrm{q}$ reduces early atherosclerosis in low-density lipoprotein receptor-deficient mice. Am J Pathol. 2007;170:416-426.

24. Thorp E, Tabas I. Mechanisms and consequences of efferocytosis in advanced atherosclerosis. J Leukoc Biol. 2009;86:1089-1095.

25. Ewing MM, de Vries MR, Nordzell M, Pettersson K, de Boer HC, van Zonneveld AJ, Frostegard J, Jukema JW, Quax PH. Annexin A5 therapy attenuates vascular inflammation and remodeling and improves endothelial function in mice. Arterioscler Thromb Vasc Biol. 2011;31:95-101.

26. Ewing MM, Karper JC, Sampietro ML, de Vries MR, Pettersson K, Jukema JW, Quax PH. Annexin A5 prevents post-interventional accelerated atherosclerosis development in a dose-dependent fashion in mice. Atherosclerosis. 2012;221:333-340.

27. Domeij H, Hua X, Su J, Backlund A, Yan Z, Frostegard AG, Haeggstrom JZ, Modeer T, Frostegard J. Annexin A5 inhibits atherogenic and pro-inflammatory effects of lysophosphatidylcholine. Prostaglandins Other Lipid Mediat. 2013;106:72-78.

28. Wan M, Hua X, Su J, Thiagarajan D, Frostegard AG, Haeggstrom JZ, Frostegard J. Oxidized but not native cardiolipin has pro-inflammatory effects, which are inhibited by Annexin A5. Atherosclerosis. 2014;235:592-598.

29. Frey B, Munoz LE, Pausch F, Sieber R, Franz S, Brachvogel B, Poschl E, Schneider H, Rodel F, Sauer R, Fietkau R, Herrmann M, Gaipl US. The immune reaction against allogeneic necrotic cells is reduced in Annexin A5 knock out mice whose macrophages display an anti-inflammatory phenotype. J Cell Mol Med. 2009;13:1391-1399.

30. Mantovani A, Garlanda C, Locati M. Macrophage diversity and polarization in atherosclerosis: a question of balance. Arterioscler Thromb Vasc Biol. 2009;29:1419-1423.

31. Marsch E, Sluimer JC, Daemen MJ. Hypoxia in atherosclerosis and inflammation. Curr Opin Lipidol. 2013;24:393-400.

32. Nissen SE, Tuzcu EM, Libby P, Thompson PD, Ghali M, Garza D, Berman L, Shi H, Buebendorf E, Topol EJ. Effect of antihypertensive agents on cardiovascular events in patients with coronary disease and normal blood pressure: the CAMELOT study: a randomized controlled trial. JAMA. 2004;292:2217-2225.

33. Cannon CP, Steinberg BA, Murphy SA, Mega JL, Braunwald E. Meta-analysis of cardiovascular outcomes trials comparing intensive versus moderate statin therapy. J Am Coll Cardiol. 2006;48:438-445.

34. Schindhelm RK, van der Zwan LP, Teerlink T, Scheffer PG. Myeloperoxidase: a useful biomarker for cardiovascular disease risk stratification? Clin Chem. 2009;55:1462-1470.

35. Wilensky RL, Shi Y, Mohler ER, 3rd, Hamamdzic D, Burgert ME, Li J, Postle A, Fenning RS, Bollinger JG, Hoffman BE, Pelchovitz DJ, Yang J, Mirabile RC, Webb CL, Zhang L, Zhang P, Gelb $\mathrm{MH}$, Walker MC, Zalewski A, Macphee CH. Inhibition of lipoprotein-associated phospholipase A2 reduces complex coronary atherosclerotic plaque development. Nat Med. 2008;14:1059-1066. 
36. Serruys PW, Garcia-Garcia HM, Buszman P, Erne P, Verheye S, Aschermann M, Duckers H, Bleie O, Dudek D, Botker HE, von Birgelen C, D’Amico D, Hutchinson T, Zambanini A, Mastik F, van Es GA, van der Steen AF, Vince DG, Ganz P, Hamm CW, Wijns W, Zalewski A. Effects of the direct lipoprotein-associated phospholipase A(2) inhibitor darapladib on human coronary atherosclerotic plaque. Circulation. 2008;118:1172-1182.

37. Soehnlein O. Multiple roles for neutrophils in atherosclerosis. Circ Res. 2012;110:875-888.

38. Drechsler M, Doring Y, Megens RT, Soehnlein O. Neutrophilic granulocytes - promiscuous accelerators of atherosclerosis. Thromb Haemost. 2011;106:839-848.

39. Doring Y, Drechsler M, Soehnlein O, Weber C. Neutrophils in Atherosclerosis: From Mice to Man. Arterioscler Thromb Vasc Biol. 2014.

40. Perretti M, Flower RJ. Annexin 1 and the biology of the neutrophil. J Leukoc Biol. 2004;76:25-29.

41. Lim LH, Solito E, Russo-Marie F, Flower RJ, Perretti M. Promoting detachment of neutrophils adherent to murine postcapillary venules to control inflammation: effect of lipocortin 1. Proc Natl Acad Sci U S A. 1998;95:14535-14539.

42. Walther A, Riehemann K, Gerke V. A novel ligand of the formyl peptide receptor: annexin I regulates neutrophil extravasation by interacting with the FPR. Mol Cell. 2000;5:831-840.

43. Bena S, Brancaleone V, Wang JM, Perretti M, Flower RJ. Annexin A1 interaction with the FPR2/ ALX receptor: identification of distinct domains and downstream associated signaling. J Biol Chem. 2012;287:24690-24697.

44. Dalli J, Consalvo AP, Ray V, Di Filippo C, D’Amico M, Mehta N, Perretti M. Proresolving and tissueprotective actions of annexin A1-based cleavage-resistant peptides are mediated by formyl peptide receptor 2/lipoxin A4 receptor. J Immunol. 2013;190:6478-6487.

45. Hayhoe RP, Kamal AM, Solito E, Flower RJ, Cooper D, Perretti M. Annexin 1 and its bioactive peptide inhibit neutrophil-endothelium interactions under flow: indication of distinct receptor involvement. Blood. 2006;107:2123-2130.

46. Vago JP, Nogueira CR, Tavares LP, Soriani FM, Lopes F, Russo RC, Pinho V, Teixeira MM, Sousa LP. Annexin A1 modulates natural and glucocorticoid-induced resolution of inflammation by enhancing neutrophil apoptosis. J Leukoc Biol. 2012;92:249-258.

47. Nakagawa M, Terashima T, D’Yachkova Y, Bondy GP, Hogg JC, van Eeden SF. Glucocorticoid-induced granulocytosis: contribution of marrow release and demargination of intravascular granulocytes. Circulation. 1998;98:2307-2313.

48. Kaminski KA, Bonda TA, Korecki J, Musial WJ. Oxidative stress and neutrophil activation--the two keystones of ischemia/reperfusion injury. Int J Cardiol. 2002;86:41-59.

49. Smith EF, 3rd, Egan JW, Bugelski PJ, Hillegass LM, Hill DE, Griswold DE. Temporal relation between neutrophil accumulation and myocardial reperfusion injury. Am J Physiol. 1988;255:H1060-1068.

50. Jordan JE, Zhao ZQ, Vinten-Johansen J. The role of neutrophils in myocardial ischemia-reperfusion injury. Cardiovasc Res. 1999;43:860-878.

51. Carbone F, Nencioni A, Mach F, Vuilleumier N, Montecucco F. Pathophysiological role of neutrophils in acute myocardial infarction. Thromb Haemost. 2013;110:501-514.

52. Oklu R, Albadawi H, Jones JE, Yoo HJ, Watkins MT. Reduced hind limb ischemia-reperfusion injury in Toll-like receptor-4 mutant mice is associated with decreased neutrophil extracellular traps. $J$ Vasc Surg. 2013;58:1627-1636.

53. Wildhagen KC, Garcia de Frutos P, Reutelingsperger CP, Schrijver R, Areste C, Ortega-Gomez A, Deckers NM, Hemker HC, Soehnlein O, Nicolaes GA. Nonanticoagulant heparin prevents histonemediated cytotoxicity in vitro and improves survival in sepsis. Blood. 2014;123:1098-1101. 
54. Saffarzadeh M, Juenemann C, Queisser MA, Lochnit G, Barreto G, Galuska SP, Lohmeyer J, Preissner KT. Neutrophil extracellular traps directly induce epithelial and endothelial cell death: a predominant role of histones. PLoS One. 2012;7:e32366.

55. Alvarez-Martinez MT, Mani JC, Porte F, Faivre-Sarrailh C, Liautard JP, Sri Widada J. Characterization of the interaction between annexin I and profilin. Eur J Biochem. 1996;238:777-784.

56. Horlacher T, Noti C, de Paz JL, Bindschadler P, Hecht ML, Smith DF, Fukuda MN, Seeberger $\mathrm{PH}$. Characterization of annexin A1 glycan binding reveals binding to highly sulfated glycans with preference for highly sulfated heparan sulfate and heparin. Biochemistry. 2011;50:2650-2659.

57. Girol AP, Mimura KK, Drewes CC, Bolonheis SM, Solito E, Farsky SH, Gil CD, Oliani SM. Antiinflammatory mechanisms of the annexin A1 protein and its mimetic peptide Ac2-26 in models of ocular inflammation in vivo and in vitro. J Immunol. 2013;190:5689-5701.

58. Leoni G, Alam A, Neumann PA, Lambeth JD, Cheng G, McCoy J, Hilgarth RS, Kundu K, Murthy N, Kusters D, Reutelingsperger C, Perretti M, Parkos CA, Neish AS, Nusrat A. Annexin A1, formyl peptide receptor, and NOX1 orchestrate epithelial repair. J Clin Invest. 2013;123:443-454.

59. Locatelli I, Sutti S, Jindal A, Vacchiano M, Bozzola C, Reutelingsperger C, Kusters D, Bena S, Parola M, Paternostro C, Bugianesi E, McArthur S, Albano E, Perretti M. Endogenous annexin A1 IS a novel protective determinant in nonalcoholic steatohepatitis (NASH). Hepatology. 2014.

60. D’Amico M, Di Filippo C, La M, Solito E, McLean PG, Flower RJ, Oliani SM, Perretti M. Lipocortin 1 reduces myocardial ischemia-reperfusion injury by affecting local leukocyte recruitment. FASEB J. 2000;14:1867-1869.

61. Qin C, Buxton KD, Pepe S, Cao AH, Venardos K, Love JE, Kaye DM, Yang YH, Morand EF, Ritchie $\mathrm{RH}$. Reperfusion-induced myocardial dysfunction is prevented by endogenous annexin-A1 and its N-terminal-derived peptide Ac-ANX-A1(2-26). Br J Pharmacol. 2013;168:238-252.

62. Gavins FN, Kamal AM, D'Amico M, Oliani SM, Perretti M. Formyl-peptide receptor is not involved in the protection afforded by annexin 1 in murine acute myocardial infarct. FASEB J. 2005;19:100-102.

63. Ritchie RH, Gordon JM, Woodman OL, Cao AH, Dusting GJ. Annexin-1 peptide Anx-1(2-26) protects adult rat cardiac myocytes from cellular injury induced by simulated ischaemia. BrJ Pharmacol. 2005; 145:495-502.

64. Gavins FN, Yona S, Kamal AM, Flower RJ, Perretti M. Leukocyte antiadhesive actions of annexin 1: ALXR- and FPR-related anti-inflammatory mechanisms. Blood. 2003;101:4140-4147.

65. Rosengarth A, Gerke V, Luecke H. X-ray structure of full-length annexin 1 and implications for membrane aggregation. J Mol Biol. 2001;306:489-498.

66. de la Fuente M, Ossa CG. Binding to phosphatidyl serine membranes causes a conformational change in the concave face of annexin I. Biophys J. 1997;72:383-387.

67. Movitz C, Brive L, Hellstrand K, Rabiet MJ, Dahlgren C. The annexin I sequence gln(9)-ala(10)$\operatorname{trp}(11)$-phe(12) is a core structure for interaction with the formyl peptide receptor 1. J Biol Chem. 2010;285:14338-14345.

68. Weng X, Luecke H, Song IS, Kang DS, Kim SH, Huber R. Crystal structure of human annexin I at 2.5 A resolution. Protein Sci. 1993;2:448-458.

69. Gao J, Li Y, Yan H. NMR solution structure of domain 1 of human annexin I shows an autonomous folding unit. J Biol Chem. 1999;274:2971-2977. 
Chapter 7 
Addendum I

Summary 


\section{Summary}

In this thesis main focus was on the role of annexin $\mathrm{A} 1$ (anxA1) and annexin A5 (anxA5) in cardiovascular disease with emphasis on atherosclerosis and ischemia-reperfusion injury. Chapter 1 highlights the importance of cardiovascular disease and potential roles that anxA1 and anxA5 may have herein. Atherosclerosis is initiated by dysfunctional endothelial cells and consequent leakage of plasma low density lipoprotein (LDL cholesterol) into the tunica intima of arteries. Oxidation of LDL activates endothelial cells and subsequently leads to the recruitment of inflammatory cells in an attempt to remove the cholesterol. Migration of monocytes into the tunica intima and subsequent differentiation into macrophages initializes the inflammatory response. Excessive uptake and accumulation of cholesterol in combination with ineffective secretion will lead to the formation of 'foamy' cells that lose the ability to egress from the plaque and eventually will die. The build-up of apoptotic/necrotic cells in combination with the inflammatory status of the plaque is a very good predictor of plaque vulnerability and can therefore form a target for molecular imaging as discussed in chapter 2 .

Viable cells retain a phospholipid asymmetry in which they confine their phosphatidylserine (PS) predominantly to the inner leaflet of the plasma membrane. Externalization of PS is one of the first hallmarks of stressed and dying cells. The two most important ways that cells can die are apoptosis and necrosis. Apoptosis is programmed and anti-inflammatory while necrosis is accidental and proinflammatory. Both during apoptosis and necrosis PS exposure serves as the most pronounced pro-phagocytotic 'eat-me' signal. AnxA5 binds with high affinity to PS thereby inhibiting phagocytosis, either simply by shielding PS from the phagocyte or even complete internalization of PS. In chapter 3 we report the impact of anxA5 depletion on atherosclerotic plaque development and progression. We found that anxA5 deficient macrophages display increased phagocytotic activity and in this way decrease plaque formation. Moreover, plaques of the anxA5 mice had less apoptotic cells and no significant necrotic core development. This finding was not caused by a difference in cell viability, but rather a difference in cell clearance. The decrease in plaque development was more pronounced in the aortic arch than in the brachiocephalic artery, possibly due to a difference in developmental speed and/or different developmental origin of the vascular cells.

The previous chapter underlines the importance of proper efferocytosis in atherosclerotic 
plaque development, so we decided to use this property in the next chapter. AnxA1 is known to be an opsonin of apoptotic cells and to facilitate phagocytosis thereby inducing an anti-inflammatory response. In addition to the opsonization, anxA1 can directly affect leukocytes by outside-in signaling through the receptor for formylated peptides (FPR). Treatment of atherosclerosis prone mice with anxA1 is the main focus of chapter 4 . We found that administration of anxA1 inhibits plaque growth and improves plaque stability. Treatment with anxA1 decreased necrotic core growth by inhibiting recruitment of neutrophils towards the plaque and/or by increasing phagocytosis of dying and dead cells.

Eventually, vulnerable plaques may rupture and release their prothrombotic content leading to thrombus formation. Occlusion of an artery by this thrombus causes ischemia and subsequent cell death. Surrounding tissue senses the ischemic damage and activates the immune system. Like in normal wound healing, neutrophils are the first cells to respond and migrate towards the infarcted area. In a complex cascade of events, neutrophils release reactive oxygen species (ROS), proinflammatory cytokines and chemokines and neutrophil extracellular traps (NETs). This results in reperfusion injury and causes enhanced cell death. The potential to intervene with neutrophil recruitment and activity using anxA1 and antithrombin affinity depleted heparin (AADH) is investigated in Chapter 5. AnxA1 and $\mathrm{AADH}$ were successful to reduce the infarct size and attain a trend towards increased functionality. This result may be neutrophil independent, since the amount of infiltrated neutrophils was unaffected after 24 hours of reperfusion.

In order to further increase the anti-inflammatory potential of anxA1, more knowledge about the exact modus operandi is needed. Structural studies using nuclear magnetic resonance (NMR) analysis with isotopically labeled proteins provides information about the orientation and behavioral properties of the protein in several (sub)physiological conditions. Chapter $\mathbf{6}$ describes different conformations of anxA1 in the presence or absence of calcium and a phospholipid surface. While anxA1 has three 'closed' conformations in the absence of calcium, the addition of calcium changes the conformation towards a single stable 'open' conformation. This knowledge may lead to the design of augmented forms of anxA1 that possess increased functionality.

Finally, chapter 7 discusses the key findings of this thesis and highlights the possible clinical significance in relation to current literature, Addendum I and II summarize the thesis in english and dutch and Addendum III reports a short valorization. 
Addendum I 
Addendum II

Nederlandse samenvatting 


\section{Samenvatting}

In dit proefschrift ligt de focus op de rol van annexine A1 (anxA1) en annexine A5 (anxA5) in hart- en vaatziekten en met nadruk op atherosclerose en ischemie-reperfusie schade. Hoofdstuk 1 toont het belang aan van het onderzoek en geeft algemene uitleg over hart- en vaatziekten en speculeert over de mogelijke bijdrage die deze annexines hierin hebben. Atherosclerose wordt geïnitieerd door slecht functionerende endotheelcellen, wat als gevolg heeft dat er lekkage optreedt van plasma 'lage dichtheid lipoproteïne cholesterol' (LDL cholesterol) in de tunica intima van de slagaders. Een oxidatie reactie van dit LDL activeert endotheelcellen, die er vervolgens voor zorgen dat ontstekingscellen worden aangetrokken in een poging om het geoxideerd LDL te verwijderen. Migratie van monocyten en de daaropvolgende specialisatie tot macrofagen is het begin van de ontstekingsreactie. Overmatige opname van cholesterol in combinatie met ineffectief uitscheiden leidt tot intracellulaire accumulatie en de vorming van zogenaamde 'schuim' cellen. Deze cellen verliezen het vermogen om uit de plaque te migreren en zullen hier uiteindelijk doodgaan. De opstapeling van deze dode cellen in combinatie met de ontstekingsreactie in de plaque is een zeer goede voorspeller van de kwetsbaarheid van een plaque en vormt daardoor een perfect doel voor moleculaire beeldvorming, zoals besproken wordt in hoofdstuk 2 .

Levende cellen zorgen voor een asymmetrie van de membraan fosfolipiden, met het fosfolipide fosfatidylserine (PS) voornamelijk gelokaliseerd aan de binnenzijde. Het naar buiten transporteren van PS is een van de eerste kenmerken van cellen die stress ervaren en van cellen die doodgaan. De twee belangrijkste manieren van celdood zijn apoptose en necrose. Hierbij is het verschil dat apoptose geprogrammeerd en ontstekingsremmend is, terwijl necrose ongepland is en ontsteking opwekt. Zowel bij apoptose als necrose is PS beschikbaar en vormt daarmee het meest bekende 'eet-mij' signaal voor fagocyten. Het eiwit anxA5 bindt met hoge affiniteit aan PS en remt hiermee de opruiming van deze cellen. Enerzijds door simpelweg PS af te schermen voor de fagocyt, anderzijds door de PS terug naar de binnenkant van de cel te transporteren. In hoofdstuk 3 beschrijven we de functie van anxA5-depletie op het ontstaan en de ontwikkeling van atherosclerotische plaques in een muismodel voor atherosclerose. We laten zien dat anxA5 deficiënte macrofagen een verhoogde fagocytose vertonen en op die manier atherosclerose afremmen. Bovendien hadden de plaques van de anxA5 deficiënte muizen minder apoptotische cellen en geen grote necrotische kern ontwikkeld. We hebben aangetoond dat dit resultaat niet werd 
veroorzaakt door een verschil in verminderde gevoeligheid voor apoptose, maar door een verschil in verbeterde opruiming van apoptotische cellen door de fagocyten. De afname van plaque ontwikkeling was meer uitgesproken in de aortaboog in vergelijking met de eerste aftakking (de truncus brachiocephalicus), wat mogelijk een gevolg is van een verschillende snelheid van ontwikkeling en/of een verschillende embryonale oorsprong van de vasculaire cellen.

In het vorige hoofdstuk is het belang van goede efferocytosis met betrekking tot atherosclerotische plaque ontwikkeling benadrukt. We hebben besloten om deze eigenschap te gebruiken in het volgende hoofdstuk. AnxA1 speelt een belangrijke stimulerende rol bij het opruimen van apoptotische cellen en wekt daarbij een ontstekingsremmende respons op. Hiernaast kan anxA1 ook direct invloed uitoefenen op witte bloedcellen door zogenaamde "outside-in" signalering via de receptor voor geformyleerde peptiden (FPR). De behandeling met anxA1 van muizen die vatbaar zijn voor atherosclerose is het onderwerp van hoofdstuk 4. We laten zien dat toediening van anxA1 de plaque groei remt en de stabiliteit verbetert. Behandeling met anxA1 resulteert bovendien in verminderde groei van de necrotische kern. Enerzijds komt dit door directe remming van neutrofiel infiltratie in de plaque en anderzijds door het verbeteren van de fagocytose van apoptotische en necrotische cellen.

Uiteindelijk kunnen plaques scheuren waarbij de stollingsgevoelige inhoud vrij komt en tot de vorming van een trombus leidt. Verstopping van een bloedvat door dit stolsel zorgt voor zuurstoftekort in het onderliggende weefsel met uiteindelijk celdood tot gevolg. Omliggend weefsel neemt deze celdood waar en activeert het immuunsysteem. Evenals bij normale wondgenezing zijn de neutrofielen de eerste cellen die reageren en migreren naar het infarctgebied. Door middel van een complexe cascade zorgen neutrofielen voor de uitstoot van reactieve zuurstofradicalen (ROS), pro-inflammatoire cytokines en chemokines en neutrofiel extracellulaire vallen (NETs). De combinatie van voorgaande factoren zorgt voor de zogenaamde reperfusie schade en verergert de initiële schade veroorzaakt door het zuurstoftekort. Behandeling met anxA1 en een aangepaste vorm van heparine $(\mathrm{AADH})$ is onderzocht in hoofdstuk 5. Deze behandelingen zijn gericht om de neutrofiel infiltratie en toxiciteit te verminderen. AnxA1 en AADH zorgen voor vermindering van infarctgrootte en neigen beide de functionaliteit van het hart te verbeteren. Dit resultaat is waarschijnlijk neutrofiel onafhankelijk, aangezien de hoeveelheid geïnfiltreerde neutrofielen na 24 uur reperfusie overanderd is. 
Om de ontstekingsremmende activiteit van anxA1 te verhogen is meer kennis nodig over de modus operandi. Structurele studies door middel van nucleaire magnetische resonantie (NMR) geven informatie over de oriëntatie/conformatie en fysische eigenschappen van eiwitten in verschillende (sub)fysiologische condities. Hoofdstuk $\mathbf{6}$ beschrijft de verschillende conformaties van anxA1 in aan- en afwezigheid van calcium en een oppervlak van fosfolipiden. Hoewel anxA1 drie verschillende "gesloten" conformaties heeft in afwezigheid van calcium, zorgt toevoeging van calcium ervoor dat deze verandert naar één enkele stabiele 'open' conformatie. Deze kennis kan leiden tot het ontwerp van aangepaste vormen van anxA1 die ervoor zorgen dat de ontstekingsremmende functionaliteit van het eiwit toeneemt.

Tot slot bediscussieert hoofdstuk 7 de belangrijkste bevindingen van dit proefschrift en wijst op mogelijke klinische relevantie in relatie tot de huidige literatuur. Addendum I en II geven een Engelse en Nederlandse samenvatting en Addendum III vermeldt kort een valorisatie van het onderzoek. 


\section{Addendum III}

Valorization of this thesis 
Valorization, to assign a value to this thesis is challenging. Knowledge valorization refers to "the process of crafting value from knowledge", by making knowledge suitable or available for social and/or economic use. This definition expects 'value' to be expressed as a direct impact on society or to be conveyed to a currency.

In my humble opinion, the primary drive for research should be curiosity rather than currency. This curiosity may or may not lead to economic gain, but should foremost expand scientific knowledge. Since we are part of a knowledge-based economy in which tax money and charities contribute to perform science, society should benefit from research one way or another. Increasing knowledge by itself does not directly impact society, but has major influence on future innovations. The principal objective of this thesis was to improve insights in the role of annexin A1 (anxA1) and annexin A5 (anxA5) in cardiovascular disease (CVD), which is the leading cause of death in the developed or in other words "wealthy" countries. It is therefore tempting to suggest that there must be both monetary and social 'value' somehow. For more information about the socioeconomic impact that molecular imaging of CVD has, I would like to refer to the final part of chapter 2 . The valorization of my thesis will focus on chapters 3 to 6 , which contain the actual experimental research.

Chapter 3 elaborates on the role of endogenous anxA5 in atherosclerosis and identified that anxA5 is involved in the clearance of death cells and therefore comprises a potential target for treatment. AnxA5 is a proven and widely used agent for in vitro and in vivo imaging of apoptosis, and forms the founding upon which MosaMedix BV and PharmaTarget BV are build. These companies offer jobs which is presently not a unnecessary luxury. Besides offering employment, the products improve diagnosis and treatment of disease. On Short-term, there is no economic or social value in this chapter. Additional research is needed to transform this target into actual therapy, but one could imagine anxA5 as target for mild inflammatory disorders, as is discussed in the clinical relevance part of the general discussion of this thesis.

Chapter $\mathbf{4}$ and chapter $\mathbf{5}$ investigate a potential therapeutic role of anxA1. We are the first and only group to produce this anti-inflammatory mature protein in sufficient amounts to test and validate efficacy in large-scale in vivo experiments. These results show great potential for anxA1 in treatment of inflammation related diseases and future research should elucidate whether anxA1 is a valuable addition to existing therapies. To 
express the scientific findings of these chapters in monetary value; the price of purified human recombinant anxA1 from Abcam is just below $€ 1500$ for $100 \mu \mathrm{g}$ of protein. We are able to produce a small multiple of this amount with relatively minute costs in commodities and labor. Based on published data and personal correspondence we have equal or better purity, stability and efficacy. In addition to anxA1, we have used a very innovative approach to reduce the damage of neutrophils. In addition, we have generated a novel form of heparin without anticoagulant activity. This therapy aims to reduce the cytotoxicity of neutrophils based on its negative charge, and has already proven efficacy very recently in an animal model of sepsis. This new form of heparin is patented for the treatment of sepsis and would be the only known effective therapy for sepsis for the first 24 critical hours. Additional research is currently carried out to confirm efficacy and test potential use in the clinic. A new company is currently arising from the patent assigned to the new heparin.

Chapter $\mathbf{6}$ focused on structural analysis of anxA1. Increasing the knowledge about structural properties of a protein paves avenues for augmentation in order to increase functionality. We have produced the protein triple isotopically labeled and analyzed the structure by nuclear magnetic resonance. In addition to novel structural insights of anxA1, the primary value of this chapter is the optimized strategy for the production of this protein. This strategy can be applied by other researchers for other proteins and therefore propel structural analysis studies and consequently novel drug development.

In conclusion, the findings in this thesis are in short term primary of value to other researchers, but in long term could be translated into commercially available products and/or services. 
Addendum III 
Addendum IV

Curriculum Vitae 


\section{About the author}

Dennis Hubertus Martinus Kusters was born on November $10^{\text {th }}, 1984$ in Brunssum, where graduated from Romboutscollege high school in 2003 completing the Nature \& Health profile.

After 1 year at the Technical University of Eindhoven (TU/e), he switched to Molecular Life Sciences at the University of Maastricht for which he obtained his bachelor's degree in 2007. Directly after completing the bachelor's program he started with the Research Master Cardiovascular Biology \& Medicine, a 2 year Master's program organized by the Cardiovascular Research Institute Maastricht (CARIM). He obtained his Master's degree in 2009 after completing an internship of two months at the Department of Cardiology from the University of California Irvine (USA) under the supervision of Prof. Dr. Narula and six months at the Department of Biochemistry of Maastricht University under the supervision of Prof. Dr. Reutelingsperger.

In 2009 he continued his work at the Department of Biochemistry starting his PhD program on the role of annexin A1 and annexin A5 in cardiovascular disease, supervised by Prof. Dr. Reutelingsperger. His PhD program was partly funded by the European Union through the Intereg IV program of Grensregio Vlaanderen-Nederland. During his PhD program he has published his data in peer-reviewed international scientific journals and presented his work on international conferences in Amsterdam, London and Kyoto. He has always had affection for teaching, which emerged from his role as teaching assistant within the Bachelor's program of Medicine and Biomedical Sciences and supervision of Bachelor and Master students during their internship.

Directly after his PhD he started as research associate of PharmaTarget BV. From March 2015 on he will continue his career as postdoctoral researcher at the Department of Pathology of the University of Michigan (USA) under supervision of Prof. Dr. Nusrat. 


\section{Over de auteur}

Dennis Hubertus Martinus Kusters werd geboren op 10 November 1984 in Brunssum, waar hij in 2003 zijn atheneum diploma haalde voor het profiel Natuur \& Gezondheid van het Romboutscollege.

Hierna heeft hij 1 jaar Biomedische Technologie gestudeerd aan de Technische Universiteit van Eindhoven (TU/e). Hij is daarna overgestapt naar Moleculaire Levenswetenschappen aan de Universiteit van Maastricht, waar hij zijn Bachelor diploma heeft gehaald in 2007. Direct na afronding van de Bachelor is hij begonnen aan de Research Master Cardiovascular Biology \& Medicine van het Cardiovascular Research Institute Maastricht (CARIM), aan de Universiteit van Maastricht. Na afronding van een eindstage van twee maanden op de afdeling Cardiologie van de Universiteit van Irvine (Californië, VS) en zes maanden op de afdeling Biochemie van de Universiteit van Maastricht behaalde hij zijn Master diploma.

Deze stageperiode mondde uit in een plek als promovendus op de afdeling Biochemie van de Universiteit van Maastricht onder de supervisie van Prof. Dr. Reutelingsperger, waarin hij een mogelijke rol van annexine A1 en annexine A5 in cardiovasculaire ziekten onderzocht. Een deel van de onderzoekskosten zijn betaald door de Europese Unie door middel van het Intereg IV programma van de Grensregio Vlaanderen-Nederland. Tijdens zijn promotie-traject heeft hij gepubliceerd in internationale peer-reviewed wetenschappelijke tijdschriften en zijn werk gepresenteerd op internationale congressen in Amsterdam, Londen en Kyoto. Zijn grote affectie als onderwijzer is gebleken uit zijn rol als onderwijsassistent binnen de Bacholor Geneeskunde en Biomedische Wetenschappen en bij de begeleiding van Bachelor en Master studenten tijdens hun stage.

$\mathrm{Na}$ afronding van zijn promotie-traject is hij begonnen als onderzoeksmedewerker bij PharmaTarget BV. Vanaf Maart 2015 zal hij zijn academische carriere voortzetten als postdoctorale wetenschapper op de afdeling Pathologie aan de Universiteit van Michigan onder supervisie van Prof. Dr. Nusrat. 
Addendum IV 
Addendum V

Publications 


\section{Publications}

Vangestel C, Peeters MN, Oltenfreiter R, D’Asseler Y, Staelens S, Van Steenkiste M, Philippé J, Kusters DHM, Reutelingsperger CPM, Van Damme N, Van de Wiele C. In vitro and in vivo evaluation of [ ${ }^{99 \mathrm{~m}} \mathrm{Tc}$ ]-labeled tricarbonyl His-annexin A5 as an imaging agent for the detection of phosphatidylserine-expressing cells. Nucl Med Biol. 2010;37:965-75 (IF - 2.458)

Kusters DHM, Tegtmeier J, Schurgers LJ, Reutelingsperger CP. Molecular imaging to identify the vulnerable plaque - from basic research to clinical practice. Mol Imaging Biol 2012;14:523-533 (IF - 3.095)

Schutters K, Kusters DHM, Chatrou ML, Montero-Melendez T, Donners MM, Deckers NM, Krysko DV, Vandenabeele P, Perretti M, Schurgers LJ, Reutelingsperger CP. Cell surface-expressed phosphatidylserine as therapeutic target to enhance phagocytosis of apoptotic cells. Cell Death Differ 2013;20:49-56 (IF - 8.385)

Leoni G, Alam A, Neumann PA, Lambeth JD, Cheng G, McCoy J, Hilgarth RS, Kundu K, Murthy N, Kusters DHM, Reutelingsperger C, Perretti M, Parkos CA, Neish AS, Nusrat A. Annexin A1, formyl peptide receptor, and NOX1 orchestrate epithelial repair. J Clin Invest 2013;123:443-454 (IF - 13.765)

De Saint-Hubert M, Bauwens M, Deckers NM, Drummen M, Douma K, Granton P, Hendrikx G, Kusters DHM, Bucerius J, Reutelingsperger CPM, Mottaghy F. In vivo molecular imaging of apoptosis and necrosis in atherosclerotic plaques using microSPECTCT and microPET-CT. Mol Imaging Biol 2014;16(2):246-54 (IF - 3.095)

Locatelli I, Sutti S, Jindal A, Vacchiano M, Bozzola C, Reutelingsperger CPM, Kusters DHM, Bena S, Parola M, Paternostro C, Bugianesi E, McArthur S, Albano E, Perretti M. Endogenous annexin A1 IS a novel protective determinant in nonalcoholic steatohepatitis (NASH). Hepatology 2014;60(2):531-44 (IF - 11.190)

Ungethum L, Chatrou ML, Kusters DHM, Schurgers LJ, Reutelingsperger CPM. Molecular imaging of cell death in tumors. Increasing annexin A5 size reduces contribution of PS-targeting function to tumor uptake. PLoS One 2014;9:e96749 (IF - 3.530) 
Burgmaier M, Schutters K, Willems BAG, Kusters DHM, Chatrou ML, Norling L, Biessen EAL, Cleutjens J, Perretti M, Schurgers LJ, Reutelingsperger CPM. AnxA5 decreases plaque inflammation of advanced atherosclerotic lesions in apoE $\mathrm{E}^{-1-}$ mice. $J$ Cell Mol Med. 2014;18:2117-24 (IF - 3.698)

Leoni G, Neumann PA, Kamaly N, Quiros M, Nishio H, Sumagin R, Hilgarth RS, Alam A, Fredman G, Argyris I, Rijcken E, Kusters DHM, Reutelingsperger C, Perretti M, Parkos CA, Farokhzad O, Neish A, Nusrat A. Epithelial extracellular vesicles or nanoparticles containing Annexin-A1 promote wound repair. J Clin Invest (IF - 13.765) Accepted

Kusters DHM, Tegtmeier J, Schurgers LJ, Reutelingsperger CPM. Inflammation in heart failure, Elsevier 2014, Chapter 12; ISBN: 9780128000397 (Book chapter)

\section{Publications (in preparation)}

Kusters DHM, Chatrou ML, Willems BAG, Schutters K, Marsch E, Gijbels M, Brachvogel B, Schurgers LJ, Reutelingsperger CPM. Annexin A5-deficiency in $\mathrm{ApoE}^{-/-}$mice promotes efferocytosis and inhibits atherosclerosis. $\mathrm{Br} \mathrm{J}$ Pharmacol (IF - 4.990) resubmitted

Kusters DHM, Chatrou ML, Willems BAG, De Saint-Hubert M, Bauwens M, van der Vorst E, Bena S, Biessen EAL, Perretti M, Schurgers LJ, Reutelingsperger CPM. Exogenous annexin A1 attenuates atherogenesis in $\mathrm{LDLR}^{-/}$mice on Western Type Diet. Cardiovasc Res (IF - 5.808) resubmitted

Kusters DHM, Schurgers LJ, Leenders P, Hemker HC, Nicolaes GA, Reutelingsperger CPM. Annexin A1 ameliorates infarct size and LV systolic function following myocardial ischemia/reperfusion injury. J Mol Cell Cardiol (IF - 5.218) submitted

Chatrou ML, Kusters DHM, Willems B, Norling L, Proudfoot D, Spronk H, Grüll H, Reutelingsperger CPM, Schurgers LJ. Vitamin K antagonists attenuate early and aggravate late atherogenesis in apoE $\mathrm{E}^{-/-}$mice. Cardiovasc Res (IF - 5.808) (submitted)

Schutters K, Cooper D, Kusters DHM, Chatrou ML, Otten J, Donners M, De SaintHubert M, Bauwens M, Krysko D, Vandenabeele P, Verbruggen A, Biessen EAL, Perretti 
M, Schurgers LJ, Reutelingsperger CPM. The pro-efferocytotic RGD-annexin A5 inhibits de novo atherosclerotic plaque formation in apoE--1-mice. Arterioscler Thromb Vasc Biol (IF 6.340) submitted

Kusters DHM, Schurgers LJ, Reutelingsperger CPM, Hackeng T, Ippel H. Synthesis and characterization of full-length anxA1 by NMR spectroscopy (in preparation)

Willems BAG, Chatrou ML, Kusters DHM, Raphaël M, Stock M, Vermeer C, Reutelingsperger CPM, Schurgers LJ. Ucma, a novel member of the class of vitamin $\mathrm{K}$ dependent proteins is involved in osteochondrogenic transdifferentiation of vascular smooth muscle cells. (in preparation)

Barth S, Ungethüm L, Deckers NM, Kusters DHM, Chatrou ML, Goossens V, Vandenabeele P, Bogner P, Szabo V, Boulette G, Micalessi MI, Bogers J-P, Saint-Hubert M, Vermaelen P, Verbruggen A, Mortelmans L, Schurgers LJ, Reutelingsperger CPM. Annexin A5-ETA fusion protein targets phosphatidylserine and inhibits tumor growth in an HT-29 colon cell xenograft mouse model. (in preparation)

\title{
Oral presentations
}

Kusters DHM, Chatrou ML, Willems BAG, Schutters K, Schurgers LJ, Reutelingsperger CPM. Deficiency of the anticoagulant annexin A5 attenuates atherosclerotic plaque development in $\mathrm{ApoE}^{-1-}$ mice. $24^{\text {th }}$ International Symposium on Thrombosis and Hemostasis (ISTH), July 2013, Amsterdam, The Netherlands.

Kusters DHM, Chatrou ML, Willems BAG, Schutters K, Schurgers LJ, Reutelingsperger CPM. Annexin A5 deficiency in ApoE ${ }^{-/}$mice: attenuated atherosclerotic plaque development. $7^{\text {th }}$ International Conference on Annexins, September 2013 London, Great Britain.

\begin{abstract}
s
Schutters K, Kusters DHM, Bitsch N, Deckers N, Kenis H, Lux P, Maassen C, Ungethüm L, Schurgers L, Buurman W, Reutelingsperger C. Annexin A5 strategies to improve the phagocytosis of apoptotic cells. Keystone Symposium: Advances in Molecular Mechanisms of Atherosclerosis, February 2010, Banff, Canada.
\end{abstract}


Kusters DHM, Chatrou ML, Willems BAG, Schutters K, Schurgers LJ, Reutelingsperger CPM. Deficiency of the anticoagulant annexin A5 attenuates atherosclerotic plaque development in $\mathrm{ApoE}^{-1-}$ mice. $24^{\text {th }}$ International Symposium on Thrombosis and Hemostasis (ISTH), July 2013, Amsterdam, The Netherlands.

Willems BAG, Chatrou ML, Kusters DHM, Theuwissen E, Simes DC, Vermeer C, Reutelingsperger CPM, Schurgers LJ. GRP/Ucma: a novel member of the class of vitamin $\mathrm{K}$ dependent proteins is involved in osteochondrogenic transdifferentiation of vascular smooth muscle cells. 24 $4^{\text {th }}$ International Symposium on Thrombosis and Hemostasis (ISTH), July 2013, Amsterdam, The Netherlands.

Kusters DHM, Chatrou ML, Willems BAG, Schutters K, Schurgers LJ, Reutelingsperger CPM. Annexin A5 deficiency in Apo $\mathrm{E}^{-1}$ mice: attenuated atherosclerotic plaque development. $7^{\text {th }}$ International Conference on Annexins, September 2013 London, Great Britain.

Kusters DHM, Chatrou ML, Willems BAG, De Saint-Hubert M, Bauwens M, van der Vorst E, Bena S, Biessen EAL, Perretti M, Schurgers LJ, Reutelingsperger CPM. Exogenous annexin A1 attenuates atherogenesis in $\mathrm{LDLR}^{-/}$mice on Western Type Diet. $7^{\text {th }}$ International Conference on Annexins, September 2013, London, Great Britain.

Burgmaier M, Schutters K, Willems BAG, Kusters DHM, Chatrou M, Biessen EAL, Cleutjens J, Schurgers LJ, Reutelingsperger CPM. AnxA5 decreases plaque inflammation of advanced atherosclerotic lesions in Apoe ${ }^{-/-}$mice. The American Heart Association (AHA) Scientific Sessions and Resuscitation Science Symposium. November 2013, Dallas, United States of America.

Chatrou ML, Kusters DHM, Willems B, Norling L, Proudfoot D, Spronk H, Grüll H, Reutelingsperger CPM, Schurgers LJ. Vitamin K antagonists attenuate early and aggravate late atherogenesis in apoE $\mathrm{E}^{-1-}$ mice. $58^{\text {th }}$ Anual meeting of the society of Thrombosis and Heamostatis Research, February 2014, Vienna, Austria.

Kusters DHM, Chatrou ML, Willems BAG, De Saint-Hubert M, Bauwens M, van der Vorst E, Bena S, Biessen EAL, Perretti M, Schurgers LJ, Reutelingsperger CPM. Exogenous annexin A1 attenuates atherogenesis in $\mathrm{LDLR}^{-/}$mice on Western Type Diet. $18^{\text {th }}$ international vascular biology meeting (IVBM), April 2014, Kyoto, Japan. 
Kusters DHM, Chatrou ML, Willems BAG, Schutters K, Marsch E, Gijbels M, Brachvogel B, Schurgers LJ, Reutelingsperger CPM. Annexin A5-deficiency in ApoE ${ }^{-1-}$ mice promotes efferocytosis and inhibits atherosclerosis. $18^{\text {th }}$ International Vascular Biology Meeting (IVBM), April 2014, Kyoto, Japan.

Willems BAG, Chatrou ML, Kusters DHM, Stock M, Rafael M, Vermeer C, Reutelingsperger CPM, Schurgers LJ. Loss of GRP/Ucma aggravates osteochondrogenic switching of vascular smooth muscle cells and induces vascular calcification. $18^{\text {th }}$ International Vascular Biology Meeting (IVBM), April 2014, Kyoto, Japan.

Quiros M, Kamaly N, Leoni G, Neumann PA, Fredman G, Nishio H, Kusters DHM, Reutelingsperger CPM, Perretti M, Parkos CA, Neish AS, Farokhzad O, Nusrat A. Epithelial extracellular vesicles or nanoparticles containing Annexin-A1 promote wound repair. FASEB meeting: Experimental Biology, April 2014, San Diego, United States of America

\section{Memberships}

Member of the North American Vascular Biology Organization (NAVBO)

Member of the Dutch Society for Thrombosis and Hemostasis (NVTH)

Member of the International Society for Thrombosis and Hemostasis (ISTH) 
Addendum VI

Dankwoord 
Aangezien ik een persoon ben van weinig woorden, zal ik het kort houden. Na een intens en leerzaam avontuur ben ik nu aangekomen bij het laatste en tevens meest gelezen deel van het proefschrift; het dankwoord. Net als iedere promovendus, heb ik veel hulp en steun mogen ontvangen van collega's, vrienden en familie.

Allereerst bedank ik graag mijn promotieteam.

Mijn promotor, Prof. Dr. Reutelingsperger, beste Chris, het is nu ongeveer 7 jaar geleden dat ik reageerde op een stageplaats in jouw groep. $\mathrm{Na}$ succesvolle afronding van deze stage bood je mij de mogelijkheid om mijn onderzoek voort te zetten als promovendus, met dit proefschrift als resultaat. De drempel van jou kantoor is altijd laag geweest, al wist ik je niet altijd te onderscheppen. De naam "Chris-als-hij-er-is" zal jou dan misschien ook bekend voorkomen. Jij hebt mij veel geleerd over alle belangrijke zaken die naast de wetenschap belangrijk zijn om te slagen binnen de academie. Ik ben enorm dankbaar voor de vrijheid en het vertrouwen dat je mij gedurende mijn hele promotieperiode hebt gegeven. Hiermee heb je de fundering gelegd voor mijn toekomstige (academische) carrière.

Mijn copromotor, Dr. Schurgers. Beste Leon, het is moeilijk om op papier uit te drukken hoe belangrijk jij bent geweest tijdens dit hele traject. Ik was ongeveer 6 maanden aan het worstelen met mijn "inteïne-project" toen jij in de groep werd geïntroduceerd. Direct tijdens de voorstelronde maakte je grote indruk op me, door het enthousiasme, de positiviteit en de rust die je uitstraalde. Ik wist direct dat jij een grote aanvulling voor onze groep zou zijn. Jouw deur staat echt altijd open, misschien zelfs wel iets te ver. Buiten het werk hebben wij ook een goede klik. We hebben ontelbare uren doorgebracht met (on)zinnige (wetenschappelijke) discussies, veelal onder het genot van een biertje. Hierbij wil ik ook direct de mogelijkheid aangrijpen om Romy, Juul en Sam te bedanken voor de gastvrijheid, als deze discussies weer eens uitliepen tot in de kleine uurtjes en ik uiteindelijk de nacht in het stapelbed (of op de bank) door mocht brengen.

Martijn, onze eerste ontmoeting was in Eindhoven tijdens de studie BMT. Door puur toeval zijn wij collega's geworden op de afdeling Biochemie, waar we ons promotie traject gelijktijdig begonnen. Jij hebt ervoor gezorgd dat ik enorm ben gegroeid, als wetenschapper en als persoon. Ik heb veel respect voor jouw kennis, gedrevenheid, doorzettingsvermogen maar vooral eerlijkheid. Ooit waren we samen studenten, we werden collega's en zijn nu vrienden. De afgelopen 5 jaar zou niet hetzelfde zijn geweest zonder jou. De stap- en 
quizavonden, niet-nader-te-noemen 'themadagen' en het biertje na(/tijdens) werk waardeer ik zeer. Te allen tijde ben je mijn steun en toeverlaat geweest, hier wil ik wil je dan ook in het bijzonder voor bedanken.

Brecht, jij kwam iets later in onze groep en werd bij twee alfa-mannen op de kamer geplaatst. Een korte acclimatisatieperiode en gebroken been verder, groeide je uit tot de Brecht die je nu bent. Onze trip naar Japan was een hele ervaring. Naast ontelbare tempels, beleefde mensen en lekker eten heeft Japan ook een fantastisch jazz-hostel, mannen genaamd Jim Beam die dansen in de Butterfly, de anti-kater burger, overheerlijke ramen van opa het Gundam-cafe en zo kan ik nog wel even doorgaan.

Frauke, naast collega ben jij een van mijn beste vrienden. Wij hebben elkaar leren kennen tijdens onze opleiding ( $>10$ jaar geleden) en uiteindelijk promoveren wij in dezelfde vakgroep. Onze gezamenlijke verjaardagsfeestjes, vakanties en stapavonden zal ik nooit vergeten, in ieder geval de meeste niet...

Dr. Schutters, beste Kristof, jij hebt mij met annexines in contact gebracht en wetenschap leren kennen. Jouw enthousiasme als stagebegeleider ligt aan de basis van dit proefschrift. Altijd alleen het goede in mensen zien en jouw uitzonderlijke positieve instelling zijn een bijzondere gave. Heel veel geluk met Kelly en jullie dochters.

Dear Mathias, it was so refreshing having you in our lab. Your unique sense of humor is a delight. You have taught me to work towards a goal and not get distracted by side issues.

Dear Robert, thanks for the pleasant conversations and your usefull input in Chapter 5 .

Cecile, Petra, Niko, Liset en Billy, bedankt om het lab draaiend te houden.

Marijke en Matthias, jullie zijn een stralend team en hebben mij enorm geholpen bij de biodistributie experimenten.

Dr. Ippel, beste Hans, zonder jou zou dit proefschrift één hoofdstuk minder tellen. Jouw NMR expertise en enthousiasme hebben mij overtuigd dit uitdagende project aan te nemen. Dit uiteindelijk heeft geleid tot een zeer mooi hoofdstuk en toekomstige publicatie. 
Beste Peter, Jacques, Agnieska en Nicole, hartelijk dank voor alle assistentie en jullie uitzonderlijke expertise bij het uitvoeren van zeer complexe dierexperimenten.

Prof. Dr. Biessen, beste Erik, bedankt voor de geweldige discussies tijdens, maar vooral na werktijd. Jouw onuitputtelijke specifieke kennis en pragmatisch denken zijn een grote bron van inspiratie. Ook wil ik je bedanken om voorzitter van de beoordelingscommissie te zijn.

I would also like to acknowledge all other members of the assessment committee; Prof. Dr. de Windt, Prof. Dr. Mottaghy, Prof. Dr. Frostegård and Prof. Dr. Brachvogel, thank you very much for assessing my thesis.

Next I would like to acknowledge my foreign collaborators. Prof. Dr. Solito, Prof. Dr. Albano and Prof. Dr. Perretti, thank you for the exquisite cooperation and profound discussions at the annexin conferences in Barcelona and London. We will meet again at the annexin conference in Maastricht in 2015.

Prof. Dr. Nusrat, dear Asma, we first met at the annexin conference in London, where you declined having dinner at the president's table to eat with me, not knowing of my large appetite and that we had to share our food. I would like to thank you for the excellent scientific cooperation we had untill now and I look forward to this new chapter ahead of us. Your outstanding knowledge and warm personality make me feel confident that this will also be very successful. I cannot wait to start!

Prof. Dr. Narula, dear Jagat, you are one of the smartest people I have ever met. Together with Nezam and Artiom you have thought me the importance of accurate and decent science. That in case experiments are performed properly, there can merely be discussion about interpretation of data, not the data itself. I would like to thank you for your guidance and hospitality during my stay in California.

Dit dankwoord zou niet volledige zijn zonder de Baas van Biochemie te bedanken, beste Trees, hartelijk dank voor alle hulp en de leuke gesprekken. Ik hoop dat je nog lang werkzaam bent bij Biochemie, want ondanks het voortreffelijke werk van Lideweij, zal het zonder jou een stuk minder zonnig zijn! 
Prof. Dr. Hackeng, beste Tilman, als vakgroepvoorzitter weet jij als de beste waar het om gaat in de wetenschap. Buiten je uitzonderlijke wetenschappelijke kennis, begrijp jij dat de sociale activiteiten naast de wetenschap ons creatieve proces voeden en het plezier wetenschapper te zijn vergroten.

Joke, Marie-Claire, Rinske, Geert-Jan en Roy, we zullen maar zeggen dat meedoen belangrijker is dan winnen. Bitterballen zijn toch ook veel lekkerder dan Whisky.

$\mathrm{Nu}$ ik het toch over bitterballen heb; beste Stella, net als in mijn 3 ingediende manuscripten verdien jij ook in dit dankwoord een eervolle vermelding. Bedankt voor het uitvoeren van de stollingsproeven maar bovenal alle gezelligheid.

Alle andere (oud) collega's van Biochemie, bedankt voor alle hulp.

Elke, Thomas, Kosta en Emiel, hartelijk dank voor de samenwerking van de afgelopen jaren. Deze samenwerking heeft Biochemie en Pathologie nader to elkaar gebracht, en heeft daarbij geleid tot additionele 'extracurriculaire activiteiten'.

Verder wil ik alle mensen van de CPV bedanken, in het bijzonder: Saskia, Richard, Rik, Clarice, Harry, Inger en Anouk. Bedankt voor alle goede zorg voor de dieren en hulp bij het papierwerk dat met dierproeven gemoeid gaat.

Beste Guillaume, bedankt voor het maken van de foto's en al je wijsheden.

Naast alle collega's zijn er ook veel vrienden die hebben bijgedragen aan de totstandkoming van dit proefschrift. De traditie om eenmaal per jaar op 'mannenweekend' te gaan zorgde voor de nodige ontspanning. Jesper, Loek, Niels, Pascal, Patrick, Pieter, Ralph, Rene en Rob, we hebben onze stempel nagelaten in Brussel, Berlijn, Dublin, Krakau en Barcelona. Ik ben ervan overtuigd dat we deze traditie ook na alle gezinsuitbreidingen gewoon in ere houden.

Het voetbalteam van SV Brunssum waarmee ik kampioen geworden ben, maar die nog beter zijn in de $3^{\mathrm{e}}$ helft: Antoine, Bjorn, Blay, Brian, David, Dean, Denny, Didier, Eddie, Ferdie, Gian, Glenn, Martijn, Martijn, Matthijs, Nick, Onno, Patrick, Philip, Pieter, Ralph, Remco, Robin, Rocco, Thomas en Timo. "Vriendschap en bier”! 
Beste Martijn, wij kennen elkaar al sinds de kleuterschool. In mijn woordenboek ben jij de definitie van 'een vriend voor het leven'. Vanwege onze drukke agenda's zien we elkaar niet meer zoveel als vroeger, maar het is altijd vertrouwd als we elkaar zien. Vriendschap is kwaliteit, geen kwantiteit. Veel succes en tot ziens in Shanghai. Bij dezen wil ik ook direct je ouders en zus bedanken. Prof. Dr. van Uden, beste Rien, beste Gerdie en Cuny, enorm bedankt voor alle jaren dat ik bij jullie thuis welkom was en de interesse die jullie getoond hebben in mijn opleiding, carrière en leven.

Tante Els, lieve peettante, bedankt voor het mooie schilderij dat aan de basis ligt van de omslag van dit proefschrift. Blijf altijd lachen!

Lieve Romy, jij begrijpt mij en het proces van promoveren als geen ander. Ik kan bij jou altijd terecht voor een luisterend oor en een goed gesprek. Mede door jou begrip, geduld, rust en liefde heb ik deze zeer stressvolle tijd toch als heel prettig ervaren. Zelfs in de moeilijkste tijden maak je me aan het lachen, veelal door je onhandigheid. Ich höb dich gaer!

Als laatste wil ik de twee personen bedanken aan wie dit proefschrift is opgedragen. Beste papa en mama, de afgelopen 30 jaar hebben jullie altijd voor mij klaargestaan, geen moeite was te veel. Jullie hebben mij altijd volledig vrij gelaten in al mijn keuzes. Ik wil jullie bedanken voor het vertrouwen, de wijsheid en de steun die ik al die jaren heb mogen ontvangen. Jullie hebben mij geholpen vanaf het moment dat ik leerde lezen en schrijven tot aan het laatste uitroepteken van dit dankwoord. Bedankt! 